\title{
WestVirginiaUniversity
}

THE RESEARCH REPOSITORY @ WVU

Graduate Theses, Dissertations, and Problem Reports

2019

\section{Experimental and Numerical Study of the Stirling Engine Robust Foil Regenerator}

Koji Yanaga

ky0010@mix.wvu.edu

Follow this and additional works at: https://researchrepository.wvu.edu/etd

Part of the Energy Systems Commons, and the Heat Transfer, Combustion Commons

\section{Recommended Citation}

Yanaga, Koji, "Experimental and Numerical Study of the Stirling Engine Robust Foil Regenerator" (2019). Graduate Theses, Dissertations, and Problem Reports. 7401.

https://researchrepository.wvu.edu/etd/7401

This Dissertation is protected by copyright and/or related rights. It has been brought to you by the The Research Repository @ WVU with permission from the rights-holder(s). You are free to use this Dissertation in any way that is permitted by the copyright and related rights legislation that applies to your use. For other uses you must obtain permission from the rights-holder(s) directly, unless additional rights are indicated by a Creative Commons license in the record and/ or on the work itself. This Dissertation has been accepted for inclusion in WVU Graduate Theses, Dissertations, and Problem Reports collection by an authorized administrator of The Research Repository @ WVU.

For more information, please contact researchrepository@mail.wvu.edu. 


\title{
Experimental and Numerical Study of the Stirling Engine Robust Foil Regenerator
}

\section{Koji Yanaga}

\author{
Dissertation Submitted to the \\ Benjamin M. Statler College of Engineering and Mineral Resources \\ At West Virginia University \\ in partial fulfillment of the requirements for the degree of \\ Doctorate of Philosophy in Mechanical Engineering
}

\author{
Songgang Qiu, Ph.D., Advisor and Chair \\ Hailin Li, Ph.D. \\ Andrew Nix, Ph.D. \\ V'yacheslav Akkerman, Ph.D. \\ Fernando Lima, Ph.D. \\ Department of Mechanical and Aerospace Engineering \\ Morgantown, West Virginia \\ 2019
}

Keywords: Stirling Engine, Robust Foil Regenerator, Oscillating Flow, Flow Loss, Heat Transfer

Copyright 2019 Koji Yanaga 


\section{Abstract \\ Experimental and Numerical Study of the Stirling Engine Robust Foil Regenerator \\ Koji Yanaga}

Conventional electricity generation wastes more than two thirds of its thermal energy while generating electricity. Combined Heat and Power (CHP) systems are an efficient energy conversion technology, which generate electricity and useful thermal energy simultaneously by utilizing waste energy for space heating and sanitation. One system that is suitable for CHP is the Stirling engine. Because of the simple design, flexible heat source (solar, biomass, waste heat), high thermal to electricity conversion efficiency, and high reliability, the Stirling engine is expected to be one of the best candidates for the applications in the future.

One of the key components that help to achieve higher efficiency for the Stirling engine is the regenerator. The regenerator is located between the heat accepter and the heat rejecter. It works as a thermal energy storage component in the engine. When the heated working fluid goes through the regenerator, the regenerator absorbs the waste energy from the working fluid. When the cold fluid passes through the regenerator to enter the heat accepter, the regenerator supplies the energy to the working fluid.

Most of the regenerators are made of woven screen or random fiber. However, the flow going through the woven screen or random fiber is similar to the cylinders in crossflow which has flow separation. To achieve higher engine efficiency, it is required to design a regenerator which has higher convective heat transfer, lower pressure drops, and lower axial conduction. One of the solutions is to configure the regenerator with parallel channels to decrease the pressure drop. In parallel channel configuration, flow separation is reduced. Therefore, a parallel channel regenerator called a robust foil regenerator was designed and manufactured.

In this study, a regenerator test rig was designed and built to measure the flow loss and heat transfer through the robust foil regenerator. The test rig is mainly composed of a heater, cooler, test section, and linear motor. Since the linear motor generates the oscillating fluid motion, all the experiments were conducted under oscillating flow conditions. To compare with the conventional regenerator, a woven screen regenerator was also manufactured. Additionally, a CFD model was developed to further understand the physics of the oscillating flow. The CFD model was validated by the experimental data. 
For the flow loss, both the experimental and the simulation results show that the robust foil regenerator has a significantly lower friction coefficient than the woven screen regenerator. Also, it was found that the friction coefficient of the robust foil regenerator is similar to that of the flows in parallel plate. For the heat transfer, the Nusselt number of the woven screen regenerator is higher than the Nusselt number of the robust foil regenerator. The high heat transfer in the woven screen regenerator is due to the flow separation induced turbulent flow.

To evaluate the overall performance of the robust foil regenerator and the woven screen regenerator, the figure of merit was utilized, which is commonly used for regenerator performance evaluation. The figure of merit is the ratio of the friction coefficient to the Nusselt number, and it is a powerful tool to evaluate the overall regenerator performance. The lower the figure of merit, the better the regenerator performance. The result shows that the robust foil regenerator has a better performance than the woven screen regenerator. Therefore, in conclusion, to increase the efficiency of the Stirling Engine, the robust foil regenerator is an excellent choice. 


\section{Acknowledgment}

It was the biggest challenge in my life to come to the US and earn a Ph.D. degree at West Virginia University. The challenge would not have been overcome without all the support I received from my adviser, thesis committee members, friends, girlfriend, and my family. In the following paragraphs, I would like to show my appreciation to all the people who supported me.

Firstly, I would like to give my utmost appreciation, and thanks to my academic advisor Dr. Songgang Qiu for all the support he gave me throughout my time at WVU. Without his advice and financial supports through my Ph.D. process, I would definitely not have earned my Ph.D. degree.

Besides my adviser, I would like to thank the thesis committee members: Dr. Hailin Li, Dr. Andrew Nix, Dr. V'yacheslav Akkerman, and Dr. Fernando Lima, for their constructive comments, suggestions, and cooperative questions during the presentation.

Also, my sincere thanks also go to my labmates: Pawan Kumar Yadav, Dr. Garrett Rinker, Dr. Laura Solmon, Dr. Yuan Gao, and Dr. Ruijie Li, who gave me valuable advice and helpful discussions during my stay. Especially, Ruijie, whose knowledge of the Stirling engine was outstanding and helped me to understand more about Stirling engine.

Many thanks also go to Dr. Fuchiwaki, my previous advisor in Japan. He was the professor who taught me various lessons and gave me the idea to come to the United States in pursuit of a Ph.D. degree.

Last but not least, I would like to thank my family and girlfriend for supporting me throughout writing this thesis and my life in general. 


\section{Table of Contents}

\section{Chapter 1: Introduction}

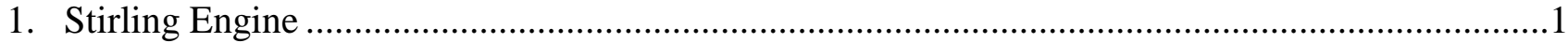

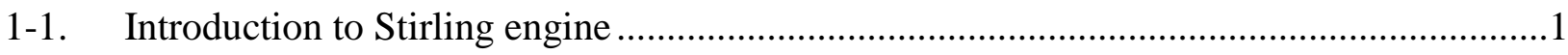

1-2. Working principle of Stirling engine …………….....................................................

1-3. History of Stirling Engine ..........................................................................................

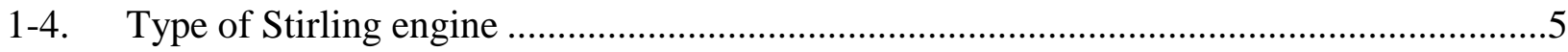

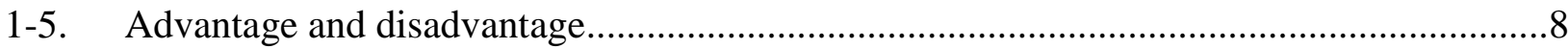

1-6. Research about Stirling engine ………………......................................................

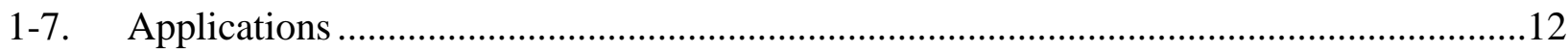

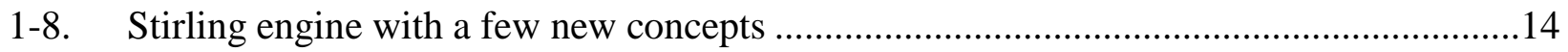

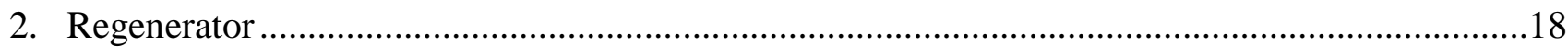

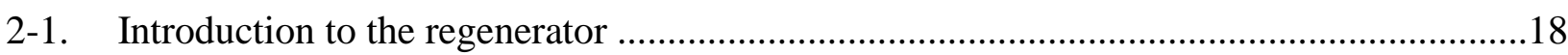

2-2. Wire media regenerator and the problem …………...................................................20

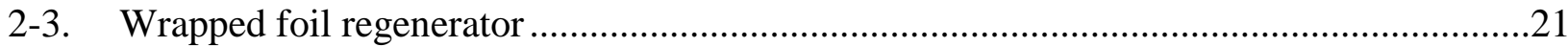

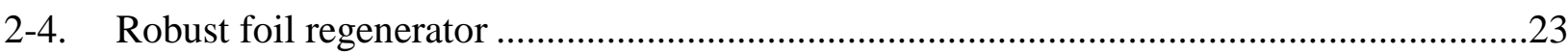

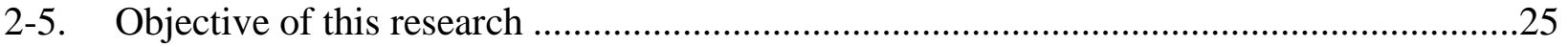

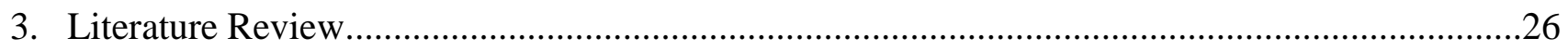

3-1. Research about various regenerators ………................................................................26

3-2. New types of regenerators from recent research................................................................31

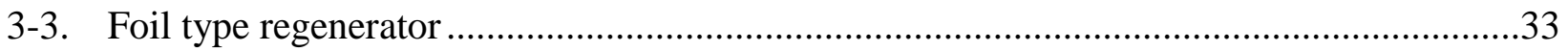

\section{Chapter 2: Test rig}

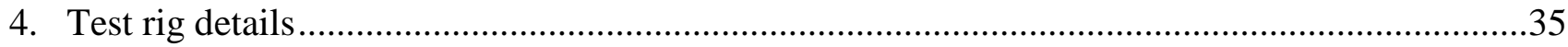

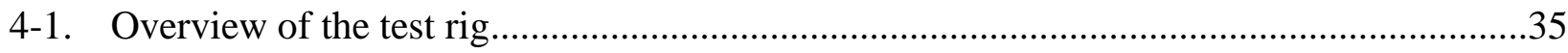

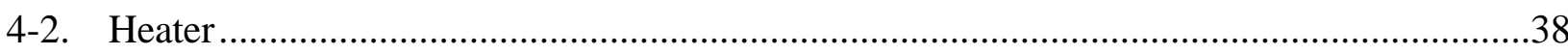

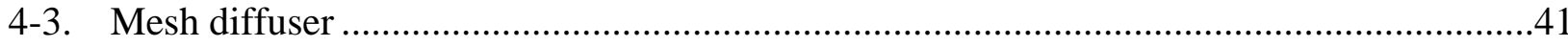




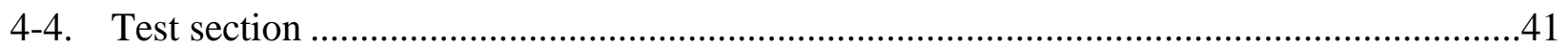

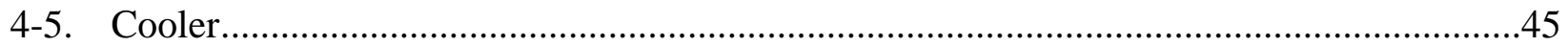

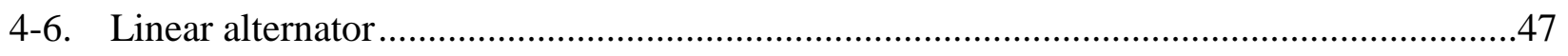

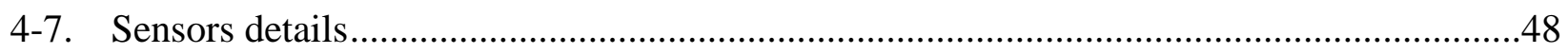

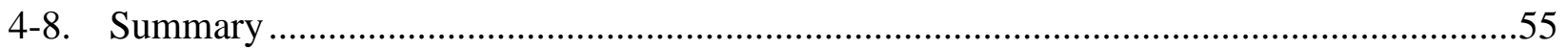

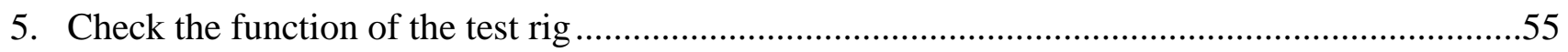

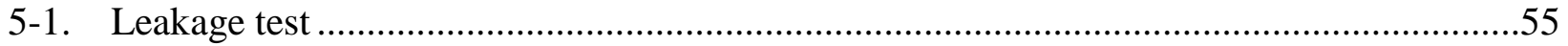

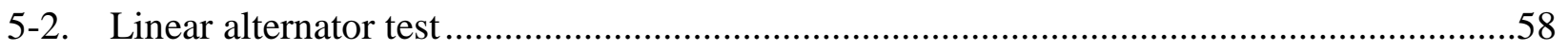

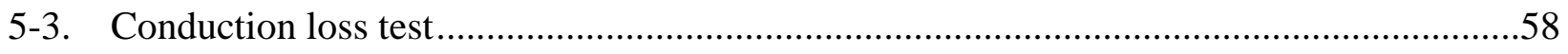

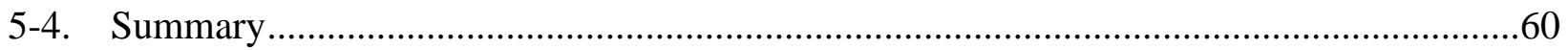

\section{Chapter 3: Flow loss test and CFD}

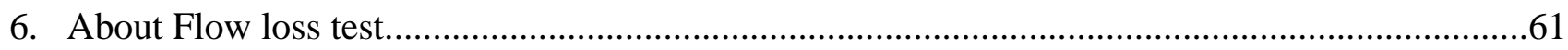

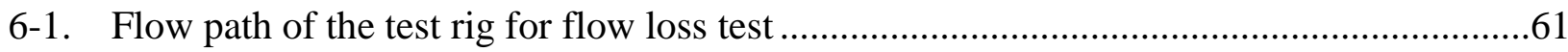

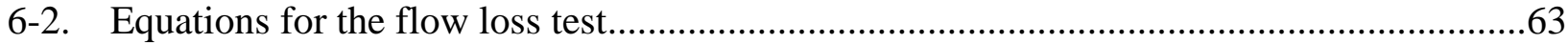

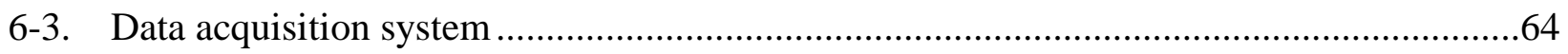

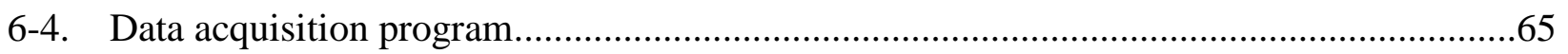

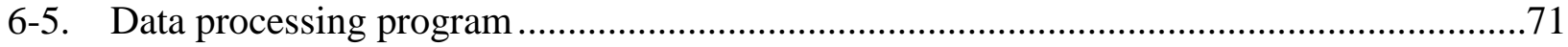

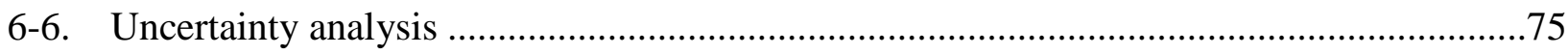

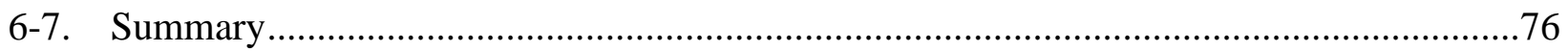

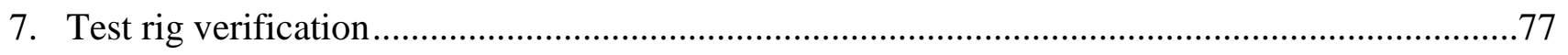

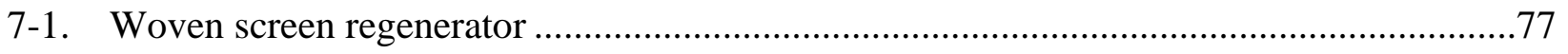

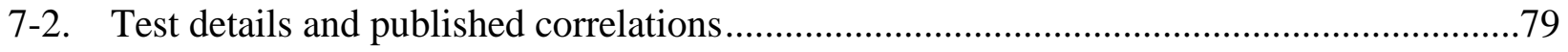

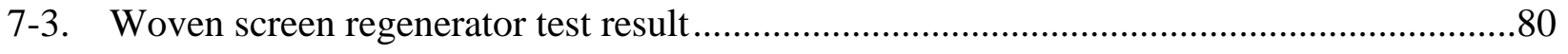

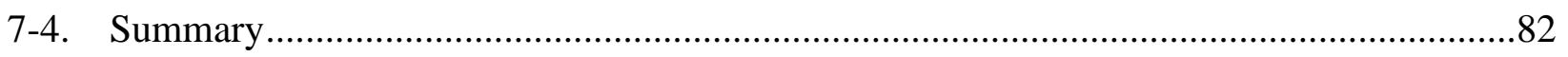

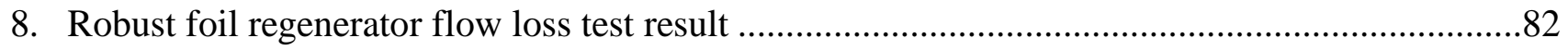

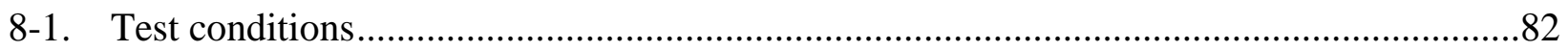




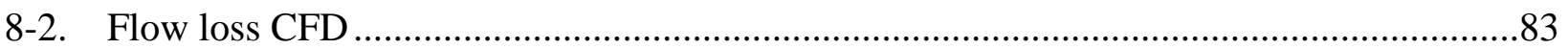

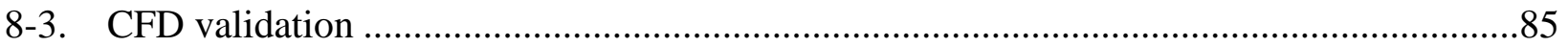

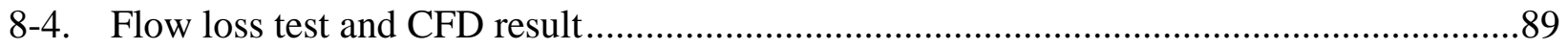

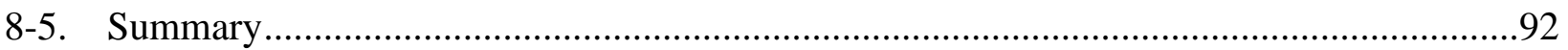

\section{Chapter 4: Heat transfer test and CFD}

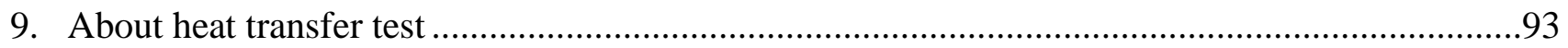

9-1. Flow path if the test rig for the heat transfer test...................................................93

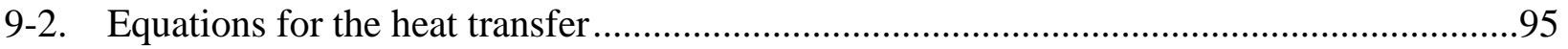

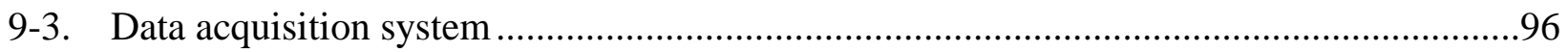

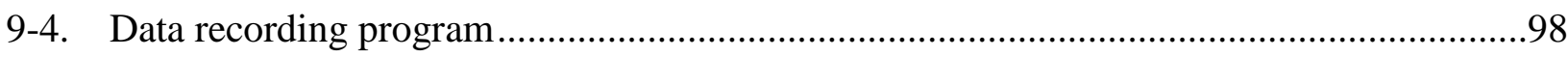

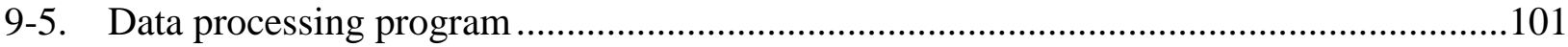

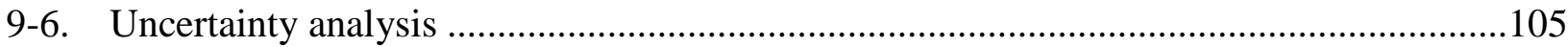

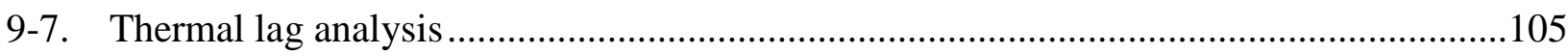

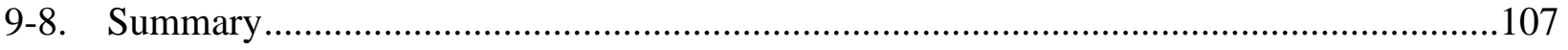

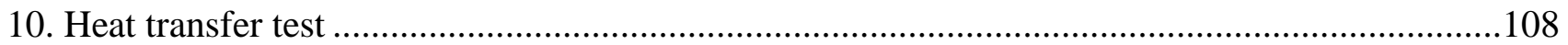

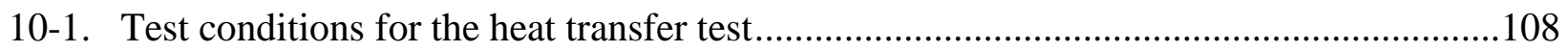

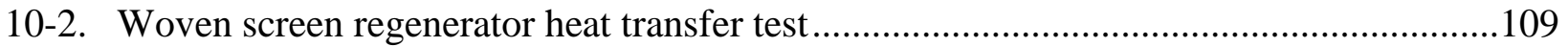

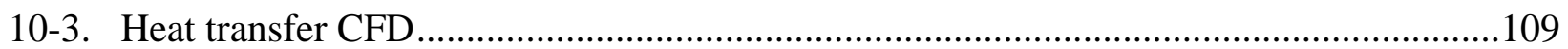

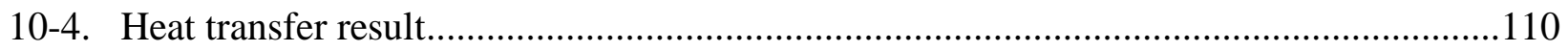

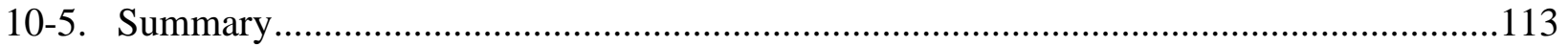

\section{Chapter 5: Overall efficiency and conclusion}

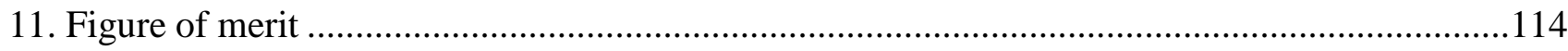

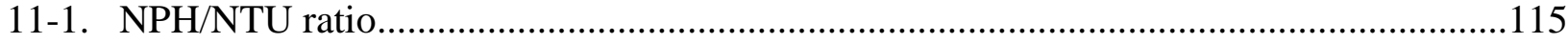

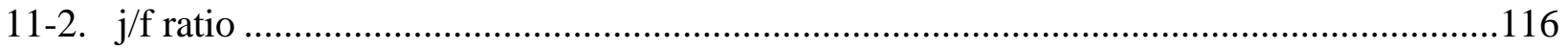

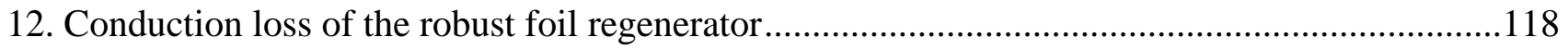


Appendix E: Temperature measurement using a voltage measurement module and a thermocouple ....148

Appendix G: Pressure transducer installation hall.....

Appendix H: Woven screen regenerator manufacturing process

Appendix J: Direct metal laser sintering. 


\section{List of figures}

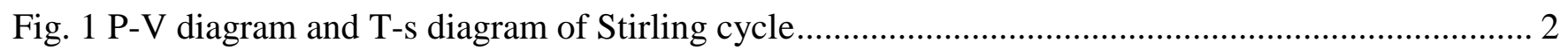

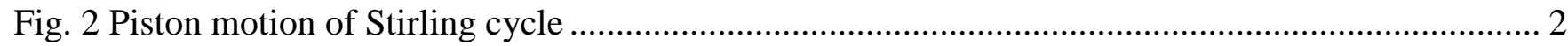

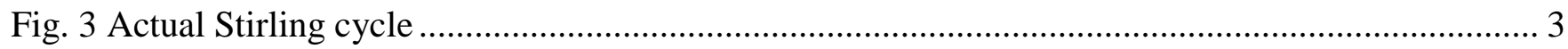

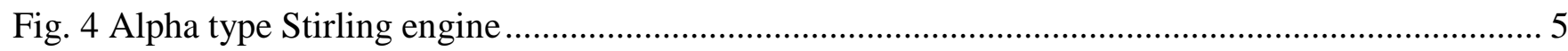

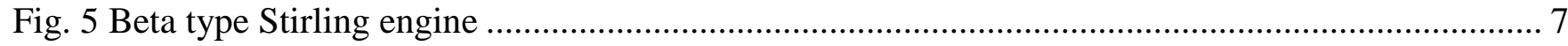

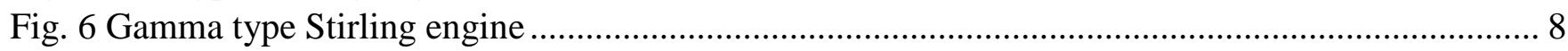

Fig. 7 Free piston Stirling engine............................................................................................. 9

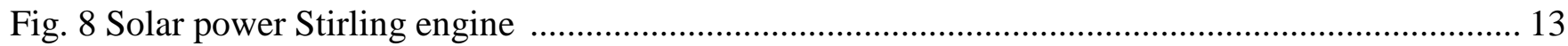

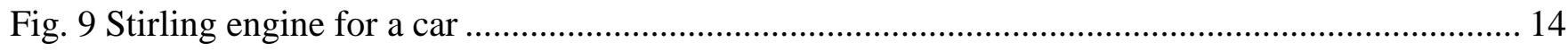

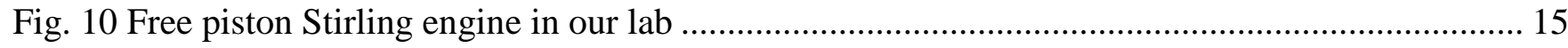

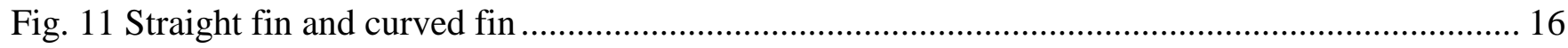

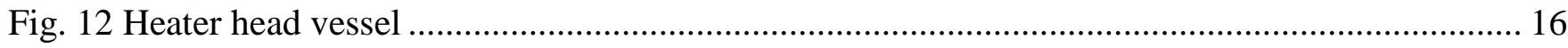

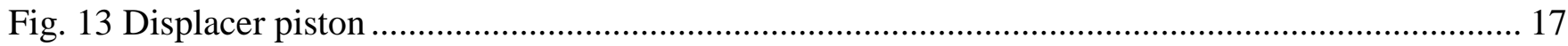

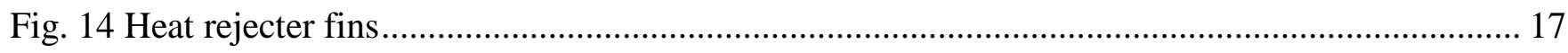

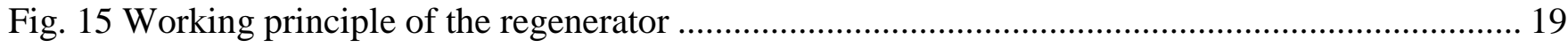

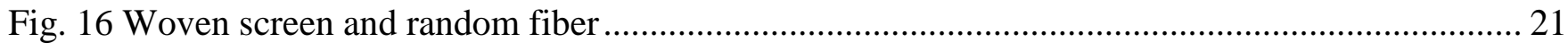

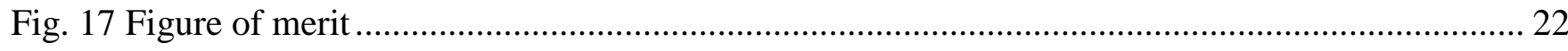

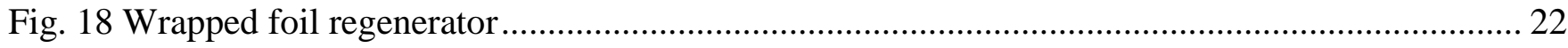

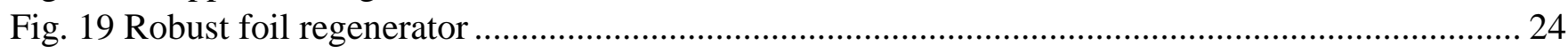

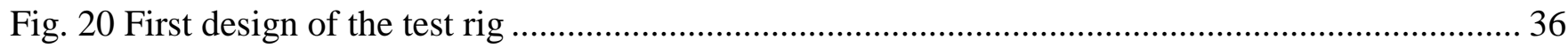

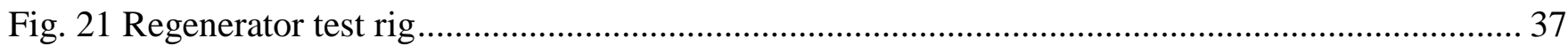

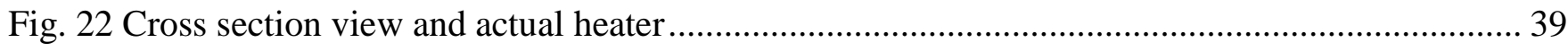

Fig. 23 Drawing sheet of the heater pressure vessel ........................................................................ 40

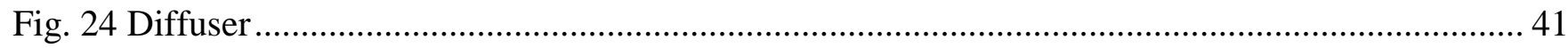

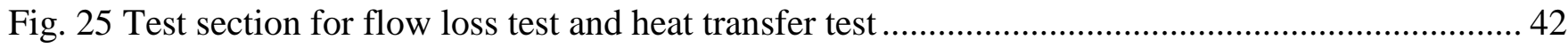

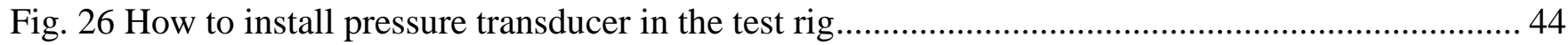

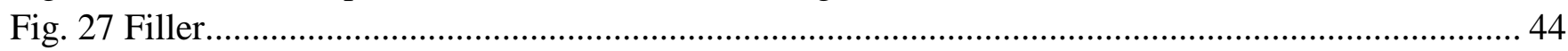

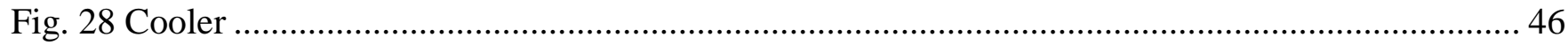

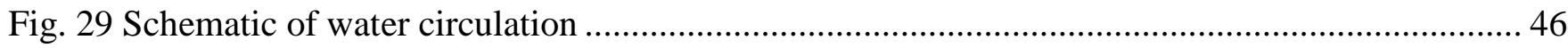

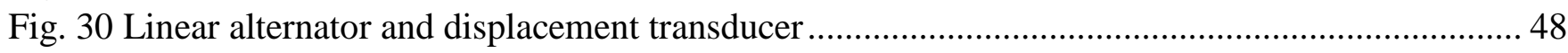

Fig. 31 CHAL-002 with stainless steel pipe ................................................................................. 49

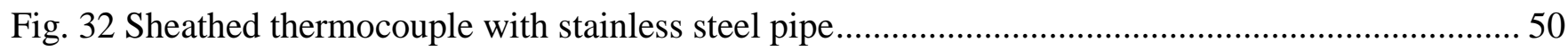

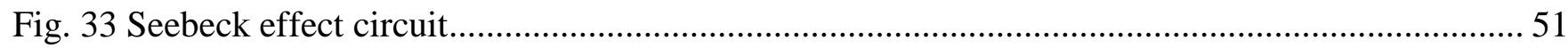

Fig. 34 Calibration result of the linear displacement transducer ........................................................52

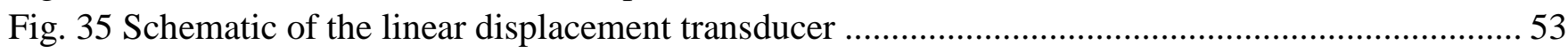

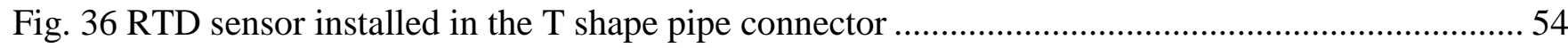

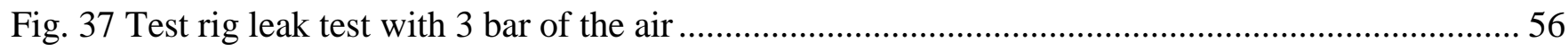

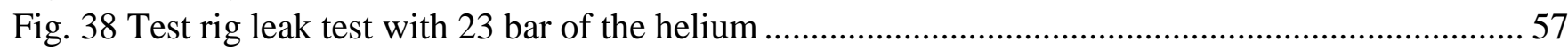

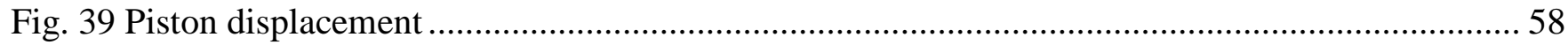

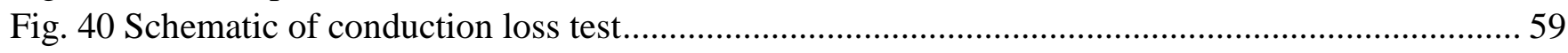

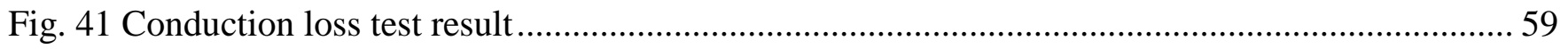




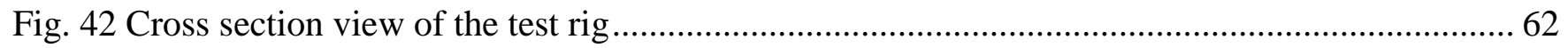

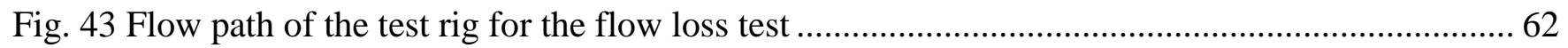

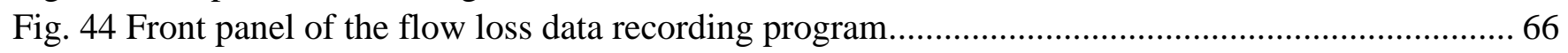

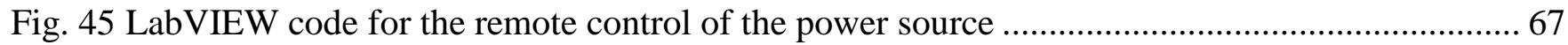

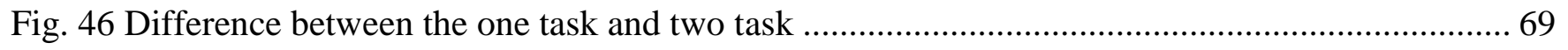

Fig. 47 Difference between the DAQ assistant and the DAQmx .............................................. 71

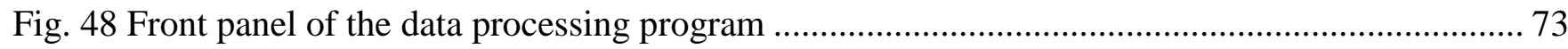

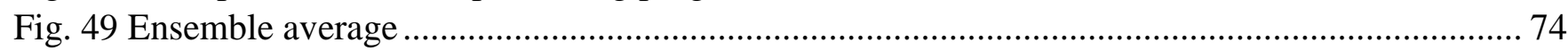

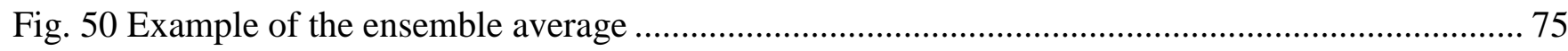

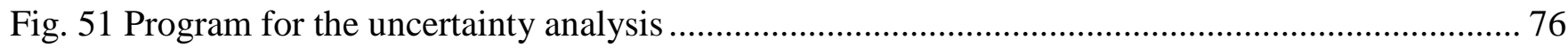

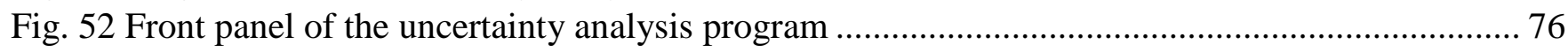

Fig. 53 Clamped mesh block by the stainless-steel plate........................................................ 78

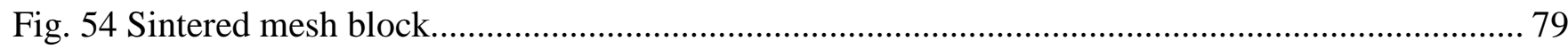

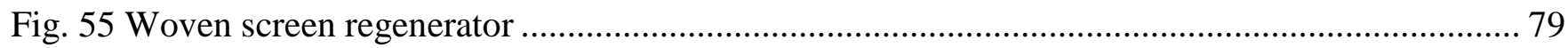

Fig. 56 Comparison of the woven screen regenerator friction factors ........................................... 81

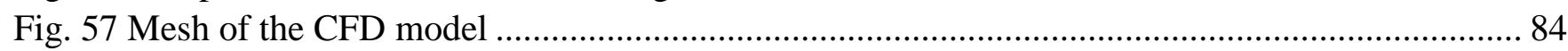

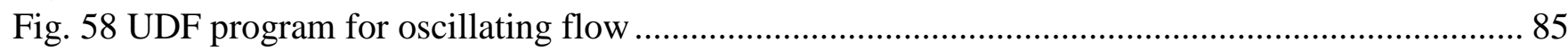

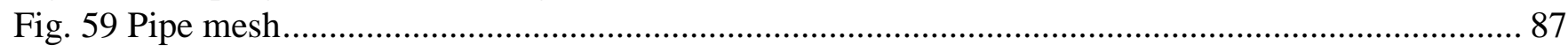

Fig. 60 Wall shear from the CFD result for 8 cycles .................................................................. 87

Fig. $61 \mathrm{Wall}$ shear from the CFD result for 40 cycles ................................................................ 88

Fig. 62 Comparison of the pipe friction factor ....................................................................... 88

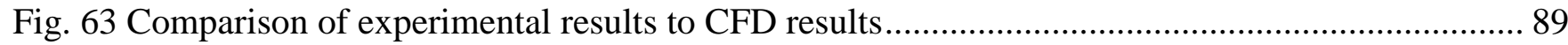

Fig. 64 Comparison of regenerator friction coefficient .............................................................. 91

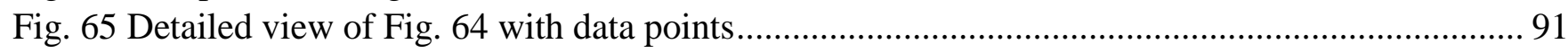

Fig. 66 Cross section view of the test rig with the band heaters.................................................... 94

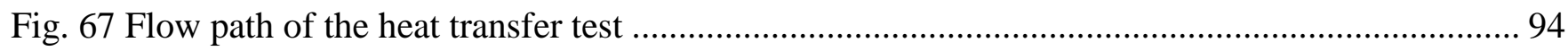

Fig. 68 Front panel of the heat transfer test data recording system ............................................. 99

Fig. 69 LabVIEW program for the RTD sensor ................................................................ 100

Fig. 70 Front panel of the heat transfer test data processing program ............................................. 103

Fig. 71 Ensemble average for small number of data points in one cycle .......................................... 104

Fig. 72 Example of the ensemble average for the heat transfer test ............................................... 105

Fig. 73 Heater side measured and corrected temperature ........................................................... 106

Fig. 74 Cooler side measured and corrected temperature ...................................................... 107

Fig. 75 Mesh of the heat transfer CFD model ......................................................................... 110

Fig. 76 Comparison of regenerator Nusselt number ......................................................... 112

Fig. 77 Turbulence difference between the foil regenerator and the woven screen regenerator ........... 112

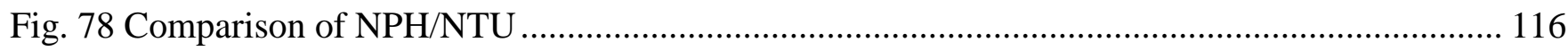

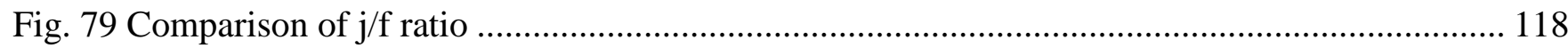

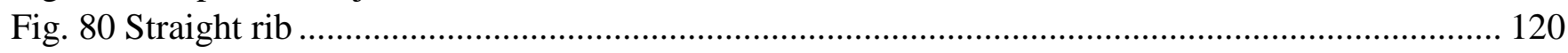

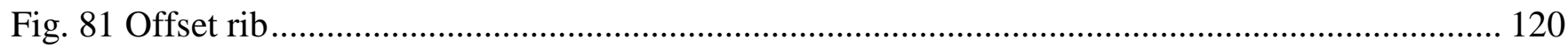

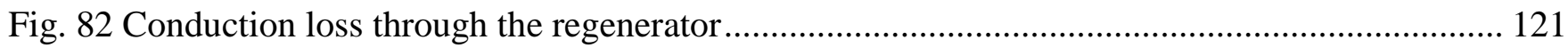




\section{Chapter 1: Introduction}

\section{Stirling Engine}

\section{1-1. Introduction to Stirling Engine}

Due to the energy crisis and environmental problems, many countries are developing renewable energy systems that are environment friendly. Conventional electricity generation wastes more than two thirds of its heat energy while generating electricity. Combined Heat and Power (CHP) is highly efficient energy conversion technology, which generates electricity and heat simultaneously by utilizing wasted heat energy. One system that can be used in CHP is the Stirling engine [1, 2, 3]. Because of its simple design, flexibility of heat source, high thermal efficiency, and high reliability, the Stirling engine is expected to be one of the best candidates for space applications in the future. The most commonly used engine currently, is the internal combustion engine. It burns fossil fuel inside the engine and generates mechanical work [4]. Different from the internal combustion engine, the Stirling engine is an external combustion engine that internally experiences the oscillatory motion of the working fluid. Thus, the Stirling engine can utilize various heat sources such as solar, bio-mass, and industrial waste. The heat applied to the working fluid contributes to the thermal expansion and compression of the working fluid. The expansion and compression lead the oscillatory piston motion which is converted to electrical energy by the linear alternator. Normally, the efficiency of the Stirling engine is $30 \%$ to $40 \%$. The operating temperature is approximately $800{ }^{\circ} \mathrm{C}$ and the operating frequency is approximately $60 \mathrm{~Hz}[5,6]$.

\section{1-2. Working principle of Stirling engine}

The Stirling engine ideally works based on the Stirling cycle. Basically, there are four steps to complete the Stirling cycle [7]. 1. Isothermal compression, 2. Constant volume heating, 3. Isothermal expansion, 4. Constant volume cooling [8]. Fig. 1 shows the P-V diagram of the Stirling cycle and 1 cycle oscillatory motion of the Stirling engine. Fig. 2 represents the schematic of the piston motion. Process 1-2 is the isothermal compression process. Due to the heat extraction from the cooling side, the piston of the cooling side 
moves towards to the regenerator. Process 2-3 is the constant volume heating process. Both of the pistons at the cooling side and heating side move to the right. Process 3-4 is the isothermal expansion process. Because the working fluid heats up from the heat addition, the pistons of the heating side move to the right. Process 4-1 is the constant volume cooling process. Both pistons at the cooling side and heating side move to the left. The Stirling cycle shown in Fig. 2 is an ideal cycle. The actual Stirling cycle is slightly different from the ideal cycle. Fig. 3 shows the actual Stirling cycle $[9,10]$.
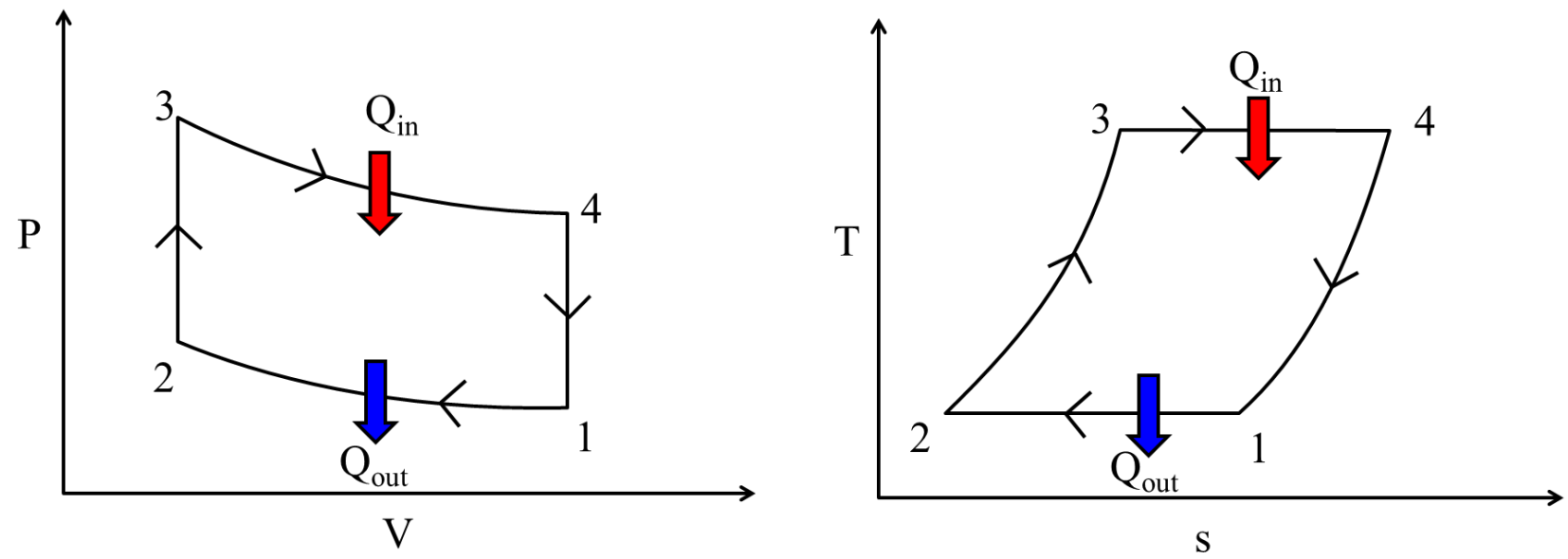

Fig. 1 P-V diagram and T-s diagram of Stirling cycle
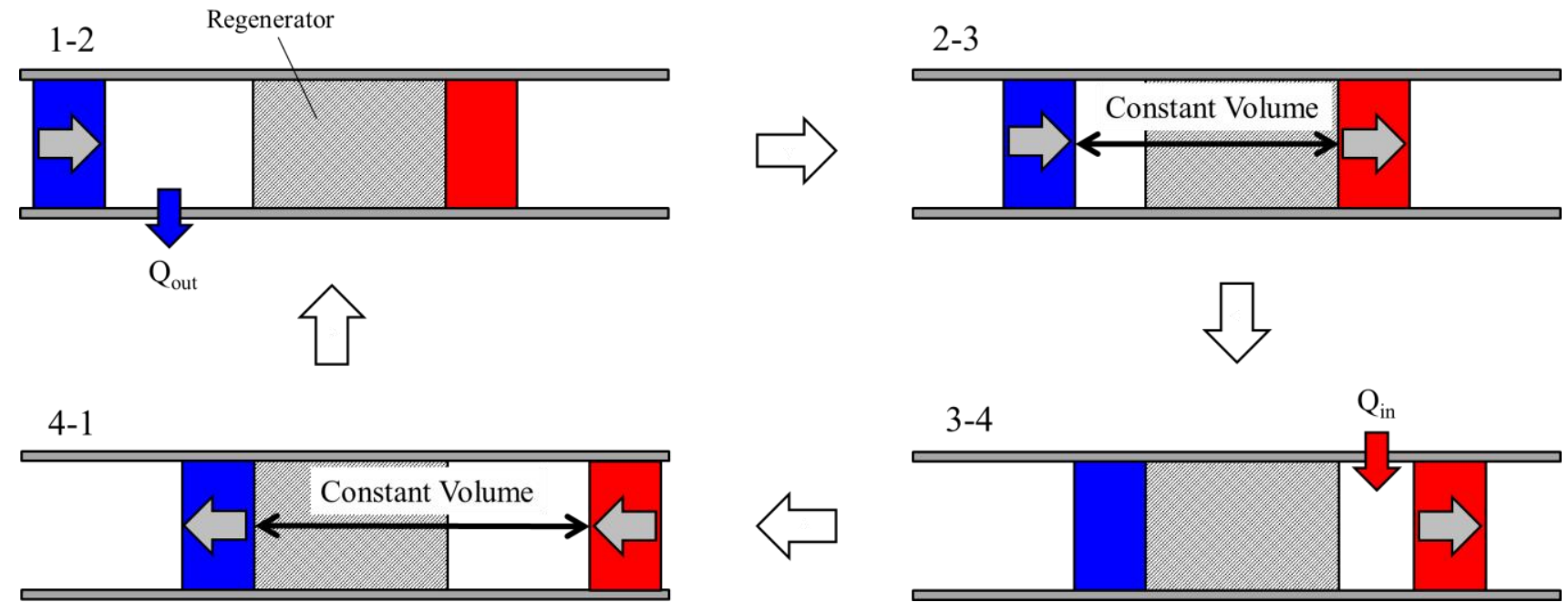

Fig. 2 Piston motion of Stirling cycle 


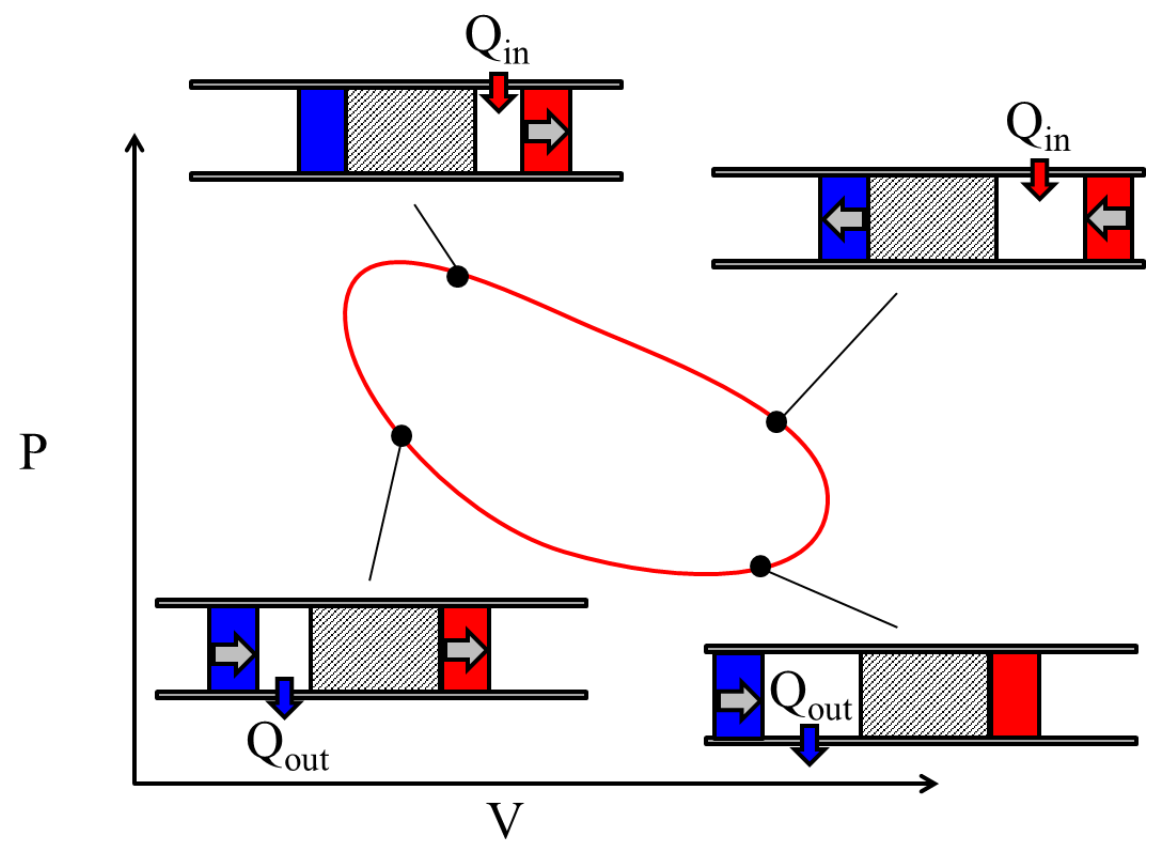

Fig. 3 Actual Stirling cycle

\section{1-3. History of Stirling Engine}

The Stirling engine (closed cycle regenerative engine) was invented by Robert Stirling with his brother in 1816 [11, 12]. For this Stirling engine, air was selected as the working fluid due to two advantages. One of the advantages is that the air Stirling engine is safer than the high-pressure steam engines [13]. Another advantage is the latent heat. The latent heat of steam is relatively high compared to air; therefore, major amounts of heat is wasted at the condenser of the steam engine [14]. One of his great ideas for the Stirling engine is a plunger-displacer which generates reciprocating motion. In his patent, the introduction of the plunger-displacer was a critical step into creating the regenerator principle.

Later, the Stirling engine was further developed by Professor McQuorne Rankine. However, due to the requirement of high temperature operating conditions for the Stirling engine, the material availability was very limited in those early years. Therefore, it never became available for commercial use in the 1800's. Instead of the Stirling engine, a steam engine was widely used because it was smaller than the Stirling engine with the same power output. After the development of steel, most of the initial problems of the Stirling engine were solved. However, it was too late. Robert Stirling mentioned “... These imperfections 
have been in great measure removed by time and especially by the genius of the distinguished Bessemer. If Bessemer iron or steel had been known thirty-five or forty years earlier there is scarce a doubt that the air engine would have been a great success... It remains for some skilled and ambitious mechanist in a future age to repeat it under favorable circumstances and with complete success...." in 1876 [15].

For a while, the Stirling engine was not prioritized because other engines were developed more quickly for applications. The Stirling engine was developed as a small power generator at the Philips Research Laboratory in Eindhoven (Holland) during the mid-1930s. It was to supply quiet and efficient electric power for radios without a regular power supply. During World War II, the Stirling engine kept on developing. From 1958 to 1970 , General Motors and the Philip Research Lab made a license agreement for the Stirling engine. The project of Stirling engine usage was for space, underwater power, vehicle, and stationary power. After the contract with General Motors and the Philips Research Laboratory, Ford Motors had a new contract for the automotive Stirling Engine until 1977. Additionally, in the early 1970s, there was an effort between the Philips Research Lab and the European companies to develop vehicle engines, and underwater power systems. Around this time of period, NASA started the Stirling engine project at the Lewis Research center [15].

In the early 1970s, the free piston Stirling engine, which we are currently developing at the WVU Energy Conversion lab, was invented by Theodor Finkelstein and William Beale, a professor at Ohio University. Beal's company, Sunpower Inc., developed the free piston Stirling engine for nuclear-fueled space power and solar powered electric generators [16].

Furthermore, the Stirling engine can be operated as a cooling engine. It was noticed in the early 1830 s by John Herschel. Unfortunately, the Stirling cooling system was not prioritized either as the technology of commercial applications until the 1940s. Dr. J. Kohler at the Philips Company also lead it project. In 1953, the first cooling system was invented. Later, some other companies joined the cooling engine field. These companies developed small cooling engines for electronic applications such as military and civil purposes [15]. 
Now, due to the environmental impact from power generation with fossil fuel and the requirement of renewable energy, the Stirling engine is gaining attention. The Stirling engines can be adapted to most of the heat sources, which can be solar, bio-mass, and industrial waste heat.

\section{1-4. Type of Stirling engine}

1. Alpha type Stirling engine [17]

The alpha type Stirling engine is composed of two power pistons in the separate cylinders, one is the heater side, and another is the cooler side. The schematic of the alpha type Stirling engine is shown in Fig. 4.

\section{Advantage}

- Due to the two power pistons, the compression ratio of the fluid can be higher, and the engine output can be enhanced.

- Unlike the other types of Stirling engine, the rod sealing is not required. Therefore, the design of the engine can be easier.

Disadvantage

- The sealing at the piston is difficult for the engine efficiency. Especially, the heater side sealing is difficult due to the high temperature.

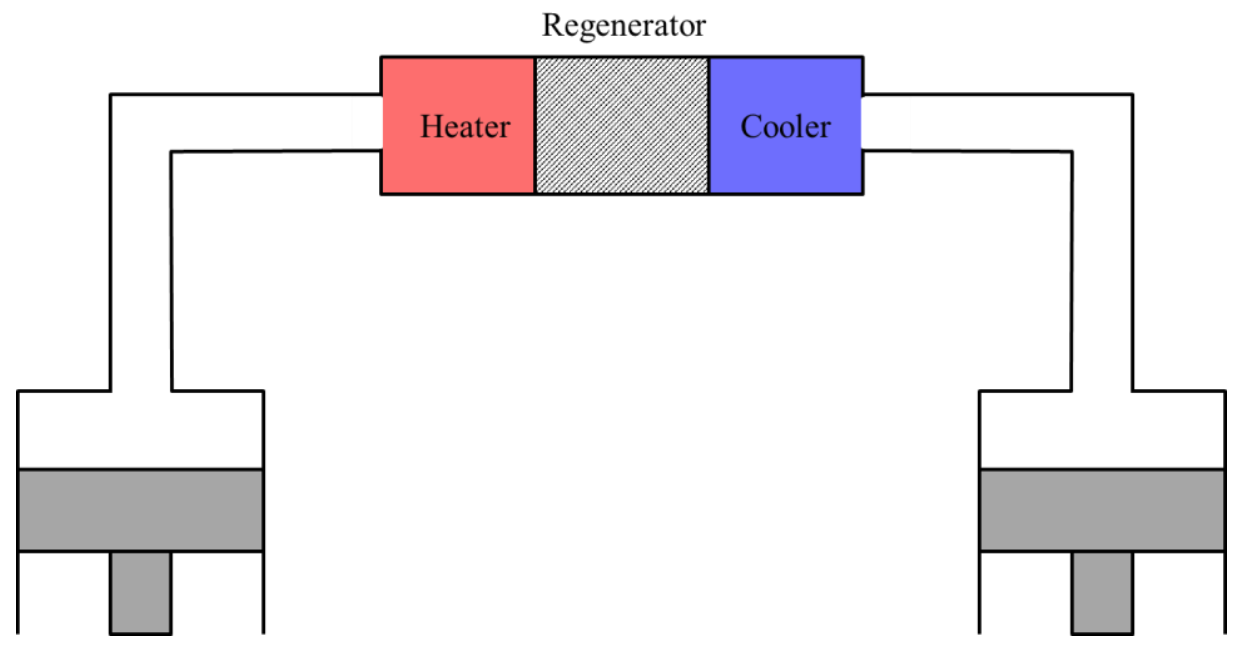

Fig. 4 Alpha type Stirling engine 
2. Beta type Stirling engine [18]

The Beta type Stirling engine has a displacer piston and power piston in the same cylinder (The diameter of two pistons are the same). Ideally, the displacer does not extract any power from the working fluid. In reality, there is some loss because of the friction and flow losses but losses are not substantial. It works as a shuttle moving the working fluid from the heater side to the cooler side, and back and forth. Because the displacer piston pushes the working fluid to the heater or cooler, the working fluid is heated up by the heater and cooled down by the cooler, resulting in expansion and compression. This expansion and compression action pushes the power piston to generate electricity. The schematic of the alpha type Stirling engine is shown in Fig. 5.

\section{Advantage}

- Because the two pistons are in one cylinder, minimizing the engine size can be achieved.

- Decreased dead volume of the engine results in the higher output of the engine.

Disadvantage

- To keep the proper phase difference between the displacer piston and the power piston while the engine is running, the design of the driving system of the engine is complex. 


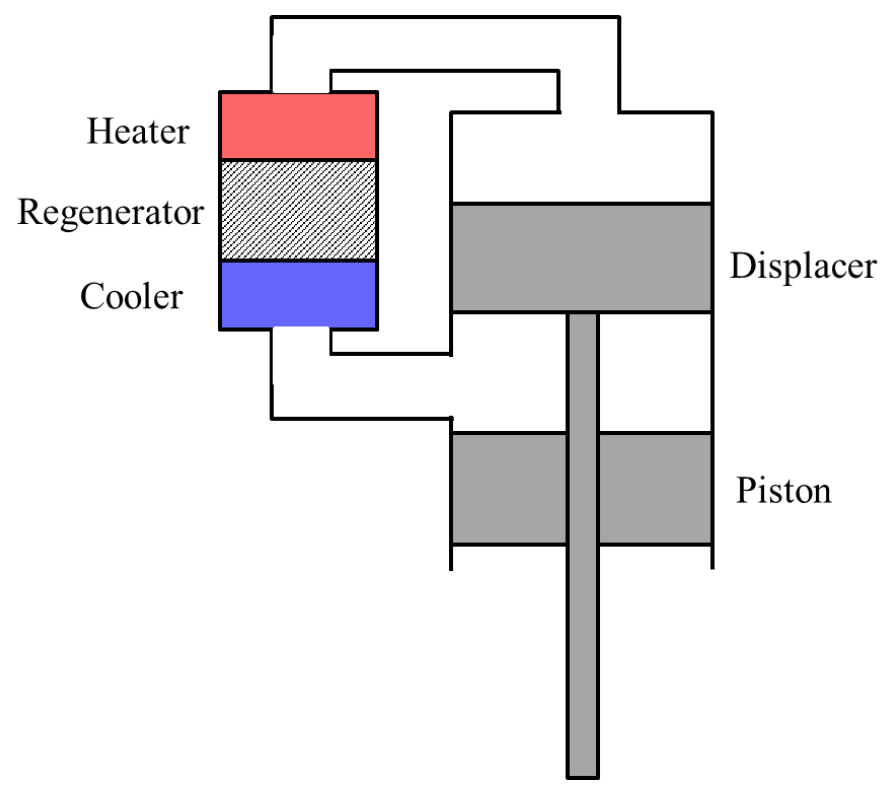

Fig. 5 Beta type Stirling engine

3. Gamma type Stirling engine [19]

The displacer piston and the power piston are placed in the different cylinders (The diameter of two pistons could be different). The displacer works the same as the one in the beta type Stirling engine. The schematic of the Gamma type Stirling engine is shown in Fig. 6.

Advantage

- The configuration flexibility of the heat exchangers is high.

- The volume ratio of the displacer cylinder and the power piston cylinder is easy to change. Therefore, Gamma type is suitable for low temperature difference engine which requires a massive heat input.

Disadvantage

- The size of the engine is bigger than the beta type engine since it has two cylinders.

- Due to the engine size problem, the dead volume of the engine is larger. Thus, the engine output gets lower. 


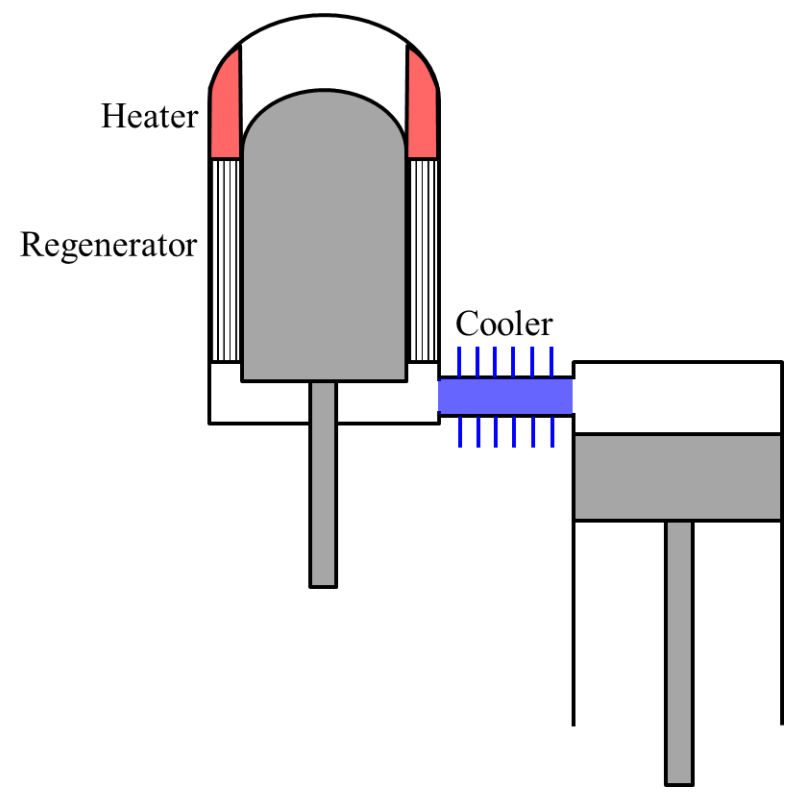

Fig. 6 Gamma type Stirling engine

4. Free piston Stirling engine

The Stirling engine became one of the CHP candidates due to the development of the modern free piston Stirling engine. It was invented by Beale in 1964 [20] [21]. The free piston engine design was manipulated to solve the leakage issues of the beta type Stirling engine. The mechanical connections were all eliminated to prevent gas leakage. The schematic of free piston Stirling engine is shown in Fig. 7.

Advantage

- No leakage due to the absence of mechanical connections. And less friction loss due to the free piston. High frequency running is achievable.

- Since there are no mechanical connections, the sealing can be done easier than the other types of the Stirling engine. Therefore, the expected lifespan of this engine is approximately 10 years. [22, 23, 24]. 


\section{Disadvantage}

- Due to the absence of mechanical connections between the displacer piston and the power piston, the phase shift of these pistons is difficult to keep at the designed phase shift.

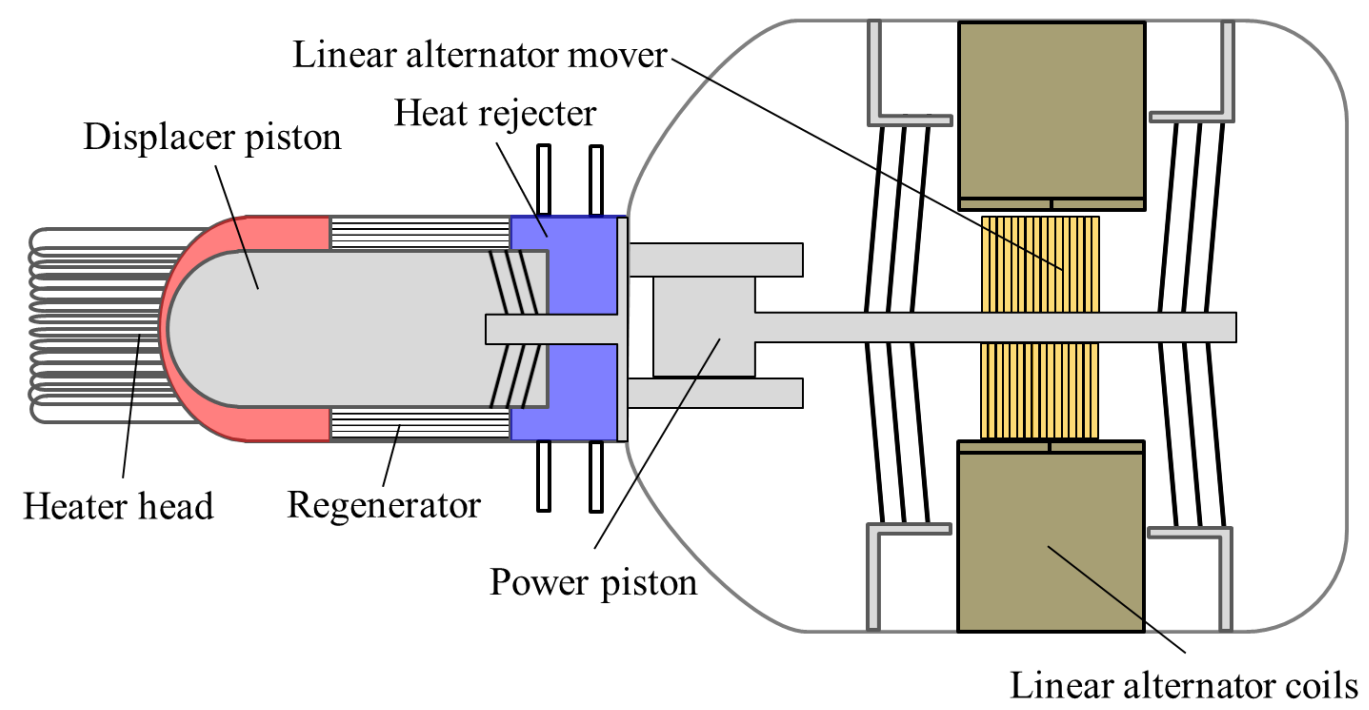

Fig. 7 Free piston Stirling engine

\section{1-5. Advantage and disadvantage of the Stirling engine}

Advantage [25]

- Flexible heat source: The Stirling engine only requires the heat from external heat sources, making the heat source choices extremely flexible. For example, solar, biomass, nuclear, and industrial waste.

- No air: The Stirling engine is a closed cycle engine, which means that no air supply is required to run this engine. Therefore, it can work in any environment such as under the water, and in space.

- Single phase working fluid: The working fluid in the Stirling engine is single phase (gas) and the pressure of the working gas does not change significantly. Thus, the risk of an explosion is low.

- Potentially high thermal efficiency, low noise, and vibration. 
Disadvantage [25]

- Cost: It is expected that the cost of a high efficiency Stirling engine could be significantly high.

- Weight: To maintain the coolant at low temperature, the cooler configuration gets complicated, requiring larger radiators, increasing the size of the engine.

- Low power density: The main problem of the Stirling engine is the low power density, which is the low power obtained per liter of engine cylinder volume even if hydrogen or helium are used as the working fluid of the engine.

- Gas leakage, large volume [5]

\section{1-6. Research about Stirling engine}

The Stirling engine research is often carried out by both numerical simulation and experimental. For the numerical simulation, many numerical models have been developed for the Stirling engine. Mahkamov et al. [26] utilized an asymmetrical $k-\varepsilon$ turbulence model to conduct the numerical simulation for the solar Stirling engine. According to Mahkamov, the proposed model showed a more accurate prediction compared to the traditional models. The models proposed by Schmidt et al. are the most commonly used for the Stirling engine numerical simulations [27, 28]. Timoumi et al. [29] used a second-order Stirling model to optimize the GPU-3 Stirling engine performance. The parameters for the engine were decided based on the simulation results. By utilizing the parameters, the efficiency of the engine increased $12 \%$. Cheng et al. [30] proposed a theoretical model for a Beta-type Stirling engine. According to the result, the periodic variation of pressure, volumes, temperatures, masses, and heat transfer were able to be accurately predicted by using the model. Due to the low experimental performance, the alpha type Stirling engine did not gather attention for Stirling engine research. However, Tlili et al. [31] used a second order simulation for the alpha type Stirling engine. It was mentioned that there are some advantages to the alpha type engine such as minimizing vibration and lateral forces of the piston. Therefore, as a result of the analysis, the engine performance is dependent on the

precision of the engine parts and the heat source efficiency. It was also reported that the 
regenerator effectiveness significantly affects the engine performance. Prior to the testing, Tavakolpour et al. [32] modeled a two-cylinder Stirling engine which was gamma type with low temperature operating conditions. The temperature difference is only approximately $80^{\circ} \mathrm{C}$. The optimization result of the engine parameters was reported in the paper. The analysis model used for a small $100 \mathrm{~W}$ displacer type Stirling engine by Hirata et al. showed a good agreement with the experiment results including the regenerator pressure loss and gas leakage [33]. Grosu et al. [34] conducted both a simulation and an experiment to examine the Stirling engine performance with the double acting pistons. Consequently, the models (Direct method and Adiabatic model) used in the paper represent a good agreement to the experiment result. Kawajiri et al. [35] carried out an experiment and the simulation to evaluate and predict the Stirling engine performance. The thermodynamics cycle simulation model was developed to clarify the losses and the heat transfer of the engine. Additionally, the burner performance simulation and the mechanical loss simulation were conducted and compared to the experimental results. As a conclusion, it was shown that the engine performance can be predicted by the combination of all three simulation results. The difference between the experiment and the simulation is $10 \%$ for the shaft power and $2 \%$ for the net thermal efficiency.

For experimental study, Kongratragool et al. [36] carried out an experiment for a gamma type Stirling engine with a solar power at the atmospheric pressure of air. The experimental result showed that the engine performance and the heater temperature are dependent on the solar intensity. It was also mentioned in the paper that the heat accepter performance should be improved to increase the engine efficiency. Iwamoto et al. [37] tested two different types of Stirling engines, a low-temperature difference Stirling engine (LDSE) and a high-temperature difference Stirling engine (HDSE). According to the Carnot efficiency $\left(=1-\mathrm{T}_{\mathrm{c}} / \mathrm{T}_{\mathrm{E}}\right)$, the LDSE and HDSE efficiency are 0.2 and 0.58 respectively. However, the LDSE can accept various heat sources since the required operating temperature is not high. Therefore, it was noted that further research is necessary to develop more efficient LDSE. Hirata et al. [38] built a gamma type Stirling engine to achieve a small and cost friendly Stirling engine. The target output power of the engine was $50 \mathrm{~W}$. As a result, it was concluded that a higher efficient heat exchanger and lower mechanical loss are required to obtain a $50 \mathrm{~W}$ output from the engine. Kwankaomeng et 
al. [39] experimentally studied a free piston Stirling engine to characterize the stability and performance of the engine. The test result indicates that the maximum output power of the engine is $0.68 \mathrm{~W}$ with $6.4 \mathrm{~Hz}$ of the operating frequency when the input thermal energy is $10 \mathrm{~W}$. The engine is the most stable when the engine operating frequency is 6.2 to $6.4 \mathrm{~Hz}$. However, due to the poor operating conditions of the working fluid, the engine output is relatively low. Xiao et al. [40] investigated a 36-tube Stirling engine heater to improve the heat transfer from the heat source. The testing conditions are similar to the actual engine operating conditions. It was found that the heat transfer correlations under oscillating flow conditions are not close to the unidirectional steady flow, especially at a high Reynolds number. Cheng et al. [41] tested a beta type $300 \mathrm{~W}$ Stirling engine. By using helium instead of air as the working fluid of the engine, the shaft power output of the engine is improved significantly and produces $32.2 \%$ of the thermal engine efficiency. The simulation was also conducted to predict the engine efficiency. The thermal efficiency of the simulation result is $36.4 \%$ and it was concluded that the simulation is valid to estimate the engine efficiency. Gheith et al. [42] carried out the experiment with a gamma type Stirling engine. It was reported that the output brake power of the engine depends on the charge pressure and the coolant flow rate of the cooler. Also, according to the temperature measurement, the asymmetric temperature distribution of the working fluid in the regenerator affects the overall performance of the engine. Li et al. [43] investigated the flow loss of the gamma type Stirling engine based on the Finite Speed Thermodynamics and Isothermal methods. In accordance with the simulation result, the regenerator causes the heat loss which heavily affects the engine performance. Also, the leakage through the gap between the piston and cylinder is important to the engine efficiency as well. Additionally, Li et al. [44] developed a Polytropic Stirling Model with Losses (PSML) to estimate the beta and gamma Stirling engine performance. The polytropic process was added to the classic adiabatic model. Moreover, many types of loss were considered. By comparing to the GPU-3 Stirling engine, the result showed that the PSML model estimates the engine output power and efficiency accurately.

\section{1-7. Applications}

- Cogeneration (CHP) 
Waste heat is always generated through the energy generation due to the second law of thermodynamics. The waste heat can be utilized by the Stirling engine for industrial or agricultural processes [45].

- Solar power generation

To heat up the working fluid of the Stirling engine, the solar power is utilized. By using a parabolic mirror, the solar energy is collected [45]. Recent research shows that the output of the solar powered Stirling engine is not high. However, high reliability and low cost are attractive features as a power generator [46].

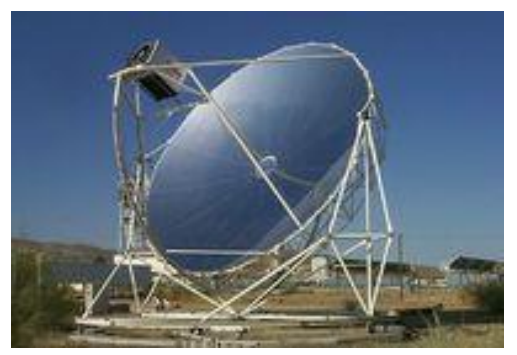

Fig. 8 Solar power Stirling engine [45]

- Cars

General Motors and Ford investigated the Stirling engine for cars in the 1970s and 1980s. Due to the difficulty of changing the power output from the Stirling engine quickly, Stirling engine was utilized for the hybrid electric cars. This idea makes the car quiet and decreases the exhaust gas produced [47]. 


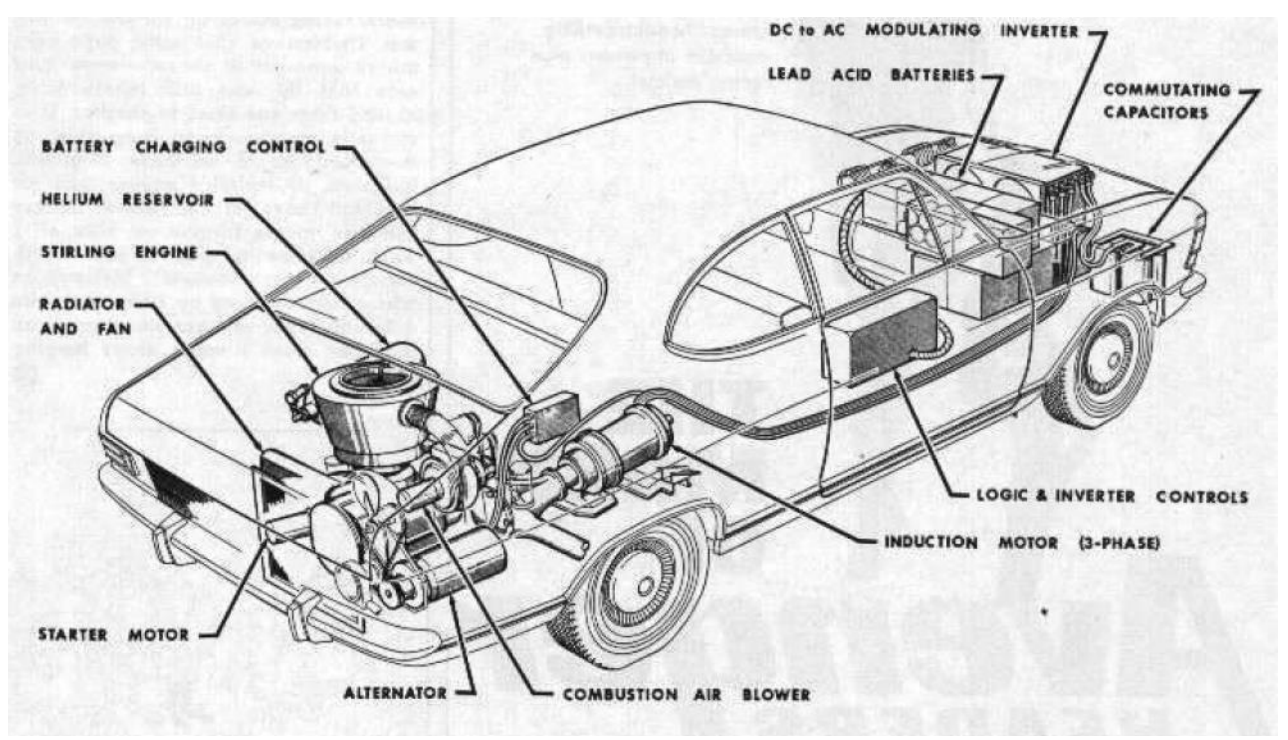

Fig. 9 Stirling engine for a car [47]

- Submarines

The first Stirling powered submarine was built by Swedish ship builder Kockums. To compare the Stirling powered submarine to the conventional submarine, the duration time to dive with the Stirling powered submarine is a week longer [45, 48].

- Nuclear plant

The Stirling engine has the potential to replace the steam turbines in nuclear reactors. Possibly, it increases the plant's efficiency in the future [45].

\section{1-8. Stirling engine with a few new concepts in WVU Energy Conversion Laboratory}

The free piston Stirling engine was built in our lab with a few improvements. All of the designing and building was done by Dr. Ruijie Li. In this section, the new concept engine is introduced briefly. Fig. 10 shows the free piston Stirling engine and the CAD model. 


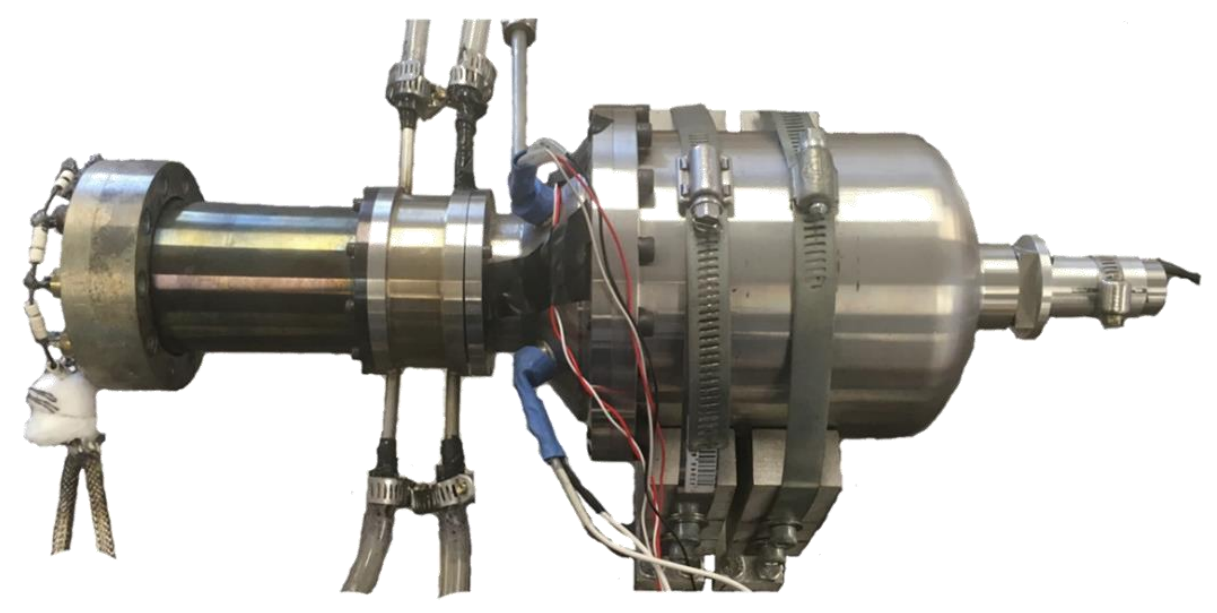

(a) Actual engine

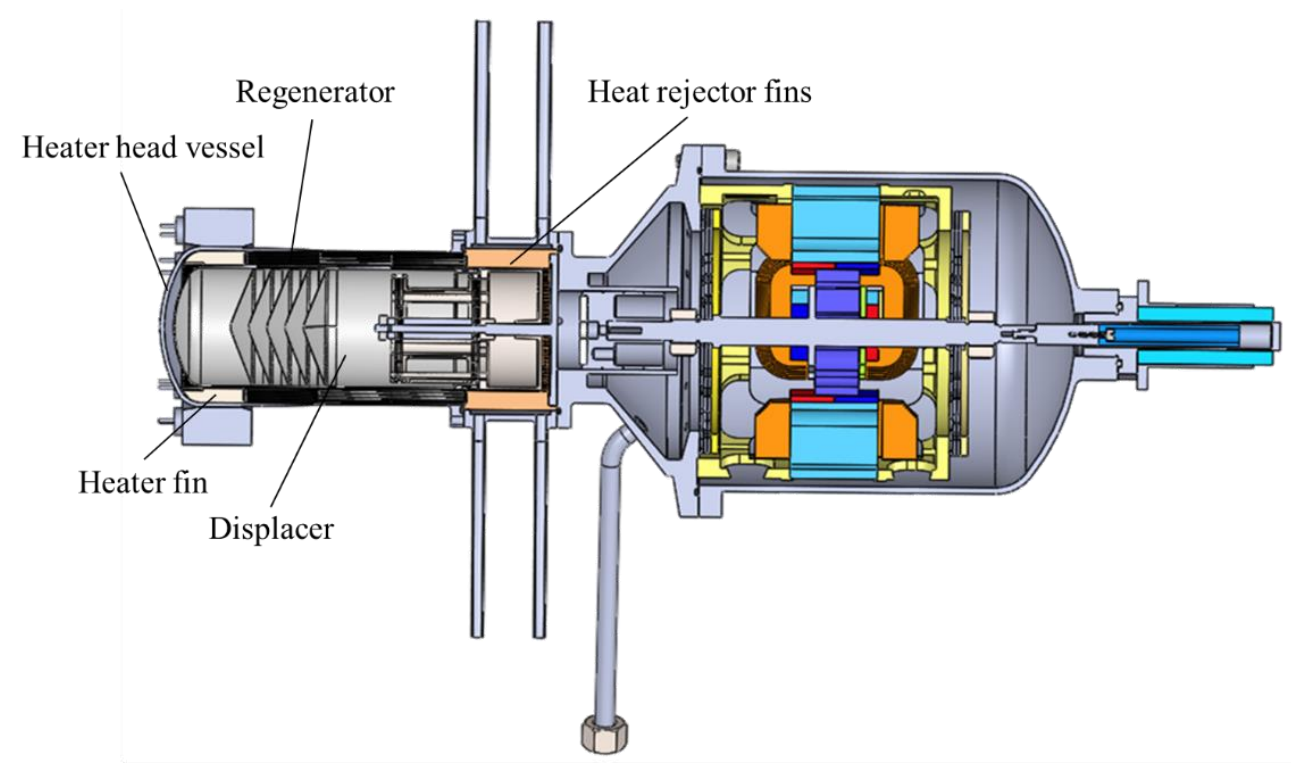

(b) CAD model

Fig. 10 Free piston Stirling engine in our lab

The details of the new concepts are below.

- Reduce the dead volume of the heat accepter

A curved fin was designed and manufactured by wire electrical discharge machining. It has 87 fins with the curved fin. Fig. shows the 3-D fin curved fin CAD model. Fig. 11 shows the straight fin and curved fin at the heat accepter. As a result, the dead volume is decreased by $27.8 \%$. 


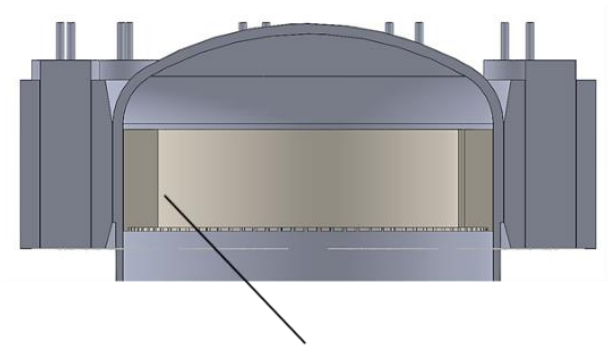

Straight Fin

(a) Straight fin

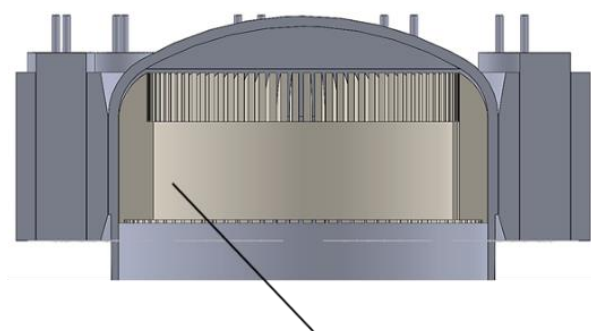

Curved Fin

(b) Curved fin

Fig. 11 Straight fin and curved fin

- Improve stress distribution and decrease conduction loss of the pressure vessel

At the top of the pressure vessel, the wall thickness is large due to the high temperatures. However, towards the bottom of the vessel, the wall is tapered to reduce the conduction loss through the pressure vessel wall. Fig. 12 shows the CAD model pressure vessel and a detailed view of the tapered wall.

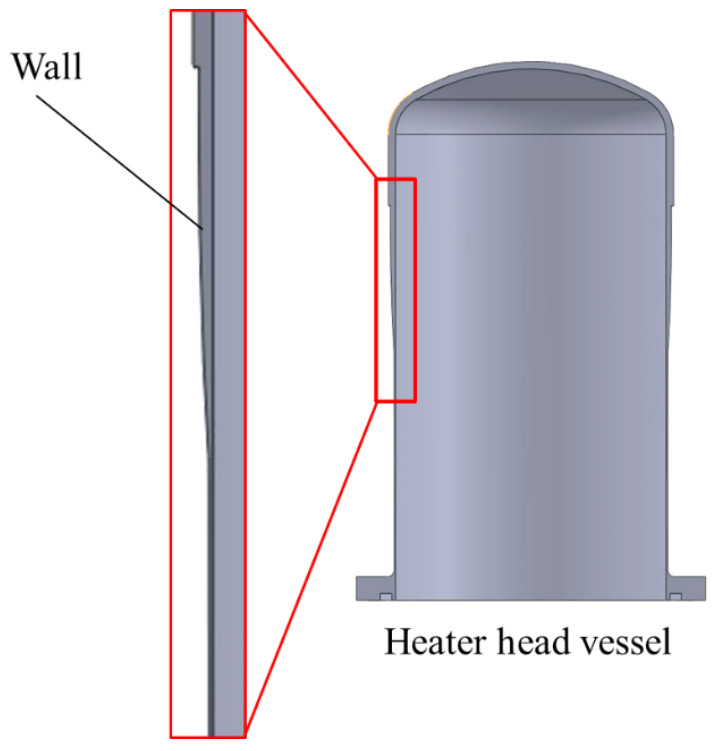

Fig. 12 Heater head vessel

- Reduce the conduction and radiation of the displacer piston 
To reduce the conduction through the displacer wall, the wall of the displacer is considerably small. In addition, to prevent heat loss due to the radiation inside the displacer, the radiation shields were installed. Fig. 13 shows the Displacer piston.

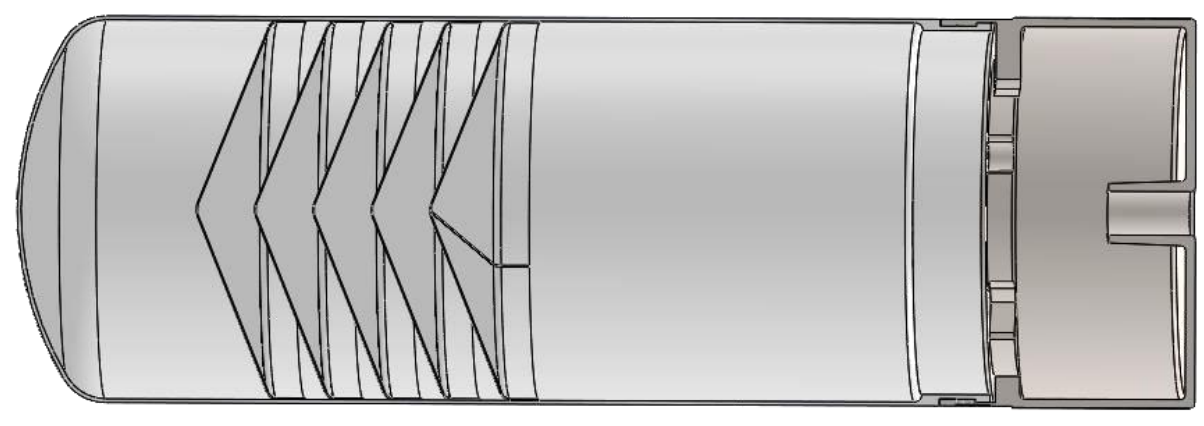

Fig. 13 Displacer piston

- Reduce flow loss at the heat rejecter

Heat rejecter is installed in the engine to cool down the working fluid. However, the flow loss of the heat rejecter affects the engine efficiency. To reduce the flow loss, a special fin was designed and manufactured by additive manufacturing. Fig. 14 shows the special fin and a detailed view. As shown in Fig. 14 , the fin is not flat and flow loss is decreased compared to the flat fin.

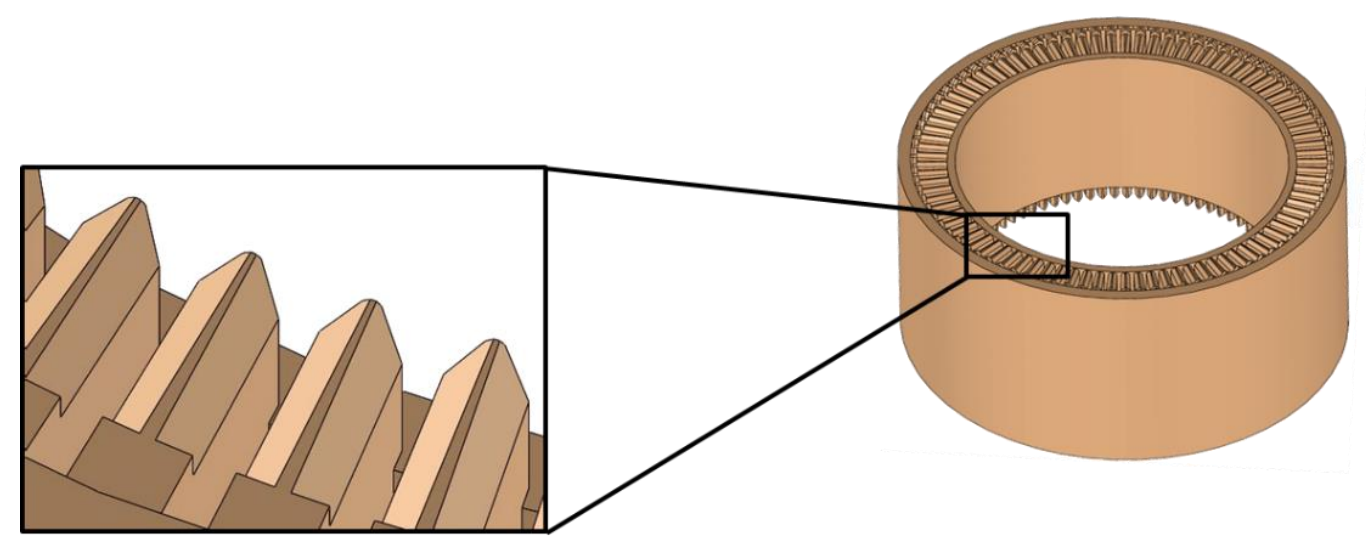

Fig. 14 Heat rejecter fins 
- New regenerator

To reduce the flow loss through the regenerator, a new foil type regenerator was designed. The flow and thermal characteristics of the regenerator were investigated in this thesis.

\section{Regenerator}

\section{2-1. Introduction to the regenerator}

The regenerator is one of the crucial components in the Stirling engine. It is located between the heater and cooler of the engine. Since it works as an energy storage device of the engine, the performance of the regenerator directly affects the engine efficiency. Fig. 15 shows the schematic of the working principle of the regenerator. As the hot fluid goes through the regenerator, the regenerator absorbs the heat energy from this hot fluid, cooling it down. Vice versa, when the cooled fluid goes through the regenerator, the regenerator supplies heat energy to heat it up [49]. Chen et al. [50] showed that the regenerator performance impacts the Stirling engine performance. In their study, the matrix screens were installed in different ways. One of them had the matrix screen surface perpendicular to the working fluid, and the other had the matrix screen parallel to the working fluid. As a result, the perpendicular installation gives a much higher engine performance than the parallel installation. 


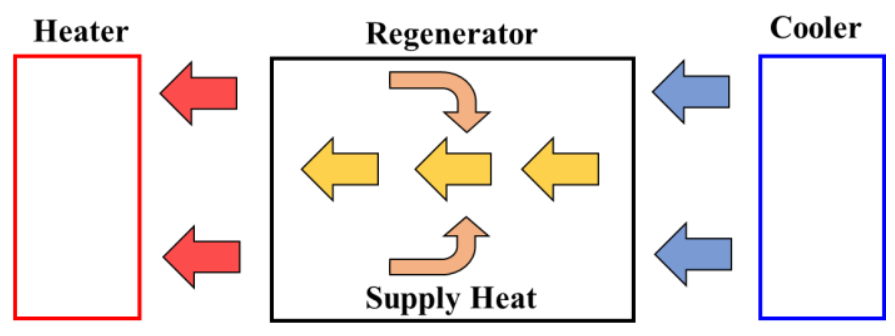

Flow from cooler to heater
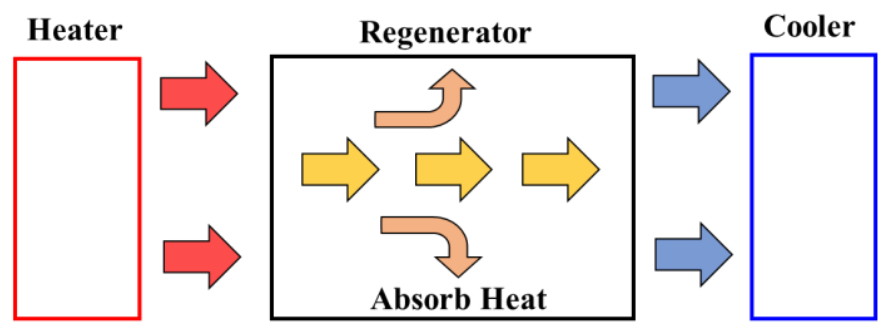

Flow from heater to cooler

Fig. 15 Working principle of the regenerator

Originally, the regenerator was invented by Robert Stirling in 1816 [51]. Back then, it was called the "economizer". It applied for a patent known as the regenerative principle in 1826. Ericson opposed to Stirling claiming the economizer, however, it was not accepted since the patent had been received already [52]. In 1833, Ericson introduced a new engine with the regenerator. The Ericson engine did not have an important impact, but it contributed to the estimation of the regenerator value. Gustav Hirn conducted the analysis of the Ericson engine to understand the amount of work that is generated in one cycle of the piston stroke [52]. Based on Hirn's point of view, Gustav Zeuner concluded that the regenerator did not make any contribution unless the air engine itself was failing to function properly. This is because he failed to notice that the heating and cooling occurs in the Stirling engine regenerator while the constant volume process of Stirling cycle. Subsequently, Rankine mentioned that utilizing the regenerator in the Stirling cycle makes the air engine to reach maximum efficiency with a smaller degree of expansion.

Due to the lack of thermodynamics development, the regenerator was evaluated as a useless component for half of the nineteenth century. Especially, because of the success of the hot air engine without a regenerator by Mauel [52]. About 100 years after Stirling's patent, Schumann's solution was the first step for regenerator research in terms of the heat transfer 
$[53,54]$. It has been the only solution until recent advanced research on the woven screen [55] despite being under the estimations of incompressible flow and uniform velocity distribution [56].

\section{2-2. Wire media regenerators and the problem of the flow loss}

There are some requirements for the regenerator material and the configuration selection [57]. One of the most important functions of the material is the large surface area to which maximizes the heat transfer of the working fluid. The second important function is the minimization of the flow loss through the regenerator which prevents low engine efficiency. Also, note that the specific heat of the material needs to be higher than the working fluid at the operating temperature. Lastly, because the regenerator is located between the cooler and the heater, the regenerator separates the cold side and the hot side of the engine, thus the axial conduction through the regenerator should be minimized as well by separating regenerator in a few pieces.

Some of the material selection requirements are in contradiction such as high heat transfer and the low flow loss. Most regenerators are made of the wire media such as random fiber and woven screen. This is because of the excellent heat transfer characteristics and the low axial conduction of the regenerator. Fig. 16 shows the image of the woven screen and the random fiber. Many researchers have conducted experiments and numerical simulations for the woven screen and random fiber regenerators. Tanaka et al. [58] tested three types of regenerators which were composed of wire netting, sponge metal, and woven screen. It was found that all three materials have a similar friction coefficient correlation regardless of the porosity. The Nusselt number correlation was also derived based on the instantaneous temperature at the inlet and outlet of the regenerator. The result showed that the wire netting regenerator's Nusselt number correlation does not change with a porosity range of $64.5 \%$ to $72.9 \%$. Subsequently, it was mentioned that the hydraulic diameter can be used to estimate the pressure drop. And, also that the thermal efficiency can be affected by the heat transfer and the flow loss of a regenerator. Ju et al. [59] also investigated the wire mesh regenerator with experimental testing as well. The results showed that the pressure drop through the regenerator is two to three times higher than the unidirectional flow at the same Re number. Costa et al. 
[60] reported that the wire mesh regenerator efficiency increases with an increase in mass flow rate, also that the efficiency of the cooling process is greater than the heating process. However, Alfarawi et al. [61] stated that the flow going through the woven screen and random fiber is similar to the cylinders in cross-flow which causes flow separation. To achieve higher engine efficiency, higher convective heat transfer, lower pressure drops, and lower axial conduction through the regenerator in the flow direction are required. One solution is to configure the regenerator with parallel channels to the oscillatory flow. In parallel channel configuration, flow separation is reduced significantly which means less flow loss through the regenerator. Ibrahim et al. [62] used microfabrication to build a segmented-involute-foil regenerator which has a smooth surface, less flow separation, and uniform flow distribution. However, the manufacturing cost is too high.
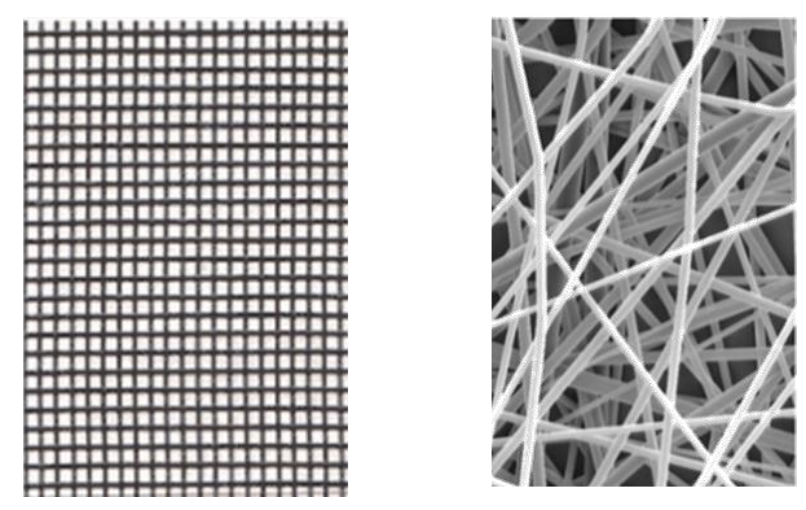

Fig. 16 Woven screen and random fiber

\section{2-3. Wrapped foil regenerator}

Theoretically, the parallel flow channel is the best configuration for the regenerator as it shows the greatest figure of merit which is usually used for the regenerator performance parameter [63]. Fig. 17 shows the figure of merit of various regenerators. Thus, in the previous study, a wrapped foil regenerator was designed to decrease the flow loss through the regenerator. Fig. 18 shows the conceptual layout of the wrapped-foil regenerator [64]. It is built by wrapping the foils layer by layer, the space between the layers is kept uniformly by dimples which were made on the foil before the wrapping process. However, because the layers are not physically connected, the foil spaces vary when repeating thermal expansion and 
compression. This causes the flow distribution inside the regenerator to no longer be uniform and, therefore, the effectiveness of the wrapped foil regenerator decreases rapidly. To correct this, a new robust foil regenerator was designed instead of the wrapped-foil regenerator [65].

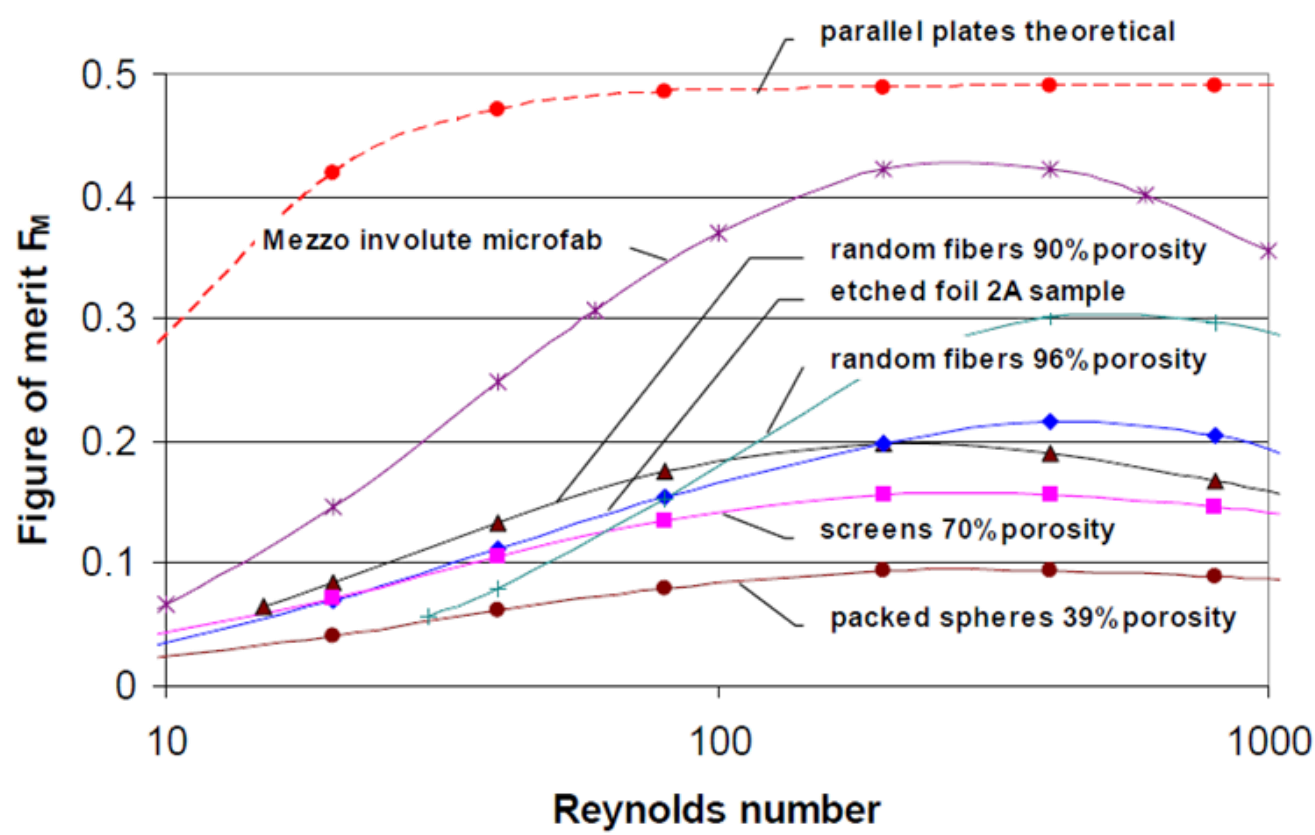

Fig. 17 Figure of merit

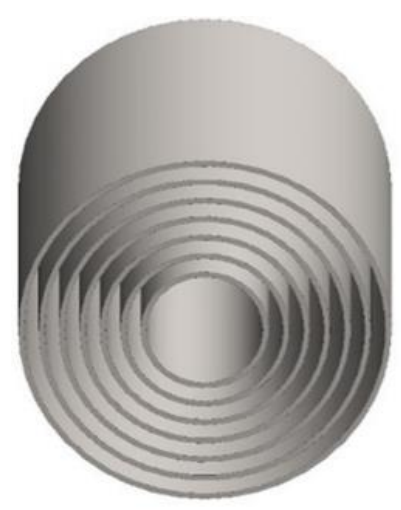

Fig. 18 Wrapped foil regenerator 


\section{2-4. Robust foil regenerator}

The first foil regenerator examined by using the one-dimensional software Sage has a foil thickness of $0.1 \mathrm{~mm}$ to check the flow loss and thermal efficiency of the foil regenerator. The Sage result showed [66] that the efficiency of the engine increases by approximately $4 \%$ when replacing the random fiber regenerator to the $0.1 \mathrm{~mm}$ foil regenerator. However, the foil thickness is beyond the current capabilities of additive manufacturing. Another way to manufacture the $0.1 \mathrm{~mm}$ foil regenerator is through macro matching, but the cost is significantly high. In order to take advantage of the cost-effectiveness of additive manufacturing, the thickness of the foils must be increased to a certain thickness which can be achieved by additive manufacturing. The thickness of the foils produced by additive manufacturing is limited by the size of the metal particles. In general, these particles have a diameter of approximately $0.05 \mathrm{~mm}$ to $0.06 \mathrm{~mm}$. According to various additive manufacturing vendors, the minimum achievable foil thickness is $0.3 \mathrm{~mm}$ to have enough stiffness of the regenerator. Consequently, a regenerator called the robust foil regenerator with the foil thickness of $0.3 \mathrm{~mm}$ was manufactured.

Fig. 19 shows the robust foil regenerator. The regenerator has a much thicker wall than the wrapped-foil regenerator with parallel flow channels. The regenerator is made of Inconel 718 and manufactured by additive manufacturing of direct metal laser sintering (DMLS) to reduce the manufacturing cost and improve the stiffness of the regenerator. The regenerator outer diameter and inner diameter are $52 \mathrm{~mm}$ and $35 \mathrm{~mm}$, respectively. The wall thickness between each channel and the fluid path thickness are both $0.3 \mathrm{~mm}$. The length in the regenerator is $50 \mathrm{~mm}$. The eight ribs were placed to obtain the radial stiffness of the regenerator. The ribs and foils are made as one part to prevent the dislocation and deformation of the regenerator foils. 

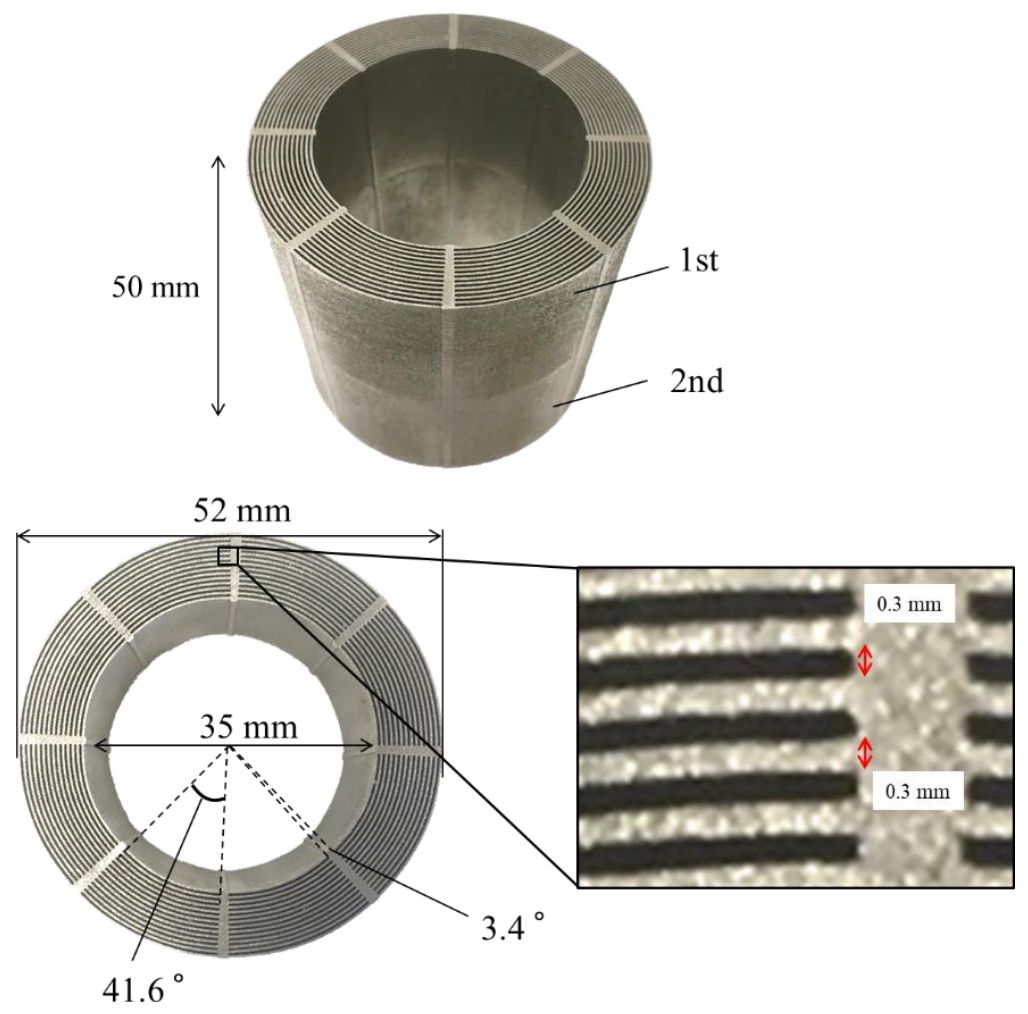

Fig. 19 Robust foil regenerator

FEA was conducted to check the change of the flow channel spaces by the thermal deformation. The top and bottom temperatures are set $810^{\circ} \mathrm{C}$ and $80^{\circ} \mathrm{C}$ respectively. The FEA result showed a maximum radial displacement of $0.58 \mathrm{~mm}$ occurs at the top of the outer most regenerator foil and the innermost channel radially deforms $0.38 \mathrm{~mm}$. This deformation may seem alarming and that the foil spacing will not be maintained. However, the deformation from foil to foil is only less than $0.02 \mathrm{~mm}[66,67]$. Thus, it was concluded that the mean foil spacing and geometry remain constant over the long time period.

Ideally, the foil thickness should be thinner in terms of the flow loss and the axial conduction of the regenerator. However, as it was explained in the previous paragraph, one major limitation of current additive manufacturing techniques is that the thickness of the generated components is limited by the particle size of the metal [68]. Based on the feedback of several additive manufacturing vendors, a minimum foil thickness of $0.3 \mathrm{~mm}$ is achievable [66]. 
In this research, to prove the effectiveness of the robust foil regenerator, the flow and heat transfer features were investigated with a regenerator test rig. This test rig was designed and built at the WVU energy conversion laboratory. The test rig is mainly composed of a heater, cooler, test section, and linear alternator. The test section is switched between the flow loss and the heat transfer test due to the temperature limitation of the dynamic pressure transducers. All tests were conducted under oscillating flow conditions via a linear alternator generating an oscillating motion. Before starting the test, the test rig verification was conducted by using the woven screen regenerator. For the flow loss test, two dynamic pressure transducers were installed in the test section to measure the pressure drop through the regenerator. The measured pressure drop was converted to the friction coefficient to compare to the conventional regenerator correlations. For the heat transfer test, the heat transfer test section was installed instead of the flow loss test section to measure the temperature difference in the regenerator. The Nusselt number was calculated based on the measured temperature drop and compared to the conventional regenerator correlations. To evaluate the overall performance of the robust foil regenerator, the NPH/NTU and $\mathrm{j} / \mathrm{f}$ ratio, which are figure of merit, were utilized based on the calculated friction coefficient and Nusselt number.

\section{2-5. Objective of this research}

This research was implemented to improve the Stirling engine efficiency by creating a new regenerator, called robust foil regenerator. Theoretically, the foil regenerator is the most efficient as the Stirling engine regenerator in terms of the figure of merit. Thus, the purpose of this study is to prove the regenerator design validity by the experiments and simulations. For the experimental study, a regenerator test rig was manufactured to find the flow loss and heat transfer characteristics of the robust foil regenerator. The simulation results were compared to the experiment results to check the validation of the experiment results. By using the flow loss and heat transfer features of the robust foil regenerator, the figure of merit was derived to evaluate the regenerator overall performance. 


\section{Literature review}

The regenerator is the critical component to achieve high efficiency of Stirling engines. The thermal energy is stored when the fluid goes through the regenerator from the hot side to the cold side and extracted when the fluid passes through the regenerator from the cold side to the hot side. Therefore, it saves a significant amount of energy in the Stirling engine [2]. Many designs have been considered to create a new generation regenerator to improve the Stirling engine system efficiency. In this section, the regenerators designed with different materials and configurations are introduced.

\section{3-1. Research about various regenerators}

Trevizoli et al. [69] developed a mathematical model of a packed bed regenerator which is composed of stainless steel spheres. The model was established based on the BrinkmanForchheimer equation to characterize the fluid flow and the temperature of the regenerator. Due to a good agreement of the model results and the experimental results, it was concluded that the established mathematical model can predict thermal effectiveness of the regenerator.

Isshiki et al. [70] tested a wire mesh regenerator to reveal the flow loss and heat transfer characteristics. As a result of the experimental study, it was clarified that the friction factor of the decelerating term is higher than the accelerating term under certain conditions of the Valensi number and the Reynolds number. The Nusselt number was derived for further analysis. Subsequently, it was found that the Nusselt number of the wire mesh regenerator is significantly higher than the spring mesh regenerator. However, because of the simple installation of the spring regenerator, the spring mesh regenerator is one of the regenerators widely used for the Stirling engine. Cha et al. [71] conducted experiments and CFD analysis for the porous structure regenerator under periodic flow. They mentioned a similar conclusion as Isshiki et al. [70] concluded that the friction factor of the regenerator under oscillating flow condition is different from the steady flow condition except for low oscillating frequency.

Tlili et al. [72] carried out the experiments with wire mesh regenerators of different porosities. The porosity of the regenerators is $91.2 \%, 83.6 \%, 75.1 \%, 72.2 \%, 66.6 \%$, and $61.1 \%$. The experiment results showed that the porosity plays an important role in the regenerator flow loss. In terms of the engine efficiency, the regenerator that had the porosity of $91.2 \%$ showed the 
lowest flow loss. However, the regenerator which had a porosity $61.1 \%$ represents the highest thermal efficiency of the engine.

Lenny G [73] measured the friction factor of random fiber. The porosity of the random fiber regenerator was $80 \%, 88 \%$, and $96 \%$. The random fiber diameter was approximately 0.0009 inches. The experiment was conducted under steady flow conditions. The result showed that $80 \%$ and $88 \%$ porosity regenerators had similar friction coefficients for the given Reynolds number. Based on this result and using GLIMPS/GLOP simulation results, the regenerator porosity of the final was $90 \%$.

Gedeon et al. [74] reported their work on the random fiber regenerator. They found friction factor correlations of the random fiber and woven screen regenerator. Also, Gheith et al. [75] studied the temperature distribution of the random fiber regenerator with a porosity of $90 \%$ and it was represented that the most efficient temperature difference through the random fiber regenerator is $20^{\circ} \mathrm{C}$. They also tested four different fiber materials for the regenerator such as stainless steel, copper, aluminum, and Monel 400 [76, 77]. The experiment results showed that stainless steel, copper, and Monel 400 represent the highest thermal efficiency. However due to the oxygen from the working fluid, the oxidation of the material causes serious degradation to the heat exchanging function of the material. On the other hand, the test results of the aluminum regenerator are acceptable in terms of the thermal efficiency, and oxidization of the material does not occur. However, aluminum has a temperature limitation. Based on these facts, it was decided that stainless steel is the best material to use for the regenerator in the Stirling engines. In addition, an experiment was conducted to find the best porosity of the stainless-steel regenerator. The regenerator with the porosity 75,85 , and $95 \%$ were used and it was mentioned that the most efficient porosity of the stainless-steel regenerator is an $85 \%$ porosity regenerator.

Kim et al. [78] used the one-dimensional software, SAGE, to analyze a random fiber and a woven screen regenerator. In accordance with the results, the random fiber regenerator shows less indicated efficiency and work compared to the woven screen regenerator. They also reported the study of the dead volume of the regenerator. The dead volume affects the amount of energy that can be exchanged in the regenerator. Therefore, the dead volume should be decreased for both the random fiber and woven screen regenerators.

Andersen et al. [79] carried out CFD analysis for the regenerator composed of metal felts. It was shown that the temperature profile of the regenerator matrix is different when the 
temperature oscillation of the matrix is considered. Especially, the temperature oscillation affects significantly at the end of the regenerator.

Imura et al. [80] investigated the temperature distribution of a mesh regenerator circumference. It was proved that the temperature non-equality in the circumference of the regenerator becomes larger as the piston stroke gets bigger. To prevent the non-homogeneous distribution, the copper meshes were installed. And, the engine performance was improved by easing the temperature concentration of the regenerator. Also, Knowles et al. [81] made a prototype carbon regenerator and the engine test result with the regenerator expresses the best thermal performance among the various regenerators. However, the single blow test result represented that the poor performance of the regenerator. Furthermore, Sun et al. [82] tested two mesh regenerators, which have different layer spacing, to verify the numerical solutions. The experiment and numerical results showed a good agreement. Due to the further numerical analysis, it was found out that the wire diameter and pore size of the regenerator has a linear relationship with the pressure drop.

Chen et al [83] used the oversized wire screen regenerator to reduce the leakage from the circumference. The flow loss and heat transfer tests were conducted with three regenerators. The heat transfer rate increases as increases the overlap because the flow does not go through the circumference of the regenerator.

Boer et al. [84] used a one-dimensional model to analyze the packed sphere and wire screen regenerators. It was found that the ratio of Stanton number and friction coefficient does not change as the Reynolds number is increased. From the regenerator analysis, the engine analysis was carried out. The result indicates that the regenerator efficiency can become higher when the power output of the engine is lower. However, as the engine power output increases, the regenerator efficiency decreases.

Nam et al. [85] derived the friction factor of the wire mesh regenerator for cryocooler under oscillating flow conditions. The friction factor was derived from the experiment results with the cryogenic temperature. By comparing the experimental results to the simulation results, it was found that the model for the simulation was significantly improved.

Ziabasharhagh et al. [86] established the model for beta type Stirling engines. According to the simulation results, some factors of the regenerator were found out as followed. 1) The heat exchange that occurs at the regenerator is the largest amount compared to the heater and cooler. 2) 
The ratio of regenerator length to diameter is important for the rate of the heat exchange in the regenerator. 3) The regenerated energy increases as the charge pressure increases. 4) The porosity of the regenerator directly affects the engine efficiency because as the porosity decreases, the efficiency of the engine decreases. By considering these factors, it was mentioned that the regenerator with a porosity of $75 \%$ is suggested for the engine regenerator.

Bim-Num et al. [87] fabricated and tested a laminate screen regenerator and tested to derive flow resistance, conduction losses, and the heat transfer coefficient. The results represent that the potential of the laminate regenerator can be higher than the single screen regenerator. Also, Wu et al. [88] conducted experiments with porosity woven screen regenerators to measure the pressure drop of the regenerator. The range of the Reynolds number and the porosity are 80 to 1200 and $83 \%$ to $92 \%$ respectively. The five empirical equations were derived for all regenerators, which are five different types of woven screen by utilizing the measured pressure data. Wakeland et al. [89] conducted experiments with a single woven screen to measure the pressure drop across the screen. The experiments were carried out under the low frequency condition and the Reynolds number range was varied from 0.002 to 400 . It was found that the friction factor is related to the Reynolds number, but there is no relationship between the friction factor and oscillation amplitude.

Xiao et al. [90] measured the pressure drop through the woven screen regenerator under steady and oscillating conditions. They reported that the pressure drop of the woven screen regenerator increases when the area of the woven screen and wire diameter increase regardless if the flow is steady or oscillating. Additionally, it is also revealed that there a correlation equation for the friction factor which is applicable to both steady and oscillating flow by using kinetic Reynolds number in a certain range. Hsu et al. [91] measured flow resistance of the woven screen regenerator under oscillating flow conditions. The test results match with the other published empirical equations for both of oscillating flow and steady flow. Also, the effective radius was tested under various oscillating frequencies.

Kurtbas et al. [92] revealed the heat transfer characteristic of the metal foam experimentally. Three different porous metal foams were used, and it was revealed that as the pore density and the Reynolds number increases, the Nusselt number increases. Shen et al. [93] proposed a new friction factor correlation for the woven screen regenerator. There are many friction factor correlations from different researchers and all of the correlations are slightly different due to the difference in 
experimental conditions. To summarize all the correlations, Shen et al. derived a new universal correlation for the woven screen regenerator with different temperatures and operating frequencies.

Kato et al. [94] revealed that the woven screen regenerator efficiency can be predicted as long as the matrix of the regenerator is the same. This prediction method can be used even if the material of the regenerator is different. Lee et al. [95] investigated various regenerator materials for higher regenerator effectiveness. Three types of regenerators (one homogeneous and two heterogeneous) were manufactured. The results showed that the flow loss can be decreased by the combination of different materials, while the porosity of the regenerators is the same. As a result of the experiment, it was mentioned that the material combination of the regenerator is important for the regenerator performance. Takizawa et al. [96] tested the engine with a stacked mesh regenerator to improve the engine efficiency. It was found that the engine which had a larger opening regenerator shows higher engine output and efficiency.

Costa et al. $[97,98]$ conducted a numerical simulation of the woven screen regenerator and the result showed that decreasing of the volumetric porosity causes a smaller hydraulic diameter and larger specific heat transfer area for the same wire mesh. They also found out that the wound woven wire matrix regenerator has a higher average friction coefficient than the stacked woven screen regenerator at a low Reynolds number (<100) [99]. However, when the Reynolds number is high, both the wound and stacked woven regenerator have the same friction factor. Fu et al. [100] conducted an experimental study for a porous media regenerator to measure the heat transfer through the regenerator. It was revealed that the surface temperature distribution of the regenerator under oscillating flow is more uniform than when under steady flow conditions. According to the Nusselt number analysis of the regenerator, oscillating flow results showed a higher Nusselt number than steady flow conditions.

Abduljalil et al. [101] tested four different types of regenerators. The four types are a ceramic catalyst with square pores, scourers, random fiber, and woven screen. The test results showed that the scourers and the random fiber regenerator illustrate the lower performance of temperature difference and pressure amplitude which is peak to peak pressure in half cycle. The balance of the flow resistance and heat transfer was also reported in the paper. As, the random fiber regenerator porosity gets higher, it causes lower flow resistance and heat transfer because there is not enough material. In other words, the balance between the flow resistance and heat transfer must be significantly to decide the regenerator performance. 
Peng et al. [102] compared sphere bed, woven screen, and open-cell foam regenerators. All the simulations were conducted under the oscillating condition and the simulation results were converted to unit volume weight, specific pumping power, and regenerator effectiveness. In terms of unit volume weight and specific pumping power, the foam regenerator showed the best performance. This indicates that the porosity is important for these two parameters. In respect to regenerator effectiveness, the sphere bed and woven screen regenerator were better than the foam regenerator. Furthermore, the porosity difference of the woven screen regenerator was investigated [103]. The result showed that the regenerator that has a larger wire diameter represents a lower pressure drop when the porosity of the regenerators is the same.

Arab et al. [104] investigated the porosity and unsymmetrical porosity gradient of the regenerator to improve the regenerator performance. Three models were established as followed. 1) Constant porosity. 2) The porosity is changed from low to high in axial direction from top to bottom. 3) The porosity is changed high to low in axial direction from top to bottom. The results showed that the second model has a slightly higher pressure drop, but the amount of energy is significantly higher than the other regenerator models. Rogdakis et al. [105] studied the relationship between the operating condition and the regenerator of the engine. The temperature of the gas and matrix temperature at the regenerator were analyzed. As a result, it was reported that the regenerator design area is relatively important for the regenerator effectiveness and the engine output.

\section{3-2. New types of regenerators from recent research}

Due to the high flow loss of the wire regenerator caused by the flow separation over the wire, new regenerators were being developed. Li et al. [106] analyzed the performance of the compact porous-sheets heat exchangers. The porous sheets are laminated, and the holes are aligned well. Thus, the flow channels of the heat exchanger are the straight flow channels. The results of the comparison of the porous sheets to the wire mesh regenerator revealed that the porous-sheets regenerator has $38 \%$ to $51 \%$ lower entropy generation. Therefore, the available work loss decreases and leads to higher thermal efficiency. In addition, the heat transfer characteristics of the porous sheet regenerator were investigated by Li et al. [107]. The Nusselt number with the kinetic Reynolds number and the Prandtl number were derived to evaluate heat transfer characteristics of the porous sheet regenerator. As the flow is fully developed laminar flow, the 
Nusselt number is almost constant at a low kinetic Reynolds number. When the kinetic Reynolds number is high, the phase shift of the wall temperature and the wall heat flux were increased. The Nusselt number agreed with the published experimental and numerical results.

Nielsen et al. [108] investigated the performance of the microchannel heat exchangers and showed that when the flow channels are not placed equally, the heat transfer performance decreases rapidly. Additionally, they also mentioned the channel thickness considerably affects the performance of the microchannel heat exchangers. Nam et al. [109] made a parallel wire regenerator to improve the regenerator performance and compared it to the woven screen regenerator. In accordance with the experimental results, the friction factor of the parallel wire regenerator is $20-30 \%$ lower than the woven screen regenerator. On the other hand, the thermal characteristic is relatively low due to the high axial conduction loss. Based on these results, it was concluded that the axial conduction of the parallel wire regenerator is high, but the overall efficiency of the parallel wire regenerator is also higher than the woven screen regenerator because of the higher porosity and lower friction losses.

Alfarawi et al. $[110,61]$ created a new miniature-channels regenerator and used CFD to investigate its characteristics. The CFD simulation showed that the small channel regenerator $(0.5$ $\mathrm{mm}$ ) has a higher potential to generate power than the random fiber regenerator. The matrix material also affects regenerator performance, especially for the axial conduction loss because of the thermal conductivity differences.

Kahleras et al. [111] designed three types of regenerators and the regenerators were manufactured by additive manufacturing. The regenerators are $30 \%$ porosity with straight channels, $40 \%$ porosity with looser mesh at the center, and $30 \%$ porosity with pyramidal mesh. In the experiments, the pressure and temperature were measured under various operating frequencies. The obtained data was converted to the friction factor and the effectiveness. The results represent that the friction factor of the regenerator with the straight channel is lower than the other regenerators.

Mancisidor et al. [112] designed the new lattice structure regenerator. The regenerator is made by metal additive manufacturing. The flow loss of the regenerator is not low compared to the wire regenerator; however, the importance of the balance of the flow loss and heat transfer was also reported. Because the low flow resistance leads lower heat transference capability. Additionally, Ni et al. [113] conducted an experiment and numerical simulation with the porous 
media to understand the oscillating flow characteristics. From the results, the phase shift of the flow between the piston and porous media was observed. To predict the phase shift, a correlation was established.

Beak et al. [114] proposed a compact micro channel heat exchanger to investigate the problem of flow maldistribution with axial conduction at the heat exchanger. The heat exchanger model was established to solve flow maldistribution and axial conduction together. To evaluate these two phenomena, the dimensionless conduction parameter and flow maldistribution coefficient were introduced. The axial conduction was reduced by changing the geometry of the heat exchanger, and the flow maldistribution was mitigated by adding a flow redistribution device inside the heat exchanger.

\section{3-3. Foil type regenerator}

Foil regenerators are theoretically very efficient because the parallel flow channel exhibits a much lower pressure drop [115]. Yu et al. [116] studied parallel flow channel experimentally and numerically under oscillating flow conditions. The results showed that the previous phase of the flow affects the temperature distribution of the following phase in oscillating flow conditions. This result indicates that the Iguchi hypothesis [117] may not always be correct.

One of the candidates of the foil regenerator is the etched foil regenerator $[118,119,120]$. The etched foil regenerator has a much higher figure of merit than the wire regenerators.

Ibrahim et al. [121, 122] designed a new segment involute foil regenerator. The regenerator has 42 disks, $19 \mathrm{~mm}$ in diameter, and $0.25 \mathrm{~mm}$ thick with microscopic involute-shaped flow channels. The finite element analysis of the regenerator showed that the regenerator has high stiffness in the axial direction, but the radial side disturbance may cause high yield stress and permanent deformation. Therefore, special cautions are required for the installation of the regenerator to prevent permanent deformation. To test the regenerator, all disks are microfabricated by using the LIGA process and electrical discharge machining. The thermal expansion in radial direction is only $0.03 \mathrm{~mm}$. Also, 2-D CFD was implemented to clarify the features of the porous media and to study the flow distribution going into the regenerator. Three cases were simulated 1) without porous media, 2) with porous media and a gap in the axial direction between the regenerator and porous media, 3) with porous media without a gap. Based on the CFD result, it was found that the porous media distributes flow very well into the regenerator compared to no 
porous media cases. Additionally, the experiments were conducted with an oscillating flow test rig to test various regenerators $[123,124]$. The test results showed that figure of merit of the segmented-involute-foil regenerator is twice as high as the $90 \%$ porosity random fiber regenerator, which is currently utilized in the small NASA Stirling engine. Finally, the regenerator was installed into the actual converter. The test result showed that the converter has an electrical efficiency of $35.16 \%$.

Qiu et al. [125] conducted thermal and structural analysis of the involute foil regenerator. As reported by Qiu et al., the extra cautions are required to install the regenerator because of the lateral deformation that could happen due to the low radial stiffness of the regenerator. By improving the radial stiffness of the regenerator, the potential degradation of the engine performance is avoidable. 


\section{Chapter 2: Test Rig}

\section{Test rig design}

In this section, the test rig design is explained for further regenerator testing. Since the testing of the robust foil regenerator is highly important to evaluate the regenerator potential, the test rig was carefully designed. Most of the parts were manufactured at Wilson Works and the WVU MAE machine shop. After troubleshooting of the test rig such as leak of the working fluid from the test rig, the test rig was finally ready to conduct the experiments.

\section{4-1. Overview of the test rig}

To characterize the robust foil regenerator in terms of the flow loss and the heat transfer, a regenerator test rig was designed based on a hoop stress analysis with a minimal safety factor of 1.5 and has been manufactured properly to measure the pressure drop and temperature difference of the regenerator. There were two design concepts for this test rig.

1. The heater and cooler must be included in the test rig to measure the temperature difference of the regenerator.

2. Because the Stirling engine drives under oscillating flow conditions, the driving system must generate the oscillating flow in the regenerator test.

A few types of test rig designs were considered to heat up and cool down the working fluid quickly under the oscillatory flow. Lee et al [95] designed a test rig for the regenerator testing. The test rig has two pistons and a heater and cooler beside the regenerator. These two pistons are connected to the motor. Therefore, the oscillating flow is generated. The heater and cooler are simply heated up or cooled down the pipe wall of the test rig. The temperature is not high and the charge pressure is automorphic pressure. Choi et al. [126] designed one end of the test rig is a piston and another end is a reservoir. Fu et al., Tanaka et al., and Leong et al. [100, 58, 127] designed similar test rigs. There is one piston connecting to the flywheel to move the piston back and forth. This design is very simple 
and looks easy to manufacture. Therefore, it was decided to design the test rig with one piston.

Fig. 20 shows the first design of the test rig. For the heater, it was realized that the heat transfer is not enough to reach the desired temperature. Therefore, the designs were updated a few times. However, the manufacturing difficulty and limited attaching surface area were the issues. Additionally, the alignment of the test rig is considerably difficult since all the components of the test rig are different sizes. In the end, to make the alignment easier, the test rig design became vertical by referring the Sunpower test report [74], a band heater was selected as a test rig heating element (see 5-2 for more details). The cooler of the test rig was designed based on the Stirling engine heat rejecter from our lab.

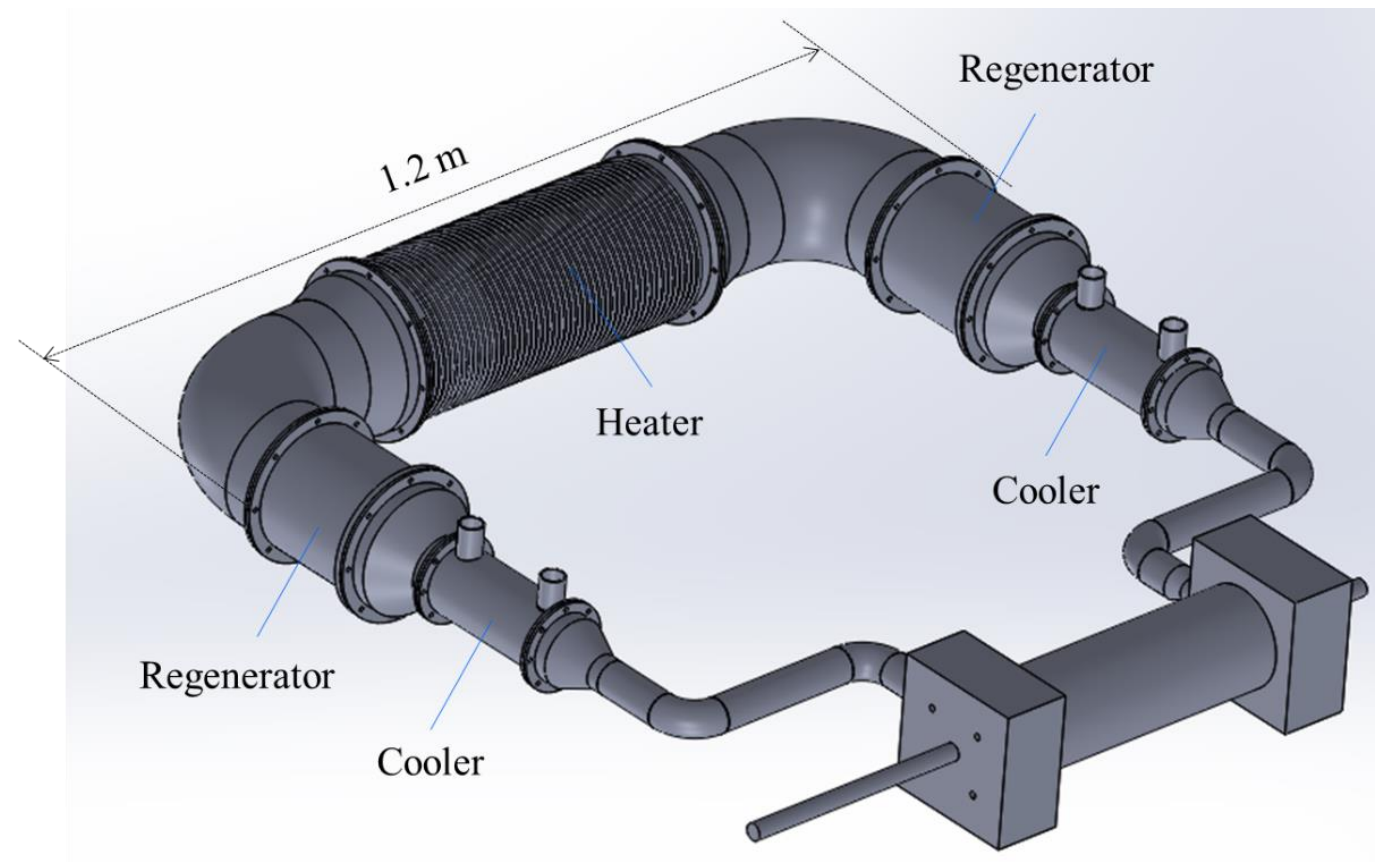

Fig. 20 First design of the test rig

For the driving system, it was considered to use the dynamic seal for the mechanical connection between inside and outside of the test rig piston as in Fig. 16. Later, however, it was noticed that the dynamic seal causes a large amount of leakage. Careful alignment and difficult installation are required to prevent leakage. Based on these factors, it was decided that the driving system of this test rig would be enclosed by the pressure vessel. 
Finally, all the designs of the test rig components were decided, and Fig. 21 shows the actual test rig and the details. The maximum charge pressure of the test rig is 45 bar. The inlet to charge the working fluid into the test rig is located at the pressure vessel of the linear alternator. Due to the linear alternator and the piston, the oscillating flow can be generated. Therefore, all the experiments in this thesis were conducted under the oscillating flow condition. Fig. 21 (a) shows the actual regenerator test rig and Fig. 21 (b) calls out key components of the regenerator test rig. In Fig. 21 (b), the test rig is composed of $1-$ hot side pressure vessel, 2 -band heater, 3 - diffuser, 4 - thermocouple, 5 - pressure transducer, 6 - test section, 7 - cooler, 8 - linear alternator piston, 9 - cold side pressure vessel, 10 - Linear alternator, 11 - displacement transducer holder, and 12 - displacement transducer. For this test rig, a flow loss test and a heat transfer test of the regenerator are separated due to the temperature limitations of the pressure transducers.

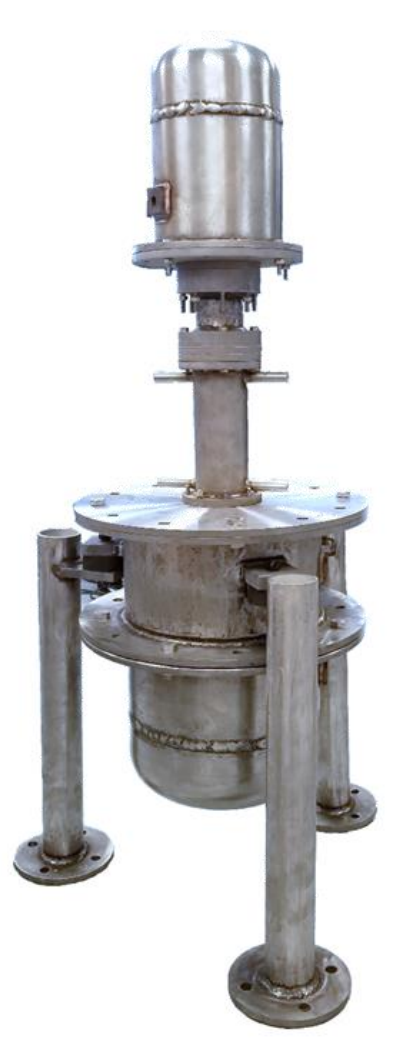

(a) Actual regenerator test rig

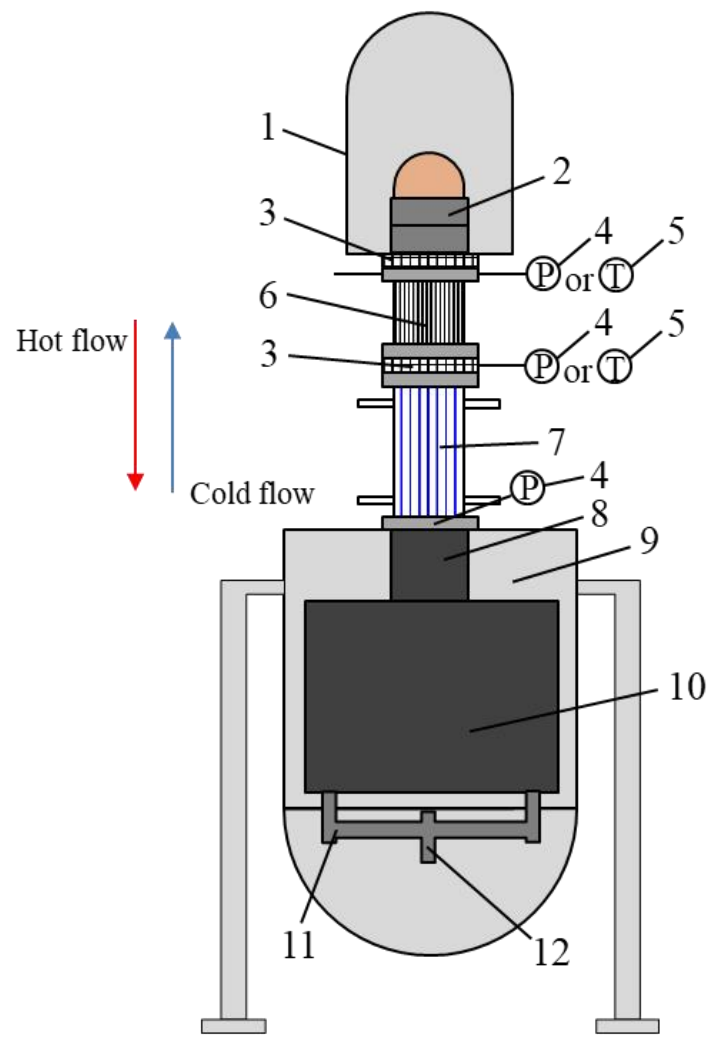

(b) Schematic of the regenerator test rig

Fig. 21 Regenerator test rig 


\section{4-2. Heater}

The heater was placed above the test section to heat up the working fluid going into the test section. At the heater, a high temperature seal is required to prevent the leakage of the working fluid from the connection. Firstly, a metal O-ring was considered, but it has a high cost and is not reusable. Thus, a silicon rubber O-ring was selected to prevent leakage. Not to exceed the temperature range of the O-ring, the heater pressure vessel was designed and is much larger than the size of the heater diameter. The heater was enclosed by the pressure vessel to keep the heating surface at a low pressure load. Fig. 22 shows the crosssection view of the heater of the regenerator test rig and the actual heater. Two pipes were mounted concentrically inside the pressure vessel, and the space between the two pipes act as the flow path with a width of $1.8 \mathrm{~mm}$ and a length of $120 \mathrm{~mm}$. Two band heaters were installed as a heating element and both are located on the outside pipe surface to supply up to $2000 \mathrm{~W}$ of heat to the working fluid. Since the diameter of the band heater is adjustable, they fit on the outside pipe perfectly. Based on the calculation, the maximum temperature of the working fluid will be $300{ }^{\circ} \mathrm{C}$. The inlet fluid temperature was assumed as $250^{\circ} \mathrm{C}$ to estimate the exit fluid temperature using constant heat flux equation $(\mathrm{Q}=\mathrm{mCpdT})$. The maximum allowable temperature of the band heater is $760{ }^{\circ} \mathrm{C}$ when $240 \mathrm{~V}$ source was used. To control the temperature of the band heater, a variable ac transformer was used to adjust input voltage. The voltage adjustment using the variable ac transformer was not accurate, therefore, LabVIEW code and NI DAQ system were utilized to monitor the voltage supply from the variable ac transformer which can supply $130 \mathrm{~V}$ at maximum. A 4-pin feedthrough was welded on the pressure vessel wall for supplying power to the band heaters. Also, a valve was installed on the pressure vessel wall to exhaust the charged working fluid.

Fig. 23 shows the drawing sheet of the heater vessel. More drawing sheets are in Appendix K. 

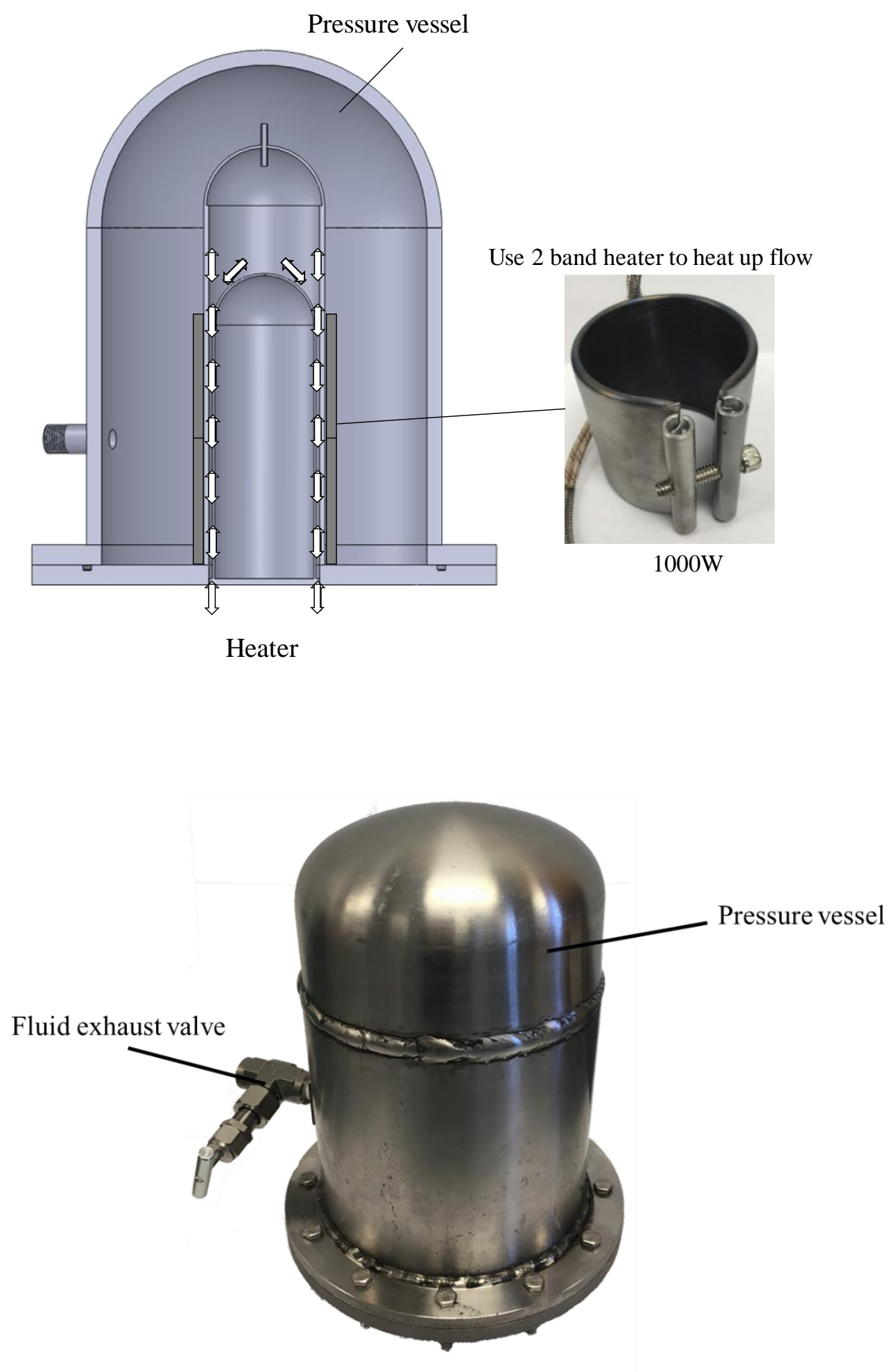

Fig. 22 Cross-section view and actual heater 


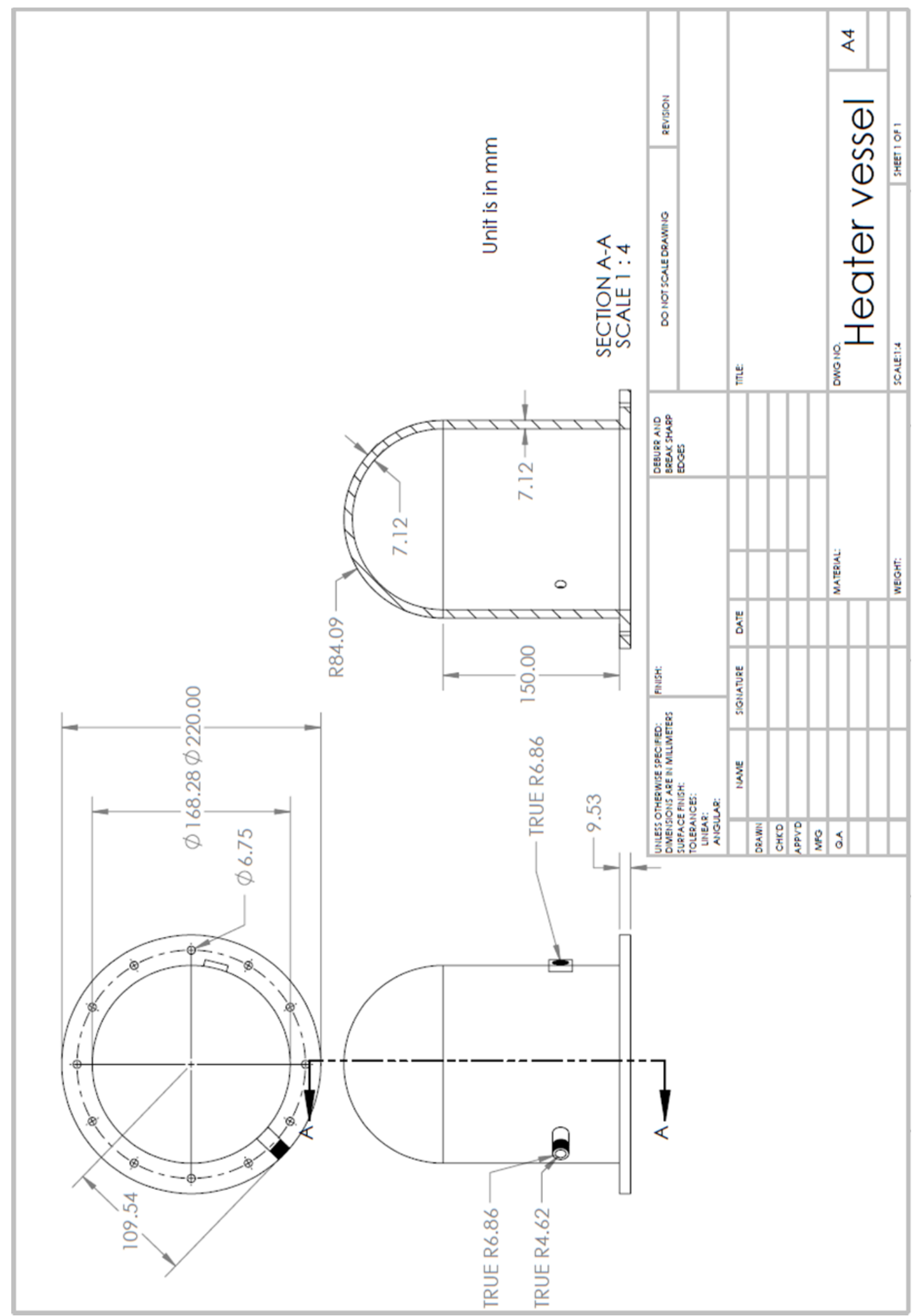

Fig. 23 Drawing sheet of the heater pressure vessel 


\section{4-3. Mesh diffuser}

Fig. 24 shows the diffuser. For a better flow distribution of the regenerator, diffusers were installed both before and after the test section. The sintered mesh was manufactured by TWP. The thickness and the diameter of the diffuser are $0.66 \mathrm{~mm}$ and $70 \mathrm{~mm}$, respectively. This mesh diffuser was chosen based on what Sunpower test rig was used in the regenerator oscillating flow test rig [74]. To fix the mesh diffuser on the flange, a special flange was designed and manufactured. It has a small step and 8 tap holes and there are 8 holes on the mesh diffuser as well. By using 8 bolts, the mesh diffuser was fixed on the flange.
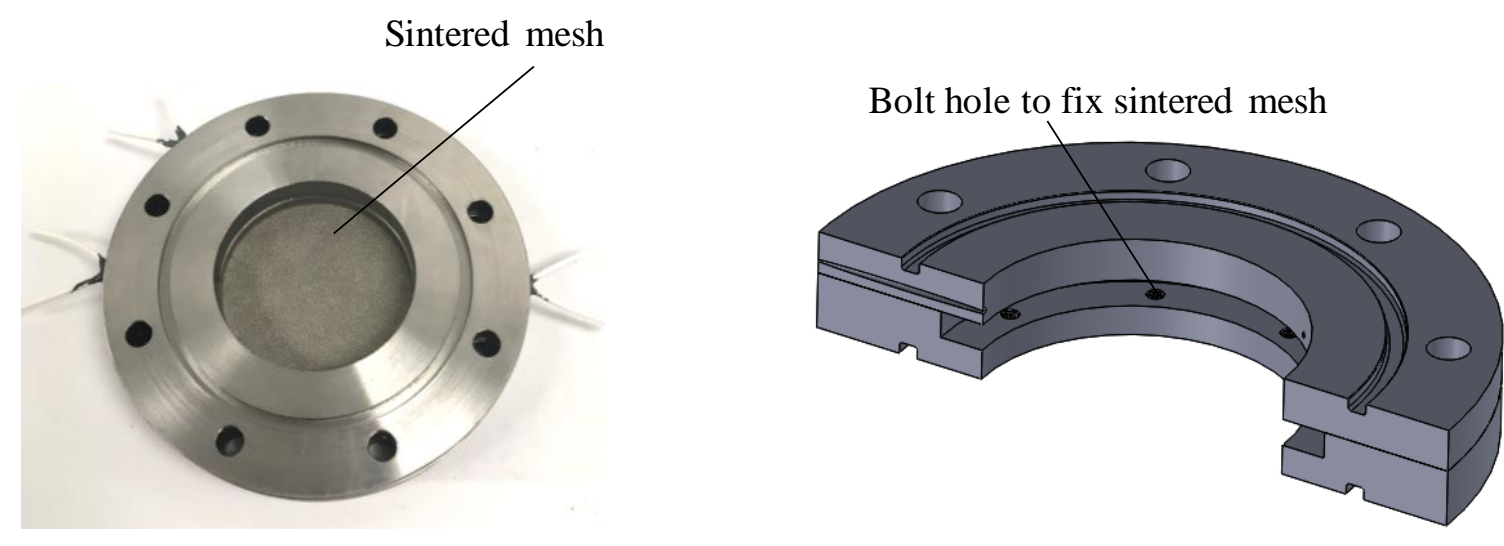

Fig. 24 Diffuser

\section{4-4. Test section}

The test section was installed between the heater and the cooler with the mesh diffusers. Two types of the test sections were designed and manufactured for both the flow loss test and the heat transfer test due to the temperature limitation of the pressure transducers. Fig. 25 (a) and (b) show the flow loss and heat transfer test section. Both test sections have an inner diameter of $54 \mathrm{~mm}$ and a length of $50 \mathrm{~mm}$ without flange thickness. Including the flange thickness, the total height of the test sections is approximately $80 \mathrm{~mm}$. The flanges are relatively thick because the sensors are installed through the flanges. 


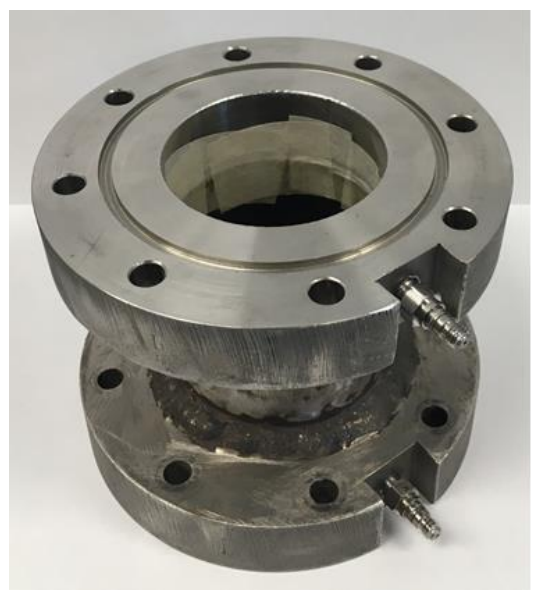

(a) Flow loss test section

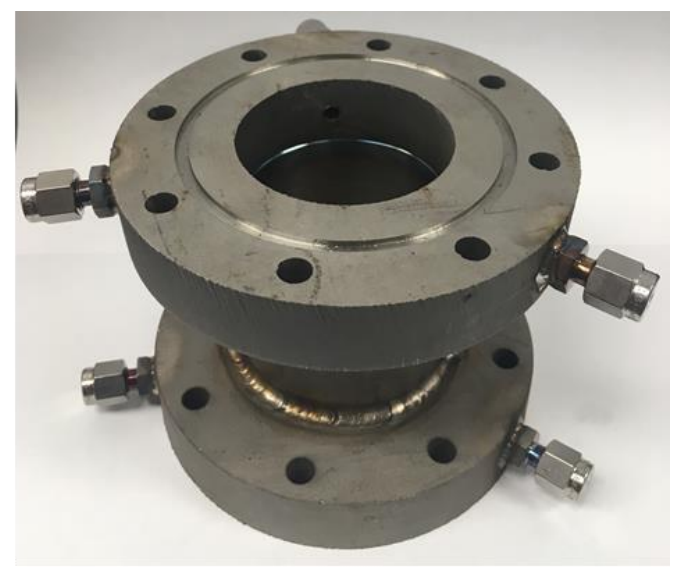

(b) Heat transfer test section

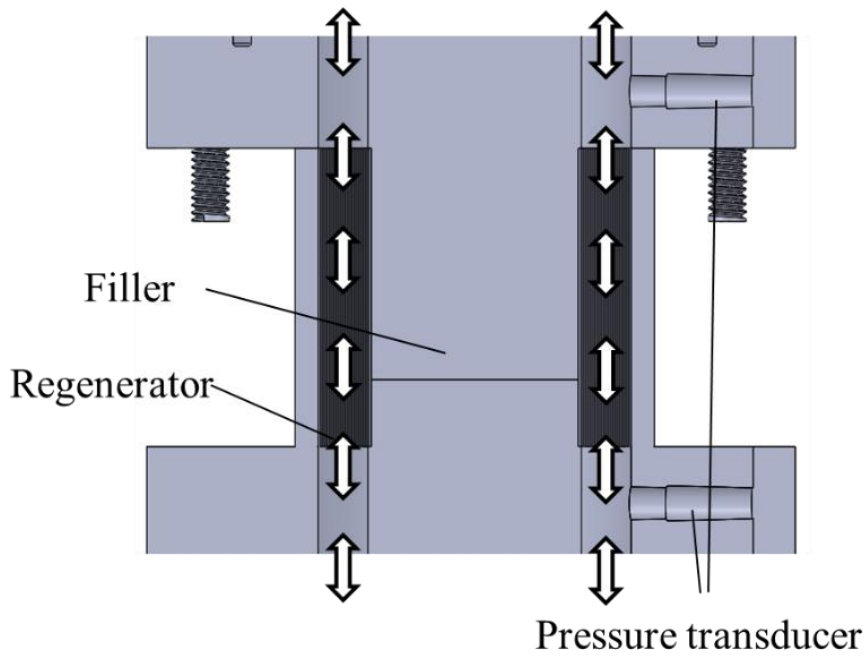

(c) Cross-section view of the test section

Fig. 25 Test section for flow loss test and heat transfer test

For the flow loss test section, there are two holes to install the pressure transducers on both top and bottom flanges. The hole demotion of the transducer installation is very important to prevent the leakage through the holes. It is recommended by the Kistler to manufacture a hole, but the machining is difficult especially for the local machine shop. Therefore, it was recommended to utilize the special installation bolt from Kistler. The pressure transducer model is 601CA from KISTLER. The special nuts were used to fix the 
pressure transducer to prevent the leakage from the pressure transducer installation holes. Fig. 26 shows how to install the pressure transducer to the test section. Additionally, due to the inaccurate machining of the threaded holes, a small leak was observed through the sensor hole after the sensor installation despite the use of a copper metal ring. To prevent leakage through the holes, a rubber O-ring was installed (see appendix A for more details). After the O-ring installation, the leakage was not found anymore.

For the heat transfer test section, there are three welded Yor-Lok connectors (Swagelok) on each top and bottom flange. As the first idea, the thermocouples were directly installed into the tiny hole. However, the thermocouple with a bare wire bead (0.001inch diameter wire) is not strong enough as you can expect. Therefore, it was predicted that the thermocouples need to be replaced often. Additionally, the bare wire thermocouples were affected by the magnetic field generated by the linear alternator. To prevent the magnetic field, some attempts were implemented (see appendix F). However, none of them worked. Thus, the thermocouples were switched to the sheathed thermocouples to avoid the magnetic field. Ideally, the thermocouples for the heat transfer test under oscillating flow conditions should be bare wire type to measure the instantaneous flow temperature. Thus, the sheathed thermocouples were not selected initially. However, it was realized that 0.01 -inch sheathed thermocouples are also a fast response thermocouple and it could detect the instantaneous temperature with thermal lag analysis (see 9-7).

The sheathed thermocouples were fixed through the small stainless-steel pipe by using a high temperature epoxy. Fixing the thermocouple into the small pipe was a necessary step to install it through the Swagelok. E-type thermocouples with a 0.01-inch sheathed diameter from Omega were used. To measure the temperature variation of the high frequency oscillatory flow, the fast response thermocouple is required. The pipe with the thermocouple was placed through the Swagelok. The Swagelok needed to be screwed tightly to prevent leakage. Fig. 25 (c) shows the cross-section view of the test section with the regenerator and the filler. The filler was made of aluminum to prevent the flow going through the center opening of the regenerator. Therefore, the working fluid only goes through the foil part of the regenerator. The filler has a step and the step will stop the filler at a certain point of the regenerator. The mesh diffusers at the top and the bottom of the test section clamped the filler to hold it. Fig. 27 shows the filler. 

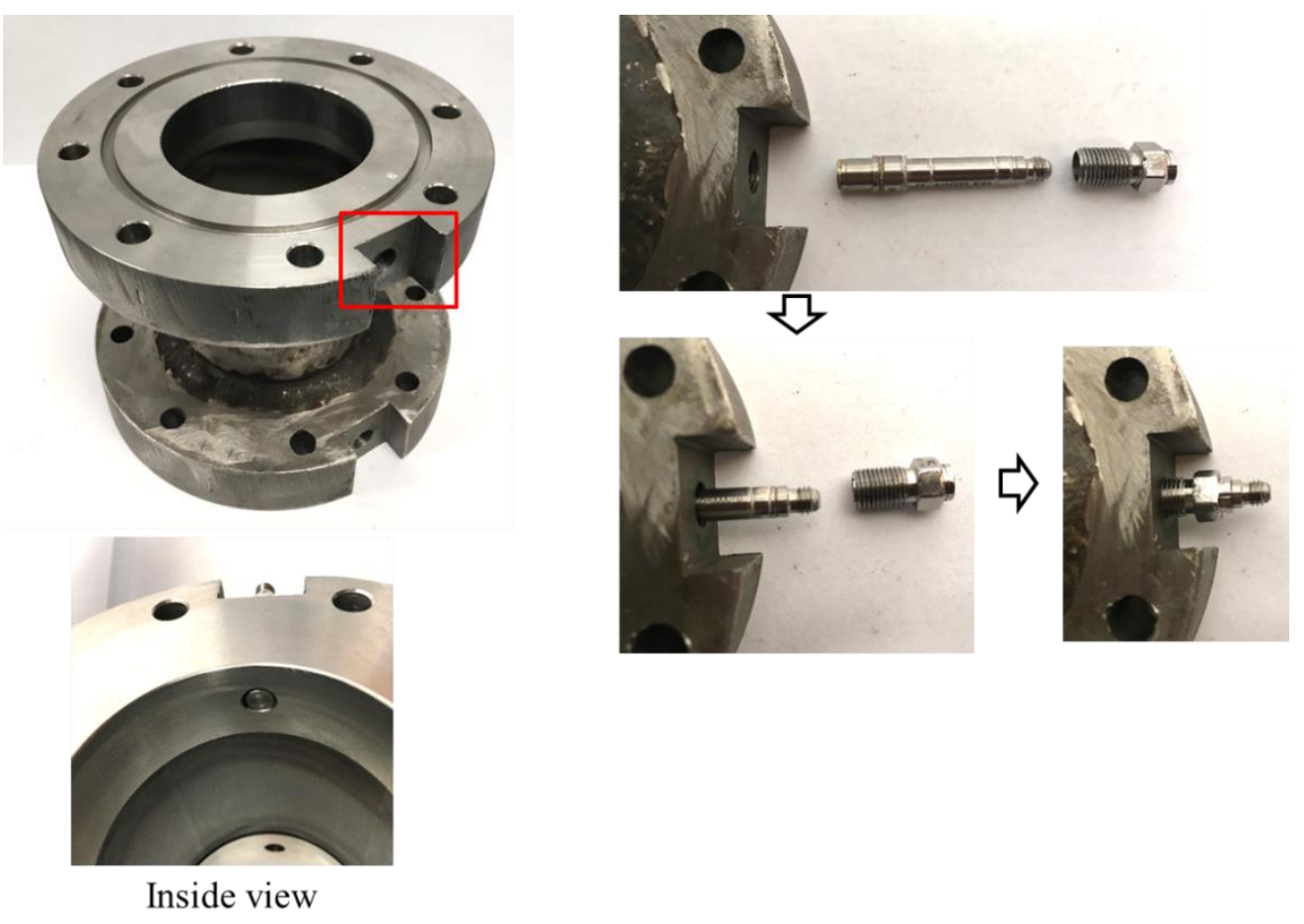

Fig. 26 How to install pressure transducer in the test rig
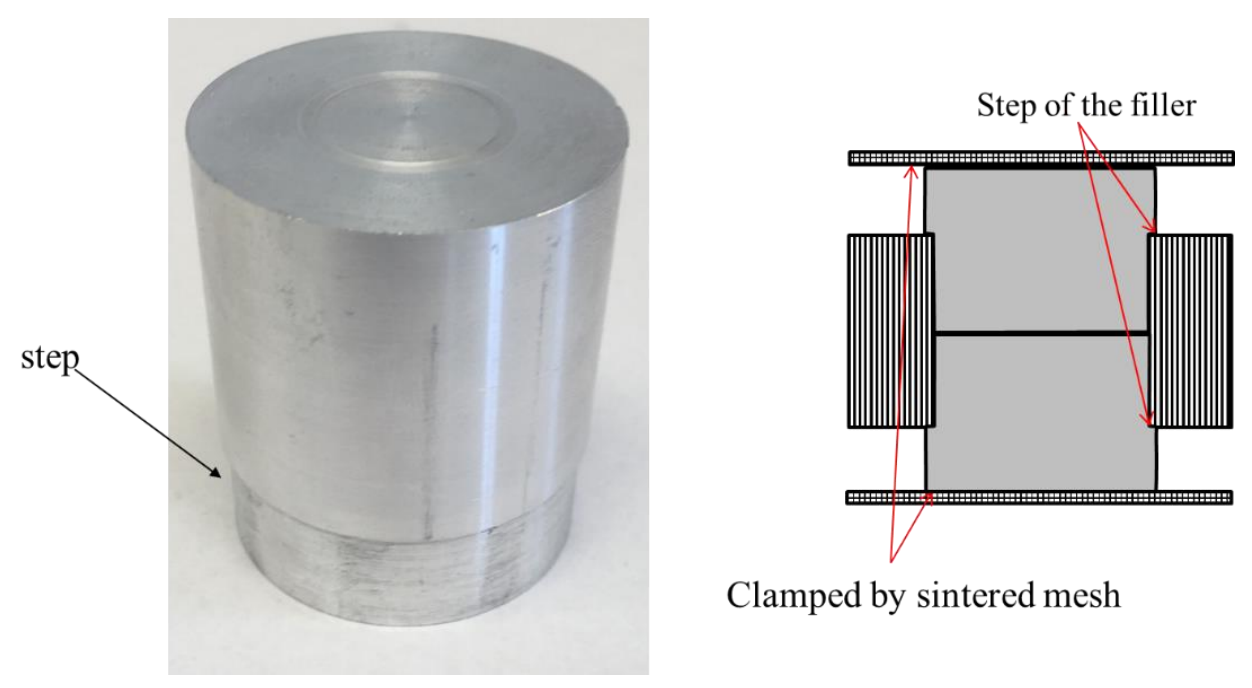

Clamped by sintered mesh

Fig. 27 Filler 


\section{4-5. Cooler}

Fig. 28 shows the cooler of the rig. The cooler is composed of an external water jacket, 4 water inlet/outlet tubes on the jacket, a copper pipe, fins, and a cooler filler. The idea of the cooler design is from the heat rejecter of the Stirling engine in our lab [128]. The water flow passage between the water jacket and copper pipe is $2 \mathrm{~mm}$ wide and $170 \mathrm{~mm}$ long. The fin dimensions are $4 \mathrm{~mm} \times 3 \mathrm{~mm} \times 170 \mathrm{~mm}$. The working fluid temperature is decreased to below $70{ }^{\circ} \mathrm{C}$ by the circulated water. The parameters of the cooler were calculated based on the fin equation [129]. To combine each component of the cooler, press-fit was implemented. However, at the press-fit part which is between the water jacket flange and copper pipe, the cooling water leaks inside the test rig. To seal the gap, an epoxy was utilized. Ideally, EB welding should be implemented to cover the gap. The working fluid is forced to go through between fins as the cooler filler blocks flow at the center opening. Fig. 29 shows the schematic of the water circulation system. UP 15-42 F/VS pump from GRUNDFOS with a maximum mass flow rate of $0.045 \mathrm{~kg} / \mathrm{s}$, was used to circulate the water to extract heat from the working fluid. The pump drugs the water from the reservoir, then reaches the water pump. A flow adjustable valve was located after the pump. It controls the flow rate very accurately. To measure the mass flow rate, a micro flow meter MICRO-FLO from OMEGA was used after the valve. After the flow meter, the water is going into the top of the cooler. Before and after water passes through the cooling jacket, RTD sensors were placed to measure the water temperature difference between the inlet and outlet to calculate the amount of the heat extracted by the cooler. The warm water is cooled down by Hydrofarm AACH10 chiller. The minimum water temperature that can be achieved by the chiller is approximately $8^{\circ} \mathrm{C} .3 / 8$ inch inner diameter reinforced tube was used to connect each water circulation component. Barbed tube connectors were also used to connect tubes to the components (see appendix I for more connection details). 

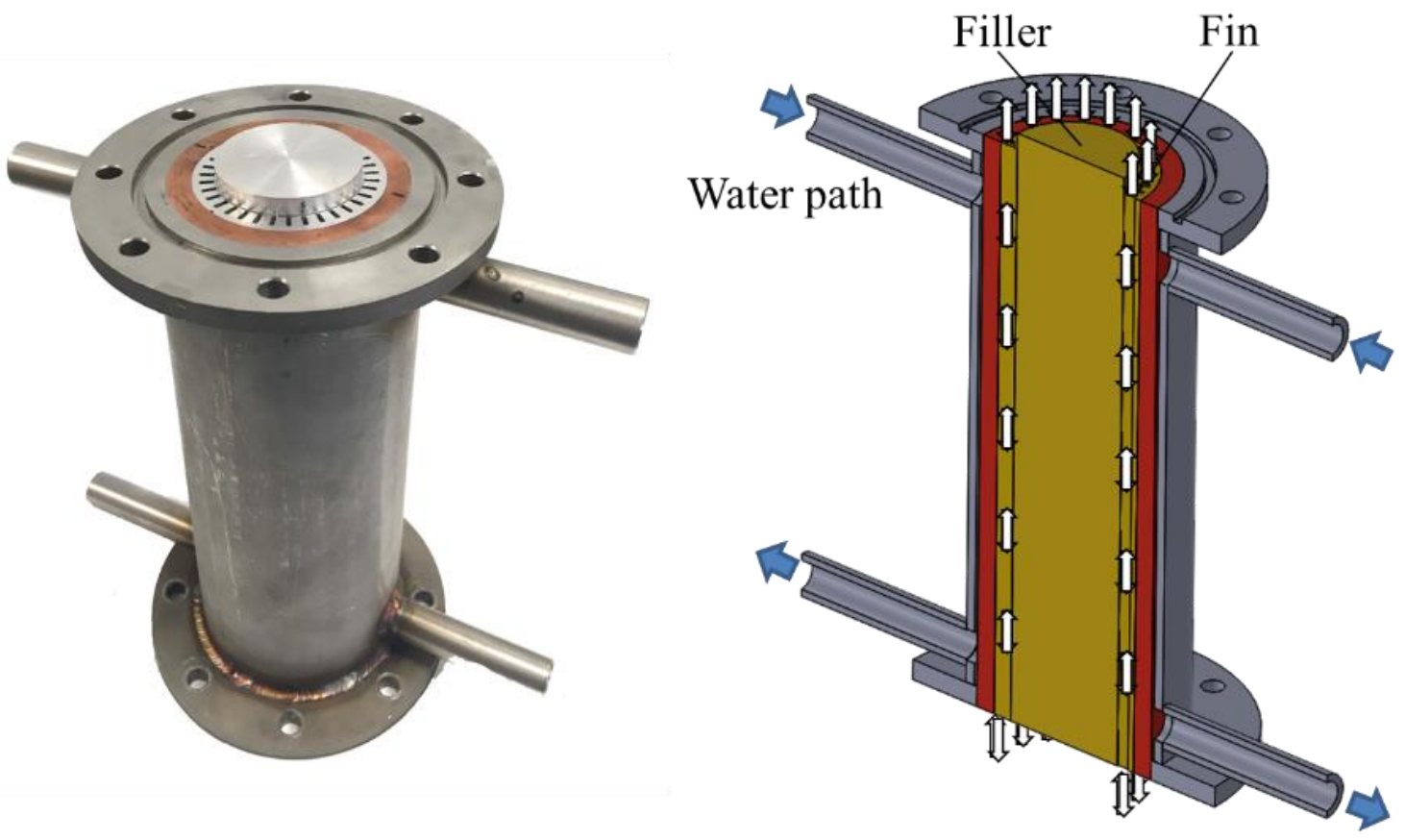

Cooler

Fig. 28 Cooler

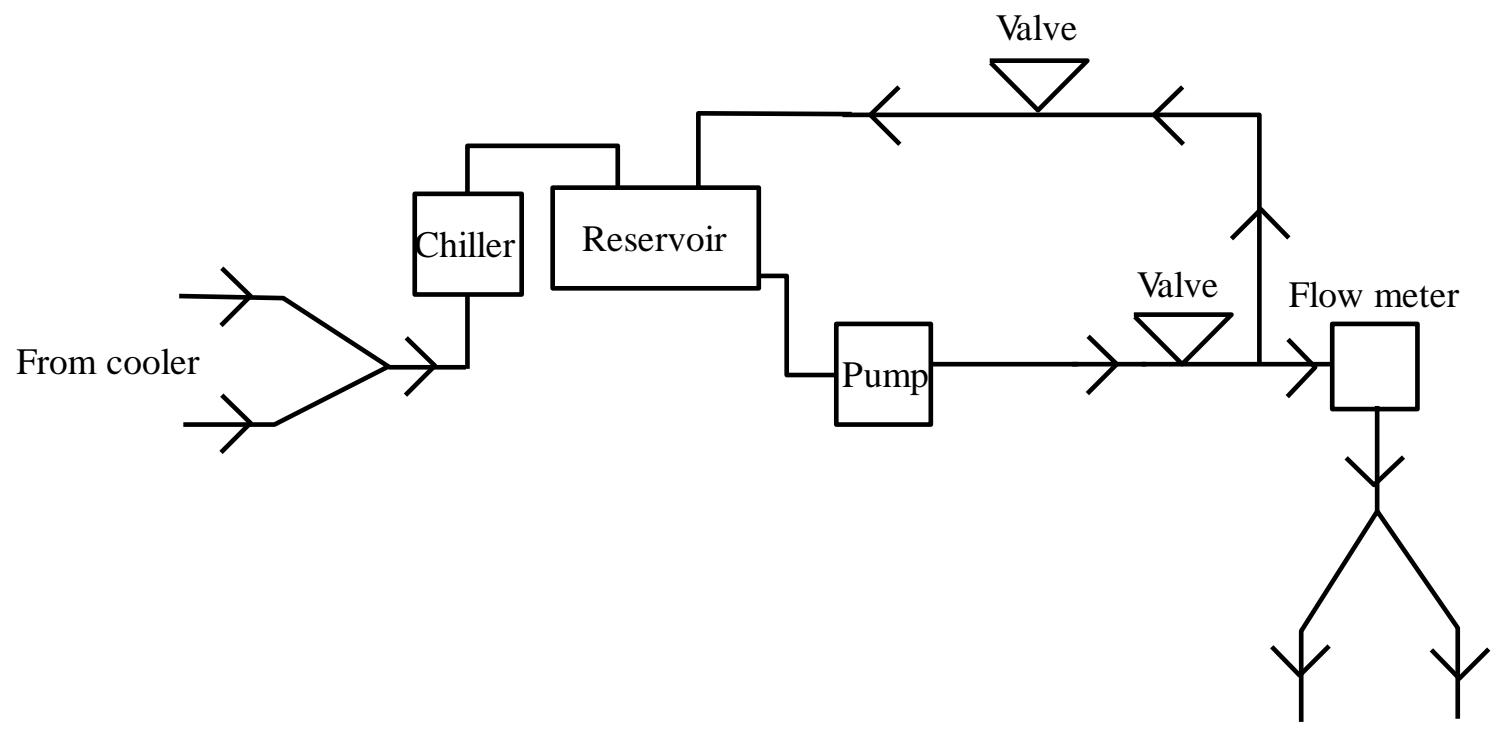

To cooler

Fig. 29 Schematic of water circulation 


\section{4-6. Linear alternator}

Fig. 30 shows the linear alternator used to generate oscillatory flow in the test section. The piston diameter of the linear alternator is $87 \mathrm{~mm}$ and the operating frequency is roughly $49 \mathrm{~Hz}$. The maximum stroke length is $24 \mathrm{~mm}$. The piston motion can be controlled by the power input from a power source by Chroma. The Chroma 61604 power source is able to control the input voltage and frequency. Also, the power source can be connected to LabVIEW, and it can be controlled by using the LabVIEW code (see 6-4).

At the bottom of the linear alternator, a position sensor holder was placed. It was designed to support a FASTER 1000 linear displacement transducer for measuring the piston displacement. Two standoff bolts were fixed at the bottom of the linear alternator firstly. Then by using two bolts, the sensor holder was placed at the bottom of the linear alternator. The center hole of the sensor holder is to hold the displacement transducer. The hole dimension is slightly larger than the displacement transducer size. A small tap hole was made on the side of the sensor holder to support the displacement transducer. By screwing in a bolt, the bolt touched the sensor and fixed it. Due to the vibration from the linear alternator, it was expected that the bolt will loosen. Therefore, LOCKTITE 272 was used as a thread locker. The displacement transducer is composed of the outer coil and core rod, and the core rod was connected to the linear alternator with the threaded rod. Thus, the core rod moves with the linear alternator piston motion. To adjust the alignment of the core rod and outer coil, shim stock was installed between the holder and outer coil. The linear displacement transducer has a maximum frequency response of $15 \mathrm{kHz}$ and a $51 \mathrm{~mm}$ maximum stroke length.

Additionally, on the pressure vessel wall, there is a 2-pin feedthrough for the linear displacement transducer to measure the piston motion of the linear alternator. Also, to supply electrical power to the linear alternator through the pressure vessel, there is another 4-pin feedthrough on the pressure vessel wall. Additionally, a valve was installed to charge the working fluid inside the test rig. 

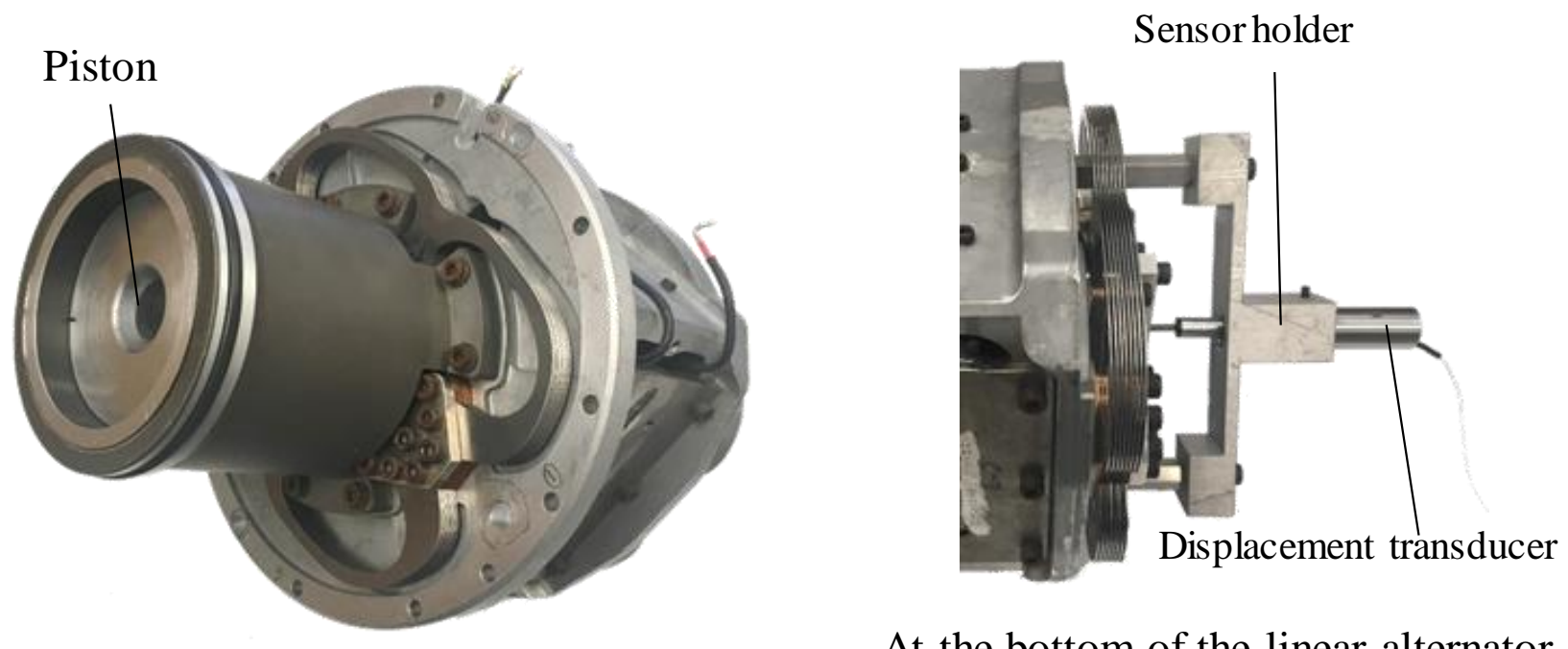

At the bottom of the linear alternator

Fig. 30 Linear alternator and displacement transducer

\section{4-7. Sensors details}

- Pressure transducers

For the flow loss test, 601CA from KISTLER is selected as a pressure transducer to measure the pressure drop through the regenerator. The pressure range of the sensor is 7 bar. The sensitivity is $714 \mathrm{mV} / \mathrm{bar}$. Note that the sensitivity varies by sensors. The measured sensitivity was sent as a separate document with the pressure transducer. The measured voltage value from the pressure transducer needs to be converted to pressure by using equation (1). The temperature range of the sensor is -55 to $120^{\circ} \mathrm{C}$. Thus, the pressure transducer should not be used in the heat transfer test. In addition, this sensor requires the excitation current ( $2 \mathrm{~mA}$ to $20 \mathrm{~mA}$ ) to measure the voltage. Therefore, it is necessary to use a data acquisition device with the excitation current function or an external current input device such as NI9234. More information is in 6-4.

$$
\text { Pressure }=\text { Measured voltage } \times \frac{1}{735.1}[\text { bar }]
$$


Note that the coefficient value is the calibration constant which varies by each sensor.

\section{Working principle}

There is a sensing element inside the pressure transducer. As force is applied to the element by the fluid pressure, the diaphragm detects the force from the fluid. Due to the force, the diaphragm deforms slightly and is converted to the electrical output. This output will be measured through the data acquisition device and converted to the pressure.

- Thermocouples

Firstly, CHAL-001 was selected to measure the instantaneous temperature at the top and bottom of the regenerator. This thermocouple is the smallest available choice from OMEGA. The thermocouples were installed through a $1 \mathrm{~mm}$ hole on the flanges at each side of the regenerator. However, due to the fragileness of the thermocouple, it was extremely difficult to handle the thin thermocouples. Therefore, a new test-section was designed for the temperature measurement. It has welded Yor-Lok connectors (Swagelok) on the flanges. To install the thermocouples by using the connectors, the thermocouples were fixed in the small pipe with the epoxy for high temperature. Fig. 31 shows the thermocouple with the small pipe.

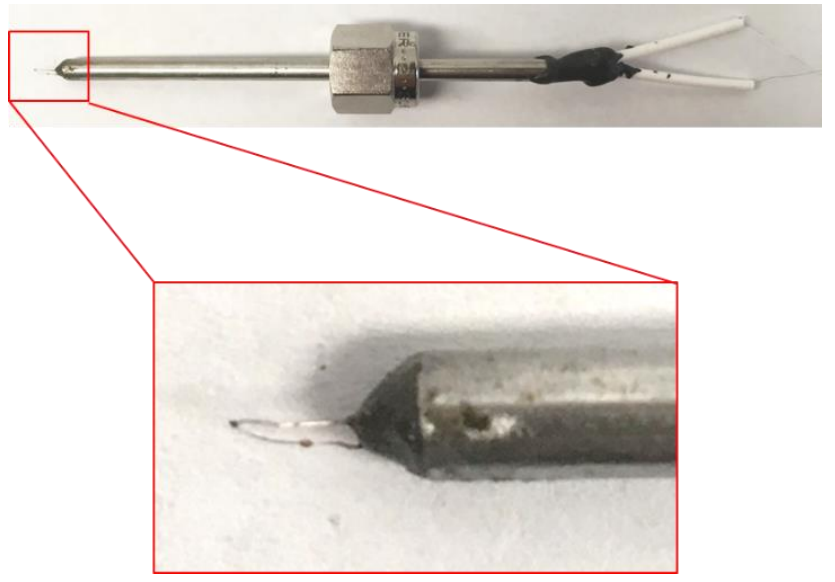

Fig. 31 CHAL-002 with stainless steel pipe 
However, the magnetic field from the linear alternator affected the thermocouples. The measured temperature was not measuring the temperature correctly. To fix this problem, the CHAL-001 bare wire thermocouples were replaced with E type sheathed thermocouples. The diameter of the thermocouple bead is 0.01 inch. The thermocouples were also placed in the small pipe to fix through the Swagelok.

Fig. 32 shows the sheathed thermocouple with the small pipe. The only concern for the sheathed thermocouple was whether it can measure the instantaneous temperature. After a few tests, it was found that the thermocouples can detect the instantaneous temperature. To see the actual instantaneous temperature, thermal lag analysis is required.

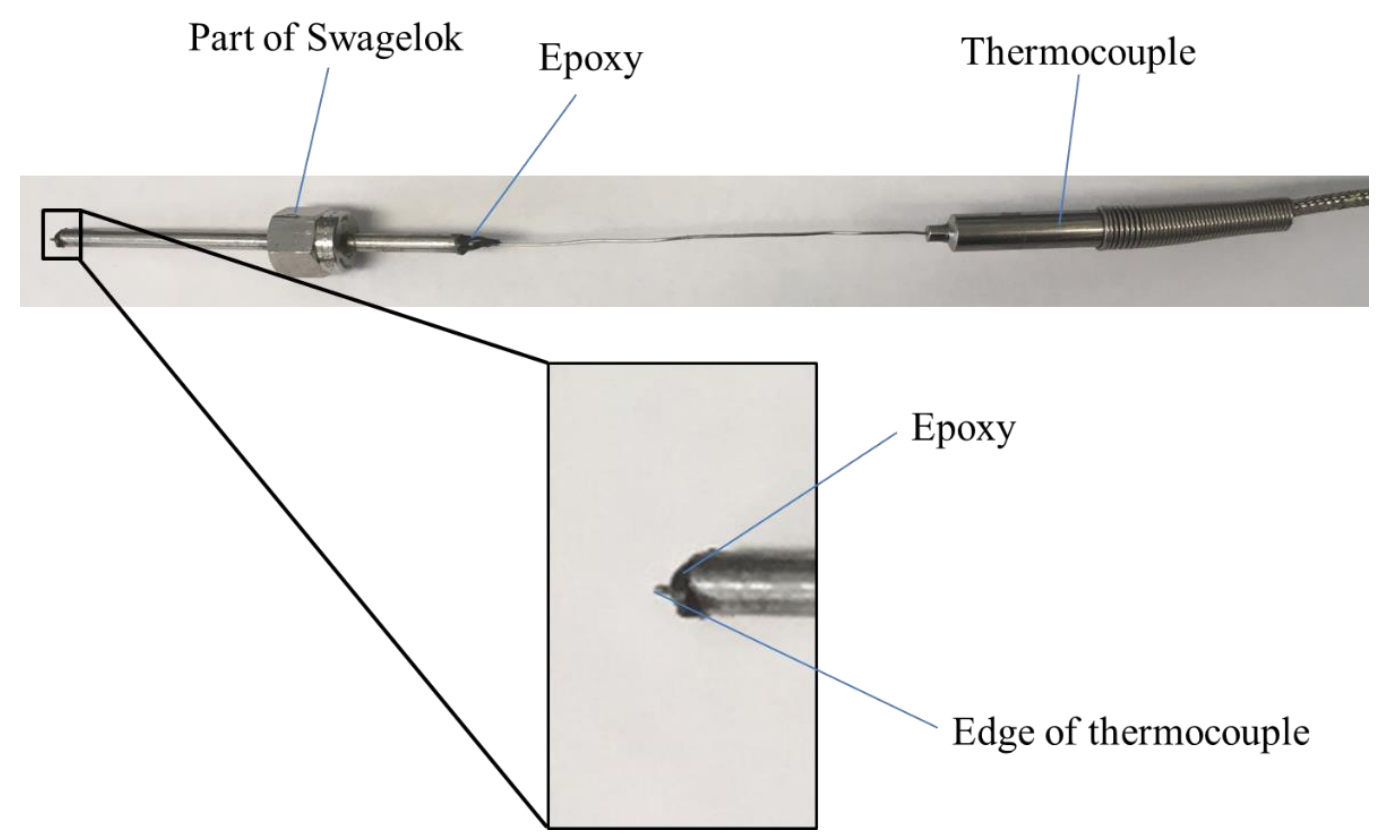

Fig. 32 Sheathed thermocouple with stainless steel pipe

\section{Working principle}

1. Seebeck effect

The Seebeck effect converts the temperature difference directly into the electricity. Fig. 33 shows the schematic of Seebeck effect. When the two different types of metals are attached, an electromotive force is generated at the 
junction of two metals by the temperature difference between the junctions. This causes a continuous current when the circuit forms a complete loop. The direction and the amount of electromotive force are dependent on the combinations of materials [130]. The voltage is expressed by equation (2). $S_{B}$ and $\mathrm{S}_{\mathrm{A}}$ are the Seebeck coefficients.

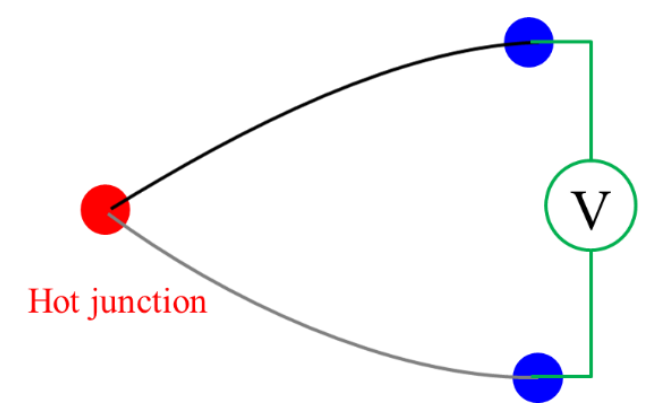

Fig. 33 Seebeck effect circuit

$$
V=\int_{T_{1}}^{T_{2}}\left(S_{B}(T)-S_{A}(T)\right) d T
$$

\section{Peltier effect}

The Pelitier effect is the inverse of the Seebeck effect. When two junctions are made with two different kinds of metal, the temperature difference between the two conductors is generated by the potential difference of the conductors [131]. The amount of heat generation at the junction is represented by equation (3). Where $\pi_{A}$ and $\pi_{B}$ are the Peltier coefficient. A and B signify the two ends of the conductors, while I is the electric current.

$$
Q=\left(\pi_{A}-\pi_{B}\right) * I
$$

3. Thomson effect

By forming the two junctions with two dissimilar metals, the voltage induces the conductor's length due to the gradient of temperature. However, in most cases, the Thomson effect is negligible [131]. 
- Displacement transducer

FS1000 from SENTECH was selected as a displacement transducer. The displacement transducer was placed at the bottom of the linear alternator to measure the piston displacement. The nonlinearity is only $0.15 \%$, and the operating temperature range is $-50^{\circ} \mathrm{C}$ to $125^{\circ} \mathrm{C}$. The response time is $35 \mu \mathrm{S}$. The accuracy of the displacement transducer is dependent on the sensor calibration. The current was measured by using N19225 and the displacement was measured by using a ruler. Fig. 34 shows the calibration result. Using equation (4), the measured current was converted to the displacement. The displacement transducer was connected to the signal conditioner which converts the signal from displacement transducer to 4$20 \mathrm{~mA}$ scale. To use the signal conditioner, a 24VDC power source is required.

$$
X_{d}=2.0381 I+24.458
$$

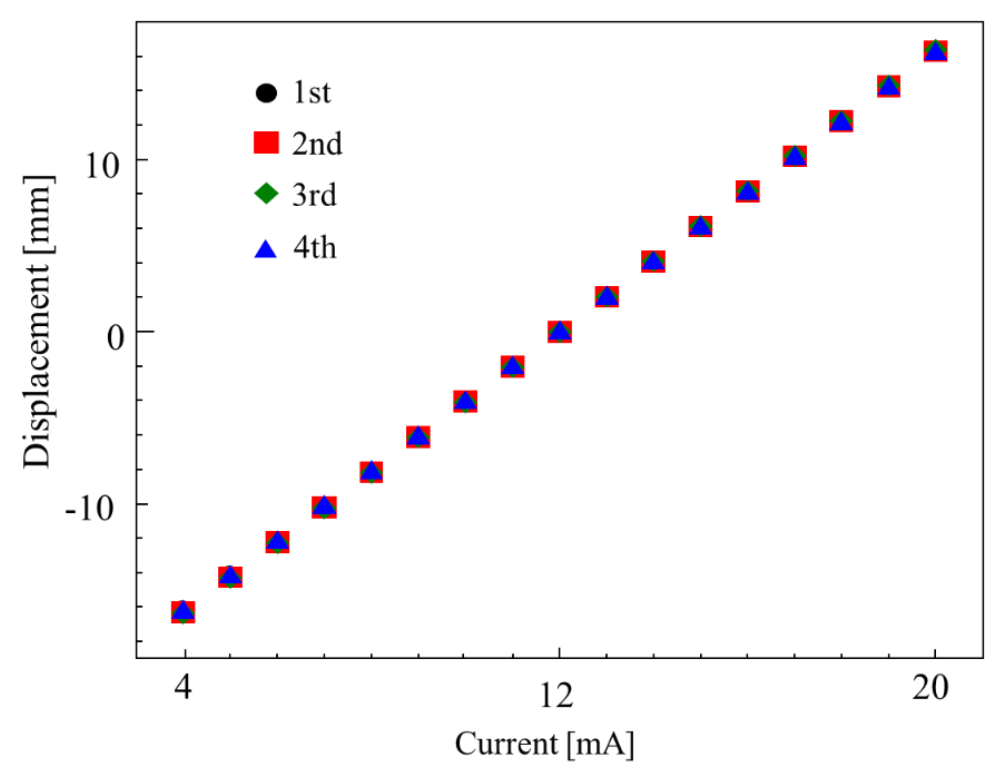

Fig. 34 Calibration result of the linear displacement transducer

\section{Working principle}

Fig. 35 shows the schematic of the displacement transducer. It is composed of a coil assembly and a core. Usually, the coil was mounted to a situational form, and the core was connected to the object which generates the motion. There are 
three coils in the coil assembly as seen in the figure. The core is able to move back and forth freely in the coil assembly. An ac source supplies the power to the inner coil. As the core moves, magnetic flux was produced by the other two coils, which induces an $\mathrm{AC}$ voltage. The generated voltage was converted to the displacement through a LabVIEW code [132].

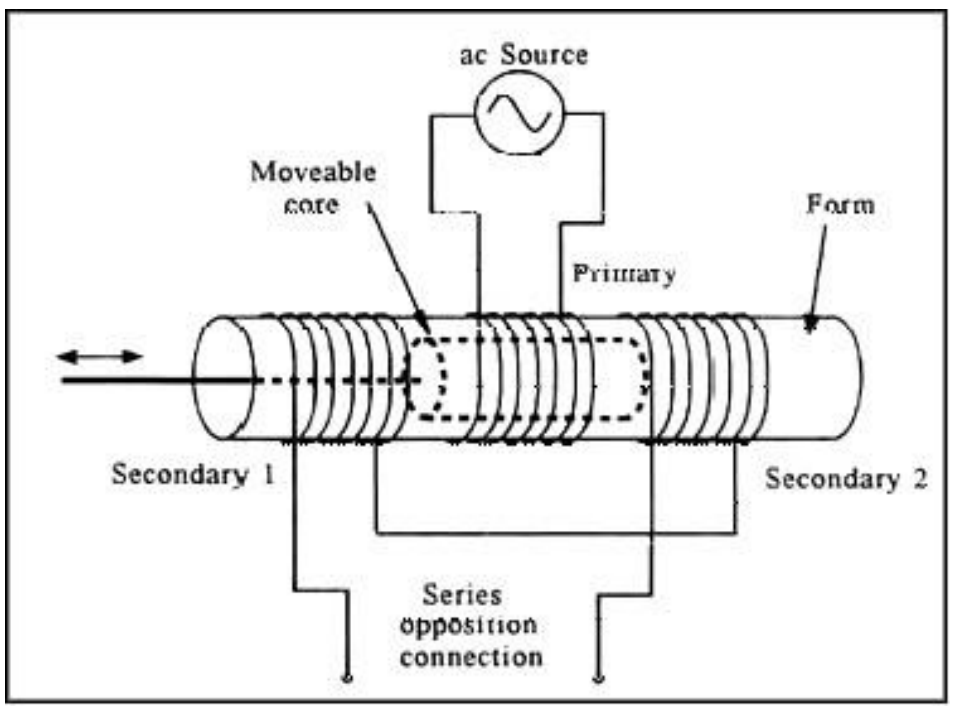

Fig. 35 Schematic of the linear displacement transducer

- $\mathrm{RTD}$

General purpose RTD probe from OMEGA was selected as a coolant temperature measurement sensor. The temperature range is $-200{ }^{\circ} \mathrm{C}$ to $600{ }^{\circ} \mathrm{C}$. The sensor type is three-wire configuration. The probe diameter is $0.25 \mathrm{inch}$ and the length is 4 inches. The accuracy is class A which is $\pm 0.06^{\circ} \mathrm{C}$. The resistance is 100 $\Omega$ at $0{ }^{\circ} \mathrm{C}$. To use the three-wire RTD sensor, a special data acquisition module is required such as NI 9219.

Fig. 36 shows the RTD sensor installation. The RTD sensors were fixed through the Swagelok and the Swagelok was installed in the T shape pipe connector. 


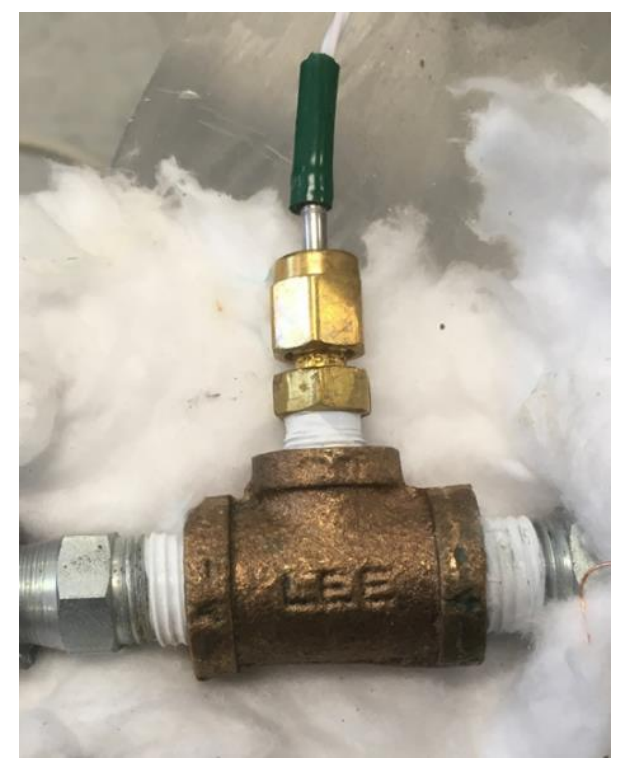

Fig. 36 RTD sensor installed in the T shape pipe connector

\section{Working principle}

RTD utilizes the correlation between temperature and metals. When the metal temperature raises up, the resistance of the metal increases. Likewise, as the temperature of the metal is used for RTD sensor changes, the resistance of the RTD varies. The common resistance of the RTD is $100 \Omega$ and the material is platinum. To measure the resistance of the RTD, the excitation current is required. The resistance is obtained by Ohm's law. The measured resistance is converted to the temperature by equation (5) (depends on the type of the RTD) [133].

$$
R(t)=R_{0}\left[1+A * T+B * T^{2}+C(t-100) * T^{3}\right]
$$

Where $A=3.93083 \times 10^{-3}, B=-5.775 \times 10^{-7}, C=-4.183 \times 10^{-4}$. 


\section{4-8. Summary of the test rig}

The test rig was designed and manufactured to reveal the flow loss and the heat transfer characteristics of the robust foil regenerator. The heater, test section, and cooler are manufactured properly, and the linear alternator was selected as the driving system of the test rig to generate the oscillating flow. The heater is composed of the two concentric cylinders and the two band heaters to heat up the working fluid. There are two test sections to separate the flow loss and the heat transfer test due to the temperature limitation of the pressure transducers. The flow going into the test section is well distributed because of the mesh diffusers located at the top and bottom of the test section. The cooler is like the heat rejecter of the Stirling engine built in our lab. It has a water jacket and fins. The coolant is water and is cooled down by the chiller after going through the cooler.

To measure the temperature of the gas and the coolant water, pressure, and piston position, the proper sensors were chosen. For the temperature measurement, the thermocouple and the RTD sensor were selected to measure the working fluid temperature and the coolant water temperature. To measure the dynamic pressure, the dynamic pressure transducer was chosen. Due to the temperature limitation of the pressure transducer, the flow loss test and the heat transfer test were separated. For the piston position measurement, the linear displacement transducer was selected. To use the linear displacement transducer, the calibration is required.

\section{Inspection of the test rig}

\section{5-1. Leakage test}

In case there is leakage from the test rig, it affects the experimental results. To check the leakage of the test rig, a leak test was conducted with the air at a pressure of 3 bars for 100 minutes. Fig. 37 shows the results of the leak test. At the beginning of the test, the system was charged with air to 3 bar. The pressure decreased gradually. After 100 minutes, the pressure dropped down to 2.914 bar. The pressure decreased by 0.086 bar over 100 minutes. However, this leakage was not significant enough to adversely affect the experiment, as the test run takes only a few minutes after it reaches quasi-steady state. 


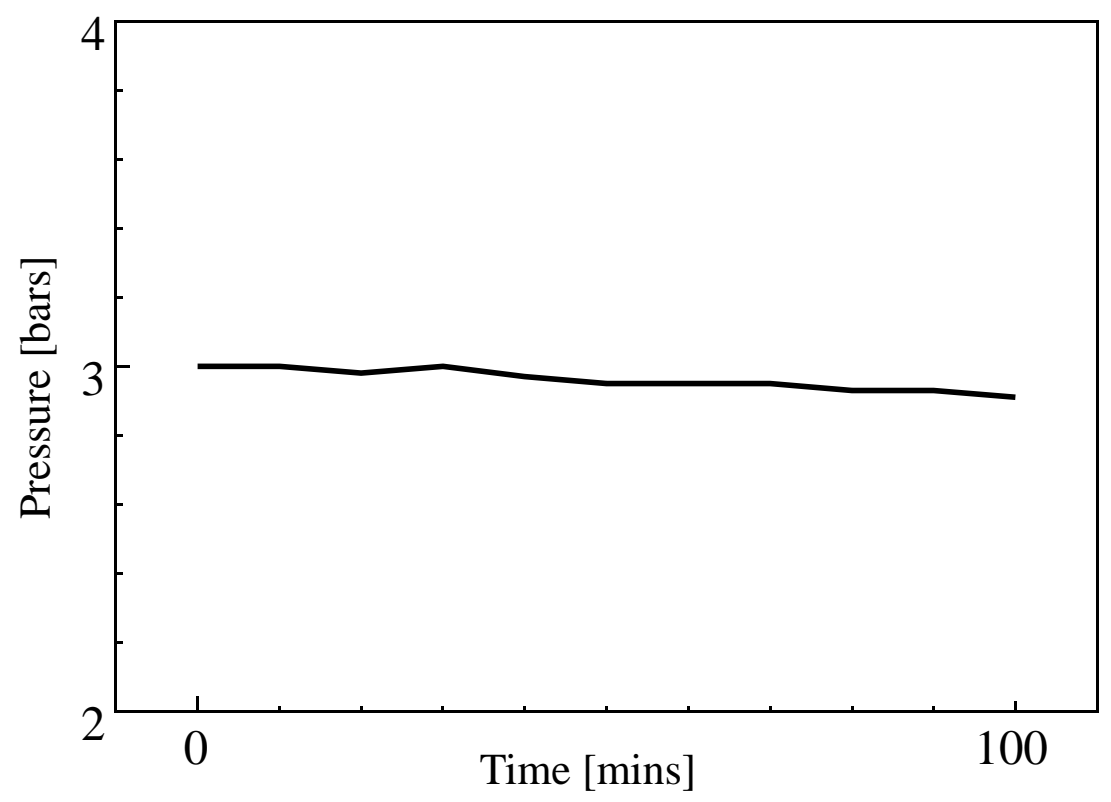

Fig. 37 Test rig leak test with 3 bar of the air

Later, it was decided to try higher charge pressure because the heat transfer test was conducted with 24 bar of charge pressure. Also, the working fluid is helium which is expected to leak easier than air. Before starting the high pressure leakage test, some holes were found at the welding part which is a typical leakage point. Ideally, a helium detector should be used to find the leak, however, we can also utilize the bubble solution. Those holes were covered by the epoxy to prevent the leakage. Fig. 38 shows the higher charge pressure test result. The charge pressure for the leakage test under the high pressure is 23 bar. The test time period is 100 minutes. The result shows a small leak which is $0.5 \%$ decreased over the test time period. This leakage is not enough to adversely affect the experiment, because the test run takes only a few minutes after it reaches quasi-steady state. 


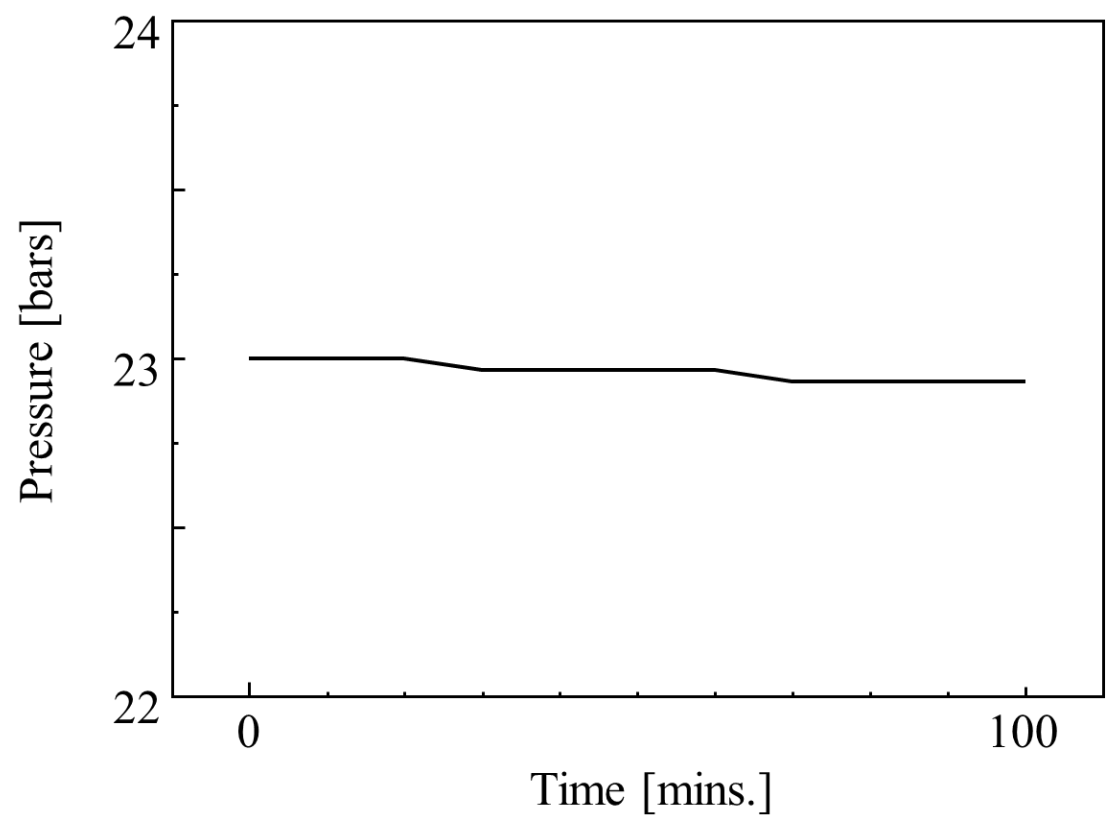

Fig. 38 Test rig leak test with 23 bar of the helium

\section{5-2. Linear alternator test}

The Linear alternator was supplied by ITC as a driving system of the regenerator test rig. The linear alternator function is considerably important for the experiment result. The piston motion was measured with the displacement transducer. The input voltage and frequency were $10 \mathrm{~V}$ and $20 \mathrm{~Hz}$ respectively.

Fig. 39 shows the piston displacement. As can be seen from Fig. 39, the motion is similar to sinusoidal motion. Therefore, the piston velocity can be expressed by equation (6). Furthermore, the linear alternator motion was checked with higher voltage, and it showed that the motion was also similar to sinusoidal motion. Therefore, it was concluded that the linear alternator can generate almost perfect sinusoidal motion regardless of the voltage.

$$
u_{p i}=X_{p} \omega \cos \omega t
$$




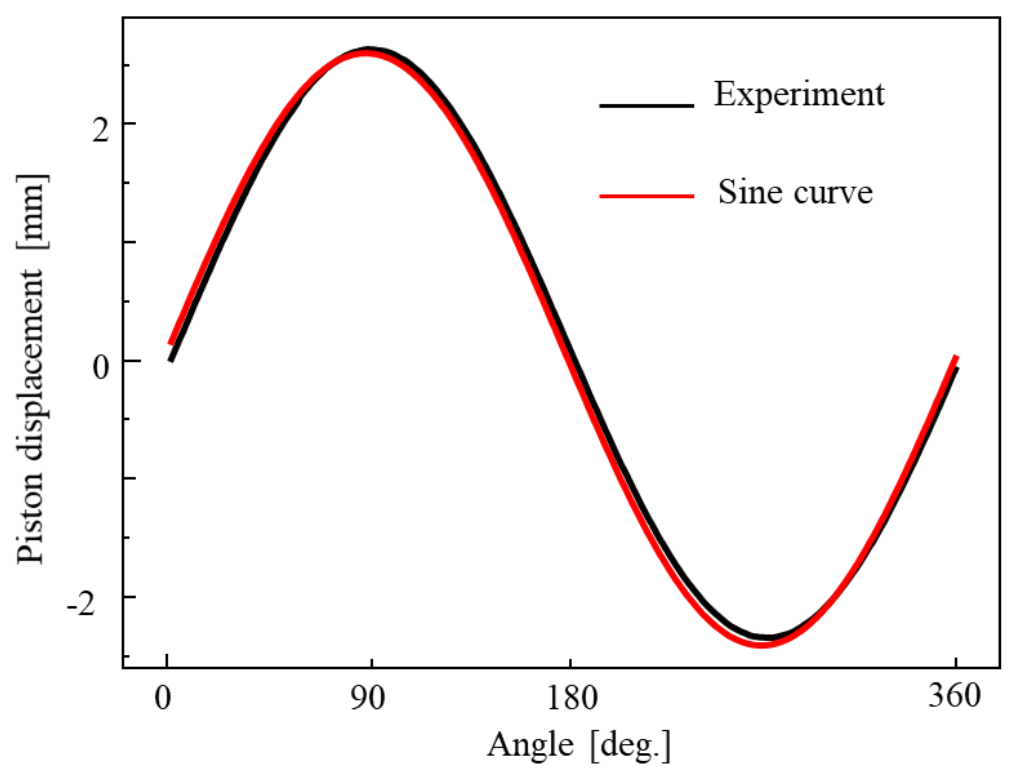

Fig. 39 Piston displacement

\section{5-3. Conduction loss calibration}

Before starting the heat transfer test, the conduction loss test was executed. The temperature difference was measured by the thermocouples located above and below the regenerator. However, the temperature difference is not only affected by the regenerator but also the conduction through the test section wall and the filler of the regenerator. Fig. 40 shows the schematic of the conduction with and without the regenerator. As shown in Fig. 40, the conduction loss test is conducted without the regenerator and working fluid movement. Reaching a thermal steady state will take several hours after starting the heater and cooler. The heater side temperature is varied between $100{ }^{\circ} \mathrm{C}$ to $120{ }^{\circ} \mathrm{C}$ and the temperature of the cooler side is fixed at $51 \pm 1{ }^{\circ} \mathrm{C}$. Fig. 41 represents the conduction loss test result. The conduction loss was calculated from the energy extracted by the cooler as shown in equation (7). The conduction loss correlation equation (8) was derived by linear curve fitting to test data. The conduction to the outside of the test rig through the thermal insulation material can be calculated by subtracting the conduction loss from the power input of the heater.

$$
Q_{\text {loss }}=\dot{m}_{w} C_{p}\left(T_{w, o u t}-T_{w, \text { in }}\right)
$$




$$
Q_{\text {loss }}=0.475 \bar{T}_{h}-22.749
$$

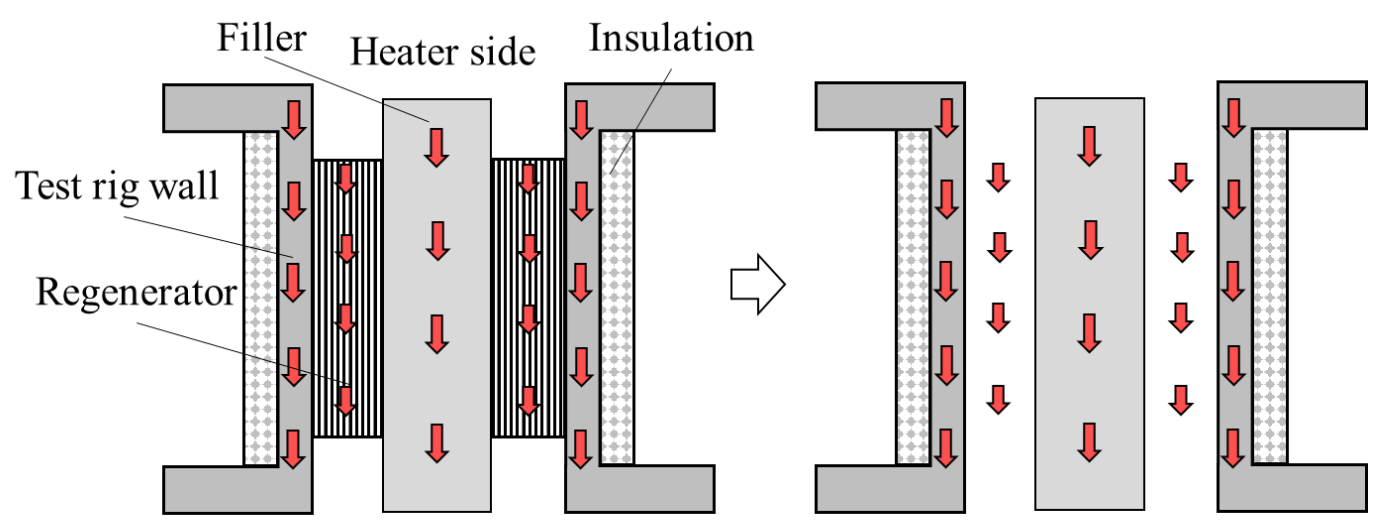

Cooler side

Fig. 40 Schematic of conduction loss test

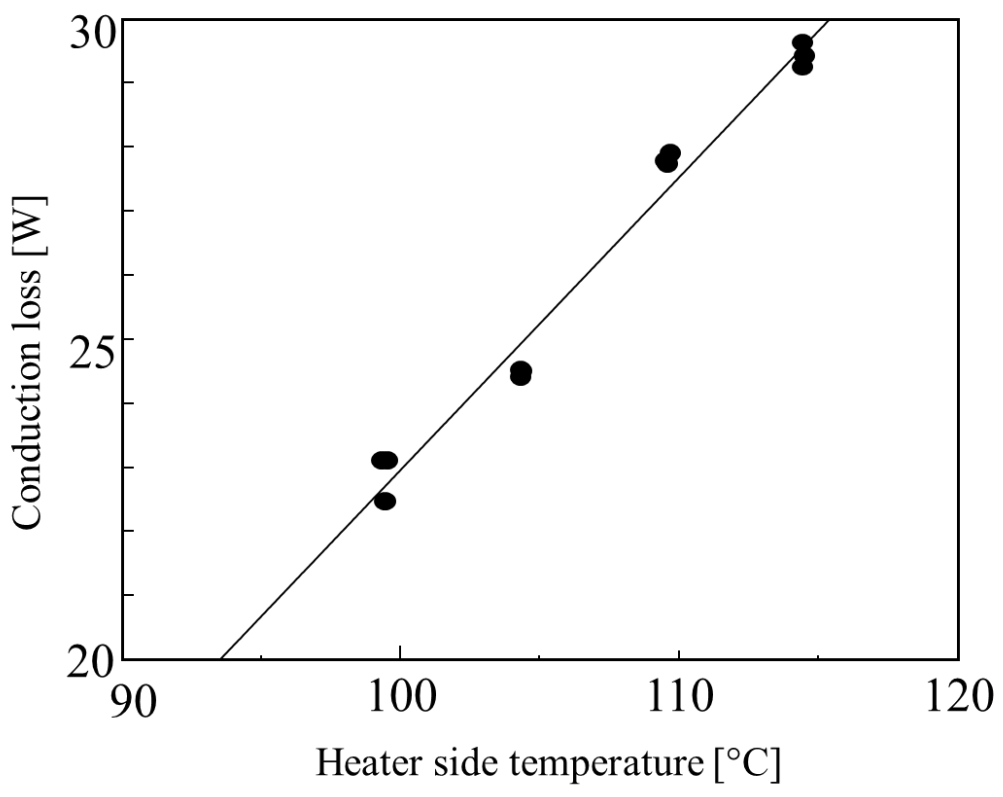

Fig. 41 Conduction loss test result 


\section{5-4. Summary}

A few experiments and simulations were conducted to check the function of the test rig. The leakage test shows that there was a small leakage in the test rig. Later it was found that the leak was from the welding part which is recognized as a typical leakage part. After covering the holes, the leakage test was conducted again with the helium which leaks easier than the air. The result indicates that there were almost no leaks in the test rig. The linear alternator test shows that the linear alternator can generate an almost perfect sinusoidal wave. Thus, the velocity of the piston is expressed by the common sine wave equation. The conduction loss test was conducted to eliminate the conduction effect through the test rig wall. The conduction loss equation was derived based on the test result. By using the equation, the conduction through the test rig wall can be calibrated out. Additionally, to check the flow distribution going into the regenerator, the CFD analysis was conducted under steady flow condition. As a result of the simulation, it was found that the flow distribution is slightly nonuniform. However, in the experiment, the mesh diffuser was installed. Thus, the nonuniformity of the flow distribution was not a problem. 


\section{Chapter 3: Flow loss test and CFD}

\section{About flow loss test}

The basis of the test rig is explained in this earlier section such as the flow path for the flow loss test and the equations to evaluate the flow loss test results. The dynamic pressure transducers are used to measure the pressure drop of the regenerator. It is then converted to the friction coefficient to compare to the other regenerator correlations. Additionally, later in this section, the details of the data acquisition system and the programs for the flow loss test are described. Prior to the flow loss experiment, the data acquisition system is selected based on the requirement of the data recording. Also, the data recording and data processing programs are made with LabVIEW 2017.

\section{6-1. Flow path of the test rig for flow loss test}

Fig. 42 shows the cross-section view of the CAD model. As in Fig. 42, the heater and the cooler are not activated in the flow loss test because of the temperature limitation of the pressure transducer located in the test section. However, the heater and cooler are still sitting in the test rig as a part of the flow path of the working fluid. Fig. 43 shows the schematic of the flow path in the test rig. The flow path from the heater to the cooler is mostly straight. When piston moves up as in Fig. 43 (a), the working fluid moves towards the heater. Vice versa, in Fig. 43 (b), as the piston goes down, the working fluid moves towards the cooler. The center opening of the cooler and the regenerator are covered by the fillers to prevent the flow going into the center opening. Therefore, the working fluid only goes between the cooler fins and also between the regenerator foils. Since the oscillating flow is generated by the piston, the pressure transducers detect oscillating pressure. 


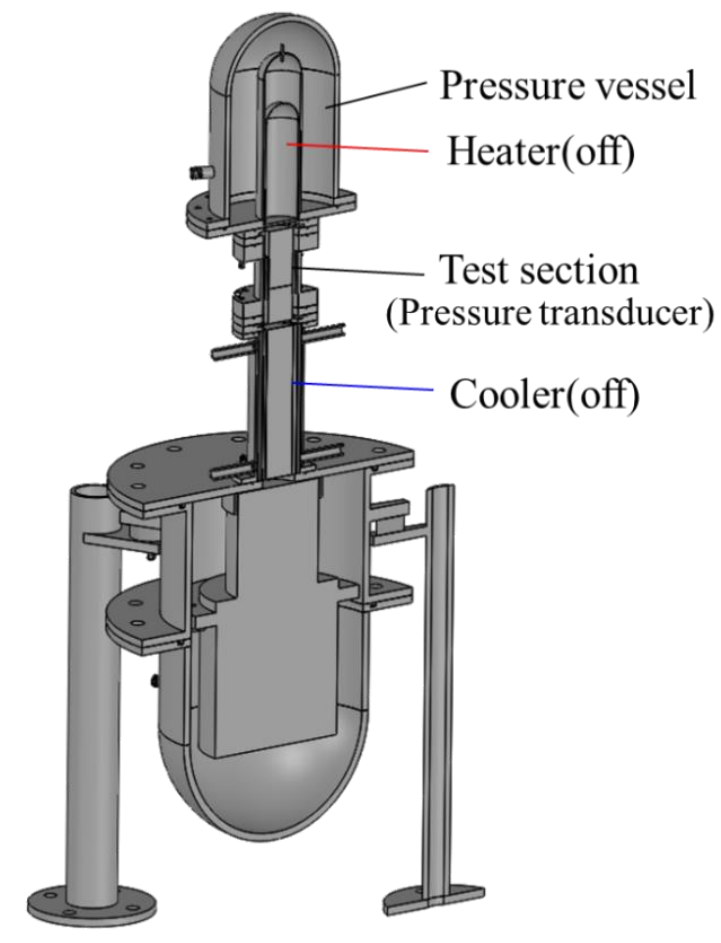

Fig. 42 Cross-section view of the test rig
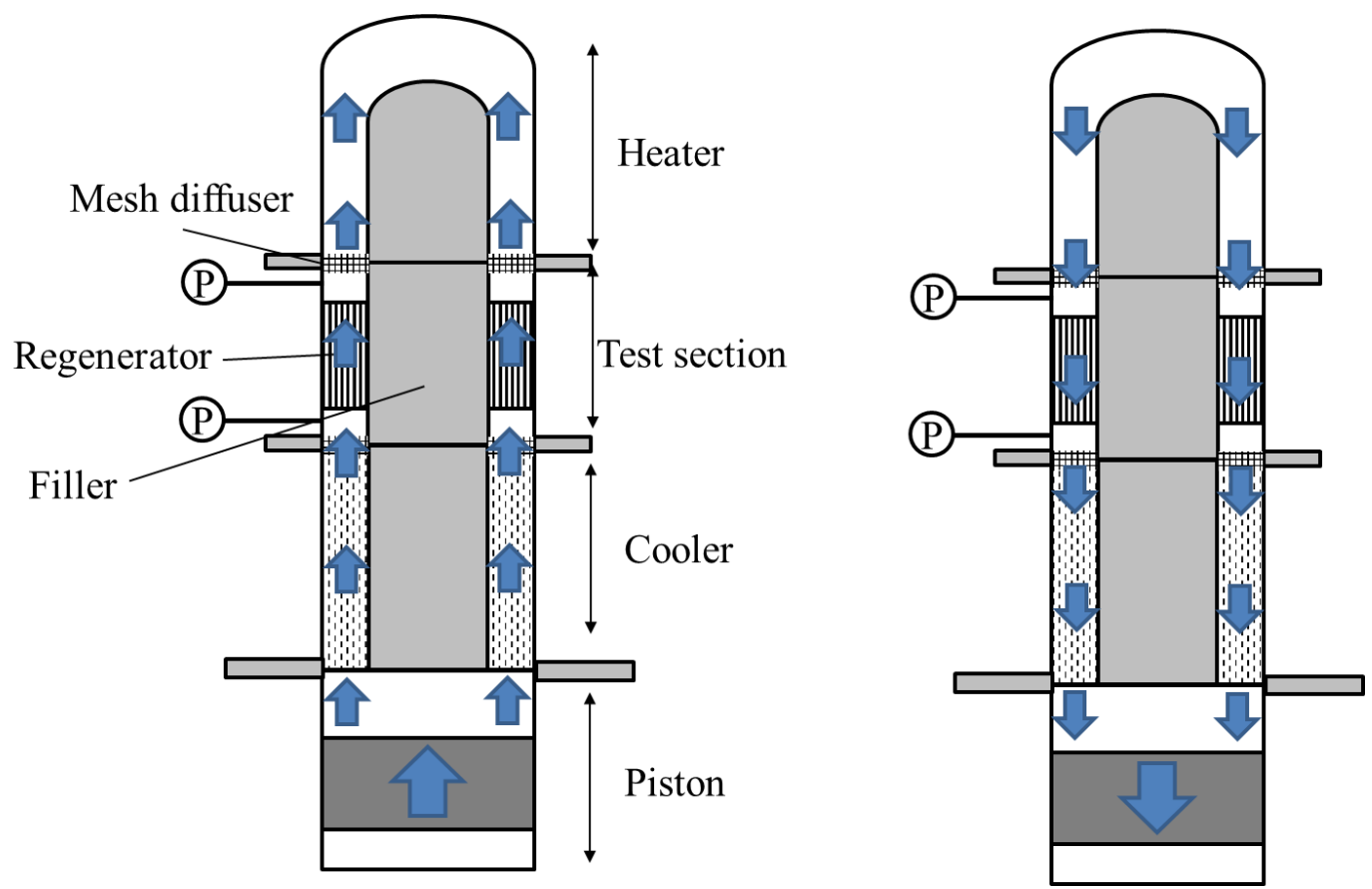

(a) Piston moves upwards

(b) Piston moves downwards

Fig. 43 Flow path of the test rig for the flow loss test 


\section{6-2. Equations for the flow loss}

To compare with the experimental results and other published correlations, the results need to be in the non-dimensional form. For the pressure data, it should be converted to the friction coefficient which is often used for the pressure measurement. Also, the Reynolds number is another dimensional number for the flow measurement. By using these two nondimensional numbers, the experimental results are fully comparable to other regenerator correlations. Therefore, the measured pressure data and the piston position data are converted to the maximum friction coefficient and the maximum Reynolds number. As the piston amplitude is increased from $1 \mathrm{~mm}$ to $15 \mathrm{~mm}$, the maximum Reynolds number was changed from 100 to 800 since the piston velocity is converted to the fluid velocity at the regenerator based on incompressible assumption. The maximum piston velocity is calculated by equation (9).

$$
u_{p i, \max }=\frac{\Delta X_{\max }}{\Delta t}
$$

$\Delta \mathrm{X}_{\max }$ is measured by the linear displacement transducer. $\Delta \mathrm{t}$ is calculated by the sampling frequency of the test. Then, the maximum mass flow rate is generated by the linear alternator piston and calculated by equation (10).

$$
\dot{m}_{\max }=\rho_{p i} A_{p i} u_{p i, \max }
$$

Due to the incompressible assumption, the mass flow rate at the piston and the regenerator are equal. Thus, the maximum velocity in the regenerator is calculated by equation (11).

$$
u_{\max }=\frac{\dot{m}_{\max }}{\rho_{r e} A_{c}}
$$

Finally, the maximum Reynolds number is derived by equation (12).

$$
R e_{\max }=\frac{u_{\max } d_{h}}{v}
$$


$d_{h}$ is the hydraulic diameter which is expressed by equation (13).

$$
d_{h}=\frac{4 A}{P}
$$

Furthermore, the maximum friction coefficient is calculated by the following equation (14) [58].

$$
C_{f, \max }=\frac{\Delta P_{\max } d_{h}}{\frac{1}{2} \rho_{r e} u_{\max }^{2} L}
$$

$\Delta \mathrm{P}_{\max }$ is the ensemble-averaged maximum pressure drop through the regenerator measured by the two dynamic pressure transducers.

\section{6-3. Data acquisition system}

All data are recorded via LabVIEW 2017 and National Instruments data acquisition devices. Through the LabVIEW code, the data from the two pressure transducers and the piston position are recorded simultaneously. The cDAQ-9178, NI9225, and NI9234 modules are used as the data acquisition systems. All the data through these devices can be obtained simultaneously.

The cDAQ-9178 is a compact data acquisition chassis for a portable sensor measurement system. It has 8 slots for NI data acquisition devices and a USB connection to the computer. Also, the built-in trigger is in the cDAQ-9178. Thus, the built-in function of the NI data acquisition devices is applicable through the cDAQ-9178.

The NI9225 module is chosen to measure the current from the displacement transducer which records the piston motion of the linear alternator. NI9225 is not the current measurement device. Thus, a shunt register is required to measure the current from the displacement transducer. Additionally, the NI9225 is used to measure the voltage output from the power source CHROMA 61604 which monitors the voltage input value of the linear alternator. The maximum and minimum sampling frequency of the NI9225 are 50 
$\mathrm{kS} / \mathrm{s}$ and $1.613 \mathrm{kS} / \mathrm{s}$ respectively. Note that the sampling frequency of the NI9225 is not flexible. When the sampling frequency is set in the LabVIEW code, the sampling frequency is automatically adjusted to the closest acceptable frequency of the device. For instance, when the sampling frequency is $60 \mathrm{kS} / \mathrm{s}$ in the LabVIEW code, the actual sampling frequency is $50 \mathrm{kS} / \mathrm{s}$. Note that the signal scale of the displacement transducer and the voltage input value are significantly different. The device is designed for high voltage measurement since the range of the voltage is $300 \mathrm{Vrms}$. However, the resolution of the device is 24-bit. Meaning that the resolution of the NI9225 is $300 / 2^{24}=1.79 \times 10^{-5}[\mathrm{~V}]$ and the resolution is small enough for the measurement of the displacement transducer. Therefore, the NI9225 can be used for both the high voltage measurement and low voltage measurement.

The NI9234 module records the pressure data through the pressure transducer. It has 4 channels with BNC terminals and the voltage range is $\pm 5 \mathrm{~V}$. Due to the requirement of the excitation current to use the pressure transducer, the NI9234 is a suitable device to utilize with the pressure transducer. The maximum and minimum sampling frequency is $51.2 \mathrm{kS} / \mathrm{s}$ and $1.652 \mathrm{kS} / \mathrm{s}$ respectively. Similar to the NI9225, the sampling frequency is automatically adjusted to a certain frequency due to the inflexibility of the device.

\section{6-4. Data acquisition program}

LabVIEW 2017 was used to make a code for data acquisition. In the data acquisition program, the data from the pressure transducer and the linear displacement transducer are recorded. Also, the voltage input to the linear alternator is obtained as well.

Fig. 44 shows the front panel of the data recording program for the flow loss test. The left upper corner is for the sensor inputs. The displacement transducer calibration constants are necessary to enter in this part. Also, the frequency of the data acquisition is controlled by the "Monitoring dt" section. The upper middle part is the input for the power source. The details of the power source controls are mentioned in the following paragraph. All the required values to start the power source are controlled in this section. The right side of the program shows the two graphs and three buttons. The graphs indicate the power source output voltage and the linear alternator piston motion. Also, the stroke length and the 
frequency of the piston are monitored in the small windows under the graph. The green buttons are used to turn on the power source and the button next to the green button starts the recording. The last button stops both the recording and the piston motion. Last, the left down corner shows the pressure value from the pressure transducers. The sensor 1 graph is the data from the heater side pressure transducer. The sensor 2 graph represents the data from the cooler side pressure transducer. Furthermore, the pressure difference can be seen in the delta $\mathrm{P}$ graph. All of the instantaneous values and the other measured values are shown in the small windows.

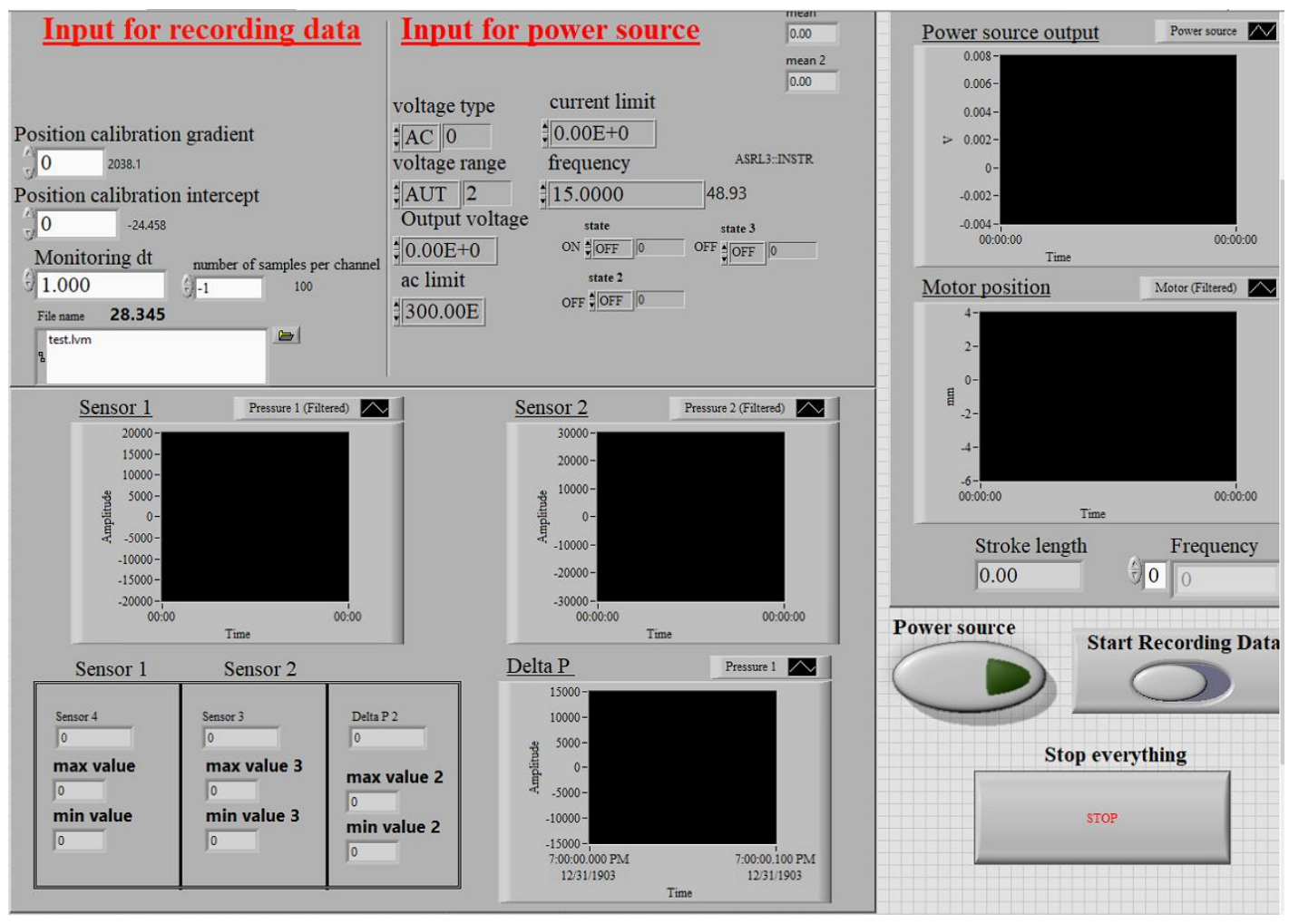

Fig. 44 Front panel of the flow loss data recording program

By installing the VI form a disk that was sent by Chroma. The power source 61604 can be controlled by the LabVIEW code. Fig. 45 shows the VI of the power sources. First, input the allocated device name to detect the power source on the LabVIEW code. Then, input voltage type (ac or dc), voltage range (depending on the piston stroke length), ac limit 
(for safety purposes), output voltage, frequency (if it is ac), and current limit. If the output value exceeds the current limit, the power source stops automatically. The computer and the power source are connected by RS-232C. It was a great choice to use this power source VI instead of controlling the power source directly because walking around the laboratory to change the power source settings was not convenient. It saved time even though it took some time to understand the power source VI.

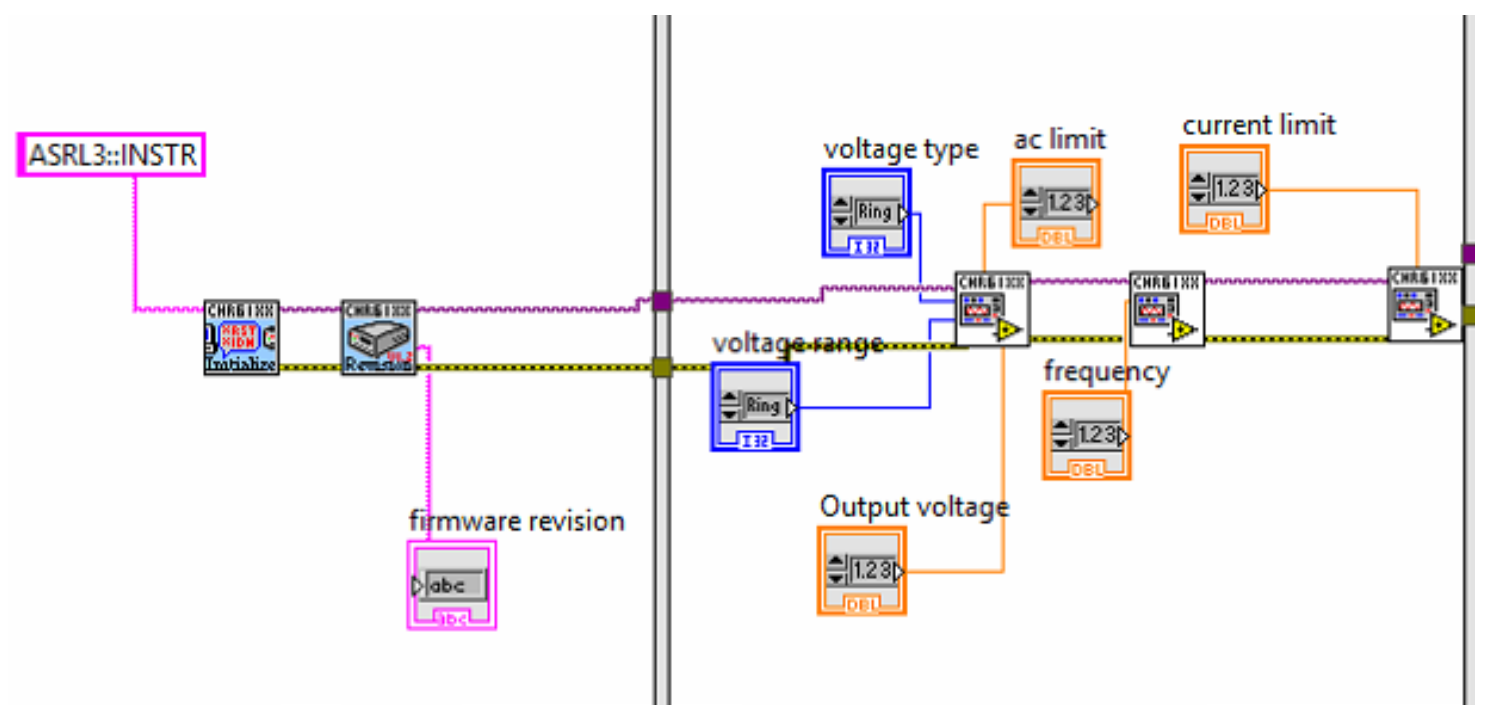

Fig. 45 LabVIEW code for the remote control of the power source

To record the data simultaneously through the data acquisition program, all the DAQ $\mathrm{mx}$ VI should be connected from one task signal which activates the data acquisition devices. Fig. 46 shows the difference between one task activation and two task activation. Based on the conversation with the National Instruments support, if the task is separated, the data synchronization is not guaranteed. However, when all the VI is from same task signal, the data recording is synchronized. 


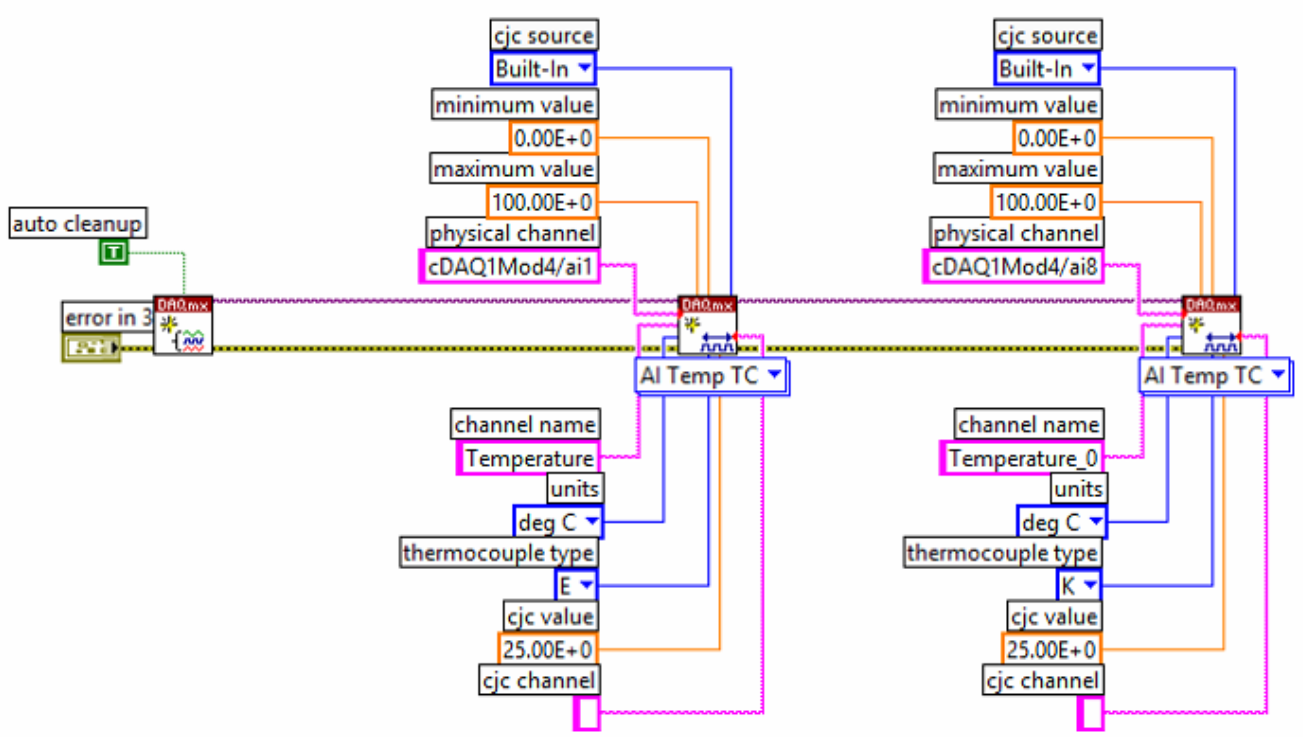

(a) One task signal 


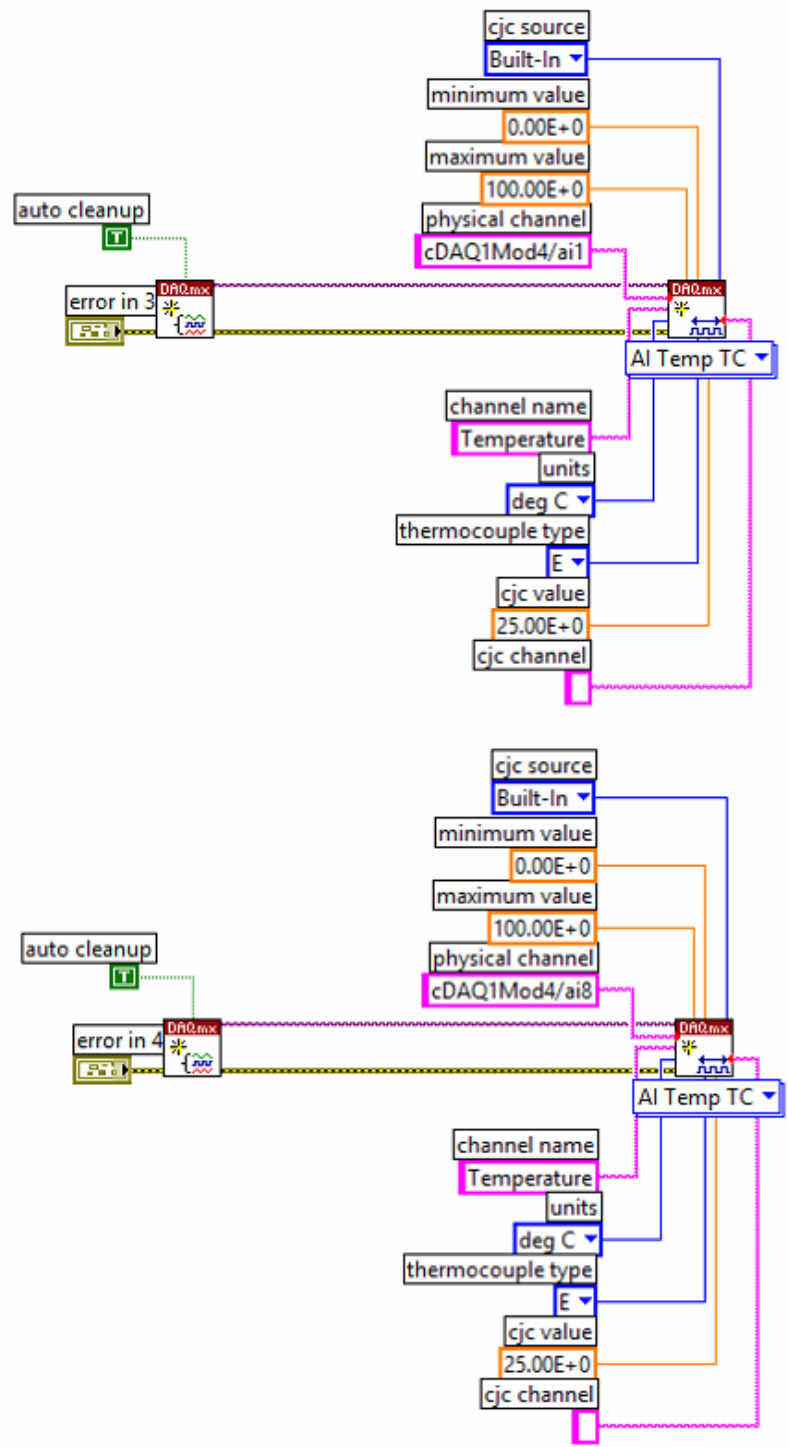

(b) Two task signal

Fig. 46 Difference between the one task and two task

For the displacement transducer, the measured current has to be converted to the displacement through the LabVIEW code. Furthermore, based on the displacement, the stroke length of the piston and the frequency were calculated. To calculate the frequency accurately, the digital filter was used in the program. The raw data from the displacement transducer was noisy and the frequency measurement cannot be accurate with the fluctuated data. Therefore, the digital filter was used to cut off the electrical noise. 
The power source voltage measurement was simply carried out. But the voltage from the power source is considerably higher than the sensor signals; thus, a thicker wire should be used to connect the power source to the NI module.

For the pressure transducer, it required the excitation current. It was slightly complicated to build the code for the excitation current. The most common data acquisition VI is the DAQ assistant. It is convenient to make a simple program such as voltage, current, and temperature measurements. However, the DAQ assistant does not have a detailed setting function in the VI. Therefore, it cannot conduct certain special functions such as the excitation current. Thus, the DAQ assistant is not the best choice to use with special functions. Instead of the DAQ assistant, the DAQmx VI is suitable for a more detailed setting. Fig. 47 shows the DAQ assistant and DAQmx. The DAQmx has many functions to add. For the excitation current, the four functions needed to be added such as the channel name, current type, excitation current source, and amount of the current. The channel name is the channel in which the pressure transducer was connected. Since NI9234 has an excitation current function, the source of the excitation current is internal. The acquired data from the pressure transducer was the voltage data, thus, it needed to be converted to the pressure in the LabVIEW code. To convert it, the calibration constant of the transducer was entered into the program. 

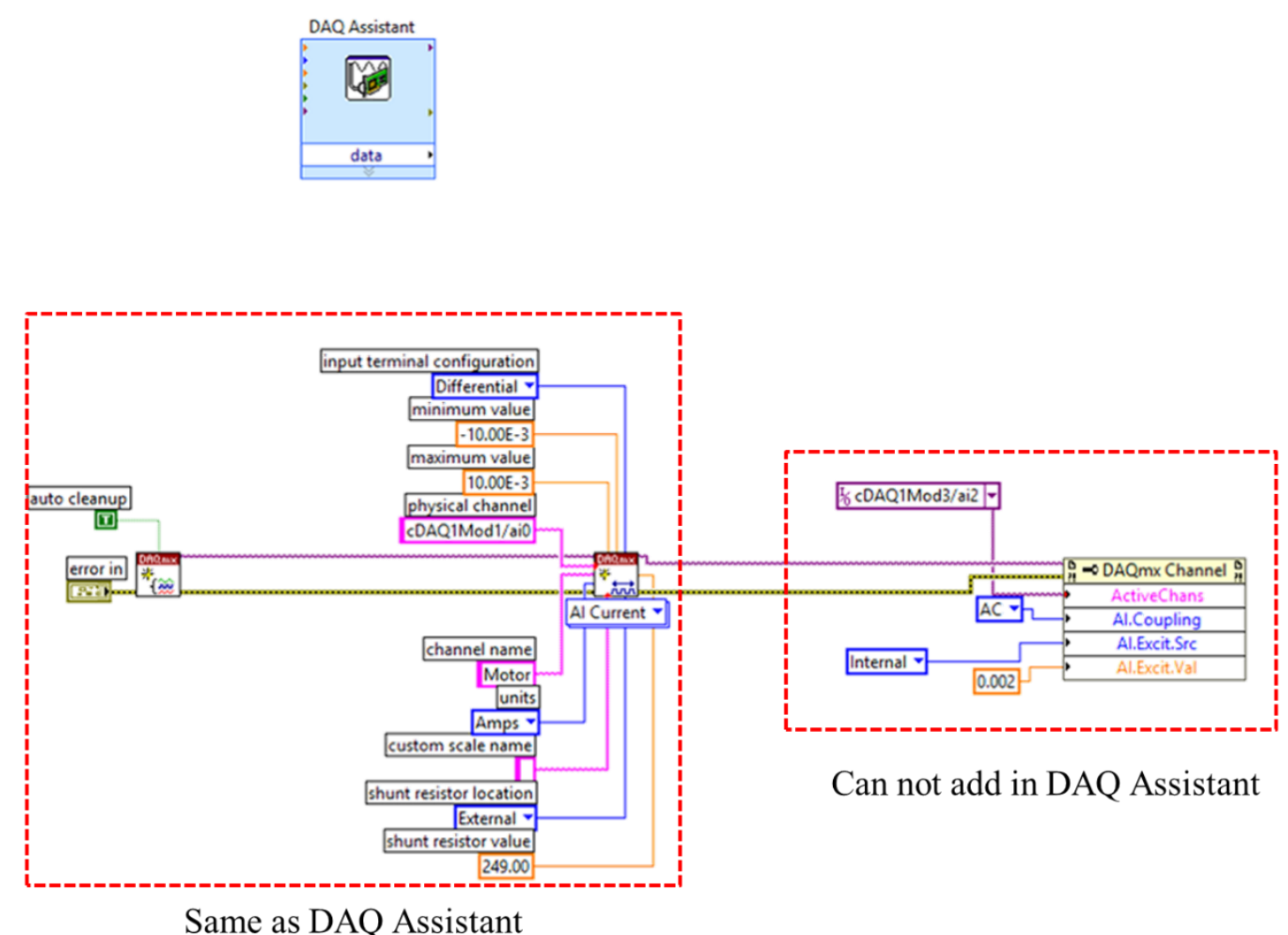

Fig. 47 Difference between the DAQ assistant and the DAQmx

\section{6-5. Data processing program}

Fig. 48 (a) and (b) show the front panel of the data processing program for the flow loss test. From Fig. 48 (a), all the input for the data processing is located in this section. The "starting points" window decides the first data point of the data set in the data processing. For example, if the data at the beginning is not in a quasi-steady state, the unsteady data can be ignored by setting "start point". Most of the experiments were started after the flow becomes a quasi-steady state. Thus, the starting point window was not necessary to use. The "Number of cycles" window is to limit the number of cycles to conduct the data processing. When the data is too large, the "Number of cycles" should be used to clip the time for the processing. The "confidence level" window decides the confidence level for the uncertainty analysis. The "Input file name" window determines to recall the recorded data through the data recording program which was saved in the 
LabVIEW data folder. The parameters of the regenerator and the fluid are controlled in this section as well. Additionally, the output file name can be decided.

In Fig. 48 (b), the raw data and the ensemble-averaged result are shown in 4 graphs. The ensemble average is the main part of this program. Since the experimental data was obtained under oscillating condition, the pressure and piston motion data are similar to the sinusoidal motion. If the average was taken, the result is zero. Therefore, the ensemble average is required. Fig. 49 shows the image of the ensemble average. To conduct the ensemble average, each cycle should have the same number of the data. Then, add all of the first data of each cycle and divided by the number of cycles. The calculation result is the first point of the ensemble-averaged cycle. Keep on going until the last data of each cycle, and all the calculated data depict one cycle which is the ensemble-averaged cycle. These calculations are implemented in the data processing program. The program details of the ensemble average are following. 1. Count the number of cycles which have the same number of data points. 2. Delete the cycles which have a different number of data points. Third, add the data which is located at the same crank angle in each cycle. Then, 3. Divide by the number of cycles used to conduct the ensemble average. Fig. 50 shows the example of the raw data and the ensemble-averaged data generated by the data processing program. From Fig. 50, it is found that the ensemble average was conducted perfectly using the data processing program.

Based on the ensemble-averaged pressure and the piston position data. The maximum friction coefficient and the maximum Reynolds number were calculated. Also, the absolute and relative uncertainty of the ensemble average was calculated. 


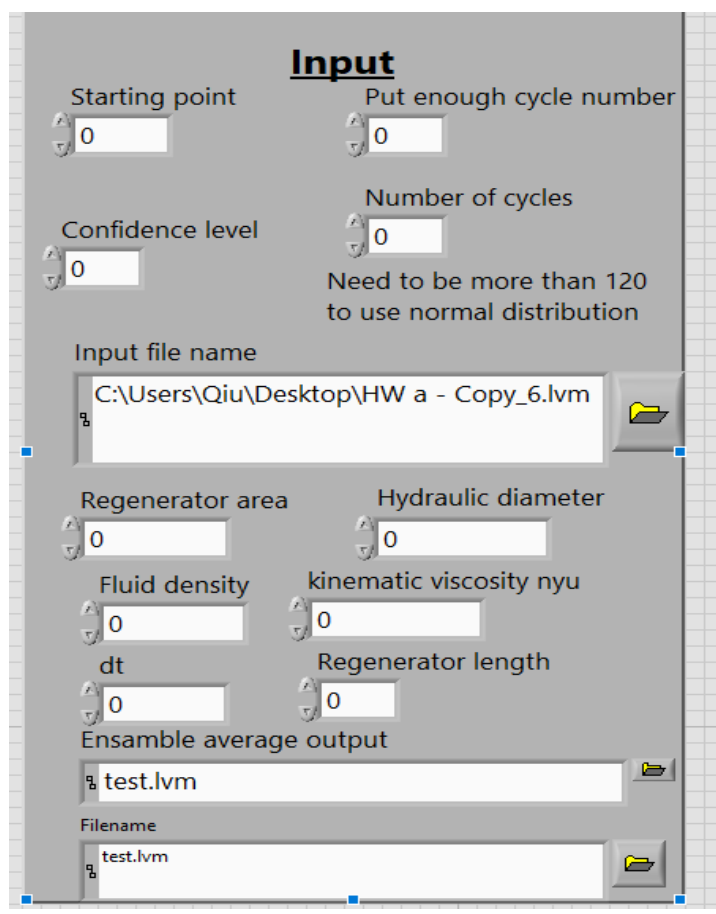

(a) Input for data processing program

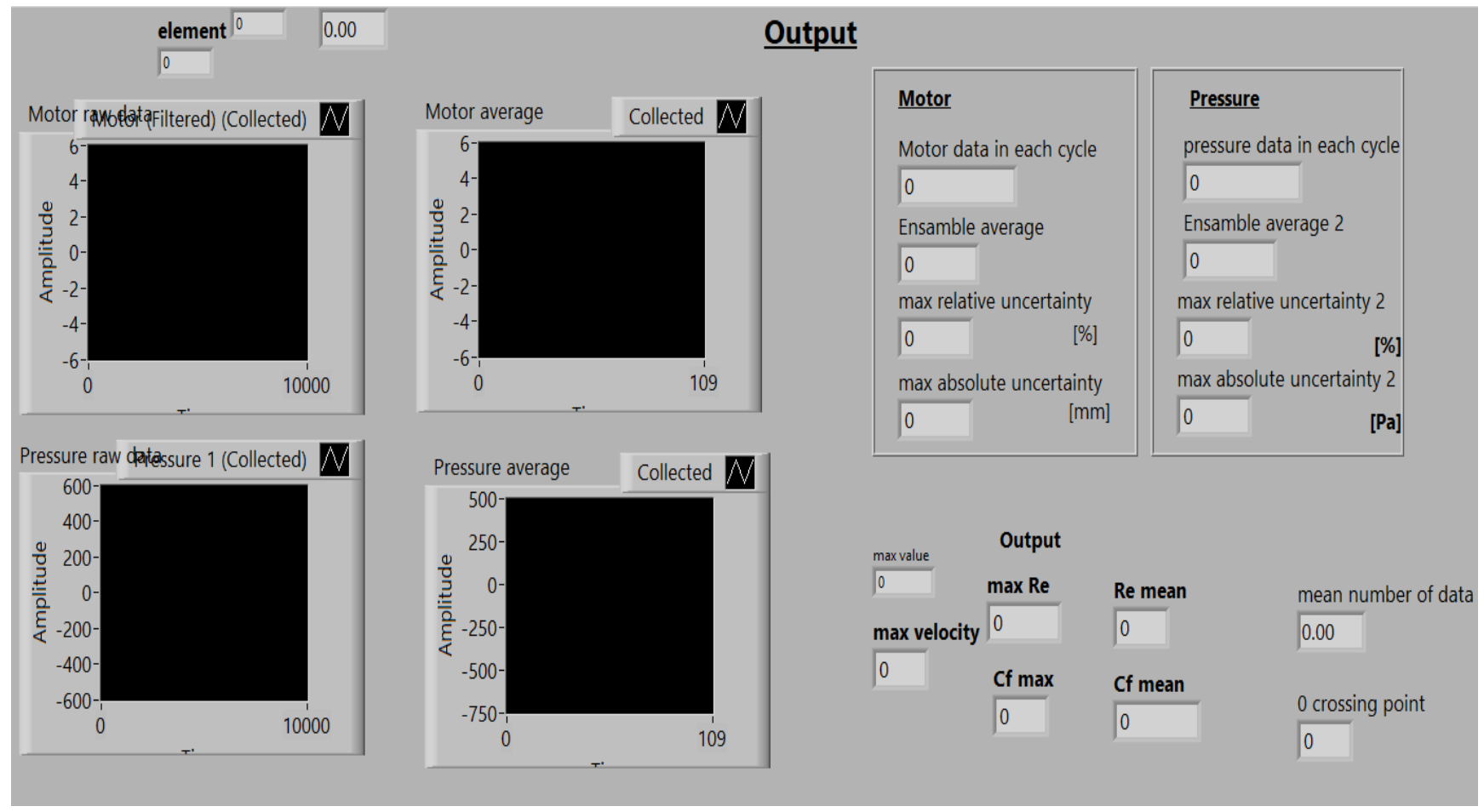

(b) Output for the data processing program

Fig. 48 Front panel of the data processing program 
(1)
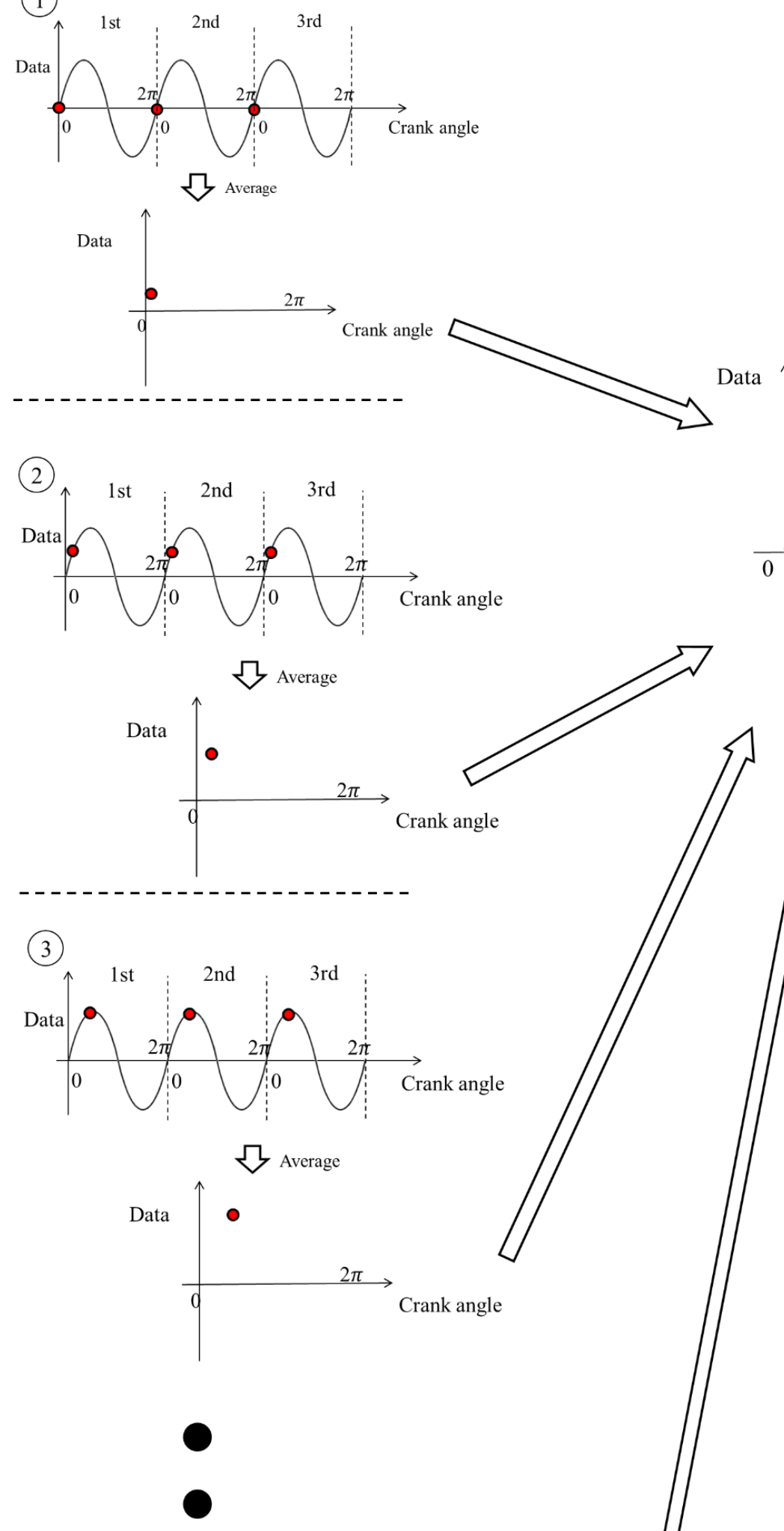

0
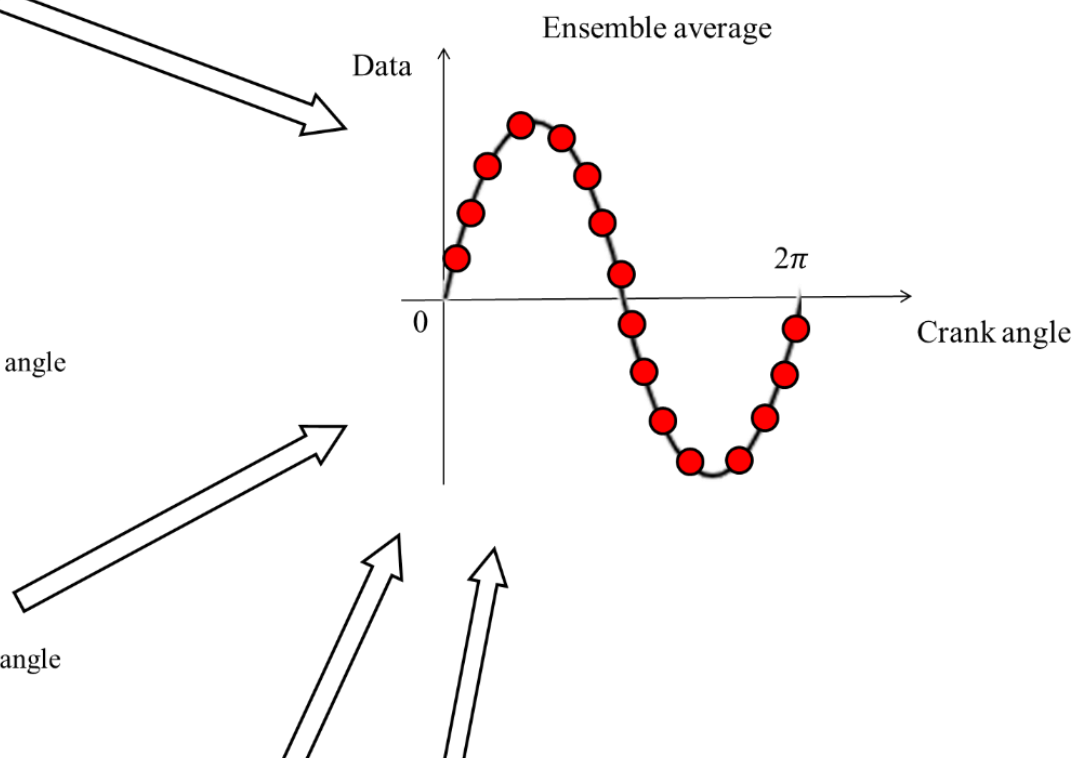

Fig. 49 Ensemble average 

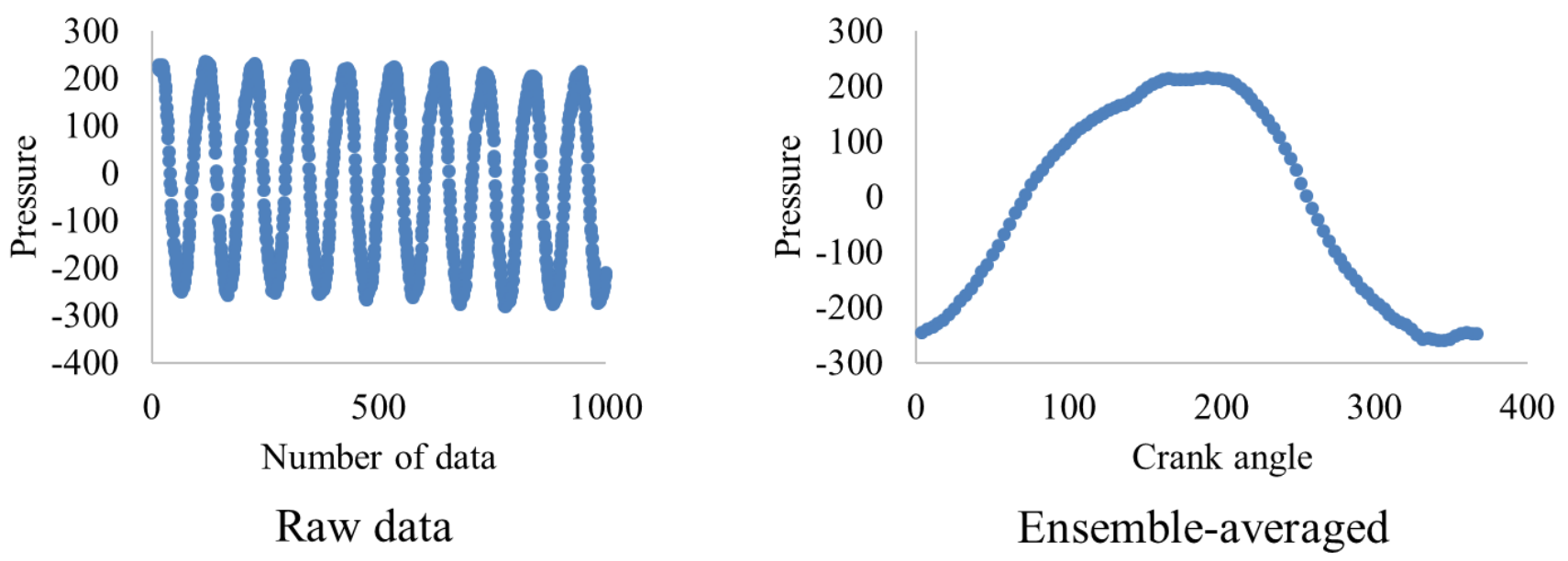

Fig. 50 Example of the ensemble average

\section{6-6. Uncertainty analysis}

The flow loss tests were conducted at least five times for each of the Reynolds number to conduct the uncertainty analysis [134]. The equations to derive the relative uncertainty are represented by equation (15).

$$
\text { Relative uncertainty }= \pm \frac{Z \frac{\sigma}{\sqrt{n}}}{\bar{x}} \times 100[\%]
$$

$\overline{\mathrm{x}}$ is the average value of the $\mathrm{x}$ represented by equation (16).

$$
\bar{x}=\frac{1}{n} \sum_{n=1}^{n} x_{i}
$$

Also, $\sigma$ is expressed by equation (17).

$$
\sigma=\sqrt{\frac{1}{n-1} \sum_{n-1}^{n}\left(x_{i}-\bar{x}\right)^{2}}
$$


All the calculations were conducted by the LabVIEW code as shown in Fig. 51 and Fig. 52. The only input to use the LabVIEW program is 5 data with the same Reynolds number and confidence level for the $\mathrm{Z}$ value in equation (15).

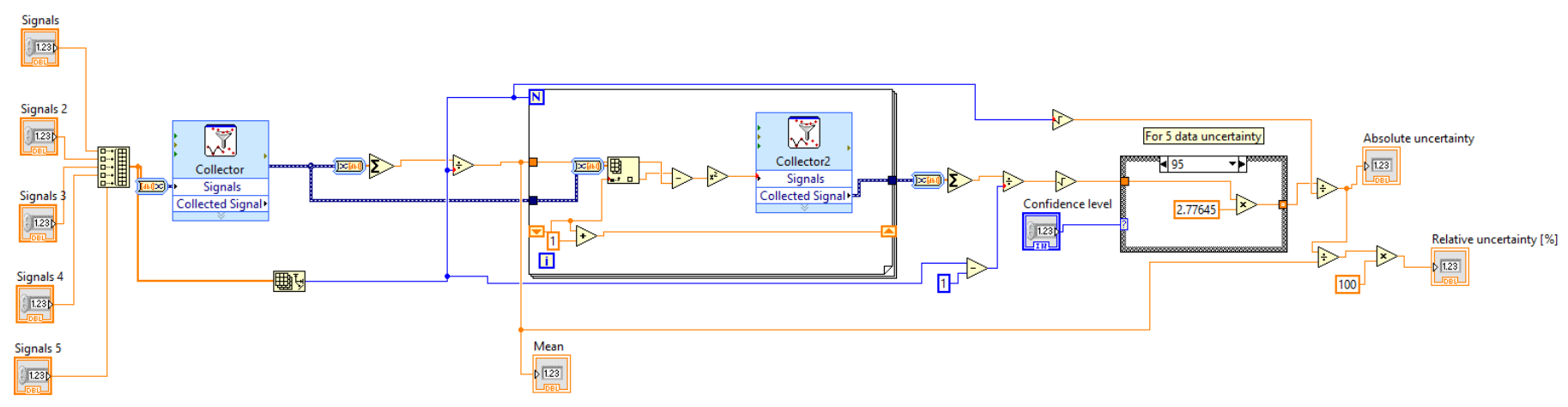

Fig. 51 Program for the uncertainty analysis

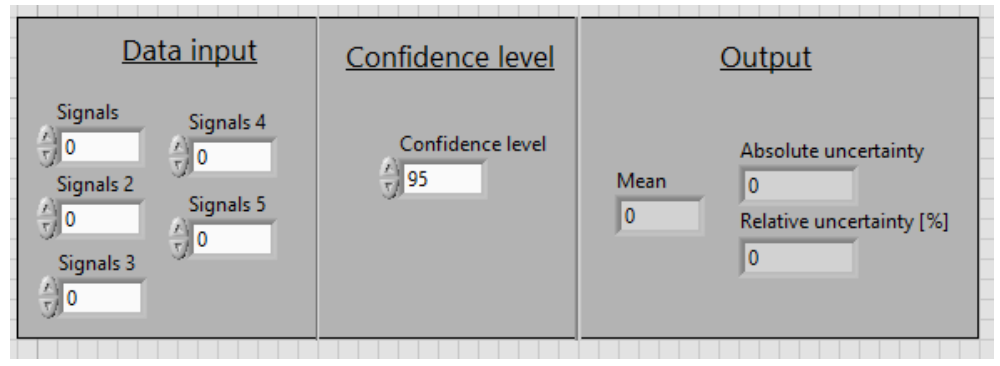

Fig. 52 Front panel of the uncertainty analysis program

\section{6-7. Summary}

In this section, the flow path of the test rig and the data processing system was explained. As seen in Fig. 43, the flow path of the test rig is very simple. To measure the pressure, piston position, and power source output voltage, the proper NI data acquisition modules were selected as the data acquisition systems. The data recording program was made to record all the data simultaneously. Due to the excitation current requirement of the pressure transducers, the program is included the excitation current function. For the data processing program, the ensemble average was conducted in the program to calculate the friction coefficient with the ensemble-averaged pressure data. Note that the ensemble average program made for the flow loss test is only for the data which has enough data 
points in one cycle. If the number of data points are not enough, this program does not work.

\section{Test Rig Verification}

In this section, a woven screen regenerator is manufactured for the test rig verification. After reading various literature, it was apparent that the test results vary with the test rig quality. To obtain correct experimental data, the woven screen regenerator experiment result was compared to the published woven screen regenerator correlations from other researchers. The test rig setup, the programs for the data recording and the data processing are the same as the robust foil regenerator experiment.

\section{7-1. Woven screen regenerator}

The test data is not always correct. The data changes because of the test rig setup and experimental conditions. To prove the validity of the test data, the test rig verification was conducted. A woven screen regenerator was designed and manufactured properly for the test rig verification. The woven screen regenerator was chosen because many research papers were published about the woven screen regenerator, and therefore it was easy to find the correlations to compare with.

A few mesh sheets were purchased firstly and cut into $5 \mathrm{~cm} \times 5 \mathrm{~cm}$ size. Three types of mesh sheets were selected.

- $200 \times 200$, wire diameter 0.0021 inch

- $200 \times 200$, wire diameter 0.0016 inch

- $80 \times 80$, wire diameter 0.007 inch

After cutting into $5 \mathrm{~cm} \times 5 \mathrm{~cm}$ size, the pieces of mesh sheets were stacked up to $5 \mathrm{~cm}$ tall. Since the test section is for the regenerator with $5 \mathrm{~cm}$ long, each of the mesh sheets were stacked in the different number of layers $(625,800$, and 195 each). The stacked meshes were clamped by the stainless-steel plate and 4 bolts. Fig. 53 shows the clamped mesh. All three types of mesh were clamped the same way and sent to Chick Machine to conduct the sintering. Fig. 54 shows the sintered mesh block. To prevent that the mesh and the stainless- 
steel plate from sticking together, the STOPIT was applied between the mesh and plate. The sintering was conducted with a temperature of $1920^{\circ} \mathrm{F}$ and 2.5 hours under vacuum pressure conditions. One of the sintered mesh blocks $(200 \times 200$, wire diameter 0.0021 inches) was sent to Northwest wire EDM to machine the mesh block. The outer diameter and the inner diameter of the machined block are $52 \mathrm{~mm}$ and $35 \mathrm{~mm}$ respectively. Fig. 55 shows the woven screen regenerator. The hydraulic diameter of the woven screen regenerator is defined by equation (18) [58]. The porosity $\beta$ is defined by equation (19) [123].

$$
\begin{gathered}
d_{h}=\frac{4 \beta}{\varphi(1-\beta)} \\
\beta=1-\left(\frac{\pi d_{w} \sqrt{P^{2}-d_{w}^{2}}}{4 P^{2}}\right)
\end{gathered}
$$

$\varphi$ is the shape factor determined as the ratio of the mesh surface area to the mesh volume $[58,99]$.

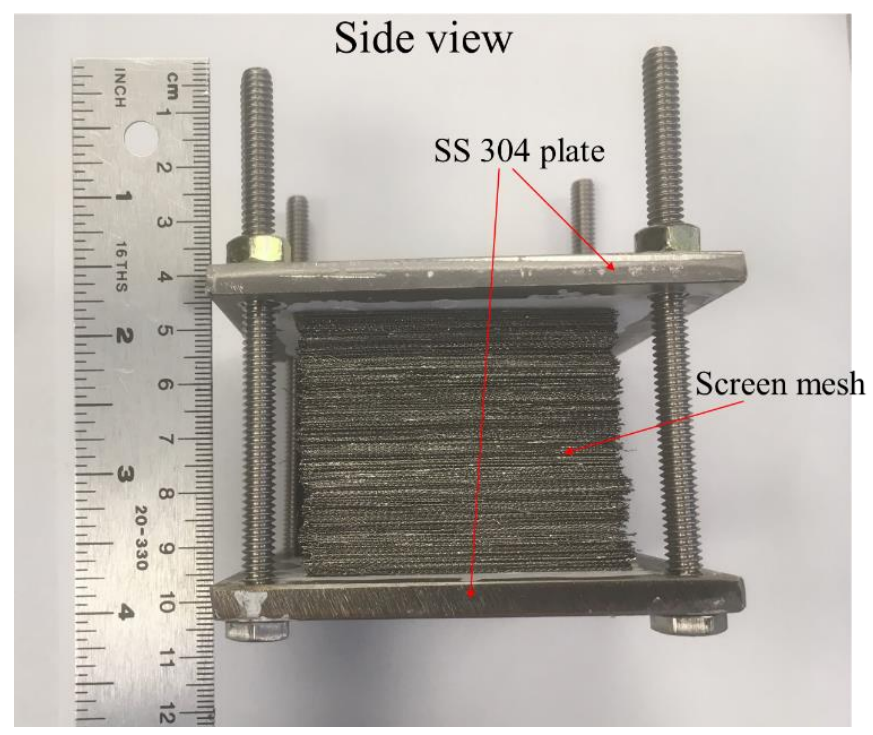

Fig. 53 Clamped mesh block by the stainless-steel plate 


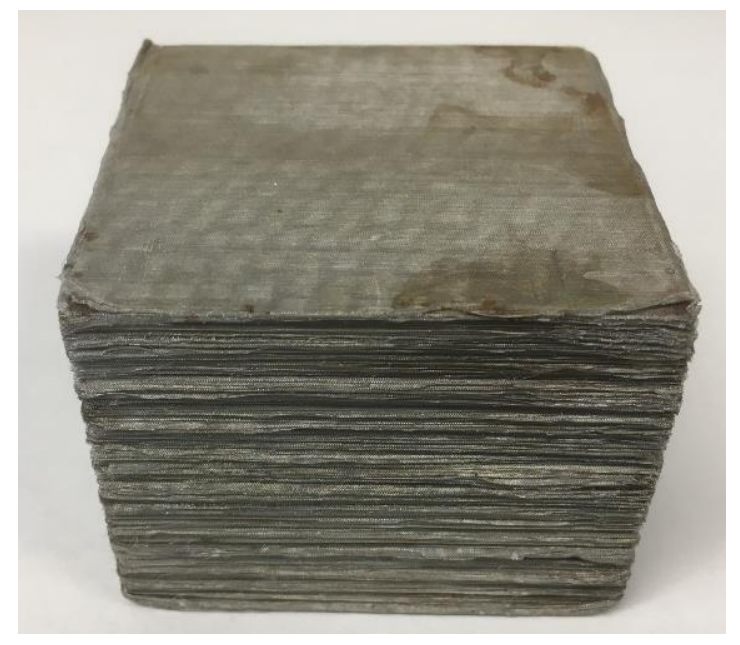

Fig. 54 Sintered mesh block
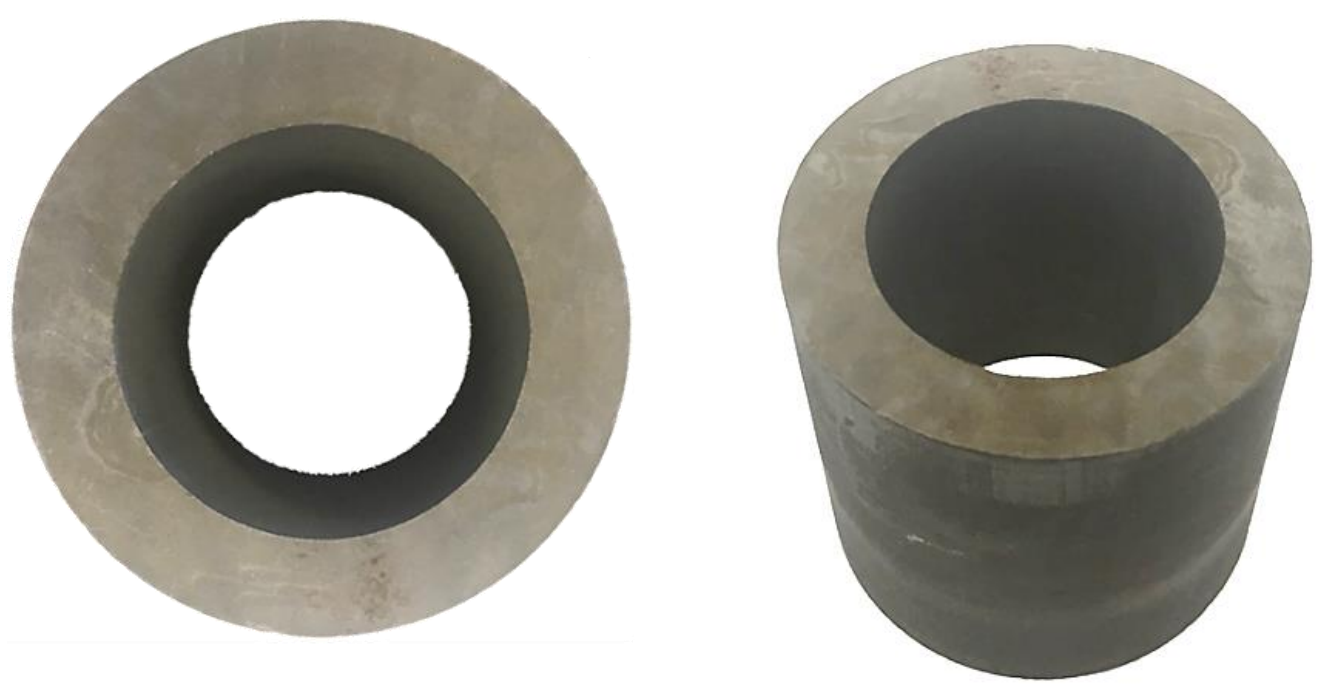

Fig. 55 Woven screen regenerator

\section{7-2. Test details and the published correlations to compare}

A woven screen regenerator was manufactured to compare the results to the published friction factor correlations. The outer diameter, inner diameter, and height are $52 \mathrm{~mm}, 35$ $\mathrm{mm}$, and $50 \mathrm{~mm}$ respectively. The wire diameter is $5.344 \times 10-5[\mathrm{~m}]$ and the porosity of the regenerator is $69 \%$. The data recording system and programs are explained in section 6 . Excluding the Reynolds number and the charge pressure, experimental conditions were also identical to the robust foil regenerator experiment. The Reynolds number range is 70 
to 700 , and the charge pressure was 7 bar. The temperature was at room temperature and the frequency of the linear alternator was $20 \mathrm{~Hz}$. The test procedure is as follows. The test rig is charged to 7 bar with air. After starting the linear alternator, wait for 10 minutes until the flow becomes a quasi-steady state. The test lasts for 30 seconds to record at least 600 cycles of the piston motion. The measured pressure data and the piston position data were converted to the friction coefficient and the Reynolds number to compare to the other published correlations.

The results were compared to the published correlations which are equation (20) (22) $[74,99,58]$, and the porosity of the regenerators are $62-78 \%, 64-75 \%$, and $39-64 \%$ respectively.

$$
\begin{aligned}
C_{f \text { Gedeon }} & =\frac{129}{R e}+2.91 R e^{-0.103} \\
C_{f \text { Tanaka }} & =\frac{175}{R e}+1.60 \\
C_{f \text { Costa }} & =\frac{123}{R e}+3.20 R e^{-0.104}
\end{aligned}
$$

\section{7-3. Woven screen regenerator test result}

The measured pressure difference at the top and bottom of the woven screen regenerator was converted to the maximum friction coefficient by utilizing the maximum pressure difference in the ensemble-averaged cycle. Fig. 56 shows the comparison of the experiment results with the other regenerator correlations. The calculated maximum friction coefficients were plotted along with the maximum Reynolds number which was calculated based on the maximum velocity at the regenerator. The experiment fit line was made with the curve fitting tool in Matlab. Equation (23) represents the experiment fit result.

$$
C_{f \text { woven screen }}=\frac{224.5}{R e}+1.43
$$


As shown in Fig. 56, the published correlations are slightly different from the researchers. However, the correlations are relatively similar regardless of the porosity difference of the regenerator. The experiment result shows that the calculated maximum friction coefficients are significantly close to the alternative published correlations. At the low Reynolds number region, the experiment results are slightly higher than the published correlations. This is because the small experimental error caused a large change due to the equation used in the low Reynolds number range. Since the flow velocity is low at the low Reynolds number region, the small error of the pressure measurement is enlarged by equation (14). However, the overall woven screen regenerator results show a good agreement to the other woven screen regenerator correlations. Therefore, it is concluded that the test rig is highly valid and the experiment results using this test rig have reliability.

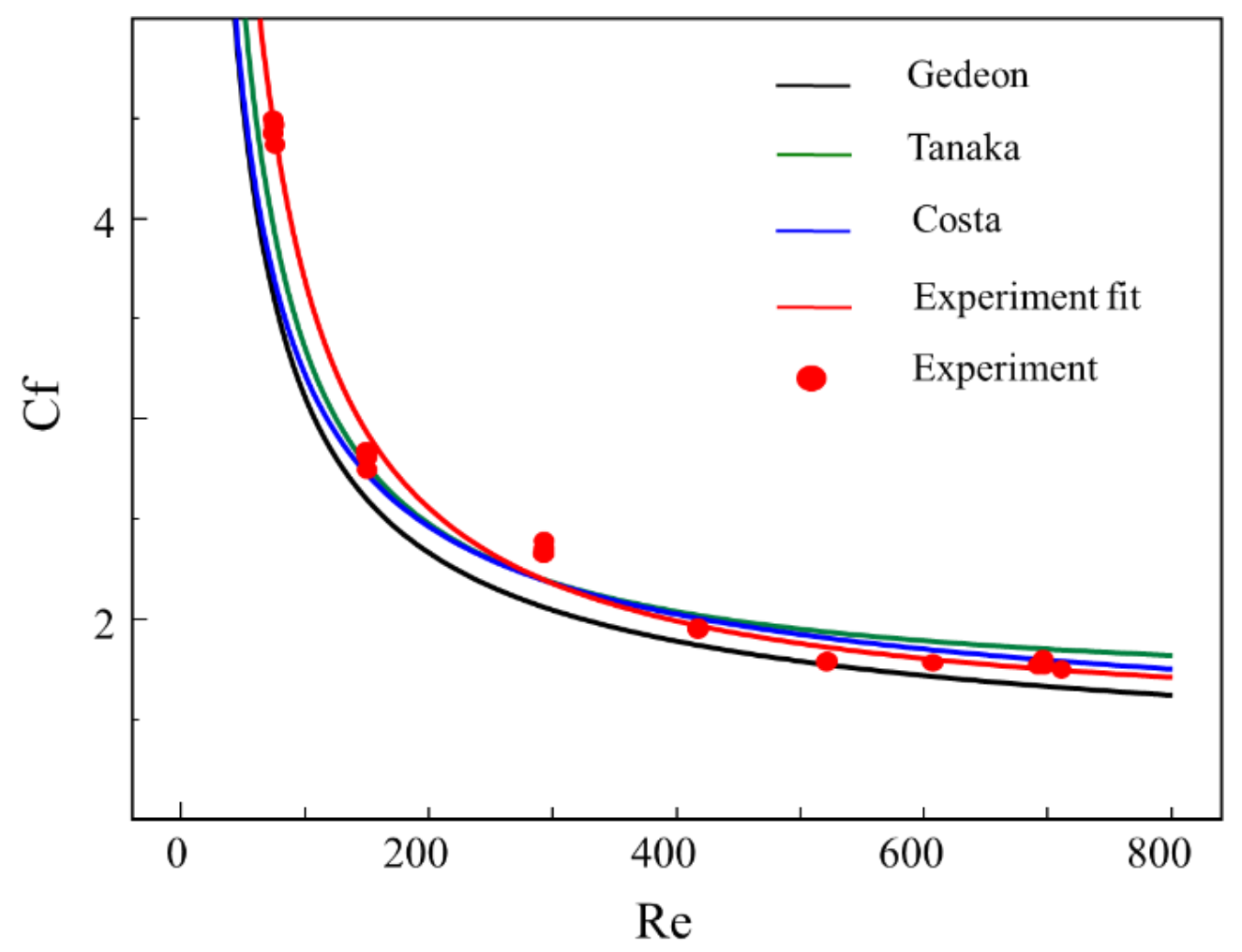

Fig. 56 Comparison of the woven screen regenerator friction factors 


\section{7-4. Summary}

The woven screen regenerator was manufactured to conduct the test rig verification by comparing the experimental results with the published woven screen regenerator correlations. Three types of mesh sheets were selected initially, and all of them were sent for the sintering. The wire EDM was utilized to cut one of the stacked mesh blocks into the regenerator shape. Using the woven screen regenerator, the flow loss test was conducted, and the measured pressure data was converted to the friction coefficient. The test rig verification results showed that the woven screen regenerator experiment results have a good agreement with the published correlations. Therefore, the test rig is valid to conduct further experiments.

\section{Robust foil regenerator flow loss result}

The flow loss of the regenerator directly affects the Stirling engine efficiency [43]. In this section, the flow loss test of the robust foil regenerator was conducted by using the test rig built for the regenerator testing. The pressure transducers were installed at the top and the bottom of the regenerator to measure the pressure drop of the regenerator. Using the data recording and data processing program, the measured pressure data was rerecorded and processed. Through the data processing program, the friction coefficient was derived. The derived friction coefficient was compared to the other regenerator correlations to evaluate the robust foil regenerator performance in terms of the flow loss. Additionally, the CFD analysis was conducted under the oscillating flow conditions to compare with the experiment results.

\section{8-1. Test conditions}

The robust foil regenerator was manufactured by additive manufacturing to reveal the flow loss and the heat transfer characteristics. For the flow loss test, the two pressure transducers were installed to measure the pressure drop of the regenerator. The pressure transducers only detect the pressure change from the charge pressure. Therefore, the charge pressure does not affect the pressure measurement. The outer diameter, inner diameter, and height of the regenerator are the same as the woven screen regenerator to fit the regenerator in the test section. The data recording system and programs were explained in section 6 . 
Excluding the Reynolds number and the charge pressure, experimental conditions were also identical to the woven screen regenerator experiment. The Reynolds number range is 100 to 800 and charge pressure was 2 bar. The charge pressure was different from the flow loss test of the woven screen regenerator to adjust the Reynolds number range of the experiment. The temperature was at room temperature and the frequency of the linear alternator was $20 \mathrm{~Hz}$. The test procedure is as follows. The test rig is charged to 2 bar with the air. After starting the linear alternator, wait until the flow becomes a quasi-steady state for 10 minutes. The test lasts for 30 seconds and records at least 600 cycles of the piston motion. The measured pressure data and the piston position data are converted to the friction coefficient and the Reynolds number to compare to the other published correlations.

\section{8-2. Flow loss CFD}

To prove the validity of the experimental results, the CFD were conducted by utilizing ANSYS Fluent. The robust foil regenerator drawings were via SolidWorks. The regenerator geometry was $1 / 8$ model of the actual regenerator to decrease the mesh number of the CFD model. ICEM CFD was utilized to generate the hexa mesh. The number of mesh is $2,228,000$. The mesh number in each of the parallel flow channels are 10 towards the radial direction. The generated meshes around the flow channel walls are relatively small. Fig. 57 shows the mesh of the CFD model and a detailed view of the mesh at the flow channels of the regenerator. The selected model is Laminar because the Reynolds number range was less than 1000. To conduct the CFD analysis under oscillating flow conditions, User Defined Function (UDF) was used for the inlet boundary condition. At the inlet, the mass flow rate boundary condition was selected, and the mass flow rate is dependent on the UDF. Fig. 58 shows the UDF program. Since the mass flow rate is given as a sinusoidal wave, the mass flow direction at the mass flow inlet/outlet depends on the UDF program. The outlet boundary condition was the pressure boundary condition. The gauge pressure was 2 bar which is same as the experimental condition. All the walls were no slip condition, and the fluid was incompressible. The simulation was conducted by the ANSYS FLUENT 19.1. The governing equations, mass conservation equation, and momentum equation are expressed by equation (24) (25). 


$$
\begin{gathered}
\frac{\partial \rho}{\partial t}+\nabla \cdot(\rho \vec{v})=0 \\
\frac{\partial}{\partial t}(\rho \vec{v})+\nabla \cdot(\rho \vec{v} \vec{v})=-\nabla p+\nabla \cdot(\overline{\bar{\tau}})+\rho \vec{g}+\vec{F}
\end{gathered}
$$

As the two channels located at the outermost and innermost of the regenerator are thinner than the other flow channels. These two channels are deleted due to the difficulty of the mesh generation. The other conditions are identical to the flow loss test. Seven cases are simulated with the maximum Reynolds number of 200, 300, 400, 500, 600, 700, and 800 . The pressure measurement points are exactly the same as the locations of the pressure transducers in the test rig. The measured pressure drop of the CFD is converted to the maximum friction coefficient by equation (14). Also, the maximum Reynolds number is calculated by equation (12).
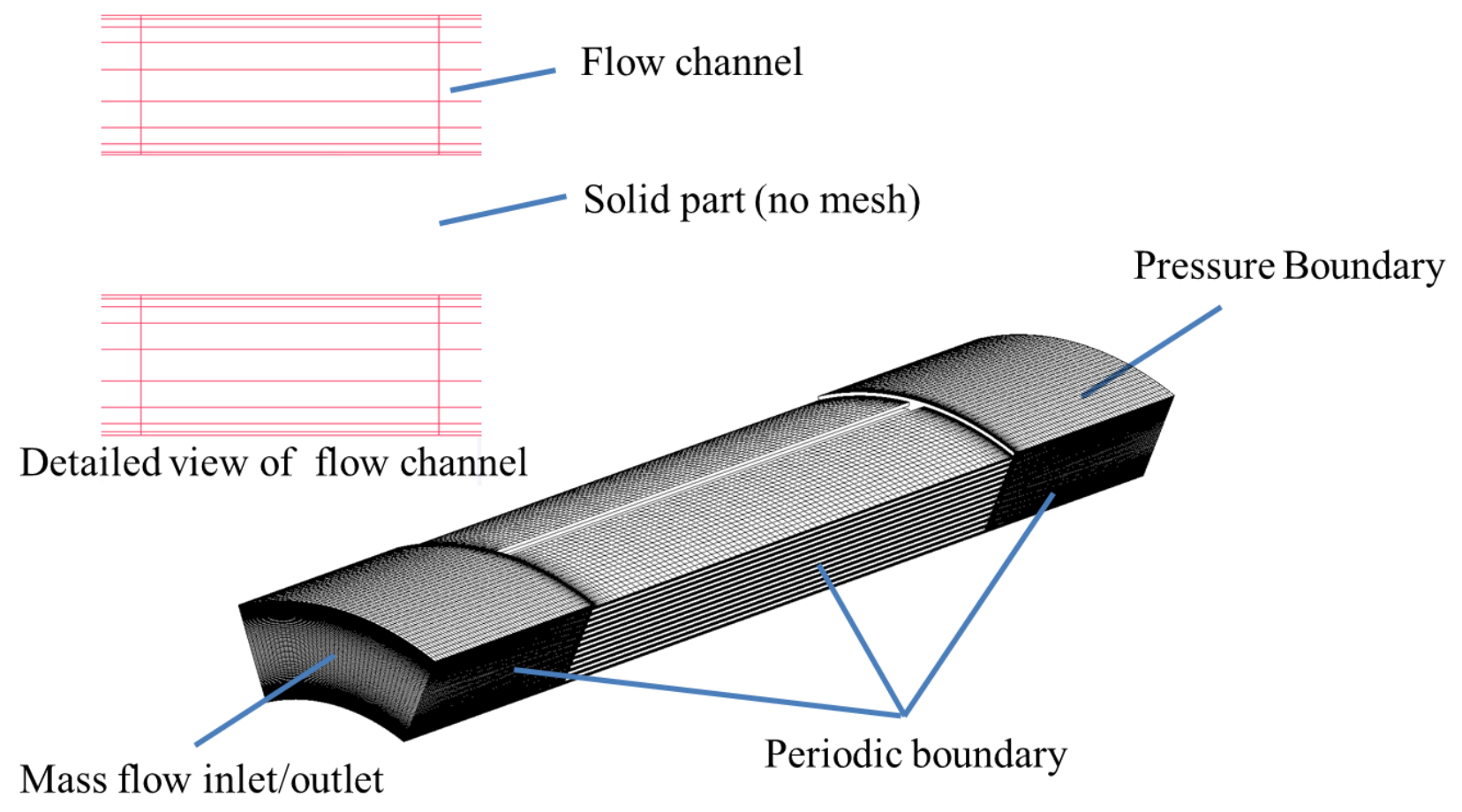

Fig. 57 Mesh of the CFD model 


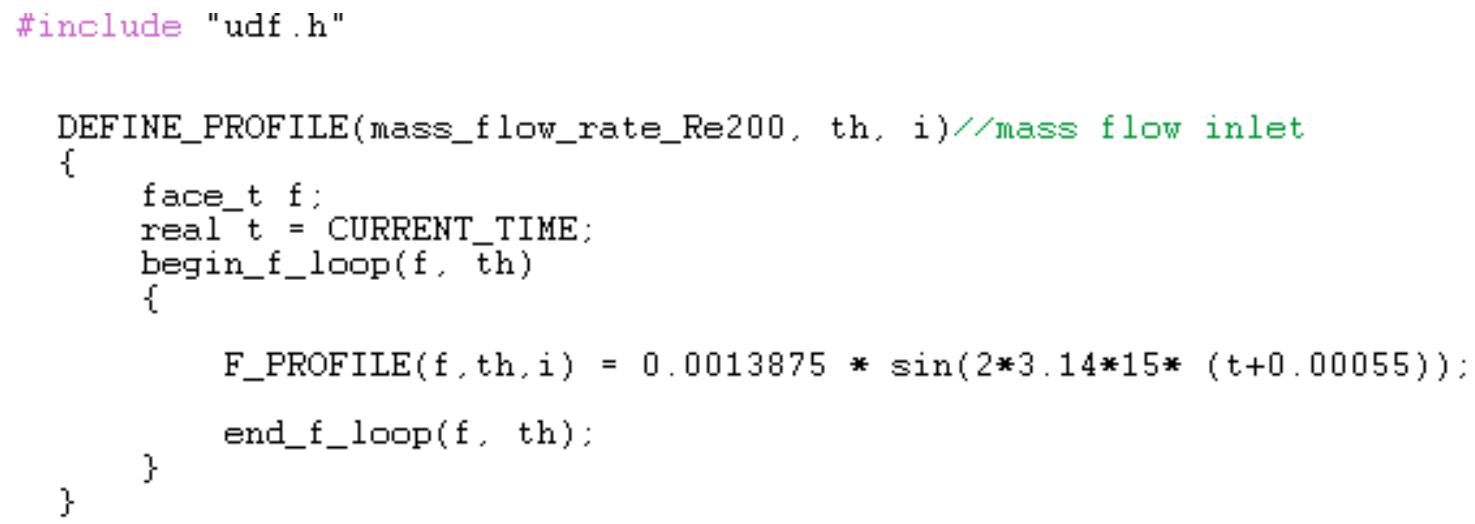

Fig. 58 UDF program for oscillating flow

\section{8-3. CFD validation}

To check the CFD model used in robust foil regenerator CFD, the CFD results should be compared to a theoretical value for the CFD result validation. The pipe oscillating flow was chosen to compare with. Zhao et al. correlation which was derived based on the experiment and analytical results [135]. The result shows that the analytical solution is in good agreement with the experimental results. The analytical solution is represented by equation $(26) \sim(28)[135]$.

$$
\begin{gathered}
R e_{\omega}=\frac{\omega D^{2}}{v} \\
A_{o}=\frac{2 u_{\max }}{\omega D} \\
C_{f}=\frac{3.272}{A_{o}\left(\operatorname{Re}_{\omega}^{0.548}-2.039\right)}
\end{gathered}
$$

According to Zhao et al., the equation (28) is the cycle-averaged friction coefficient. Equation (28) was derived from the simulation results by Zhao. Equation (29) and (30) show the definition of the friction coefficient and the cycle-averaged friction coefficient. 


$$
\begin{gathered}
C_{f}=\frac{\tau}{\frac{1}{2} \rho u_{\max }^{2}}=\frac{\mu\left(\frac{\partial u}{\partial r}\right)}{\frac{1}{2} \rho u_{\max }^{2}} \\
\overline{C_{f}}=\frac{1}{2 \pi} \int_{0}^{2 \pi}\left|C_{f}\right| d t
\end{gathered}
$$

From equation (29), (30) and the simulation results, the friction factor of the simulation results was derived.

The inner diameter and the outer diameter of the pipe are $1 \mathrm{~cm}$ and $2 \mathrm{~cm}$ respectively. The length of the pipe is $20 \mathrm{~cm}$. Fig. 59 shows the mesh of the pipe generated by ICEM CFD. The mesh number is $1,472,000$. The inlet boundary condition is mass flow inlet. The same UDF of the robust foil regenerator CFD was used to generate the oscillating flow. The outlet boundary is the pressure boundary. The simulation was conducted by ANSYS Fluent 19.1. The ensemble average was conducted for 5 to 10 cycles except for 2 cycles from the beginning of the simulation because the shear stress was not stable. Fig. 60 and Fig. 61 show the wall shear output for 8 cycles and 40 cycles. The shear stress of the oscillating pipe flow was relatively stable after 2 cycles of the simulation. Thus, the simulation only lasted for 10 cycles. The wall shear was converted to the friction coefficient and the cycle average friction coefficient by equation (29) and (30).

Fig. 62 shows the simulation results and the friction coefficient calculated by equation (30). From Fig. 62, the simulation results and the calculated results are in good agreement. Therefore, the simulation model is highly valid. 


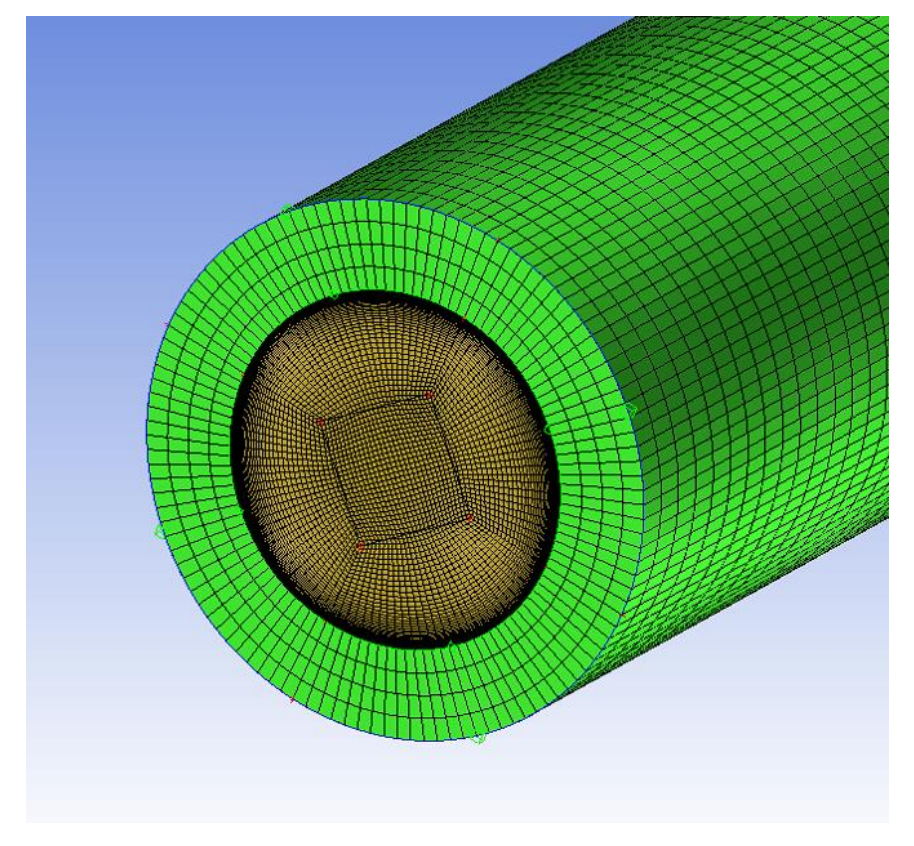

Fig. 59 Pipe mesh

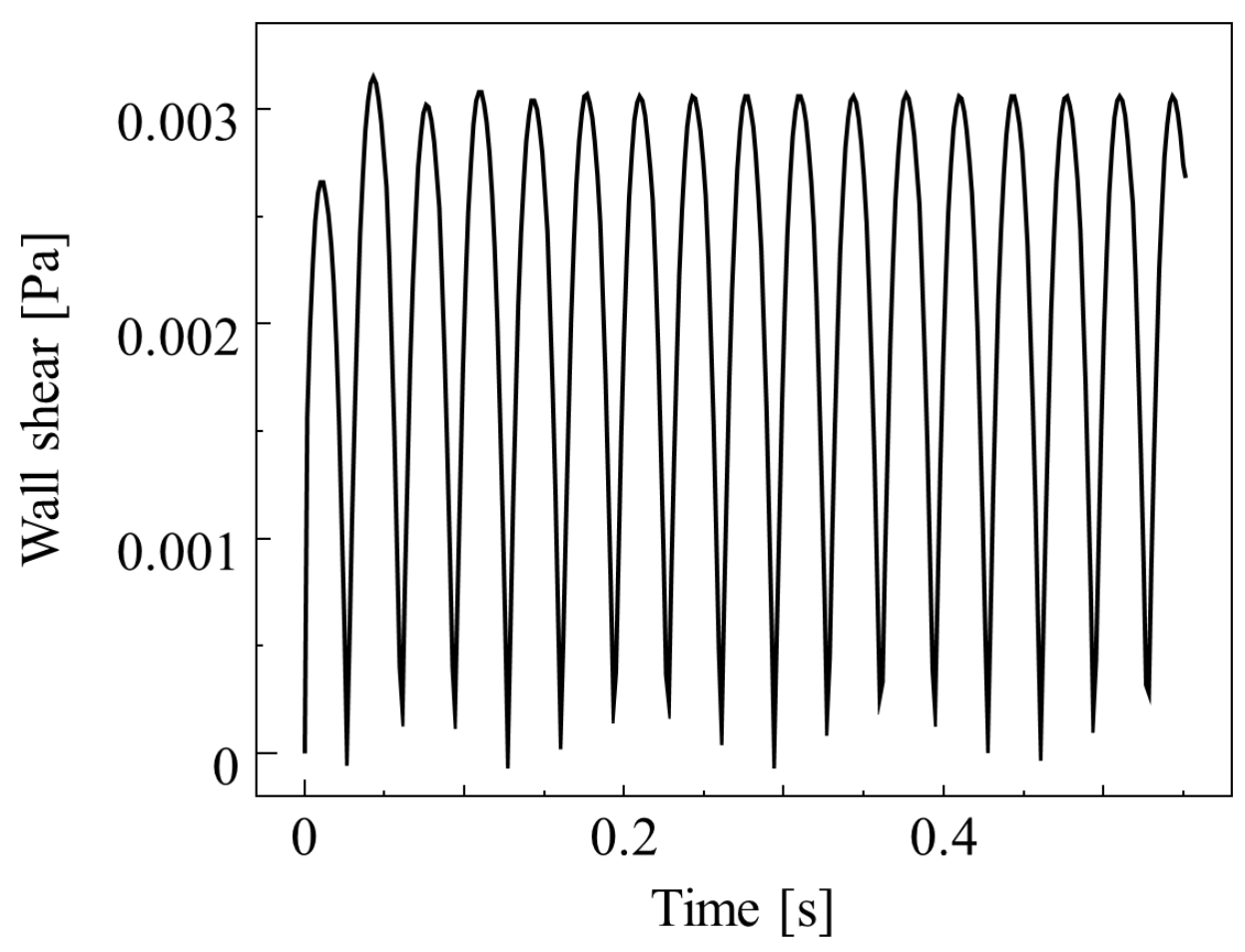

Fig. 60 Wall shear from the CFD result for 8 cycles 


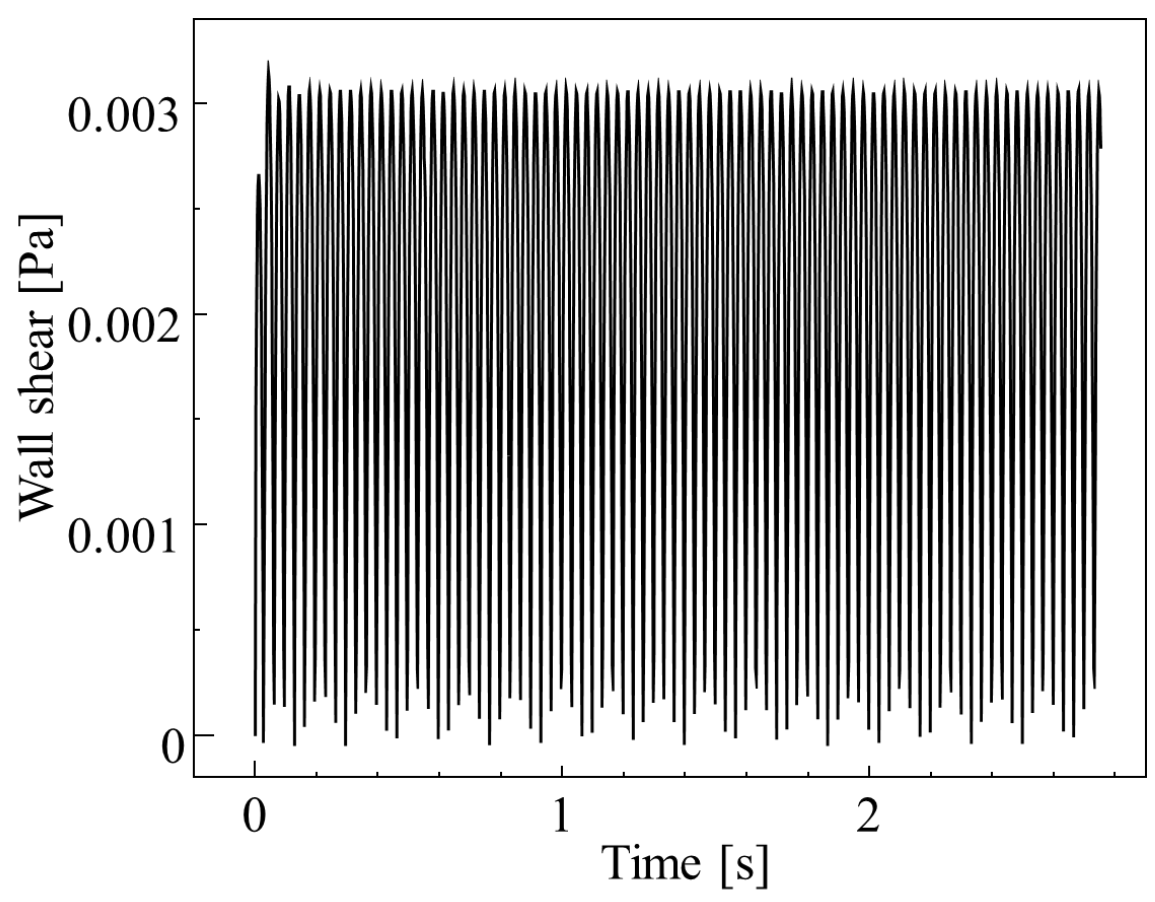

Fig. 61 Wall shear from the CFD result for 40 cycles

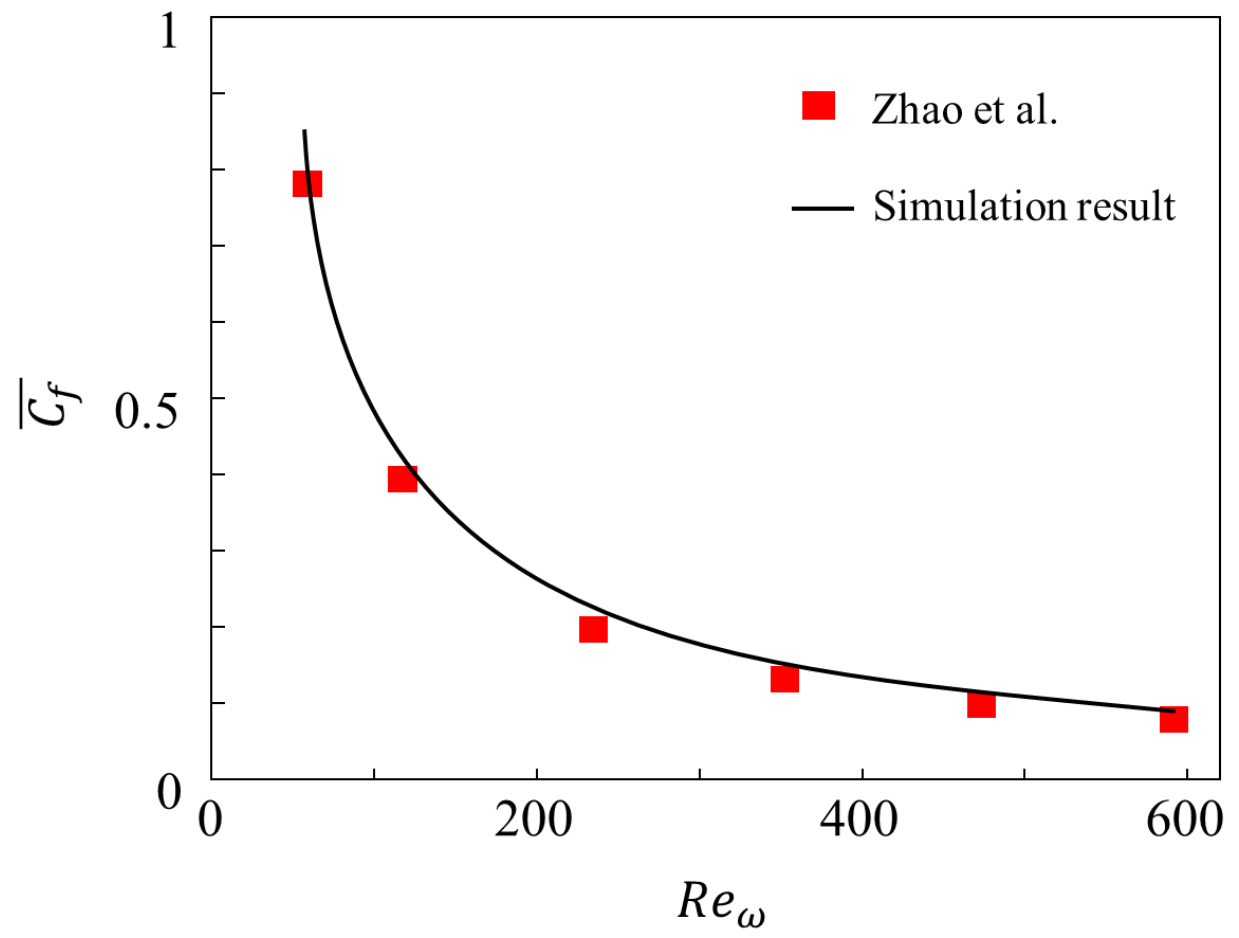

Fig. 62 Comparison of the pipe friction factor 


\section{8-4. Flow loss test and CFD result}

Fig. 63 illustrates the maximum pressure drop versus the maximum Reynolds number. As shown in Fig. 63, the maximum pressure drop of the CFD and the experiment increases linearly as the maximum Reynolds number increases. This is in general agreement with the CFD results of the miniature-channels Stirling engine regenerator reported in Alwfari et al. [110]. Because the hydraulic diameters are slightly different between the CFD model and manufactured regenerator, the pressure drop was not quite the same. However, the result shows the same linear trend.

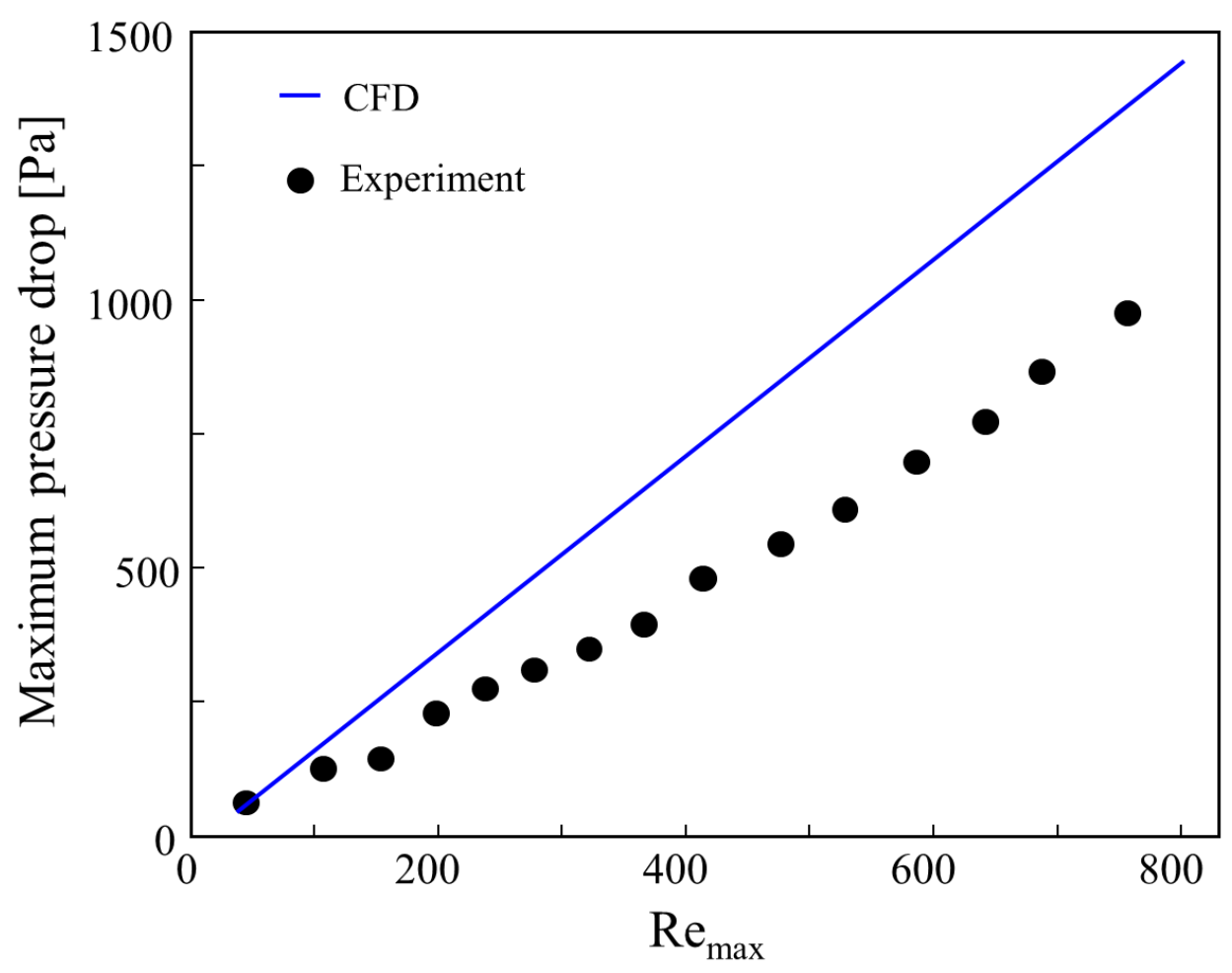

Fig. 63 Comparison of experimental results to CFD results

Fig. 64 depicts the comparison of the measured friction coefficient to the parallel plate (31), tested woven screen (23), and random fiber (32) [63].

$$
C_{f \text { Parallel }}=\frac{96}{R e}
$$




$$
C_{\text {frandom fiber }}=\frac{192}{R e}+\frac{4.53}{R e^{0.067}}
$$

Consequently, the correlations generated by a curve fitting of the experiment results and CFD results are represented by equation (33) and (34) respectively.

$$
\begin{aligned}
& C_{f \text { test }}=\frac{80.51}{R e}+0.0598 \\
& C_{f C F D}=\frac{91.5}{R e}+0.01252
\end{aligned}
$$

Fig. 65 shows a zoom-in view of Fig. 64. The flow loss test was conducted five times and the maximum relative uncertainty is $\pm 6.83 \%$. Because the robust foil regenerator is composed of parallel flow channels, the friction coefficient is considerably lower compared to the conventional wire regenerators. This indicates that the flow separation is inhibited inside the robust foil regenerator. Additionally, the regenerator friction coefficient is relatively close to the parallel plate friction coefficient correlation, representing that the flow channels of the robust foil regenerator were successfully manufactured as the parallel flow channels by DMLS method.

Furthermore, the CFD results show a good agreement with the experiment results. The friction coefficient difference between the test result and the CFD results were provoked by the connection of the robust foil regenerator and the surface roughness. The robust foil regenerator is composed of two pieces. Therefore, as these two pieces were not perfectly matching, the connection part of the regenerator caused an extra pressure drop. Ideally, unlike the actual regenerator, the CFD model was designed to be one continuous piece. Thus, the CFD results do not show an extra pressure drop produced from the regenerator connection step and shows a lower friction coefficient. In addition, because the robust foil regenerator was manufactured by additive manufacturing, the surface roughness is considerably higher than the CFD model (see appendix J). This also led to the experimental results having a higher friction coefficient than the CFD. 


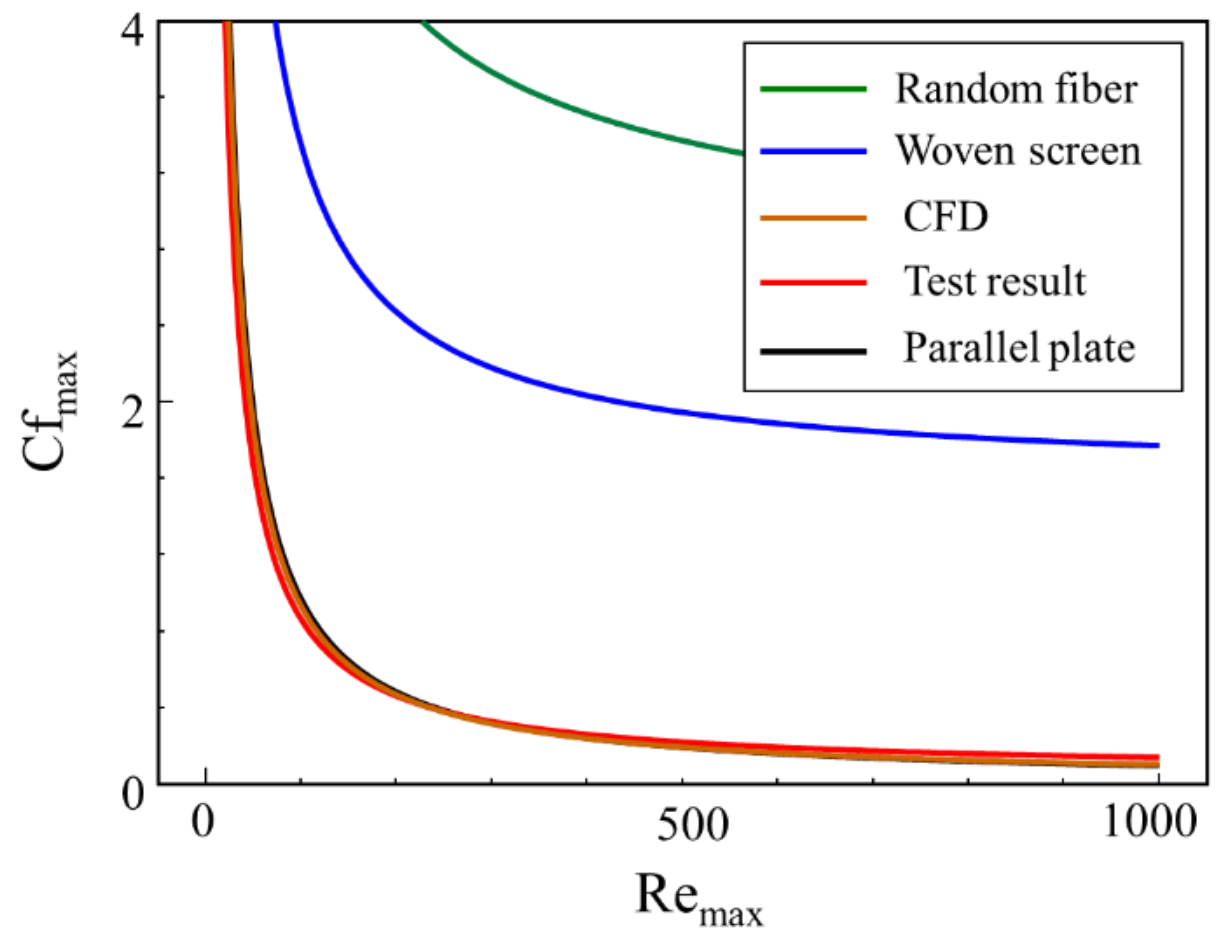

Fig. 64 Comparison of regenerator friction coefficient

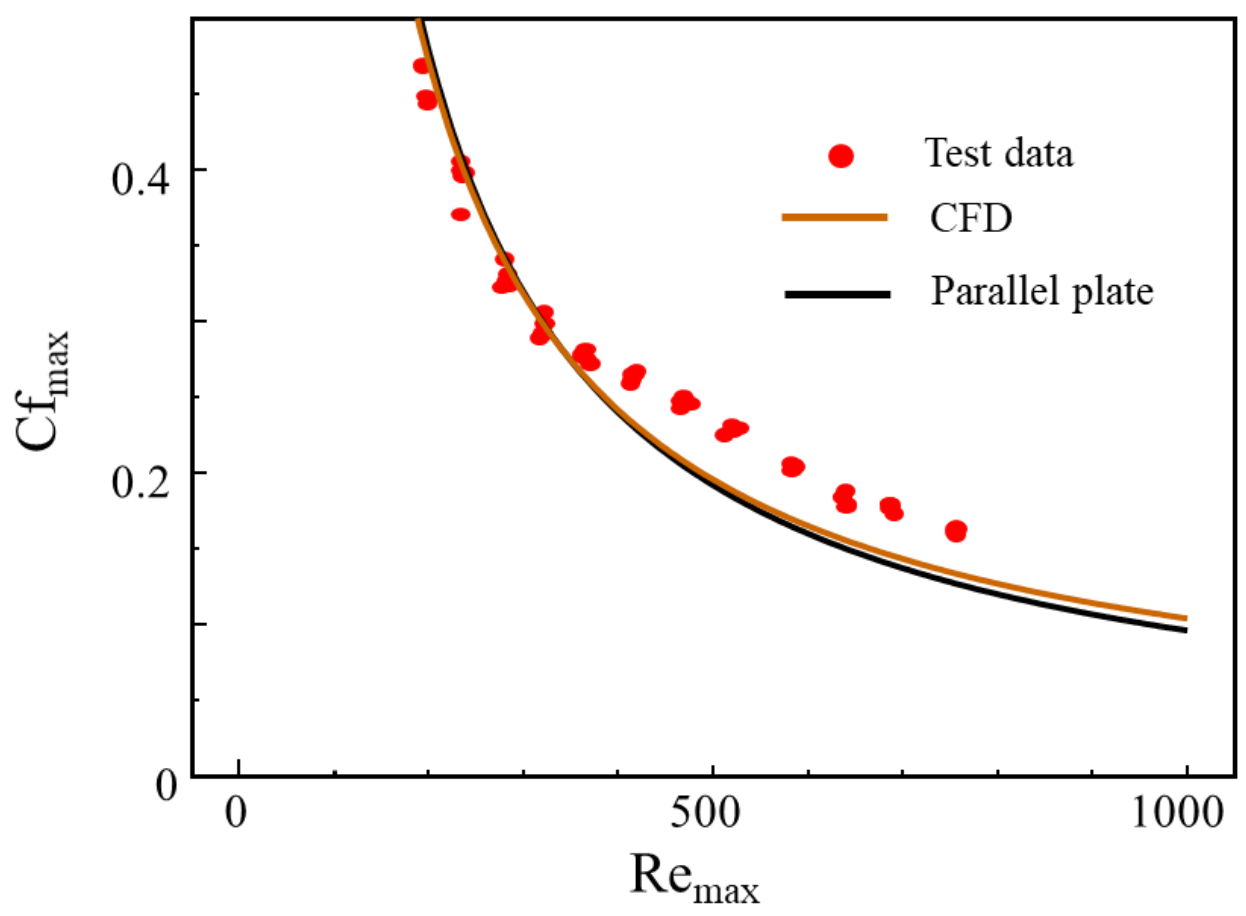

Fig. 65 Detailed view of Fig. 64 with data points 


\section{8-5. Summary}

The experiment conditions were decided based on the required Reynolds number range. For the CFD analysis, the mesh was created prior to the simulation, and the boundary conditions were determined along with the experimental conditions. Similar to the experiment, the CFD analysis was conducted under the oscillating flow conditions as well.

Before the flow loss test of the robust foil regenerator, the test rig verification was conducted using the woven screen regenerator. The woven screen regenerator was manufactured properly for the test rig verification and compared to the robust foil regenerator. The test rig verification results showed that the experimental results of the woven screen regenerator were similar to the other published correlations of the woven screen regenerator. Thus, it was concluded that the test is highly valid for further testing.

The flow loss test was conducted with the robust foil regenerator. The pressure transducers were used to measure the flow loss through the regenerator. The test results showed that the robust foil regenerator has a significantly lower friction coefficient than the random fiber and the woven screen regenerator. By comparing the experimental results with the parallel plate correlation, it was found that the experiment results are relatively close to the parallel plate friction coefficient. This indicates that the parallel flow channels of the robust foil regenerator were successfully made by additive manufacturing. Additionally, the comparison of the experiment results and the CFD results represented that the experiment results were slightly higher than the CFD results. This is because of the surface roughness of additive manufacturing and the number of parts the regenerator is made of. The surface roughness of additive manufacturing is higher than a machined surface. The surface roughness was not modeled in the CFD. Therefore, the roughness difference produced the difference between the experiment and the CFD. Also, the actual regenerator was made of two pieces to reduce the conduction loss through the regenerator. However, the surface between the regenerator pieces was not perfectly aligned, which created a tiny step inside the regenerator. Thus, it was expected that the step causes a higher pressure drop. 


\section{Chapter 4: Heat transfer test and CFD}

\section{About Heat transfer test}

The basis of the heat transfer test is explained in this section. Information on the flow path for the heat transfer test and the equations to evaluate the heat transfer test results are found here. Since it is a heat transfer test, the working fluid has a temperature gradient, and it is converted to the Nusselt number to compare with the woven screen regenerator. Additionally, later in this section, the details of the data acquisition system and the programs for the heat transfer test are described. For the heat transfer test, some data acquisition modules are added based on the requirement of the data recording. Also, the data recording and data processing programs are made with LabVIEW 2017 to record and process the recorded data.

\section{9-1. Flow path of the test rig for heat transfer test}

Fig. 66 represents a cross-section view of the test rig with two band heaters. The band heaters were installed as a heating element of the heat transfer test. Also, the coolant water was circulated through the cooler to decrease the working fluid temperature inside the test rig. The coolant water was then cooled down by the chiller to keep the coolant temperature low. At the test section, two thermocouples were installed at the top and bottom of the regenerator instead of pressure transducers. Fig. 67 shows the schematic of the flow path in the test rig for the heat transfer test. It is the same as the flow loss test except that the flow has temperature distribution due to the heater and the cooler. In Fig. 67 (a), the regenerator supplies the heat energy to the working fluid when the working fluid travels from the cooler to the regenerator. In Fig. 67 (b), as the piston goes down, the working fluid moves from the heater to the regenerator. Therefore, the regenerator absorbs the heat energy from the working fluid. 


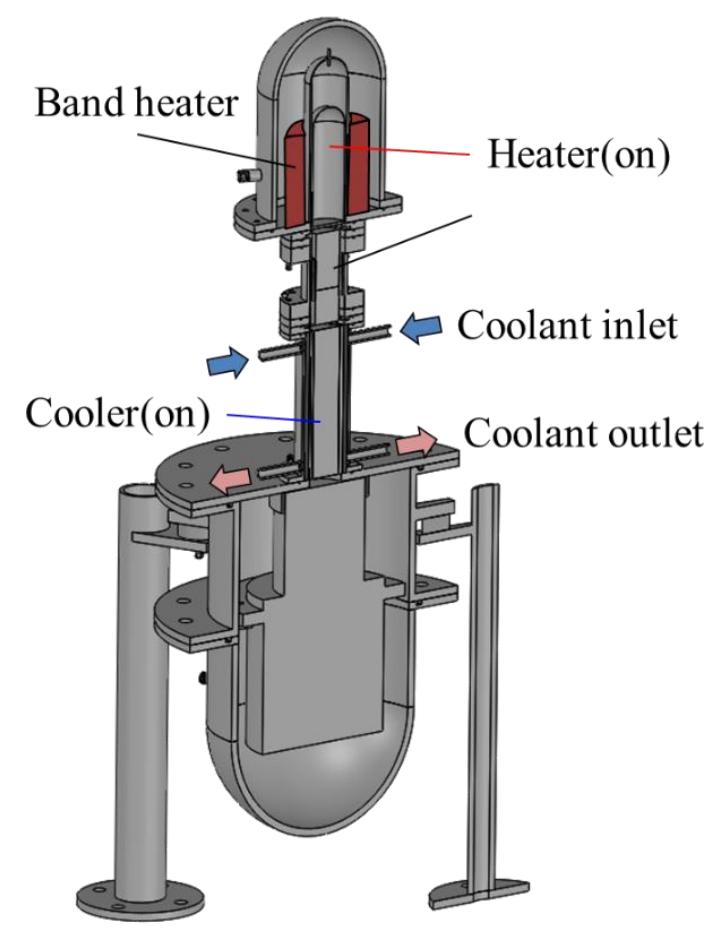

Fig. 66 Cross-section view of the test rig with the band heaters

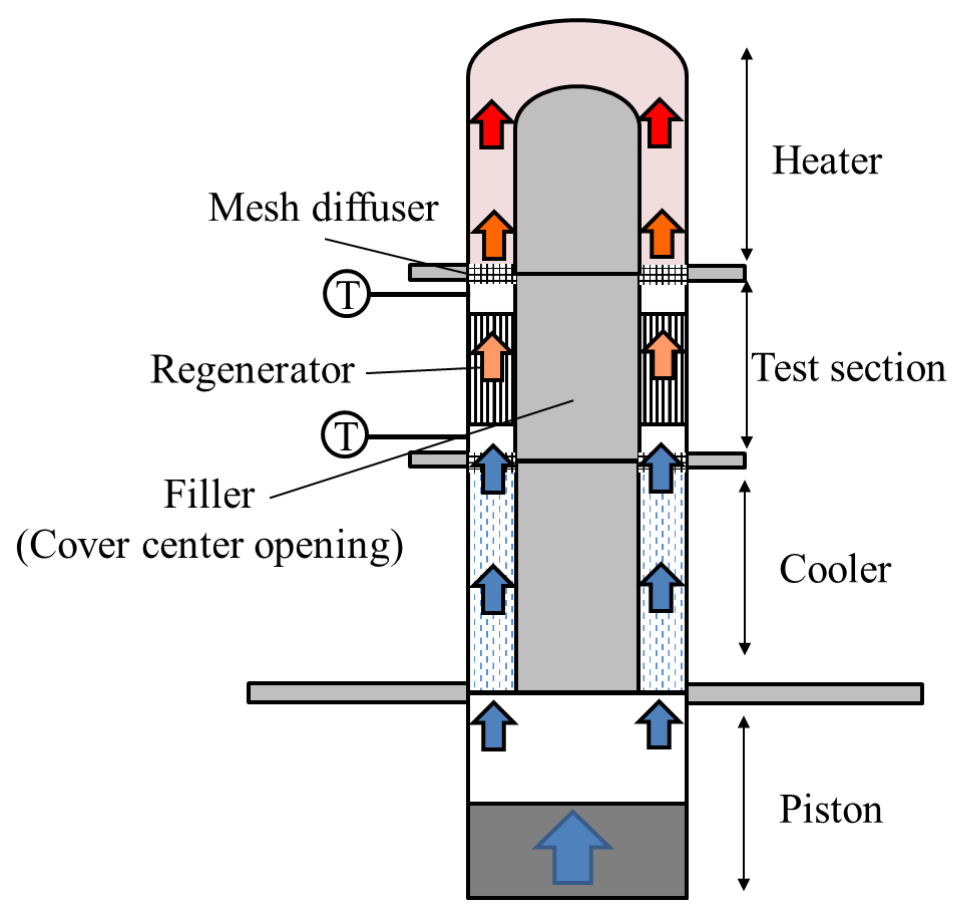

(a) Piton moves upwards

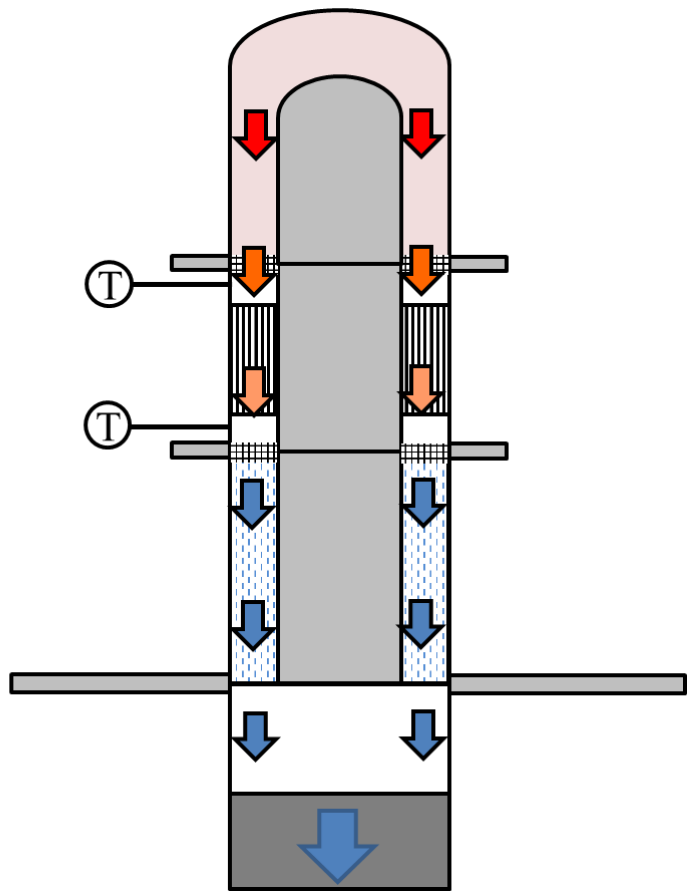

(b) Piston moves downwards

Fig. 67 Flow path of the heat transfer test 


\section{9-2. Equations for the heat transfer}

To compare to the experimental results and the woven screen regenerator correlations, the results need to be in the non-dimensional form. For the temperature data, it should be converted to the Nusselt number, which is commonly used for the comparison of the heat transfer measurement. Also, Reynolds number is another dimensional number widely utilized for the flow measurement. By using these two non-dimensional numbers, the experimental results are fully comparable to the woven screen regenerator correlations. Thus, the measured temperature data and the piston position data were converted to the Nusselt number and the Reynolds number. As the charge pressure was increased from 3 bar to 24 bar, the Reynolds number was changed from 50 to 450 . The piston amplitude was fixed at $9.5 \mathrm{~mm}$ for certain reasons (details in 10-1).

The measured piston amplitude was converted to the maximum Reynolds number by equation (12), and root mean square (RMS) Reynolds number was calculated by equation (35).

$$
R e_{r m s}=\frac{u_{\max } d_{h}}{v} \frac{1}{\sqrt{2}}
$$

To evaluate the heat transfer, the calculation started from the thermal efficiency of the regenerator. To calculate the efficiency of the regenerator, equation (36) was used [58]. The Qloss is the conduction loss which can be calculated by equation (8).

$$
\eta=\frac{Q_{h, \text { in }}-Q_{c, \text { out }}-Q_{\text {loss }}}{Q_{h, \text { in }}-Q_{c, \text { in }}-Q_{\text {loss }}}
$$

Based on the measured temperature data, $\mathrm{Q}_{\mathrm{h}, \text { in }}, \mathrm{Q}_{\mathrm{c}, \text { in }}$, and $\mathrm{Q}_{\mathrm{c} \text {,out }}$ were calculated by the following equations $(37) \sim(39)$ [58].

$$
\begin{gathered}
Q_{h, i n}=C_{p} \int_{\dot{m}>0} \dot{m} \cdot T_{h} \cdot d t \\
Q_{c, i n}=C_{p} \int_{\dot{m}<0} \dot{m} \cdot T_{c} \cdot d t
\end{gathered}
$$




$$
Q_{c, \text { out }}=C_{p} \int_{\dot{m}>0} \dot{m} \cdot T_{c} \cdot d t
$$

The local mass flow rate in equation (37), (38), and (39) are represented by equation (40) and (41). The local mass flow rate was derived by using the incompressible assumption of the working fluid.

$$
\begin{aligned}
& u_{p i}=\frac{\Delta X}{\Delta t} \\
& \dot{m}=\rho_{p i} A_{p i} u_{p i}
\end{aligned}
$$

NTU was obtained by equation (42) [58]. Again, the $\mathrm{Q}_{\text {loss }}$ is the conduction loss which can be calculated by equation (8).

$$
N t u=\frac{2\left(Q_{h, \text { in }}-Q_{c, \text { in }}-Q_{\text {loss }}\right)}{\left(Q_{c, \text { out }}-Q_{c, \text { in }}\right)}
$$

NTU can also be expressed by equation (43).

$$
N t u=\frac{A_{s} h}{C_{p} \dot{m}_{\max }}
$$

The heat transfer coefficient was then calculated by equation (22) and (23). Finally, the Nusselt number is illustrated in equation (44) and compared to the other regenerator Nusselt number correlations.

$$
N u=\frac{h \cdot d_{h}}{k}
$$

\section{9-3. Data acquisition system}

All data was recorded via LabVIEW 2017 and National Instruments data acquisition devices. Through the LabVIEW code, regenerator temperature, heater input voltage, linear motor input voltage, coolant water temperature, and the piston position were recorded. The cDAQ-9178, 
NI9225, NI9213, and NI9219 modules were used as the data acquisition systems. All the data through these devices was obtained simultaneously.

Information about the cDAQ-9178 and the NI9225 are explained in section 6-3. NI9225 was utilized to measure the power source voltage and voltage from the linear displacement transducer. Additionally, NI9225 was used to measure the band heater input voltage from a variable ac transformer (Variac). To conduct the heat transfer test, the band heaters were installed inside the heater pressure vessel. The wires of the band heaters were connected to the feedthrough; then the other end of the feedthrough was connected to the Variac. The maximum voltage supply from the Variac is the $130 \mathrm{Vrms}$. It is within the voltage range of the NI9225. Thus, it was decided to measure the voltage of the Variac with the NI9225. Note that the Variac has a knob to adjust the voltage and it shows the voltage approximately, but it is not accurate.

NI9213 module is the device for the temperature measurement by the thermocouples. It has 16 channels and 1 internal cold junction compensation channel. The voltage range is $\pm 78 \mathrm{mV}$ and the resolution is 24 bit. The maximum sampling frequency is $100 \mathrm{~S} / \mathrm{s}$. For the cold junction compensation (CJC) setting in the LabVIEW program, the built-in function can be selected for the thermocouple temperature measurement since the NI9213 has an internal CJC channel. The operating temperature of the NI 9213 is $-40{ }^{\circ} \mathrm{C}$ to $70{ }^{\circ} \mathrm{C}$. However, the accuracy of the measurement is not absolute when the temperature of the NI9213 is higher than room temperature. Therefore, the NI 9213 should be placed away from the test rig while the heat transfer test is conducted.

NI9219 can be used for temperature measurement of the thermocouples and RTD sensors (for Pt 1000 and Pt 100). Also, it can be utilized for resistance measurement and simple voltage and current measurement. It has 4 channels and the voltage range is $0 \mathrm{~V}$ to $60 \mathrm{~V}$ for the voltage measurement. The maximum sampling frequency is 100S/s. The resolution of the NI9219 is 24 bit. In the heat transfer experiment, the NI 9219 was utilized to measure the temperature using the RTD sensors (Pt 100). The RTD sensors ware located in the coolant circulation system and used to measure the coolant water temperature before and after the cooler of the test rig. Therefore, two RTD sensors were used to measure the temperature rise through the cooler. Unlike the thermocouple measurement under oscillating flow conditions, the coolant temperature was almost constant, and the high frequency measurement was not required. Thus, the RTD sensors 
are suitable for the coolant temperature measurement. The accuracy of the temperature measurement using the RTD sensor (Pt 100) is $\pm 0.1{ }^{\circ} \mathrm{C}$.

All the NI modules used in the heat transfer test have the operating temperature range (mostly $-40{ }^{\circ} \mathrm{C}$ to $70{ }^{\circ} \mathrm{C}$ ). Therefore, it was necessary that all the devices should be placed away from the test rig during the heat transfer test.

\section{9-4. Data recording program}

LabVIEW 2017 was used to make a code for data acquisition. In the data acquisition program, the data from the thermocouples, the linear displacement transducer, and the RTD sensors were recorded. Additionally, the voltage output from the power source of the linear alternator and the Variac for the band heaters were recorded through the same LabVIEW program.

Fig. 68 shows the front panel of the data recording program for the heat transfer test. The calibration constants of the displacement transducer entry are required to be entered in this section. Additionally, the frequency of the data acquisition system is controlled by "temp rate" window. The upper middle part is the input for the power source of the linear alternator. Basically, all the required values to start the power source are controlled at this section. When the "Switch to change" button is clicked, the voltage and frequency of the power source can be changed while the program is running. However, when using the "Switch to change" button, all the input values need to be entered before starting the program. The right side of the program represents the two graphs and three buttons. The graphs indicate the output voltage from the power source and the piston position data from the linear displacement transducer. At the small windows under the graph, the stroke length and the frequency of the piston are monitored. The green buttons activate the power source, and the button next to the green button starts the recording. The last button stops both the recording and the piston motion. At the bottom center part of the program, there are three graphs and a few windows. The graphs indicate the coolant water temperature from the RTD sensors. The RTD sensors were placed before and after the water path of the cooler, and they can measure the temperature transition through the cooler. The "Water in" graph represents the water temperature before going into the cooler of the test rig. The "Water out" graph expresses the water temperature after going through the cooler. The "Temp difference" graph shows the water temperature difference at the inlet and outlet of the cooler. The small window "Heater rms" indicates the voltage supply to the band heaters from the Variac. Lastly, at the bottom left corner 
of the program, there are two graphs representing the temperature measured by the thermocouples at the top and bottom of the regenerator. The "Sensor 1" is the data from the thermocouple located at the top of the regenerator and the "Sensor 4" is from the bottom of the regenerator.

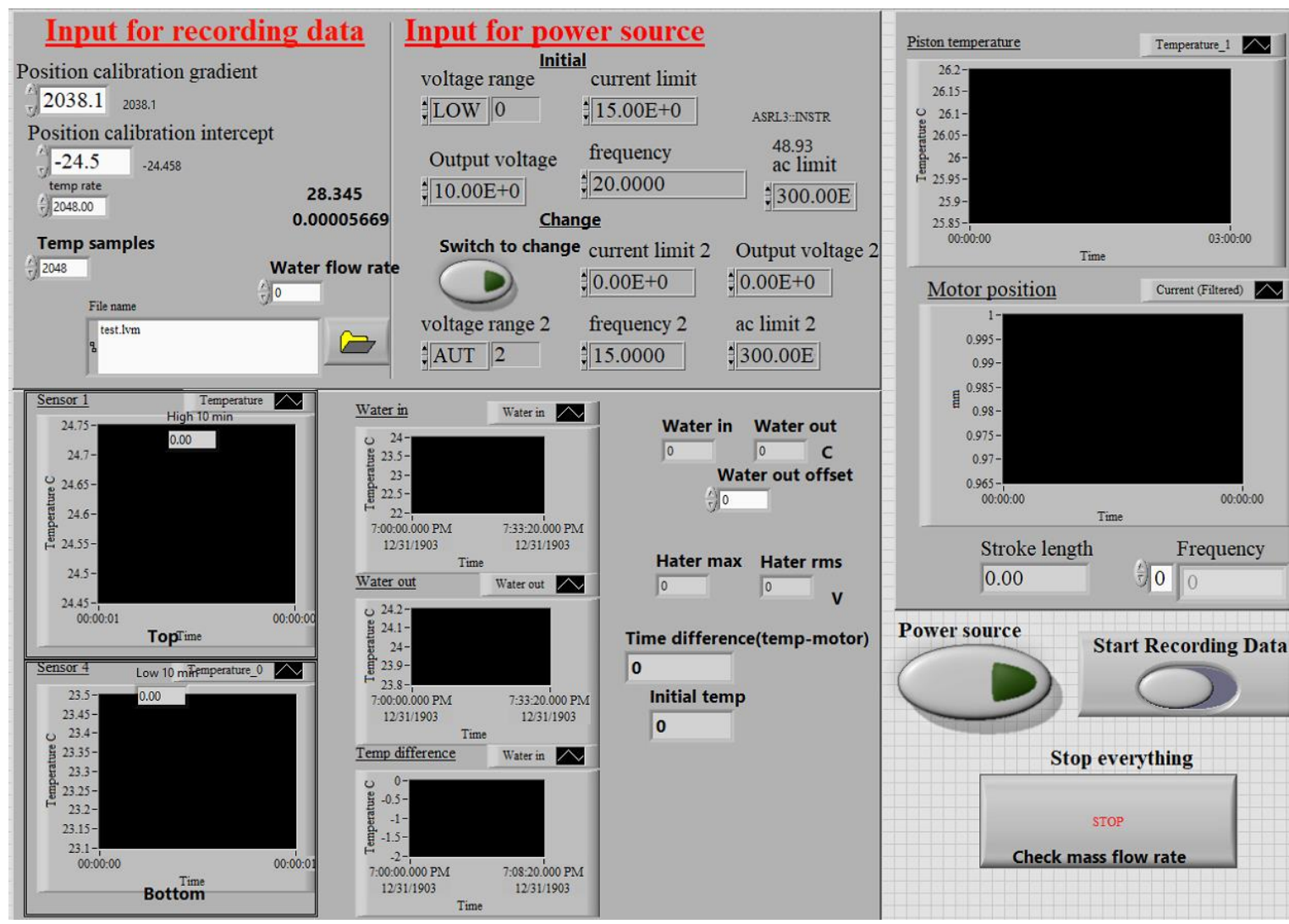

Fig. 68 Front panel of the heat transfer test data recording system

As it is mentioned in 6-4, all the DAQ mx VI were activated by the same task signal for data synchronization. However, the heater voltage measurement and the coolant water temperature measurement did not need to be recorded simultaneously. Because the two data were almost constant over the time period of the heat transfer test. Therefore, the task signal for the heater voltage and the coolant temperature measurement could be separated from the other DAQmx VI.

For the details about the displacement transducer measurement program and the power source voltage measurement program, see section 6-4.

For the thermocouple temperature measurement, simply used the DAQmx function to decide the thermocouple type and range of the voltage. Additionally, the cold junction compensation 
(CJC) function needs to be used for the thermocouple measurement. Since the NI9213 has a CJC function, the CJC source was "built-in" to set the CJC function in LabVIEW. Moreover, to increase the sampling frequency of the thermocouples, the ADC Timing Mode was selected as "High Speed". Otherwise, the sampling frequency of the thermocouple would be fixed at the 1S/s.

For the RTD sensors, the 3-wire type was selected at the DAQmx since the RTD sensors in our lab are 3 wire configuration. Different from the thermocouple temperature measurement, the "High resolution" was selected as the sampling mode. Furthermore, the excitation current was required for the RTD sensors. Due to the NI9219 having an internal current source, the excitation current can be supplied by the NI9219. Therefore, simply choose the "Built-in" for the excitation current source in the program. Another matter is that the calibration constants are required for the RTD sensors. The constants can be found in section 4-7. Fig. 69 shows the example settings of the RTD sensors in LabVIEW.

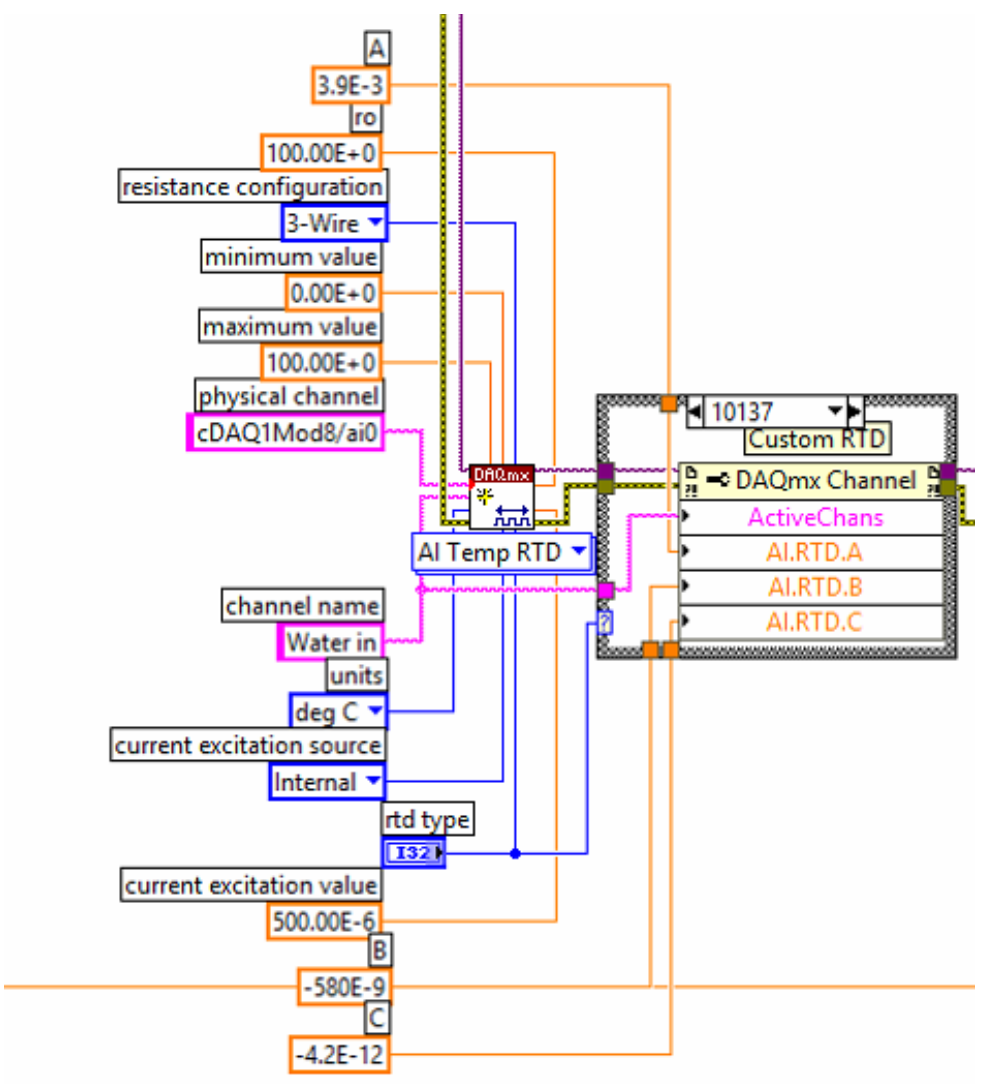

Fig. 69 LabVIEW program for the RTD sensor 


\section{9-5. Data processing program}

To proceed with the data processing for the experimental data, the data processing program was made. The basic concepts of the program were similar to the flow loss data processing program, but the method of the ensemble average was slightly different due to the low sampling frequency of the thermocouples.

Fig. 70 (a) and (b) show the front panel of the data processing program for the heat transfer test. From Fig. 70 (a), all the required input for the data processing program are located in this section. At the left side of the front panel, these are input based on the measurement data. The "dt" window indicates the time step of the experimental results. Based on the sampling frequency of the heat transfer test, the time step should be entered here. The "Number of data of motor" is used to decide the number of data to process in the program. The "Motor sample frequency" and the "Thermocouple sample frequency" are just the input of each measurement sampling frequency. The recorded data file from the data recording program should be selected at the "Input file name". At the center of the input front panel, all the helium parameters to calculate the Nusselt number calculation should be entered. Also, some of the regenerator parameters need to be entered in this part. By changing the regenerator parameters, this data processing program can be used for both of the robust foil regenerator and the woven screen regenerator. The "Increment" is related to the curve fitting and will be explained in a later paragraph. Two graphs on the right side of the front panel represent the cold side temperature data from the recorded data file and the velocity calculated from the mass flow data.

In Fig. 70 (b), all the outputs are displayed in this section. Two graphs represent the plots of the measured temperature along the crank angle of the linear alternator. The "Temp hi" shows the measured heater side temperature and the "Temp low" expresses the measured cooler side temperature. The other windows show the calculation results of the various thermal parameters and the Reynolds number. As it explained in 6-5, under the oscillating conditions, the measured data needs to be ensemble averaged. However, the ensemble average explained in 6-5 is for the measurement which has enough number of data in one cycle to depict the sinusoidal wave. In the heat transfer measurement, the experimental data numbers in one cycle are not enough to depict a sinusoidal wave. Therefore, the ensemble average in section 6-5 cannot be applied for the data processing of the heat transfer test. 
To conduct the ensemble average for fewer numbers of the data sets in one cycle, a new ensemble average method was considered as followed. Fig. 71 shows the new ensemble average method. First, calculate the crank angle for each data point of the temperature based on the linear alternator piston position data. Then, plot the data along the crank angle. Fig. 72 shows the plotted data along the crank angle. Using curve fitting VI in the LabVIEW, the equation for the ensembleaveraged data is obtained. Compared to the ensemble average in 6-5, the curve fitting result is not accurate. However, due to the sampling frequency limitations of the thermocouple measurement, this is the best method to conduct the ensemble average.

Now, back to the "Increment" mentioned in the previous paragraph. After the curve fitting, the equation of the curve fitting is used to derive the Nusselt number in the data processing program. To use the equation for the Nusselt number calculation, it is required to decide the number of data points in one cycle. Based on the number of data points, the "Increment" is derived ( $2 \pi /$ number of data points). For instance, if 100 data points are required in one cycle, then the "Increment" should be $2 \pi / 100$. When the "Increment" is too large, the distance of each data point is too far. Therefore, it should be 0.03 or less for data processing.

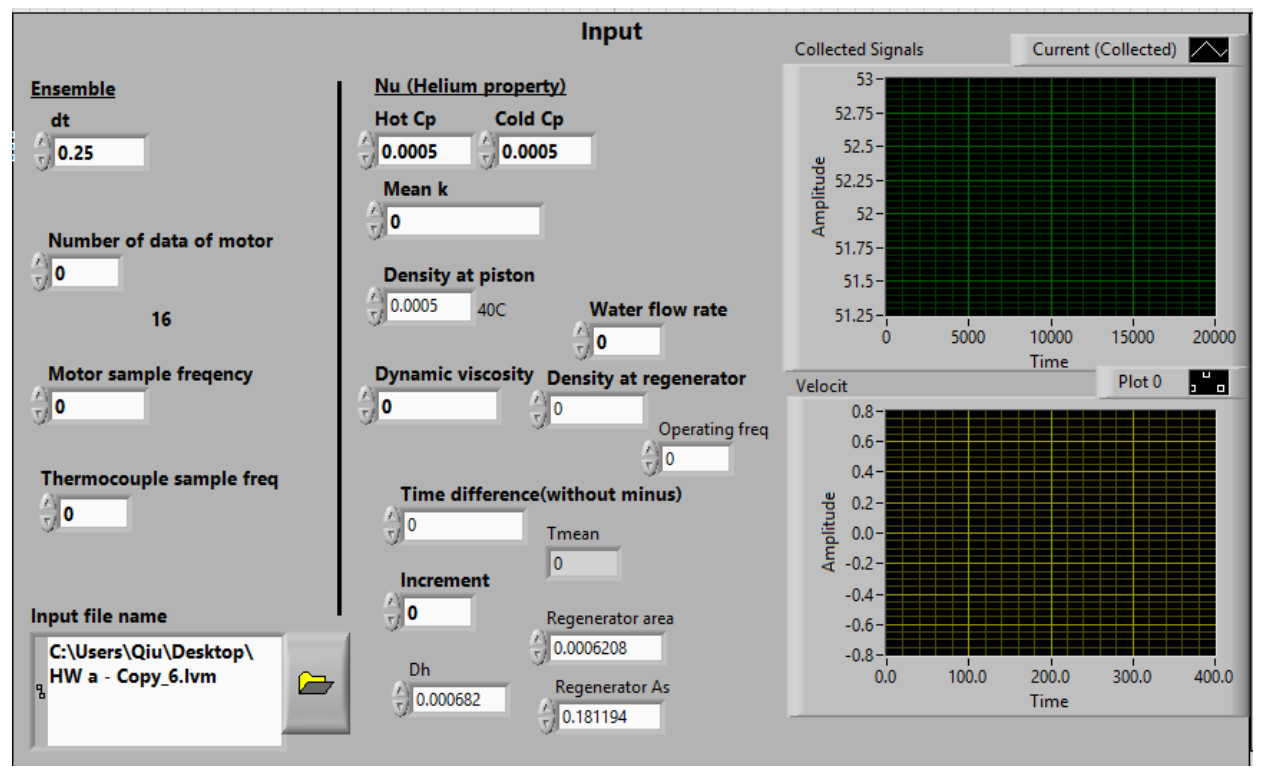

(a) Input of the front panel for the heat transfer test 


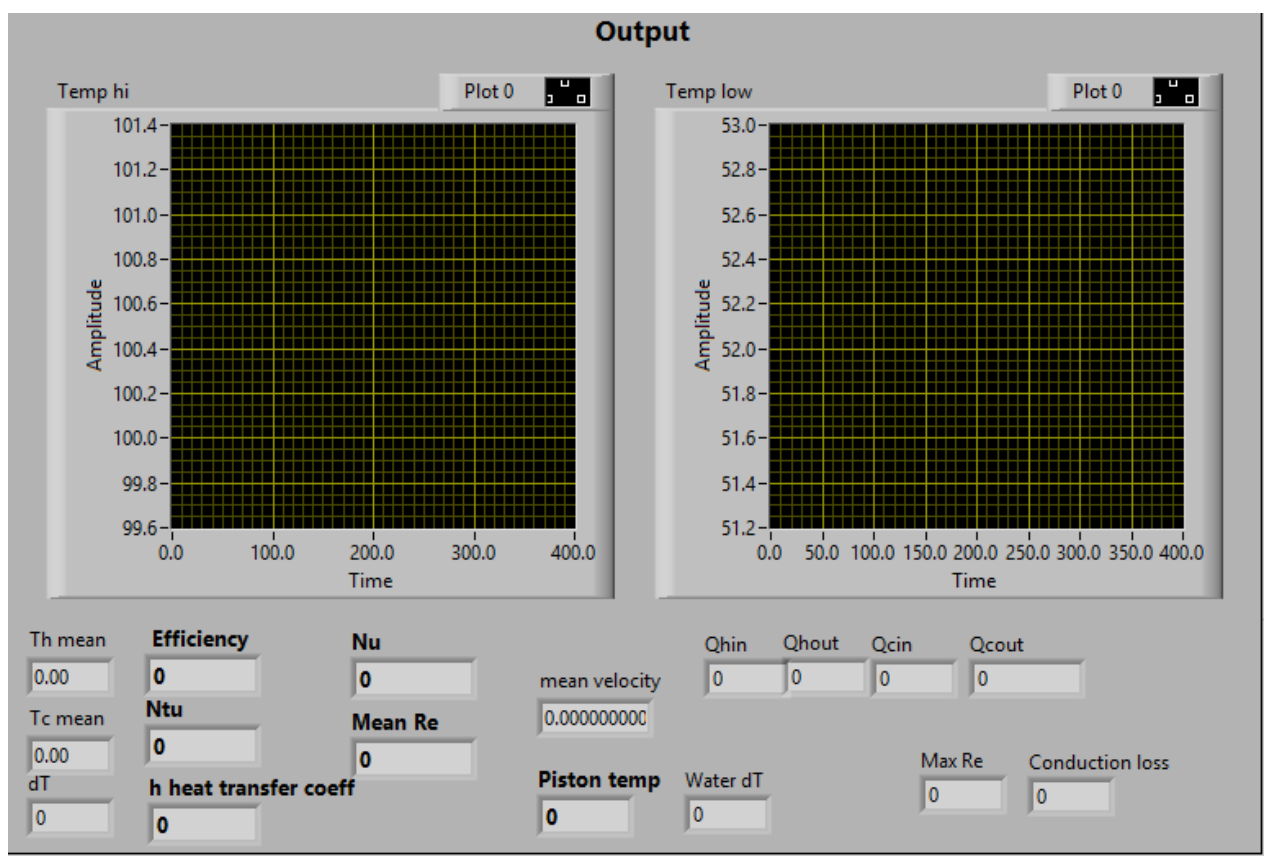

(b) Output of the front panel for the heat transfer test

Fig. 70 Front panel of the heat transfer test data processing program 


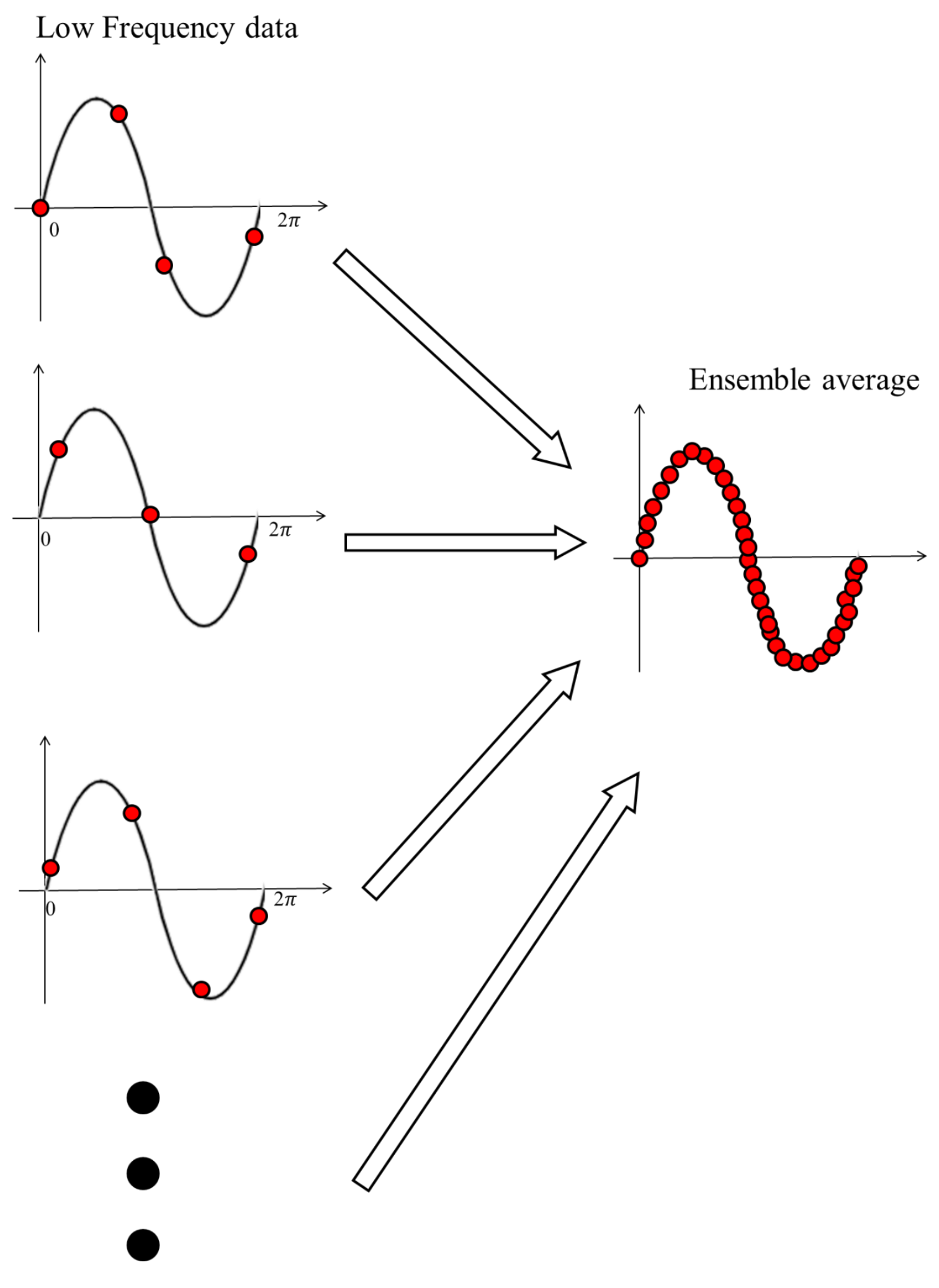

Fig. 71 Ensemble average for small number of data points in one cycle 

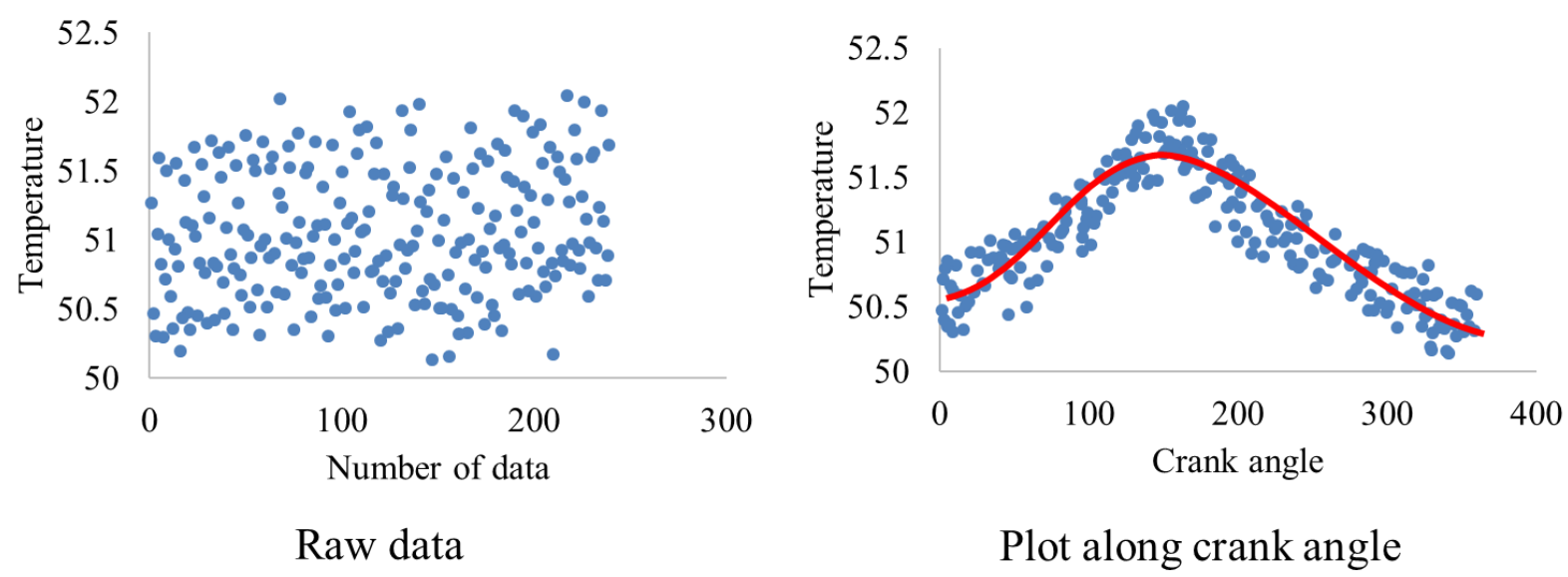

Fig. 72 Example of the ensemble average for the heat transfer test

\section{9-6. Uncertainty analysis}

The equations and the program for the heat transfer test uncertainty analysis were the same as the flow loss test in 6-8.

\section{9-7. Thermal lag analysis}

After a few tests of the thermocouples under the oscillating flow conditions, it was apparent that the temperature oscillation because of the oscillating flow was smaller than we anticipated. This indicates that the measured temperature was affected by the thermal lag of the thermocouple.

Some research papers mention thermal lag analysis. D. J. David et al. said that a thermal lag occurs through the thermocouple at the rate at which heat is received by the measuring side of the differential couple. Which becomes highly dependent upon sample size, heating rate, and the thermal diffusivity of the sample [136]. Also, Shannon et al. tested the thermocouple error in a fire environment. The suggestions to decrease the thermal lag is 1) use the smallest thermocouple bead if it is possible, 2) utilize newly polished thermocouples, radiation heating can be minimized at low emissivity [137]. Moffat et al. also mentioned that the recorded temperature, which indicates the working gas temperature, must be corrected by the lag of the thermocouples [138].

According to Tanaka et al., equation (45) can be utilized to correct the temperature due to the thermal lag of the thermocouple [58]. 


$$
C_{p s} M \frac{d T}{d t}=U A\left(T_{g}-T\right)
$$

Tg is the corrected gas temperature. Fig. 73 and Fig. 74 show the measured temperature and the corrected gas temperature. Since the thermocouple was sheathed and the mass of the thermocouple is considerably large, the thermal lag affected the measured gas temperature tremendously. In order to decrease the thermal lag, a smaller thermocouple without a sheath was preferred. However, because the driving system of the test rig is the linear alternator, the magnetic field generated by the linear alternator affected the thermocouple measurement. Therefore, the thermocouple must have a grounded sheath to avoid unexpected measurement errors generated by the magnetic field.

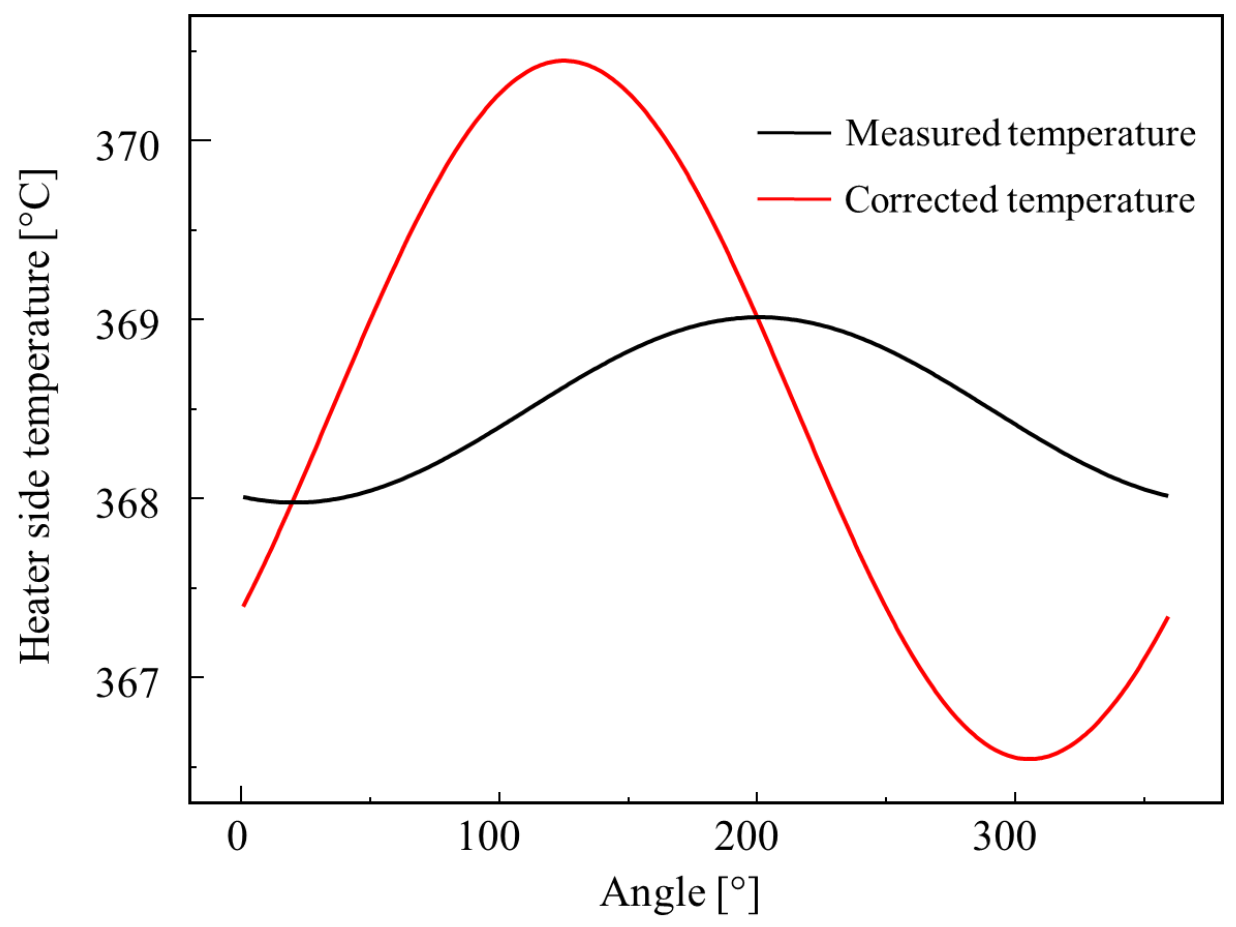

Fig. 73 Heater side measured and corrected temperature 


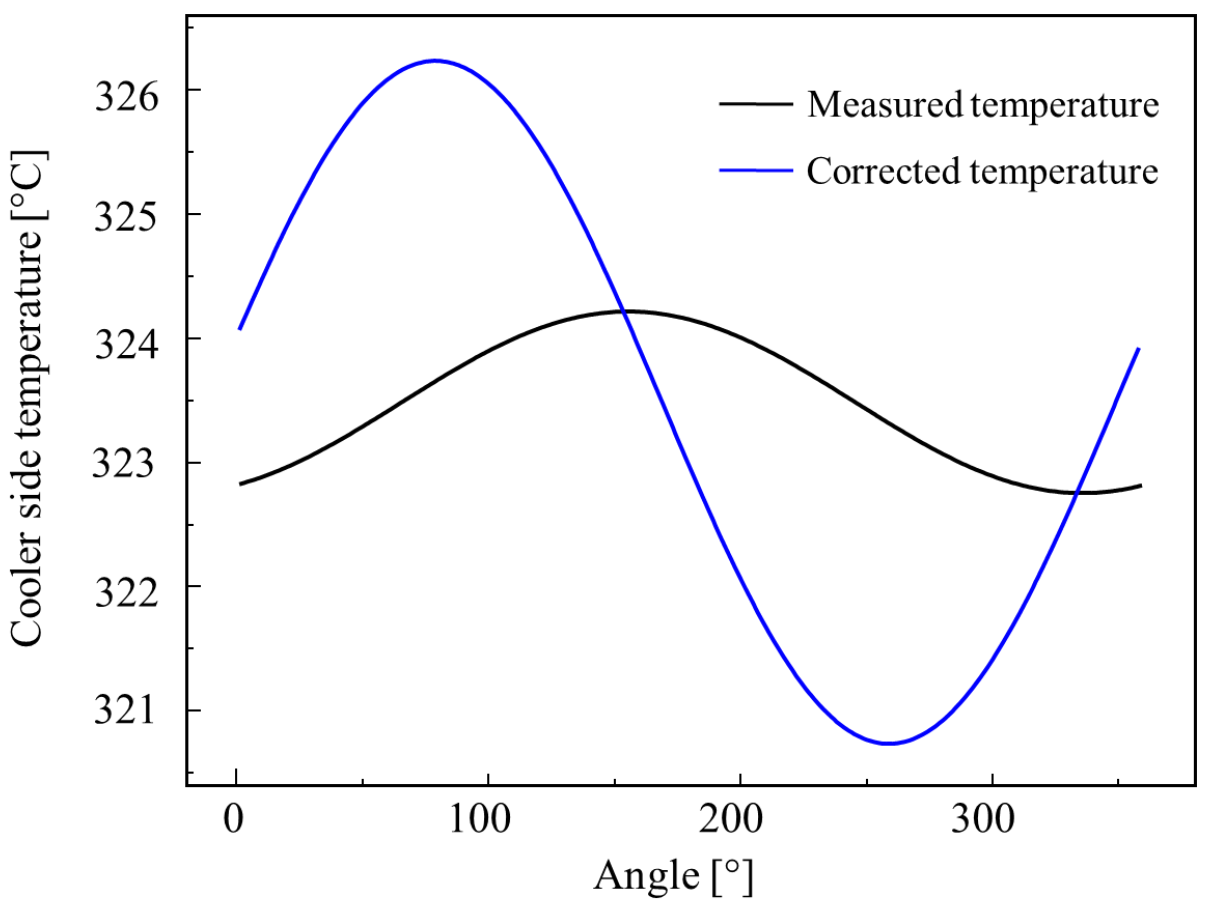

Fig. 74 Cooler side measured and corrected temperature

\section{9-8. Summary}

The flow path of the heat transfer test was similar to the flow loss test, but the working fluid had a temperature gradient due to the heater and the cooler. Two band heaters were installed as the heating element of the heater to heat up the working fluid. The cooler was used to decrease the temperature of the working fluid. The thermocouples were placed at the top and bottom of the regenerator to measure the local temperature. The measured temperature was converted to the Nusselt number to compare to the woven screen regenerator. Some data acquisition modules were added for the temperature measurement. The RTD sensors also required the excitation current to use it. The data recording program was made for the heat transfer test with the excitation current function for the RTD sensors. The data processing program for the heat transfer test was not the same as the flow loss test. The largest difference was the ensemble average method. The ensemble average for the flow loss test was for the large sampling frequency, meaning that the number of data points are enough to draw the sinusoidal wave in each cycle. However, for the heat transfer test, the sampling frequency was not high enough because of the thermocouple response time. Therefore, the number of data points in each cycle was not enough for the ensemble average method of the flow loss test. To process the ensemble-average a new method was used in the data 
processing program. The data processing program also calculated the Nusselt number and the Reynolds number automatically.

\section{Heat transfer test}

In section 8-4, it was found that the friction factor of the robust foil regenerator was significantly lower than the woven screen regenerator. Because of that, it was proven that the robust foil regenerator decreases the flow loss of the regenerator. Another important factor for the regenerator performance is the heat transfer. In this section, the heat transfer test of the robust foil regenerator and woven screen regenerator were explained. The experimental results are converted to the Nusselt number and the Reynolds number to compare with the results of the robust foil regenerator and the woven screen regenerator. In addition, the CFD analysis of the robust foil regenerator was carried out to compare to the experimental results.

\section{0-1. Test conditions for the heat transfer test}

The robust foil regenerator was manufactured by additive manufacturing to reveal the flow loss and the heat transfer characteristics. For the heat transfer test, the two thermocouples were installed at the top and the bottom of the regenerator. The data recording system and programs for the heat transfer test were explained in section 9. Excluding the Reynolds number and the charge pressure, experimental conditions were also identical to the woven screen regenerator experiment. The Reynolds number range was 50 to 450 and charge pressure was from 3 bar to 24 bar using helium. Since the piston amplitude cannot be too small to measure the instantaneous temperature of the oscillating flow, the piston amplitude was fixed at $9.5 \mathrm{~mm}$. Therefore, the charge pressure was changed from 3 bar to 24 bar to change the Reynolds number with the fixed piston amplitude. The temperature varied based on the heater and the cooler of the test rig, and the frequency of the linear alternator was $20 \mathrm{~Hz}$. The test procedure was as followed. The testing begins when the temperature at the top and bottom of the regenerator reaches a quasi-steady state after starting the linear alternator. Generally, it will take several hours to achieve a quasi-steady state. The data recording lasts for 30 seconds to record at least 600 cycles of the piston motion. The working fluid temperature at the top of the regenerator was approximately $100{ }^{\circ} \mathrm{C}$ and $51 \pm 1^{\circ} \mathrm{C}$ at the bottom of the regenerator. The measured temperature data and the piston position 
data were converted to the Nusselt number and the Reynolds number and compared to the published correlations and the heat transfer test result of the woven screen regenerator.

\section{0-2. Woven screen regenerator heat transfer test}

The heat transfer test for the woven screen regenerator was conducted to compare the results to the robust foil regenerator results. The woven screen regenerator used for the heat transfer test was the same as the flow loss test. The working fluid was the helium and the charge pressure was 7 bar to 23 bar. The stroke length of the linear alternator piston was fixed at $12.0 \mathrm{~mm}$. To change the Reynolds number, the charge pressure was varied. The other conditions were the same as the robust foil regenerator heat transfer test conditions (see 10-1).

\section{0-3. Heat transfer CFD}

To prove the validity of the heat transfer experimental results, the CFD analysis was conducted by utilizing ANSYS Fluent. The geometry of the regenerator is the same as the geometry of the flow loss CFD. ICEM CFD was utilized to generate the hexa mesh. Contrary to the flow loss CFD, the mesh was also generated at the solid part of the regenerator by ICEM CFD to consider the conduction and convection of the solid part of the regenerator. Fig. 75 shows the mesh of the CFD model. The number of meshes is 1,080,000 including solid part and fluid part mesh. The Laminar model was selected as the flow model. The UDF used for the heat transfer CFD was the same as the UDF utilized in the flow loss CFD. The inlet and outlet thermal boundary conditions were at a constant temperature which was $323 \mathrm{~K}$ and $373 \mathrm{~K}$ respectively. The actual experiment inlet/outlet boundary condition should not be a constant temperature, similar to sinusoidal temperature distribution. However, if the inlet and outlet boundary conditions are sinusoidal temperature distribution, the simulation period becomes significantly longer then when it is at constant temperature. The simulation was conducted by the ANSYS FLUENT 19.1. Mass conservation equation and momentum equation are expressed by equation (24) and (25). Additionally, the energy equation is expressed by equation (46) [139].

$$
\frac{\partial}{\partial t}(\rho E)+\nabla \cdot(\vec{v}(\rho E+p))=\nabla \cdot\left(k_{e f f} \nabla T-\sum_{j} h_{j} \vec{J}_{j}+\left(\overline{\bar{\tau}}_{e f f} \cdot \vec{v}\right)\right)
$$


As the two channels at the outermost and innermost channels are thinner than the other flow channels, these two channels were deleted due to the difficulty of the mesh generation. Six cases were simulated for the RMS Reynolds number 180, 250, 310, 370, 430, and 490. The temperature measurement points were exactly the same as the locations of the thermocouples in the test rig. The measured temperature of the CFD was converted to the Nusselt number by equation (44). Also, the RMS Reynolds number was calculated by using equation (35).

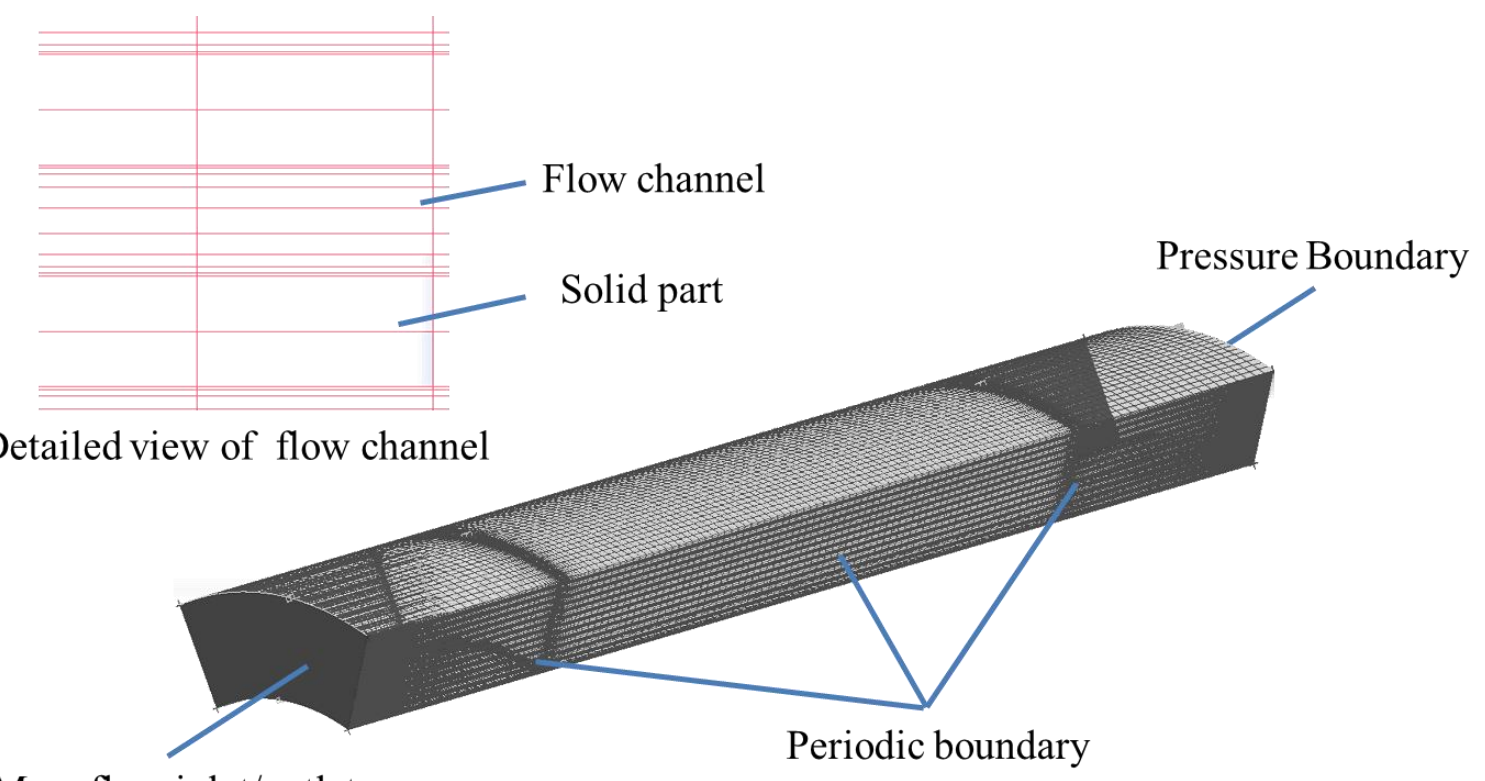

Mass flow inlet/outlet

Fig. 75 Mesh of the heat transfer CFD model

\section{0-4. Heat transfer result}

Fig. 76 shows the comparison of the Nusselt number to the published regenerator correlations. The curve fitting equation of the experimental results is expressed by the equation (47). Also, the Nusselt number of Tanaka [58] and tested woven screen are represented by equation (48) and (49) respectively.

$$
\begin{aligned}
N u_{\text {test }} & =1.06 R e_{\max }{ }^{0.40}-5.423 \\
N u_{\text {Tanaka }}=0.27 R e_{\max } & 0.67
\end{aligned}
$$




$$
N u_{\text {woven screen }}=0.23 R e_{\max }^{0.72}+0.14
$$

The heat transfer test was conducted five times and the maximum relative uncertainty is \pm 8.41 $\%$ which was derived by the LabVIEW program for the uncertainty analysis. As shown in Fig. 76, the experimental results are clearly lower than Tanaka's regenerator and woven screen regenerator. This is due to the difference of the turbulence and the thermal boundary layer thickness between the robust foil regenerator and the woven screen regenerator. Fig. 77 shows the difference of the turbulence between the regenerators. Since the robust foil regenerator is composed of the parallel flow channels, the turbulence is extremely small. However, the woven screen regenerator is composed of wires, therefore, the turbulence is large as in Fig. 77 . The turbulence brings the momentum and the thermal energy into the boundary layer which is created around the wire of woven screen and wall of thee robust foil regenerator. Therefore, the higher turbulence leads the higher heat transfer inside the regenerator.

The CFD analysis was conducted to compare to the experimental results. The result shows that the Nusselt number of the CFD is slightly smaller than the experimental results. This is similar to the situation with the lower friction coefficient, the Nusselt Number is affected by the same issue. First, there is a tiny step in the middle of the regenerator since the actual regenerator is composed of two pieces. Second, the surface roughness of the actual regenerator is excessive due to additive manufacturing. By considering these two factors, the turbulence of the experiment result is relatively higher than the CFD. Thus, the heat transfer occurs more in the experiment, and it indicates that the Nusselt number of the experiment is higher than the CFD. 


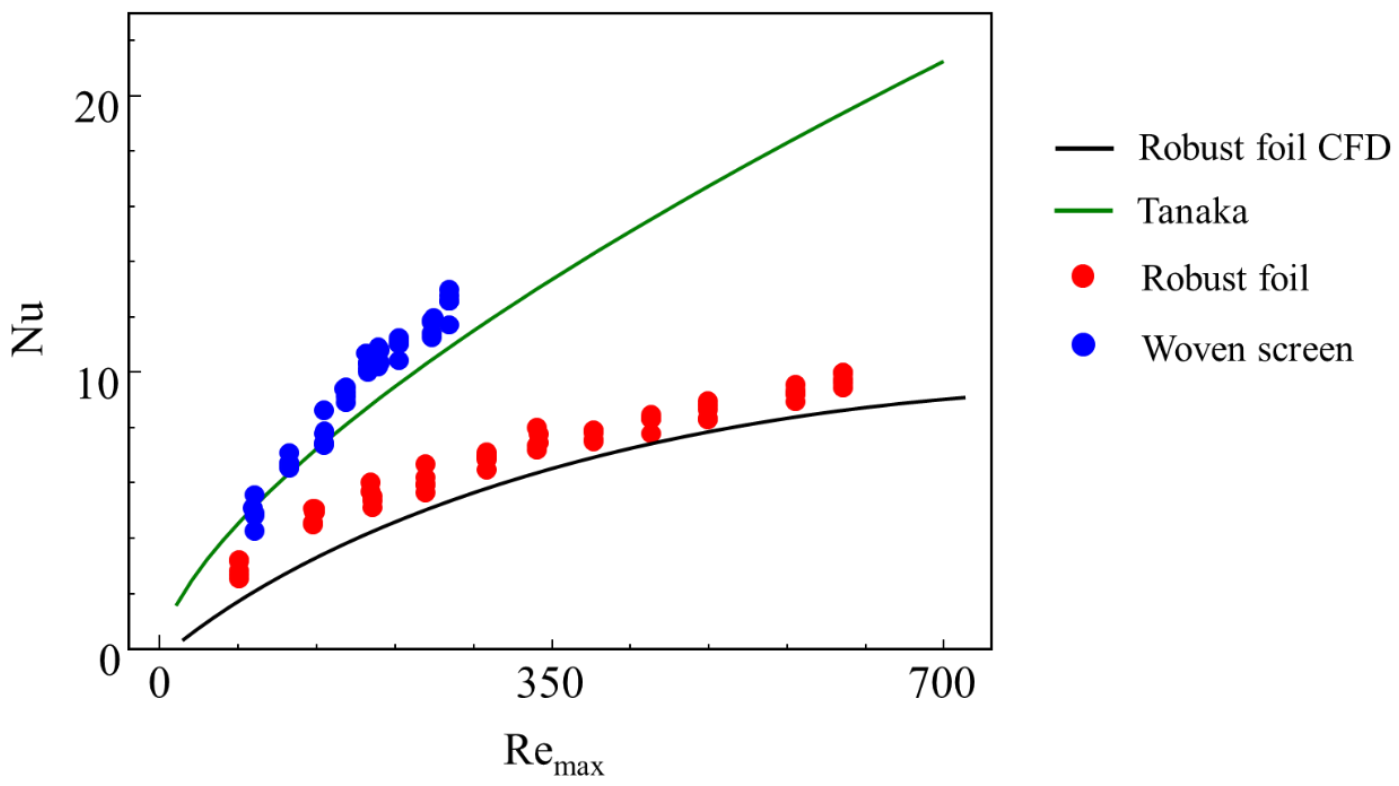

Fig. 76 Comparison of regenerator Nusselt number
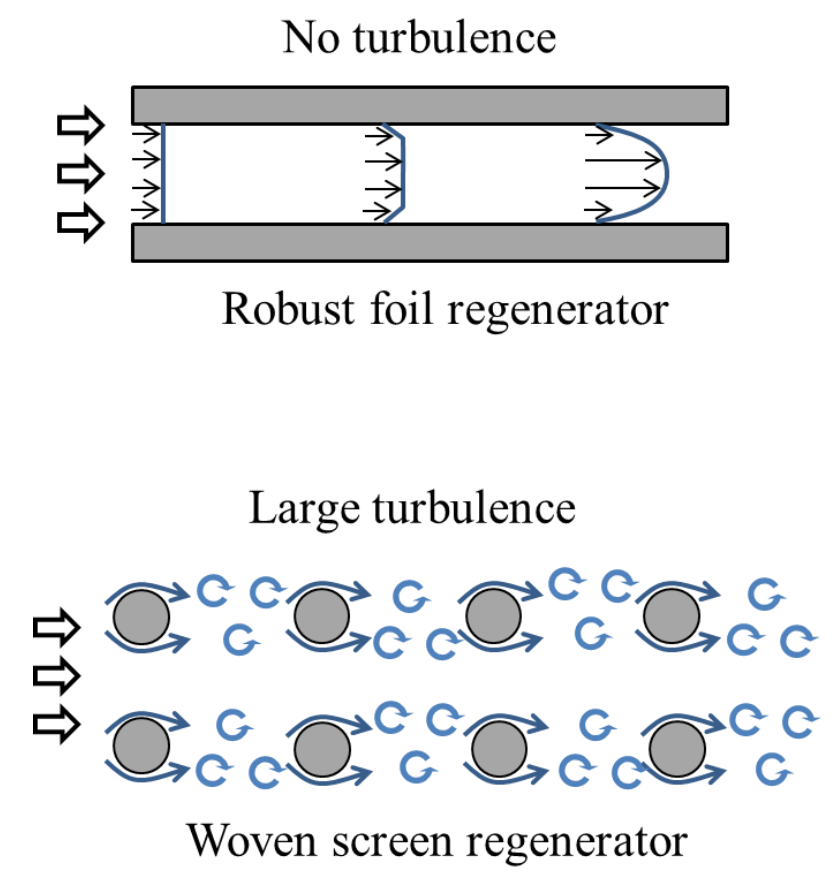

Fig. 77 Turbulence difference between the foil regenerator and the woven screen regenerator 


\section{0-5. Summary}

The heat transfer test was conducted for both the robust foil regenerator and the woven screen regenerator. To adjust the Reynolds number range, the charge pressure was different between these two experiments. Overlooking the charge pressure, all the experimental conditions are the same. The measured temperature data was converted to the Nusselt number using the data processing program for further comparison.

Prior to the heat transfer test, the thermal lag analysis was considered to measure the temperature without the thermal lag of the thermocouple. Ideally, the thermocouple bead size should be minimized to reduce the thermal lag of the thermocouple. However, because of the magnetic field generated by the linear alternator, the bare wire bead thermocouple was unavailable since the thermocouple was affected by the magnetic field. Thus, the sheathed thermocouple was selected, and the thermal lag analysis was conducted to eliminate the thermal lag of the thermocouple.

The heat transfer test results showed that the Nusselt number of the robust foil regenerator was smaller than the woven screen regenerator. This means that the amount of heat transfer that occurs through the robust foil regenerator was less than the woven screen regenerator. It was found that the Nusselt number difference was caused by the turbulence difference. For the robust foil regenerator, the flow channels are the parallel flow channels, and the turbulence of the flow is incredibly small since it is the parallel plate flow. However, the turbulence in the woven screen regenerator is significantly larger than the robust foil regenerator. Since the higher turbulence leads the higher heat transfer, the woven screen regenerator showed the higher Nusselt number.

The CFD analysis was conducted to compare with the experimental result. The results showed that the Nusselt number of the CFD was slightly smaller than the experimental result. This is because the actual regenerator is made by two pieces and the surface roughness is high. These factors caused the higher turbulence inside the regenerator during the experiment. 


\section{Chapter 5: Robust foil regenerator evaluation}

\section{Figure of merit}

After the experiments and the CFD analyses, the flow loss and heat transfer features were characterized based on the friction coefficient and the Nusselt number. From the flow loss results, it was found that the robust foil regenerator has the lower friction coefficient compared to the woven screen regenerator. Therefore, the robust foil regenerator is more suitable than the woven screen regenerator in terms of the friction coefficient. From the heat transfer results, it was shown that the woven screen regenerator has the higher Nusselt number than the robust foil regenerator. Thus, the woven screen regenerator is a better regenerator than the robust foil regenerator with respect to the Nusselt number.

To evaluate the overall performance which includes the flow loss and the heat transfer, the figure of merit was used. The figure of merit is the ratio between the flow loss and the heat transfer, and it is a great way to compare the regenerator performance. Ibrahim et al. [63] utilized the figure of merit to appraise the involute foil regenerator. The involute foil regenerator has the substantially higher figure of merit than the wire media regenerators, including a $90 \%$ porosity random fiber regenerator. Equation (50) represents the figure of merit which Ibrahim et al. used.

$$
F_{M}=\frac{1}{C_{f}\left(\frac{R_{e} P_{r}}{4 N_{u}}+\frac{N_{k}}{R_{e} P_{r}}\right)}
$$

Costa et al. used another figure of merit. The problem of the figure of merit is that the results change due to the definition of figure of merit. To prevent the error of the figure of merit, equation (51) was reported as the figure of merit [140].

$$
F_{M_{C S}}=\frac{1}{\left(\frac{\Delta P V_{d r} \dot{Q}_{t}}{P_{m} V_{e} \dot{Q}_{r}}\right)}
$$


However, this method requires the regenerator wall temperature to calculate. Therefore, it is not applicable in this research because the wall temperature was not able to measure. Thus, in this research, $\mathrm{NPH} / \mathrm{NTU}$ and $\mathrm{j} / \mathrm{f}$ ratio were selected as the figure of merit to appraise the regenerator performance.

\section{1-1. NPH/NTU ratio}

In order to evaluate the overall performance of the regenerator with respect to both of the flow loss and heat transfer, The NPH/NTU was used $[112,141]$. The NPH describes the pressure drop in a certain length of the regenerator. The NTU means the quality of the heat transfer. The $\mathrm{NPH} / \mathrm{NTU}$ is the number of pressure heads per number of the heat transfer unit. A smaller value of NPH/NTU means a better geometrical configuration of the regenerator. Theoretically, the parallel plates show the lowest NPH/NTU which is equal to 2 . The equation (52) (54) represent $\mathrm{NPH}, \mathrm{NTU}$, and NPH/NTU respectively.

$$
\begin{aligned}
& N P H=C_{f} * \frac{L}{d_{h}} \\
& N T U=\frac{N u}{R e_{\max } P r} * \frac{4 L}{d_{h}} \\
& \frac{N P H}{N T U}=\frac{C_{f} * R e_{\text {max }} * P r}{4 N u}
\end{aligned}
$$

Fig. 78 shows the comparison of the NPH/NTU for the robust foil, woven screen, and Tanaka's regenerator. As a result of the flow loss test and the heat transfer test, both the friction coefficient and the Nusselt number of the robust foil regenerator are lower than the wire media regenerators. As shown in Fig. 78, the NPH/NTU of Tanaka's regenerator has five times higher than the robust foil regenerator. Moreover, the woven screen regenerator represents a lower $\mathrm{NPH} / \mathrm{NTU}$ than the robust foil regenerator. Additionally, the NPH/NTU of the robust foil regenerator is similar to that of the parallel plates, which is theoretically the best. Because of the surface roughness and the step at the regenerator connection, the NPH/NTU of the robust foil regenerator is slightly higher than the parallel plate. However, compared to the conventional wire 
regenerators, the regenerator geometry is highly efficient. Therefore, in terms of the NPH/NTU, the robust foil regenerator is more suitable as the Stirling engine regenerator.

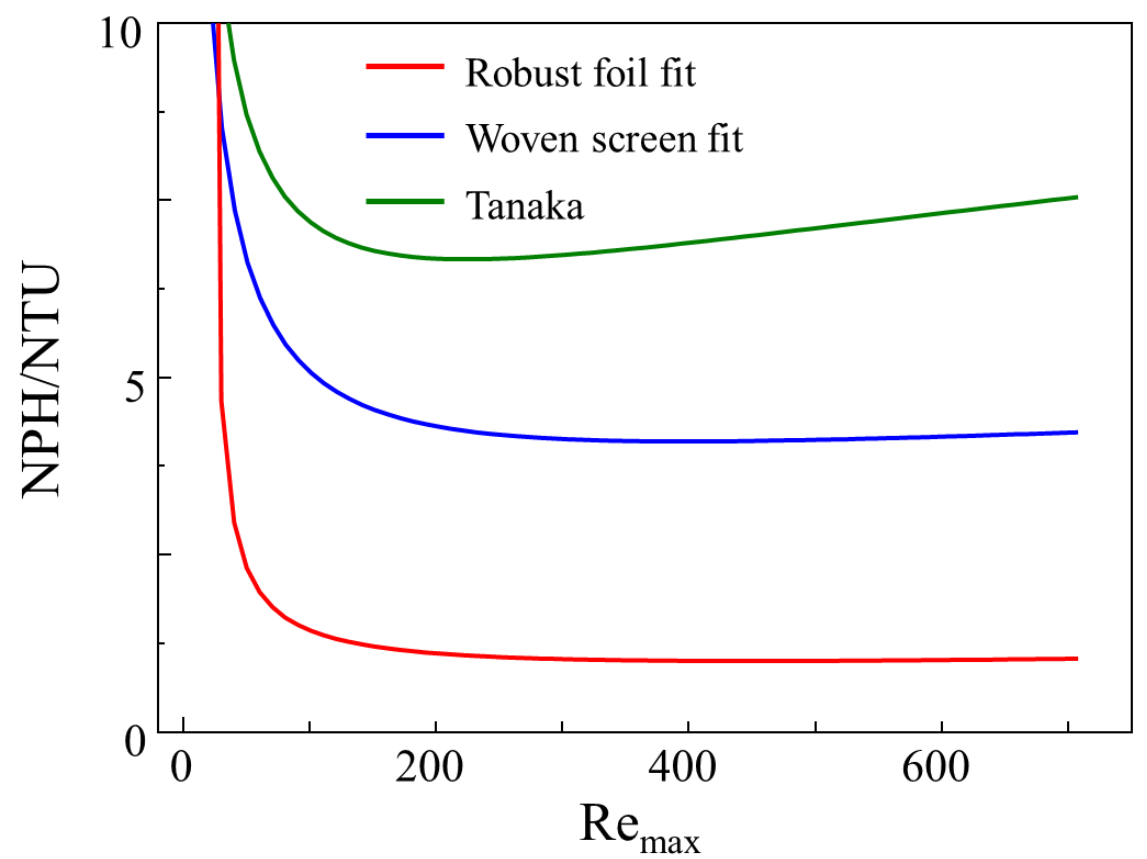

Fig. 78 Comparison of NPH/NTU

\section{1-2. $\mathrm{j} / \mathrm{f}$ ratio}

As Costa et al. mentioned that the different figure of merit sometimes disagree with each other [140], another figure of merit should be considered. Therefore, in this study, another figure of merit was selected to make sure the robust foil regenerator is a better regenerator than the woven screen regenerator.

A ratio between the friction factor and the heat transfer was proposed by Radebaugh et al. to evaluate the regenerator function $[142,140]$. It is the ratio of the Colburn number to the Fanning friction factor. The Colburn number and the Fanning friction factor are represented by equation (55) and (56).

$$
f=\frac{\Delta P_{\max } d_{h}}{2 \rho_{\text {re }} u_{\max }^{2} L}
$$




$$
j=\frac{N u}{R e_{\max } \operatorname{Pr}^{\frac{1}{3}}}
$$

The $\mathrm{j} / \mathrm{f}$ ratio is expressed by equation (57).

$$
\frac{j}{f}=\frac{N u}{R e_{\max } \operatorname{Pr}^{1 / 3} f}
$$

Fig. 79 shows the comparison of the $\mathrm{j} / \mathrm{f}$ ratio. Separate from Fig. 78, the Tanaka's regenerator and the woven screen regenerator show the similar $\mathrm{j} / \mathrm{f}$. The friction factor of the Tanaka and woven screen regenerator are relatively close, therefore, the Nusselt number difference is the only factor that affects the NPH/NTU and j/f ratio. By comparing with Fig. 78 and Fig. 79, it was found that the Nusselt number difference affects the NPH/NTU ratio more than the $j / f$ ratio. Moreover, the robust foil regenerator shows a considerably the higher $\mathrm{j} / \mathrm{f}$ ratio than the conventional wire regenerators. As a result, the two figure of merit, NPH/NTU and $\mathrm{j} / \mathrm{k}$ ratio, show slightly different results. However, the robust foil regenerator represents a significantly high potential as the Stirling engine regenerator in both cases. 


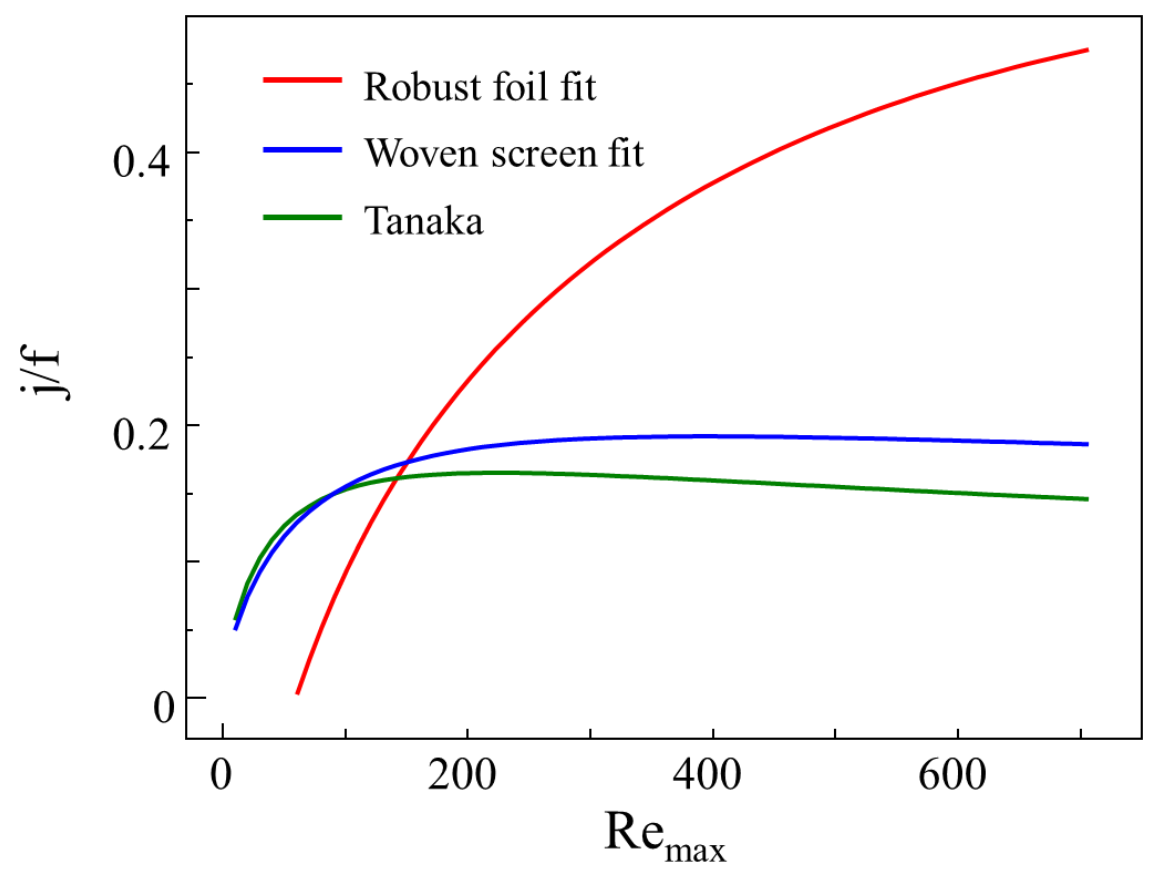

Fig. 79 Comparison of $\mathrm{j} / \mathrm{f}$ ratio

\section{Conduction loss of the robust foil regenerator}

The largest concern about using the robust foil regenerator was the conduction through the regenerator. Because the regenerator is located between the heater and the cooler of the Stirling engine, the conduction through the regenerator directly affects the engine efficiency. Therefore, conduction through the regenerator was measured by the finite element analysis (FEA). The geometry of the regenerator was generated by using SolidWorks. ANSYS Mechanical was utilized to generate the mesh and to run the simulation. Fig. 80 shows the simulation geometry and mesh. Furthermore, to decrease the conduction loss through the regenerator rib, the offset configuration was generated. The offset geometry and the mesh are shown in Fig. 81. Because the rib faces of the upper and lower part of the regenerator are not matching, the conduction loss should be decreased.

Also, the difference in the thermal contact resistance was considered in the simulation. To compare the conduction loss with and without the thermal contact resistance, two cases were simulated for both of the regenerator configurations. For the no contact resistance regenerator, the contact boundary condition was bonded; thus, the contact resistance between the regenerator contact surfaces did not exist. On the other hand, for the regenerator with the contact resistance, the contact resistance 
was added in the simulation. To sum up the conduction simulations, there were 4 case simulations as followed.

Case 1: Straight configuration without the contact resistance

Case 2: Straight with the contact resistance

Case 3: Offset configuration without the contact resistance

Case 4: Offset configuration with the contact resistance

The temperature at the bottom of the regenerator was fixed at $60{ }^{\circ} \mathrm{C}$ and the top of the regenerator was varied $120^{\circ} \mathrm{C}$ to $180^{\circ} \mathrm{C}$ for each case. Fig. 82 represents the FEA result of the robust foil regenerator. The theoretical value was calculated without the contact resistance by 1-D conduction equation (58).

$$
q=k \frac{\Delta T}{\Delta x}
$$

From Fig. 82, the theoretical value and Case 1 show a good agreement; therefore, and the FEA result is valid. As expected, due to the contact resistance, the heat flux of the regenerator with the contact resistance, which is Case 2 and Case 4, are less than the regenerator without the contact resistance. Additionally, by comparing the offset and the non-offset configuration, the heat flux of the offset configuration is smaller than the non-offset configuration. Therefore, the robust foil regenerator should be used in offset configuration to decrease the conduction loss and to improve Stirling engine efficiency. 

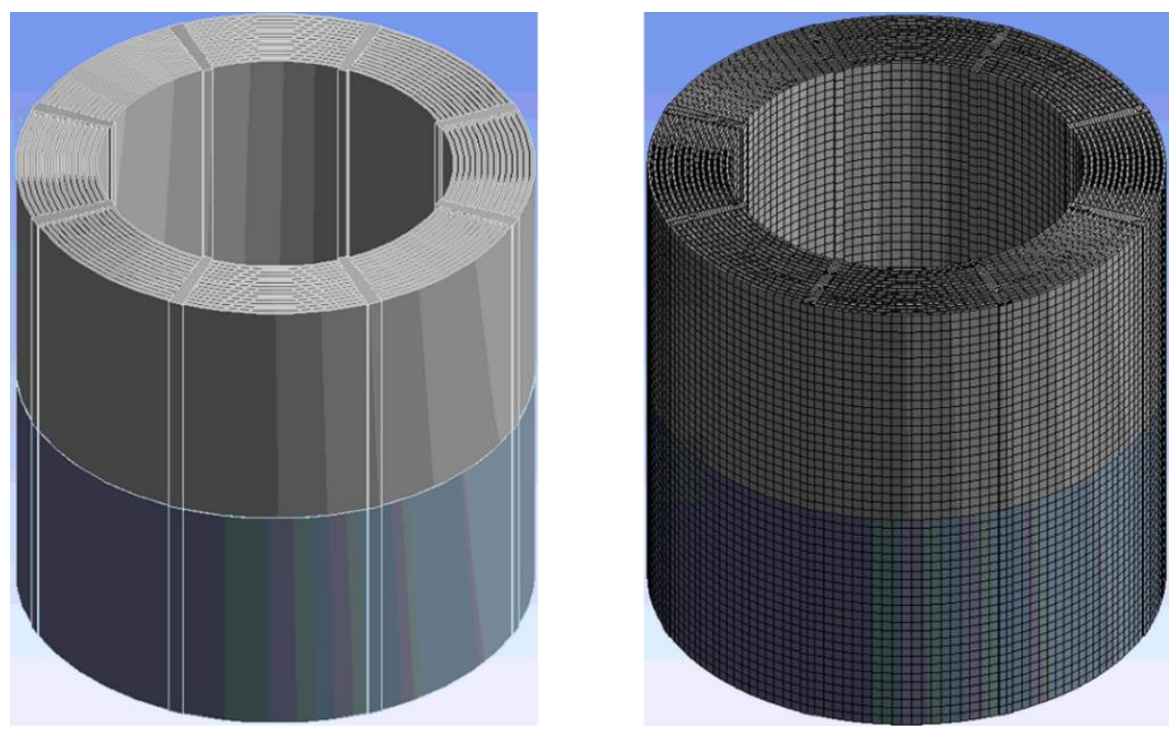

Fig. 80 Straight rib
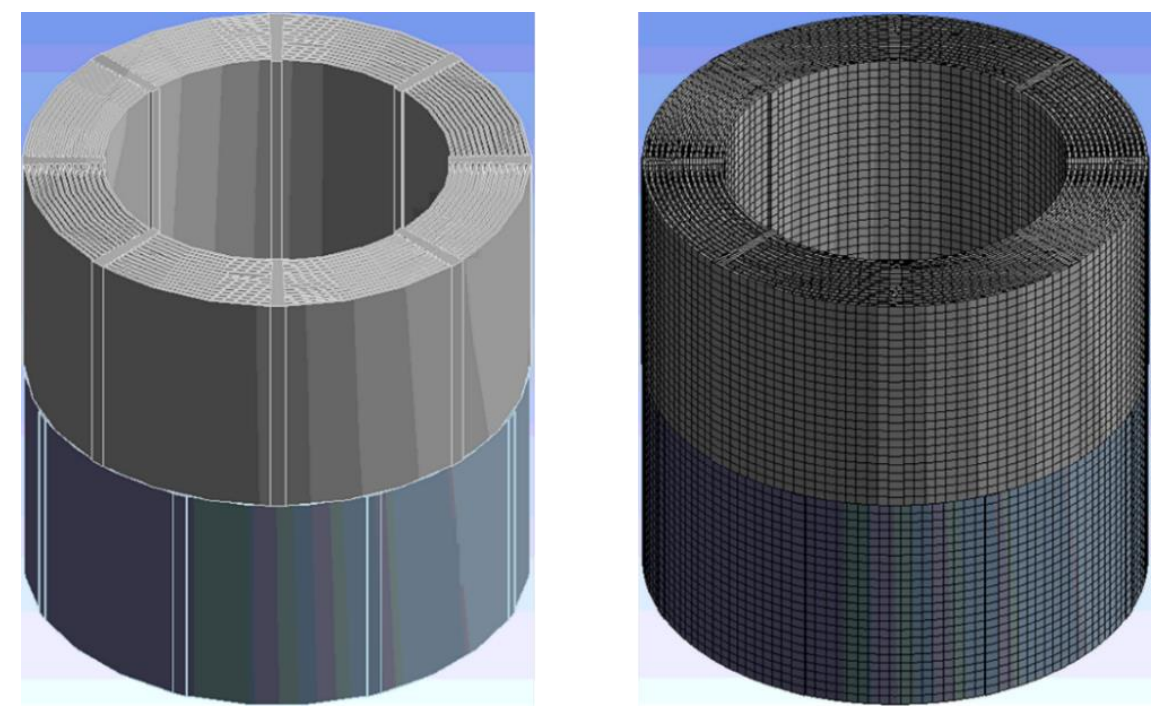

Fig. 81 Offset rib 


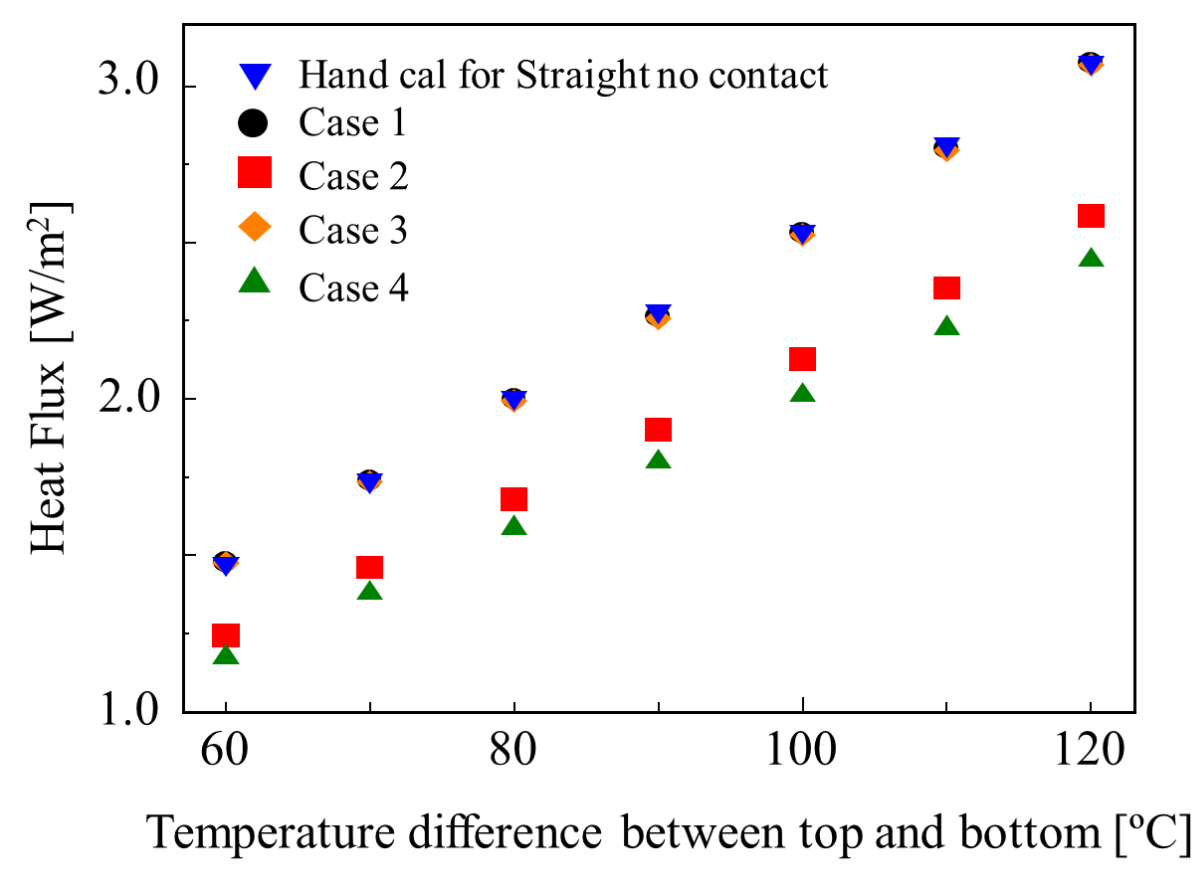

Fig. 82 Conduction loss through the regenerator 


\section{Chapter: 6 Conclusion}

\section{Test rig}

The test rig for the regenerator experiment was designed and successfully built to conduct the flow loss test and the heat transfer test of the robust foil regenerator. The regenerator test rig is mainly composed of the heater, test section, cooler, and linear alternator.

The heater is enclosed by the pressure vessel due to safety purposes. Two band heaters were installed inside the pressure vessel as heating elements. A 4-pin feedthrough was inserted in the pressure vessel to supply power to the band heaters. The working fluid temperature reached approximately $100{ }^{\circ} \mathrm{C}$ through the heater.

Two types of the test sections were manufactured to separate the flow loss and heat transfer test due to the temperature limitation of the pressure transducers. For the flow loss test section, two pressure transducers were placed above and below the regenerator to measure the pressure difference through the regenerator. For the heat transfer test section, instead of the pressure transducers, two thermocouples were installed in the test section. The data from the pressure transducers and the thermocouples were recorded by the NI data acquisition devices and LabVIEW 2017.

The cooler was designed to cool down the working fluid that heated up at the heater. It is mainly composed of the fin and the water jacket. The fin is cooled down by the coolant water going through the water jacket. A chiller is used to keep the coolant at low temperature. The working fluid temperature was approximately $50{ }^{\circ} \mathrm{C}$ after the cooler.

As a driving system of the test rig, the linear alternator was selected. The natural frequency of the linear alternator is $49 \mathrm{~Hz}$ and the maximum stroke length is $24 \mathrm{~mm}$. Because the linear alternator generates the oscillating motion, all the experiments were conducted under oscillating flow conditions. At the bottom of the linear alternator, a linear displacement transducer was installed to monitor the piston motion of the linear alternator. The data from the displacement transducer was recorded by utilizing NI data acquisition module and LabVIEW 2017.

To check the test rig function, a few tests were conducted before moving on with the experiments. The first test was the leakage test for the test rig. The results showed that the test rig has a small leak. However, the test time period was not long enough to be affected by the leak. 
The second test was the linear alternator test to check the linear alternator motion. As a result, it was found that the motion of the linear alternator was similar to the sinusoidal wave. The last test was the conduction loss test. To measure the heat transfer through the regenerator, the conduction through the test rig wall should be calibrated out. Based on the test result, an equation was derived to remove the conducting loss.

\section{Flow loss}

Before the flow loss test, a woven screen regenerator was manufactured to check the validity of the acquired test data using the test rig. The flow loss test results of the woven screen regenerator were compared to the published woven screen regenerator correlations. By comparing the results, the test result of the woven screen regenerator showed a good agreement to the other correlations. Thus, it was concluded that the measured data from the test rig was highly valid.

Two programs were made for the data recording and the data processing by using LabVIEW 2017. The data recording program recorded the pressure data, piston position data, and power source voltage for the linear alternator. The data processing program conducted the ensemble average and calculated the friction coefficient.

The flow loss test for the robust foil regenerator was conducted to clarify the flow loss characteristic of the robust foil regenerator. The charge pressure of the test rig was 2 bars with air and the Reynolds number range was 100 to 800 . The measured pressure data was converted to the maximum friction coefficient to compare to the other regenerator correlations. The flow loss test results showed that the friction coefficient of the robust foil regenerator is significantly lower than the woven screen regenerator. This was expected because the robust foil regenerator is only composed of the parallel flow channels to decrease the flow loss. Additionally, the CFD was conducted and compared to the experimental result. The results showed that the CFD results are slightly smaller than the experimental results. This was because the actual robust foil regenerator is made by two pieces, and the surface between the two pieces was not perfectly matching. Therefore, the small step inside the regenerator caused a higher pressure drop than the CFD results. Another explanation for the higher friction factor in the experiment is the surface roughness. The surface roughness of additive manufacturing is high. Thus, the surface roughness affected the pressure drop of the experiment. In addition, the regenerator friction coefficient was close to the 
parallel plate friction coefficient. Therefore, the flow channels of the robust foil regenerator were successfully manufactured as the parallel flow channels by additive manufacturing.

\section{Heat transfer}

For the heat transfer test, two programs were made for data recording and data processing. The data recording program was almost the same as the data recording program of the flow loss test. Instead of the pressure transducers, the thermocouples data was recorded, and the input voltage for the band heaters was also monitored in this program. The data processing program was made to derive the Nusselt number and the Reynolds number. Different from the data recording program, the data processing program was a completely new program because the method of the ensemble average was different.

The heat transfer test was conducted to reveal the heat transfer characteristic of the robust foil regenerator. Also, the woven screen regenerator was tested to compare with the robust foil regenerator. To measure the temperature at the regenerator, the thermocouples were installed instead of the pressure transducers. The charge pressure of the test rig was from 3 bar to 24 bars using helium and the Reynolds number range was 50 to 450. The measured temperature was converted to the Nusselt number by the data processing program. The result showed that the robust foil regenerator has a lower Nusselt number than the woven screen regenerator. Due to the parallel flow channels of the robust foil regenerator, the turbulence inside the regenerator was smaller than the woven screen regenerator. This low turbulence causes a smaller heat transfer. Therefore, the robust foil regenerator showed a lower Nusselt number than the wire media regenerators.

\section{$>$ Figure of merit}

The flow loss and heat transfer results showed that the robust foil regenerator is outstanding in terms of the flow loss, but the heat transfer is not as high as the woven screen regenerator. To evaluate the overall performance of the robust foil regenerator, the figure of merit was selected as the parameter for the regenerator evaluation. Two kinds of figure of merit were selected and both of them demonstrated that the robust foil regenerator is better than the woven screen regenerator. Therefore, the robust foil regenerator has the higher potential to improve the efficiency of the Stirling engine. 


\section{$>$ Conduction loss of the robust foil regenerator}

4 cases of the simulation were carried out to check the conduction loss of the robust foil regenerator. According to the FEA results, the offset configuration is better than the non-offset configuration in terms of the heat flux through the regenerator. Additionally, as the contact resistance decreases the conduction through the regenerator, the regenerator with contact resistance could decrease the heat flux of the regenerator. Therefore, the regenerator which has the offset configuration with the multiple pieces is the better regenerator for the Stirling engine.

\section{Accomplishment of this research}

One of the crucial components in the Stirling engine is the regenerator because of the pressure drop. To improve the engine efficiency, the pressure drop of the regenerator should be decreased. One idea is to use a parallel channel regenerator. The parallel channel regenerator (robust foil regenerator) is theoretically the most efficient regenerator in terms of figure of merit. In this research, the experiments and the simulations were conducted to prove the design validity of the robust foil regenerator. The experiments were conducted by making a regenerator test rig. The test rig verification was carried out with the woven screen regenerator, and it was proved that the test rig is valid. To evaluate the overall performance of the regenerator, the flow loss test and the heat transfer test were conducted. The experiment results were compared to the simulation results, and it was found that the experiment results are valid. To evaluate the regenerator performance, the figure of merit was calculated based on the experiment results. As a result, it was shown that the robust foil regenerator is the better regenerator than the conventional regenerator. Therefore, the Stirling engine efficiency must be improved by using the robust foil regenerator.

\section{NOMENCLATURE}

A $\quad\left[\mathrm{m}^{2}\right] \quad$ Cross-section area of the thermocouple bead

$\mathrm{A}_{\mathrm{c}} \quad\left[\mathrm{m}^{2}\right] \quad$ Cross-section area at regenerator

As $\quad\left[\mathrm{m}^{2}\right] \quad$ Regenerator heat transfer area 


\begin{tabular}{|c|c|c|}
\hline \multicolumn{2}{|c|}{$\mathrm{A}_{\mathrm{pi}} \quad\left[\mathrm{m}^{2}\right]$} & Piston area \\
\hline \multicolumn{2}{|l|}{$\mathrm{C}_{\mathrm{f}}$} & Friction coefficient \\
\hline \multicolumn{2}{|c|}{$\mathrm{C}_{\mathrm{f} \text { CFD }}$} & Friction coefficient of robust foil regenerator from CFD \\
\hline \multicolumn{2}{|c|}{$\mathrm{C}_{\mathrm{f} \text { Costa }}$} & Friction coefficient of woven screen regenerator from Costa et al. \\
\hline \multicolumn{2}{|c|}{$\mathrm{C}_{\mathrm{f} \text { Gedeon }}$} & Friction coefficient of woven screen regenerator from Gedeon et al \\
\hline \multicolumn{2}{|c|}{$\mathrm{C}_{\mathrm{f}, \max }$} & Maximum friction coefficient \\
\hline \multicolumn{2}{|c|}{$\mathrm{C}_{\mathrm{f} \text {, random fiber }}$} & Friction coefficient of random fiber regenerator \\
\hline \multicolumn{2}{|c|}{$\mathrm{C}_{\mathrm{f} \text {, Parallel }}$} & Friction coefficient of parallel plate \\
\hline \multicolumn{2}{|c|}{$\mathrm{C}_{\mathrm{f}}$ Tanaka } & Friction coefficient of woven screen from Tanaka et al. \\
\hline \multicolumn{2}{|c|}{$\mathrm{C}_{\mathrm{f}, \text { test }}$} & Friction coefficient of robust foil regenerator from experiment \\
\hline \multicolumn{2}{|c|}{$\mathrm{C}_{\mathrm{f} \text {, woven screen }}$} & Friction coefficient of woven screen regenerator from experiment \\
\hline $\mathrm{C}_{\mathrm{p}}$ & {$[\mathrm{J} / \mathrm{K} \cdot \mathrm{kg}]$} & Average specific heat of the working fluid \\
\hline $\mathrm{C}_{\mathrm{ps}}$ & {$[\mathrm{J} / \mathrm{K} \bullet \mathrm{kg}]$} & Specific heat of the stainless steel \\
\hline$d_{h}$ & {$[\mathrm{~m}]$} & Hydraulic diameter \\
\hline $\mathrm{d}_{\mathrm{w}}$ & {$[\mathrm{m}]$} & Wire diameter \\
\hline f & & Fanning friction factor \\
\hline $\mathrm{F}_{\mathrm{M}}$ & & Figure of merit from Gedeon \\
\hline $\mathrm{F}_{\mathrm{MCS}}$ & & Figure of merit from Costa \\
\hline $\begin{array}{l}\mathrm{h} \\
{[\mathrm{W} / \mathrm{m}}\end{array}$ & & Heat transfer coefficient \\
\hline I & {$[\mathrm{mA}]$} & Current \\
\hline j & & Colburn number \\
\hline $\mathrm{k}$ & {$[\mathrm{W} / \mathrm{m} \cdot \mathrm{K}]$} & Thermal conductivity \\
\hline $\mathrm{L}$ & {$[\mathrm{m}]$} & Regenerator length \\
\hline M & {$[\mathrm{kg}]$} & Mass of the thermocouple bead \\
\hline$\dot{\mathrm{m}}$ & {$[\mathrm{kg} / \mathrm{s}]$} & Local mass flow rate \\
\hline$\dot{\mathrm{m}}_{\max }$ & {$[\mathrm{kg} / \mathrm{s}]$} & Maximum mass flow rate \\
\hline
\end{tabular}




\begin{tabular}{|c|c|c|}
\hline$\dot{\mathrm{m}}_{\mathrm{rms}}$ & {$[\mathrm{kg} / \mathrm{s}]$} & RMS mass flow rate \\
\hline$\dot{\mathrm{m}}_{\mathrm{w}}$ & {$[\mathrm{kg} / \mathrm{s}]$} & Water mass flow rate pf the cooler \\
\hline $\mathrm{n}$ & & Number of data \\
\hline $\mathrm{N}_{\mathrm{k}}$ & & Axial conductivity \\
\hline NPH & & Number of pressure heads pressure drop \\
\hline $\mathrm{Nu}$ & & Nusselt number \\
\hline $\mathrm{Nu}_{\text {test }}$ & & Experiment Nusselt number \\
\hline $\mathrm{Nu}_{\text {wire } \mathrm{n}}$ & netting & Wire netting Nusselt number \\
\hline $\mathrm{Nu}_{\text {woven }}$ & n screen & Woven screen Nisselt number \\
\hline NTU & & Number of transfer units \\
\hline $\mathrm{P}$ & {$[\mathrm{m}]$} & Perimeter \\
\hline$\Delta \mathrm{P}_{\max }$ & {$[\mathrm{Pa}]$} & Maximum pressure drop \\
\hline $\operatorname{Pr}$ & & Prandle number \\
\hline q & {$[\mathrm{W} / \mathrm{m} 2]$} & Heat flux \\
\hline Q & {$[\mathrm{W}]$} & Heat \\
\hline Qloss & {$[\mathrm{W}]$} & Conduction loss \\
\hline $\mathrm{Q}_{\mathrm{h}, \text { in }}$ & {$[\mathrm{W}]$} & Hot side heat going into regenerator \\
\hline$Q_{c, i n}$ & {$[\mathrm{~W}]$} & Cold side heat going into regenerator \\
\hline $\mathrm{Q}_{\mathrm{c}, \text { out }}$ & {$[\mathrm{W}]$} & Cold side heat going out from regenerator \\
\hline $\mathrm{r}$ & {$[\mathrm{m}]$} & Radius \\
\hline $\mathrm{R}(\mathrm{t})$ & & Resistance \\
\hline $\operatorname{Re}$ & & Local Reynolds number at regenerator \\
\hline $\operatorname{Re}_{\mathrm{rms}}$ & & RMS Reynolds number \\
\hline $\operatorname{Re}_{\max }$ & & Maximum Reynolds number at regenerator \\
\hline $\operatorname{Re}_{\mathrm{w}}$ & & Kinetic Reynolds number \\
\hline $\mathrm{t}$ & {$[\mathrm{s}]$} & Time \\
\hline $\mathrm{T}$ & {$\left[{ }^{\circ} \mathrm{C}\right]$} & Measured temperature \\
\hline
\end{tabular}




\begin{tabular}{|c|c|c|}
\hline $\mathrm{T}_{\mathrm{c}}$ & {$\left[{ }^{\circ} \mathrm{C}\right]$} & Cooler side temperature \\
\hline $\mathrm{T}_{\mathrm{g}}$ & {$\left[{ }^{\circ} \mathrm{C}\right]$} & Actual working fluid temperature \\
\hline $\mathrm{T}_{\mathrm{h}}$ & {$\left[{ }^{\circ} \mathrm{C}\right]$} & Heater side temperature \\
\hline$\overline{\mathrm{T}_{\mathrm{h}}}$ & {$\left[{ }^{\circ} \mathrm{C}\right]$} & Heater side mean temperature \\
\hline$\overline{\mathrm{T}_{\mathrm{re}}}$ & {$\left[{ }^{\circ} \mathrm{C}\right]$} & Average temperature at regenerator \\
\hline $\mathrm{T}_{\mathrm{w}, \text { in }}$ & {$\left[{ }^{\circ} \mathrm{C}\right]$} & Water temperature at the cooler inlet \\
\hline $\mathrm{T}_{\mathrm{w}, \text { out }}$ & {$\left[{ }^{\circ} \mathrm{C}\right]$} & Water temperature at the cooler out \\
\hline $\mathrm{u}_{\max }$ & {$[\mathrm{m} / \mathrm{s}]$} & Maximum velocity at regenerator \\
\hline $\mathrm{u}_{\mathrm{pi}, \max }$ & $\mathrm{x}[\mathrm{m} / \mathrm{s}]$ & Maximum velocity of piston \\
\hline $\mathrm{u}_{\mathrm{pi}}$ & {$[\mathrm{m} / \mathrm{s}]$} & Local piston velocity \\
\hline $\mathrm{U}$ & {$\left[\mathrm{W} / \mathrm{m}^{2} \cdot \mathrm{K}\right]$} & Overall heat transfer coefficient \\
\hline $\mathrm{V}$ & {$[\mathrm{V}]$} & Voltage \\
\hline$\Delta \mathrm{X}$ & {$[\mathrm{m}]$} & Delta piston displacement \\
\hline $\mathrm{X}_{\mathrm{d}}$ & {$[\mathrm{mm}]$} & Piston displacement \\
\hline $\mathrm{Xp}$ & {$[\mathrm{m}]$} & Piston amplitude \\
\hline$\Delta \mathrm{X}_{\max }$ & $\mathrm{x}[\mathrm{m}]$ & Maximum piston displacement \\
\hline $\mathrm{Z}$ & & Confidence level \\
\hline$\rho_{\text {re }}$ & {$\left[\mathrm{kg} / \mathrm{m}^{3}\right]$} & Fluid density at regenerator \\
\hline$\rho_{\mathrm{pi}}$ & {$\left[\mathrm{kg} / \mathrm{m}^{3}\right]$} & Fluid density at piston \\
\hline$v$ & {$\left[\mathrm{~m}^{2} / \mathrm{s}\right]$} & Kinematic viscosity \\
\hline$\Pi_{v}$ & & Regenerator porosity \\
\hline$\mu$ & {$[\mathrm{Pa} \mathrm{s}]$} & Dynamic viscosity \\
\hline$\phi$ & {$[1 / \mathrm{m}]$} & Shape factor \\
\hline$\omega$ & {$[1 / \mathrm{s}]$} & Angular velocity \\
\hline$\sigma$ & & Standard deviation \\
\hline
\end{tabular}




\section{References}

1. J. G. Schreiber, Assessment of the stirling power option for space science applications, 2000 IEEE Aerospace Conference. Proceedings (Cat. No. 00TH8484), IEEE, 2000, pp. 39-46.

2. W. R. Martini, Stirling engine design manual, US Department of Energy, Office of Conservation and Solar Applications ...1978.

3. L. G. Thieme, J. G. Schreiber and L. S. Mason, Stirling technology development at nasa grc, AIP Conference Proceedings, AIP, 2002, pp. 872-879.

4. D. o. Energy, "Internal combustion engine basics," 2013.

5. A. Sowale, A. J. Kolios, B. Fidalgo, T. Somorin, A. Parker, L. Williams, M. Collins, E. McAdam and $\mathrm{S}$. Tyrrel, Thermodynamic analysis of a gamma type stirling engine in an energy recovery system, Energy conversion and management 165 (2018), 528-540.

6. B. Kongtragool and S. Wongwises, Thermodynamic analysis of a stirling engine including dead volumes of hot space, cold space and regenerator, Renewable Energy 31 (2006), no. 3, 345-359.

7. $\quad$ ScienceDirect, "Stirling cycle."

8. T. Biwa, Y. Tashiro and T. Yazaki, How does stirling engine work?, Journal of Power and Energy Systems 2 (2008), no. 5, 1254-1260.

9. $\quad$ SUNPOWER, "Stirling cycle."

10. M. He, "Stirling engine for solar thermal electric generation," University of California, Berkeley2016.

11. J. S. Reid, Stirling stuff, arXiv preprint arXiv:1604.02362 (2016).

12. G. Walker, Stirling-cycle machines, Clarendon Press Oxford1973.

13. J. Stirling, Stirling's air engine, Mechanics' magazine 45 (1846), 559.

14. G. H. Babcock, Substitutes for steam, Transactions of the American Society of Mechanical Engineers 7 (1886), 680-741.

15. G. Walker, Dual function concept stirling engine for automotive application, Automotive Engineer 5 (1980), no. 5.

16. University of Ohio, "The sunpower eg-1000 stirling engine/generator."

17. D. Kirkley, Determination of the optimum configuration for a stirling engine, Journal of Mechanical Engineering Science 4 (1962), no. 3, 204-212. 
18. E. I. Eid, R. A. Khalaf-Allah, A. M. Soliman and A. S. Easa, Performance of a beta stirling refrigerator with tubular evaporator and condenser having inserted twisted tapes and driven by a solar energy heat engine, Renewable Energy 135 (2019), 1314-1326.

19. N. Parlak, A. Wagner, M. Elsner and H. S. Soyhan, Thermodynamic analysis of a gamma type stirling engine in non-ideal adiabatic conditions, Renewable Energy 34 (2009), no. 1, 266-273.

20. T. S. Oros, I. Vadan, R. Pop and C. Brad, Linear generator for a free piston stirling engine, Journal of Electrical and Electronics Engineering 7 (2014), no. 1, 111.

21. S. Zare, A. Tavakolpour-Saleh and A. Omidvar, From beale number to pole placement design of a free piston stirling engine, Archive of Mechanical Engineering 64 (2017), no. 4, 499-518.

22. W. T. Beale, "Free piston stirling engines-some model tests and simulations," SAE Technical Paper1969.

23. W. Beale and G. Chen, Small stirling free piston stirling engines for cogeneration, Sunpower inc., Athens (1992).

24. J. Boucher, F. Lanzetta and P. Nika, Optimization of a dual free piston stirling engine, Applied Thermal Engineering 27 (2007), no. 4, 802-811.

25. T. Marciniak, J. Bratis, A. Davis and C. Lee, "Assessment of stirling engine potential in total and integrated energy systems," Argonne National Lab., IL (USA)1979.

26. K. Mahkamov, An axisymmetric computational fluid dynamics approach to the analysis of the working process of a solar stirling engine, Journal of solar energy engineering 128 (2006), no. 1, 45-53.

27. G. Schmidt, The theory of lehmann's calorimetric machine, Zeitschrift Des Vereines Deutscher Ingenieure 15 (1871), no. 1.

28. D. Thombare and S. Verma, Technological development in the stirling cycle engines, Renewable and Sustainable Energy Reviews 12 (2008), no. 1, 1-38.

29. Y. Timoumi, I. Tlili and S. B. Nasrallah, Design and performance optimization of gpu-3 stirling engines, Energy 33 (2008), no. 7, 1100-1114.

30. C.-H. Cheng and Y.-J. Yu, Numerical model for predicting thermodynamic cycle and thermal efficiency of a beta-type stirling engine with rhombic-drive mechanism, Renewable Energy 35 (2010), no. 11, 2590-2601.

31. I. Tlili and A. Sa'ed, Thermodynamic evaluation of a second order simulation for yoke ross stirling engine, Energy conversion and management 68 (2013), 149-160. 
32. A. R. Tavakolpour, A. Zomorodian and A. A. Golneshan, Simulation, construction and testing of a two-cylinder solar stirling engine powered by a flat-plate solar collector without regenerator, Renewable Energy 33 (2008), no. 1, 77-87.

33. K. Hirata, S. Iwamoto, F. Toda and K. Hamaguchi, Performance evaluation for a $100 \mathrm{w}$ stirling engine, Proceedings of 8th International Stirling Engine Conference1997, pp. 19-28.

34. L. Grosu, C. Dobre and S. Petrescu, Study of a stirling engine used for domestic microcogeneration. Thermodynamic analysis and experiment, International Journal of Energy Research 39 (2015), no. 9, 1280-1294.

35. K. Kawajiri, M. Fujiwara and T. Suganami, Analysis of stirling engine performance, Proceedings of the 24th Intersociety Energy Conversion Engineering Conference, IEEE, 1989, pp. 23412346.

36. B. Kongtragool and S. Wongwises, A four power-piston low-temperature differential stirling engine using simulated solar energy as a heat source, Solar Energy 82 (2008), no. 6, 493-500.

37. S. Iwamoto, F. Toda, K. Hirata, M. Takeuchi and T. Yamamoto, Comparison of low-and hightemperature differential stirling engines, Proceedings of eighth International Stirling engine conference1997, pp. 29-38.

38. K. Hirata, Development of a small 50w class stirling engine, Proceedings of the 6th International Symposium on Marine Engineering, Tokyo, Japan, Citeseer, 2000, pp. 23-27.

39. S. Kwankaomeng, B. Silpsakoolsook and P. Savangvong, Investigation on stability and performance of a free-piston stirling engine, Energy Procedia 52 (2014), 598-609.

40. G. Xiao, C. Chen, B. Shi, K. Cen and M. Ni, Experimental study on heat transfer of oscillating flow of a tubular stirling engine heater, International Journal of Heat and Mass Transfer 71 (2014), 1-7.

41. C.-H. Cheng, H.-S. Yang and L. Keong, Theoretical and experimental study of a 300-w betatype stirling engine, Energy 59 (2013), 590-599.

42. R. Gheith, F. Aloui, M. Tazerout and S. Ben Nasrallah, Experimental investigations of a gamma stirling engine, International journal of energy research 36 (2012), no. 12, 1175-1182.

43. R. Li, L. Grosu and D. Queiros-Condé, Losses effect on the performance of a gamma type stirling engine, Energy Conversion and Management 114 (2016), 28-37.

44. R. Li, L. Grosu and W. Li, New polytropic model to predict the performance of beta and gamma type stirling engine, Energy 128 (2017), 62-76. 
45. University of Calgary, "Energy education."

46. B. Kongtragool and S. Wongwises, A review of solar-powered stirling engines and low temperature differential stirling engines, Renewable and Sustainable energy reviews 7 (2003), no. 2, 131-154.

47. C. Maier, A. Gil, R. Aguilera, L. Shuang and X. Yu, Stirling engine, University of Gavle (2007).

48. H. Nilsson, Submarine power systems using the v4-275r stirling engine, Proceedings of the Institution of Mechanical Engineers, Part A: Power and Process Engineering 202 (1988), no. 4, 257-267.

49. A. J. Organ, The regenerator and the stirling engine, vol. 624, Mechanical Engineering Publications London1997.

50. W.-L. Chen, K.-L. Wong and H.-E. Chen, An experimental study on the performance of the moving regenerator for a $\gamma$-type twin power piston stirling engine, Energy conversion and management 77 (2014), 118-128.

51. University of Roma, "Stirling international."

52. E. E. Daub, The regenerator principle in the stirling and ericsson hot air engines, The British journal for the history of science 7 (1974), no. 3, 259-277.

53. A. Organ, Two centuries of the thermal regenerator, Proceedings of the Institution of Mechanical Engineers, Part C: Journal of Mechanical Engineering Science 214 (2000), no. 1, 269-288.

54. T. E. Schumann, Heat transfer: A liquid flowing through a porous prism, Journal of the Franklin Institute 208 (1929), no. 3, 405-416.

55. W. M. Kays, A. L. London and E. Eckert, "Compact heat exchangers," American Society of Mechanical Engineers Digital Collection1960.

56. J. E. Coppage, The heat transfer and flow friction characteristics of porous media, Department of Mechanical Engineering, Stanford University.1952.

57. J. Weisend, Regenerators, (2014).

58. M. Tanaka, I. Yamashita and F. Chisaka, Flow and heat transfer characteristics of the stirling engine regenerator in an oscillating flow, JSME international journal. Ser. 2, Fluids engineering, heat transfer, power, combustion, thermophysical properties 33 (1990), no. 2, 283-289.

59. Y. Ju, Y. Jiang and Y. Zhou, Experimental study of the oscillating flow characteristics for a regenerator in a pulse tube cryocooler, Cryogenics 38 (1998), no. 6, 649-656. 
60. S.-C. Costa, M. Tutar, I. Barreno, J.-A. Esnaola, H. Barrutia, D. García, M.-A. González and J.-I. Prieto, Experimental and numerical flow investigation of stirling engine regenerator, Energy 72 (2014), 800-812.

61. S. Alfarawi, R. Al-Dadah and S. Mahmoud, Transient investigation of mini-channel regenerative heat exchangers, (2017).

62. M. B. Ibrahim, D. Danila, T. Simon, S. Mantell, L. Sun, D. Gedeon, S. Qiu, G. Wood, K. Kelly and J. McLean, A microfabricated segmented-involute-foil regenerator for enhancing reliability and performance of stirling engines: Phase ii final report for the radioisotope power conversion technology nra contract nas3-03124, (2007).

63. M. B. Ibrahim and R. C. Tew Jr, Stirling convertor regenerators, CRC Press2016.

64. S. Qiu and L. Solomon, "Free-piston stirling engine generators," Energy conversion-current technologies and future trends, IntechOpen2018.

65. S. Qiu, Y. Gao, G. Rinker and K. Yanaga, Development of an advanced free-piston stirling engine for micro combined heating and power application, Applied energy 235 (2019), 9871000.

66. G. R. Laura Solomon, Songgang Qiu, Development of an additively manufactured regenerator for stirling engine convertors, Preparing to submit.

67. G. T. Rinker, Design and optimization of a $1 \mathrm{kw}$ stirling engine, (2018).

68. L. Hirt, A. Reiser, R. Spolenak and T. Zambelli, Additive manufacturing of metal structures at the micrometer scale, Advanced Materials 29 (2017), no. 17, 1604211.

69. P. V. Trevizoli and J. R. Barbosa Jr, Thermal-hydraulic behavior and influence of carryover losses in oscillating-flow regenerators, International Journal of Thermal Sciences 113 (2017), 89-99.

70. S. Isshiki, A. Sakano, I. Ushiyama and N. Isshiki, Studies on flow resistance and heat transfer of regenerator wire meshes of stirling engine in oscillatory flow, JSME International Journal Series B Fluids and Thermal Engineering 40 (1997), no. 2, 281-289.

71. J. Cha, S. Ghiaasiaan and C. Kirkconnell, Oscillatory flow in microporous media applied in pulse-tube and stirling-cycle cryocooler regenerators, Experimental thermal and fluid science 32 (2008), no. 6, 1264-1278.

72. I. Tlili, Y. Timoumi and S. B. Nasrallah, Analysis and design consideration of mean temperature differential stirling engine for solar application, Renewable Energy 33 (2008), no. 8, 1911-1921. 
73. L. G. Thieme, Friction factor characterization for high-porosity random fiber regenerators, (2001).

74. D. Gedeon and J. Wood, Oscillating-flow regenerator test rig: Hardware and theory with derived correlations for screens and felts, (1996).

75. R. Gheith, F. Aloui and S. B. Nasrallah, Study of temperature distribution in a stirling engine regenerator, Energy conversion and management 88 (2014), 962-972.

76. R. Gheith, F. Aloui and S. B. Nasrallah, Determination of adequate regenerator for a gammatype stirling engine, Applied energy 139 (2015), 272-280.

77. ---, Study of the regenerator constituting material influence on a gamma type stirling engine, Journal of Mechanical Science and Technology 26 (2012), no. 4, 1251-1255.

78. B. G. Kim, W.-S. Park, B.-G. Koo and S. Park, Effects of regenerator structure on performance of free piston stirling engine (fpse), Journal of Mechanical Science and Technology 32 (2018), no. 9, 4473-4484.

79. S. K. Andersen, H. Carlsen and P. G. Thomsen, Preliminary results from simulations of temperature oscillations in stirling engine regenerator matrices, Energy 31 (2006), no. 10-11, 1371-1383.

80. J. Imura, N. Iwata, H. Yamamoto, Y. Ohashi, H. Nomachi, N. Okumura, S. Nagaya, T. Tamada and N. Hirano, Optimization of regenerator in high capacity stirling type pulse tube cryocooler, Physica C: Superconductivity 468 (2008), no. 15-20, 2178-2180.

81. T. R. Knowles, Composite matrix regenerator for stirling engines, (1997).

82. H. Sun, S. Bu and Y. Luan, A high-precision method for calculating the pressure drop across wire mesh filters, Chemical Engineering Science 127 (2015), 143-150.

83. P.-H. Chen, Z.-C. Chang and B.-J. Huang, Effect of oversize in wire-screen matrix to the matrixholding tube on regenerator thermal performance, Cryogenics 36 (1996), no. 5, 365-372.

84. P. De Boer, Optimal regenerator performance in stirling engines, International Journal of Energy Research 33 (2009), no. 9, 813-832.

85. K. Nam and S. Jeong, Investigation of oscillating flow friction factor for cryocooler regenerator considering cryogenic temperature effect, Cryogenics 45 (2005), no. 12, 733-738.

86. M. Mahmoodi and M. Ziabasharhagh, Numerical solution of beta-type stirling engine by optimizing heat regenerator for increasing output power and efficiency, Basic Appl. Sci. Res 2 (2012), no. 2. 
87. U. Bin-Nun and D. Manitakos, Low cost and high performance screen laminate regenerator matrix, Cryogenics 44 (2004), no. 6-8, 439-444.

88. W. Wu, J. Liu, W. Li and W. Hsieh, Measurement and correlation of hydraulic resistance of flow through woven metal screens, International Journal of Heat and Mass Transfer 48 (2005), no. $14,3008-3017$.

89. R. S. Wakeland and R. M. Keolian, Measurements of resistance of individual square-mesh screens to oscillating flow at low and intermediate reynolds numbers, Journal of Fluids Engineering 125 (2003), no. 5, 851-862.

90. G. Xiao, H. Peng, H. Fan, U. Sultan and M. Ni, Characteristics of steady and oscillating flows through regenerator, International Journal of Heat and Mass Transfer 108 (2017), 309-321.

91. S. H. Hsu and T. Biwa, Modeling of a stacked-screen regenerator in an oscillatory flow, Japanese Journal of Applied Physics 56 (2017), no. 1, 017301.

92. I. Kurtbas and N. Celik, Experimental investigation of forced and mixed convection heat transfer in a foam-filled horizontal rectangular channel, International Journal of Heat and Mass Transfer 52 (2009), no. 5-6, 1313-1325.

93. Q. Shen and Y. Ju, A new correlation of friction factor for oscillating flow regenerator operating at high frequencies, AIP Conference Proceedings, AIP, 2008, pp. 267-274.

94. Y. Kato and K. Baba, Empirical estimation of regenerator efficiency for a low temperature differential stirling engine, Renewable energy 62 (2014), 285-292.

95. G. T. Lee, B. H. Kang and J.-H. Lee, Effectiveness enhancement of a thermal regenerator in an oscillating flow, Applied thermal engineering 18 (1998), no. 8, 653-660.

96. H. Takizawa, N. Kagawa, A. Matsuguchi and S. Tsuruno, Performance of new matrix for stirling engine regenerator, IECEC'02. 2002 37th Intersociety Energy Conversion Engineering Conference, 2002., IEEE, 2002, pp. 491-496.

97. S. Costa, I. Barreno, M. Tutar, J.-A. Esnaola and H. Barrutia, The thermal non-equilibrium porous media modelling for cfd study of woven wire matrix of a stirling regenerator, Energy conversion and management 89 (2015), 473-483.

98. S. Costa, H. Barrutia, J. A. Esnaola and M. Tutar, Numerical study of the heat transfer in wound woven wire matrix of a stirling regenerator, Energy conversion and management 79 (2014), 255264. 
99. ---, Numerical study of the pressure drop phenomena in wound woven wire matrix of a stirling regenerator, Energy Conversion and Management 67 (2013), 57-65.

100. H. Fu, K. Leong, X. Huang and C. Liu, An experimental study of heat transfer of a porous channel subjected to oscillating flow, Journal of heat transfer 123 (2001), no. 1, 162-170.

101. A. S. Abduljalil, Z. Yu and A. J. Jaworski, Selection and experimental evaluation of low-cost porous materials for regenerator applications in thermoacoustic engines, Materials \& Design 32 (2011), no. 1, 217-228.

102. W. Peng, M. Xu, X. Huai, Z. Liu and X. Lü, Performance evaluation of oscillating flow regenerators filled with particles, wire screens and high porosity open-cell foams, Applied Thermal Engineering 112 (2017), 1612-1625.

103. Y. Peng, G. Xu, X. Luo, H. Li and Y. Liu, Experimental study on the influence of wire diameter on the internal flow behaviour of woven metal screens, IOP Conference Series: Materials Science and Engineering, IOP Publishing, 2017, p. 012003.

104. M. Arab and M. Majidi, "Experimental and numerical study of porosity gradient in a stirling engine regenerator," SAE Technical Paper2017.

105. E. Rogdakis, G. Antonakos and I. P. Koronaki, Influence of a regenerator on stirling engine performance, Journal of Energy Engineering 142 (2016), no. 2, E4016002.

106. Z. Li, Y. Haramura, Y. Kato and D. Tang, Analysis of a high performance model stirling engine with compact porous-sheets heat exchangers, Energy 64 (2014), 31-43.

107. Z. Li, Y. Haramura, D. Tang and C. Guo, Analysis on the heat transfer characteristics of a micro-channel type porous-sheets stirling regenerator, International Journal of Thermal Sciences 94 (2015), 37-49.

108. K. K. Nielsen, K. Engelbrecht, D. Christensen, J. B. Jensen, A. Smith and C. Bahl, Degradation of the performance of microchannel heat exchangers due to flow maldistribution, Applied Thermal Engineering 40 (2012), 236-247.

109. K. Nam and S. Jeong, Development of parallel wire regenerator for cryocoolers, Cryogenics 46 (2006), no. 4, 278-287.

110. S. Alfarawi, R. Al-Dadah and S. Mahmoud, Potentiality of new miniature-channels stirling regenerator, Energy conversion and management 133 (2017), 264-274.

111. M. S. KAHLERAS, G. LAYES, F. LANZETTA and P. NIKA, Friction factor and regenerator effectiveness in an oscillating gas flow. 
112. A. M. Mancisidor, E. Gil, F. Garciandia, M. San Sebastian, O. Lizaso and M. Escubi, Stirling engine regenerator based on lattice structures manufactured by selective laser melting, Procedia CIRP 74 (2018), 72-75.

113. M. Ni, H. Peng, U. Sultan, K. Luo and G. Xiao, A quantitative method to describe the flow characteristics of an oscillating flow including porous media, International Journal of Heat and Mass Transfer 119 (2018), 860-866.

114. S. Baek, C. Lee and S. Jeong, Effect of flow maldistribution and axial conduction on compact microchannel heat exchanger, Cryogenics 60 (2014), 49-61.

115. S. Qiu and J. Augenblick, Stirling convertor heater head redesign to increase durability, 1st International Energy Conversion Engineering Conference (IECEC)2003, p. 6041.

116. Z. Yu, X. Mao and A. J. Jaworski, Experimental study of heat transfer in oscillatory gas flow inside a parallel-plate channel with imposed axial temperature gradient, International Journal of Heat and Mass Transfer 77 (2014), 1023-1032.

117. M. IGUCHI, M. OHMI and K. MAEGAWA, Analysis of free oscillating flow in a u-shaped tube, Bulletin of JSME 25 (1982), no. 207, 1398-1405.

118. M. Mitchell and D. Fabris, "Improved flow patterns in etched foil regenerator," Cryocoolers 12, Springer2003, pp. 499-505.

119. M. Mitchell, D. Gedeon, G. Wood and M. Ibrahim, Testing program for etched foil regenerator material, 3rd International Energy Conversion Engineering Conference2005, p. 5515.

120. M. P. Mitchell, "Foil structures for regenerators," Google Patents2005.

121. M. Ibrahim, D. Danila, T. Simon, S. Mantell, L. Sun, D. Gadeon, S. Qiu, G. Wood, K. Kelly and J. McLean, A microfabricated segmented-involute-foil regenerator for enhancing reliability and performance of stirling engines, (2007).

122. M. Ibrahim, R. Tew, D. Gedeon, G. Wood and J. McLean, Microfabrication of a segmentedinvolute-foil regenerator, testing in a sunpower stirling convertor, and supporting modeling and analysis, 6th International Energy Conversion Engineering Conference (IECEC)2008, p. 5716.

123. D. Gedeon and J. G. Wood, Oscillating-flow regenerator test rig: Woven screen and metal felt results, (1992).

124. J. G. Wood, Oscillating-flow loss test results in rectangular heat exchanger passages, (1991).

125. S. Qiu and J. E. Augenblick, Thermal and structural analysis of micro-fabricated involute regenerators, AIP Conference Proceedings, AIP, 2005, pp. 394-401. 
126. S. Choi, K. Nam and S. Jeong, Investigation on the pressure drop characteristics of cryocooler regenerators under oscillating flow and pulsating pressure conditions, Cryogenics 44 (2004), no. 3, 203-210.

127. K. Leong and L. Jin, Heat transfer of oscillating and steady flows in a channel filled with porous media, International communications in heat and mass transfer 31 (2004), no. 1, 63-72.

128. R. Li, S. Qiu and Y. Gao, Development of an advanced free piston stirling engine of space power system, AIAA Propulsion and Energy 2019 Forum2019, p. 4064.

129. Y. Cengel, Heat and mass transfer: Fundamentals and applications, McGraw-Hill Higher Education2014.

130. efunda, "Thermoelectric effect."

131. B. H. Engineering, "What is a thermocouple \& how does it work? Principle of working of thermocouple."

132. National Instruments, "Measuring position and displacement with lvdts."

133. Thermo Sensor Corporation, "Application and technical data."

134. isobudgets, "Introduction to statistic for uncertainty analysis."

135. T. Zhao and P. Cheng, The friction coefficient of a fully developed laminar reciprocating flow in a circular pipe, International Journal of Heat and Fluid Flow 17 (1996), no. 2, 167-172.

136. D. David, Determination of specific heat and heat of fusion by differential thermal analysis. Study of theory and operating parameters, Analytical Chemistry 36 (1964), no. 11, 2162-2166.

137. K. Shannon and B. Butler, A review of error associated with thermocouple temperature measurement in fire environments, Proceedings of the 2nd International Wildland Fire Ecology and Fire Management Congress2003, pp. 16-20.

138. R. Moffat, Designing thermocouples for response rate, ASME 1957 Gas Turbine Power Conference, American Society of Mechanical Engineers, 1957, pp. V001T001A008V001T001A008.

139. Ansys theory guide, "Ansys fluent theory guide."

140. S.-C. Costa Pereira, I. Barreno, M. Tutar and J. Esnaola, Figure of merit analysis of a stirling engine regenerator matrix through experimental studies 2014.

141. I. Rühlich and H. Quack, New regenerator design for cryocoolers, 17th International Cryogenic Engineering Conference, Bournemouth, England, Citeseer, 1998, pp. 291-294. 
142. R. Radebaugh and B. Louie, A simple, first step to the optimization of regenerator geometry, (1985).

143. Y. Gao, S. Qiu and R. Li, Design and development of a heater head for free-piston stirling engine, AIAA Propulsion and Energy 2019 Forum2019, p. 3975.

144. stratays, "Direct metal laser sintering (dmls)."

145. RAPID PROTOTYPING SERVICES, "Dmls-direct metal laser sintering." 


\section{Appendix A: How to setup test rig}

The manufactured regenerator test rig is not simple to set up. In this appendix, the way to set up the test rig is explained in detail. Since the linear motor generates noisy vibration, the damper should be placed between the test rig and the floor of the lab. For the first try, only one damper was placed for each leg as shown in Fig. A-1. The legs were mounted on the floor without any dampers. However, the dampers could not cancel the vibration and the whole entire room was vibrating as the motor runs. Thus, an aluminum plate and three dampers for each corner of the plate were added as shown in Fig. A-1. Also, one damper was added between the plate and the legs. The dampers between the plate and floor are fixed on the anchor bolt on the floor. After adding dampers, the vibration of the room got much smaller. So when someone tries to use this test rig, the dampers should be installed properly to prevent the huge vibration.

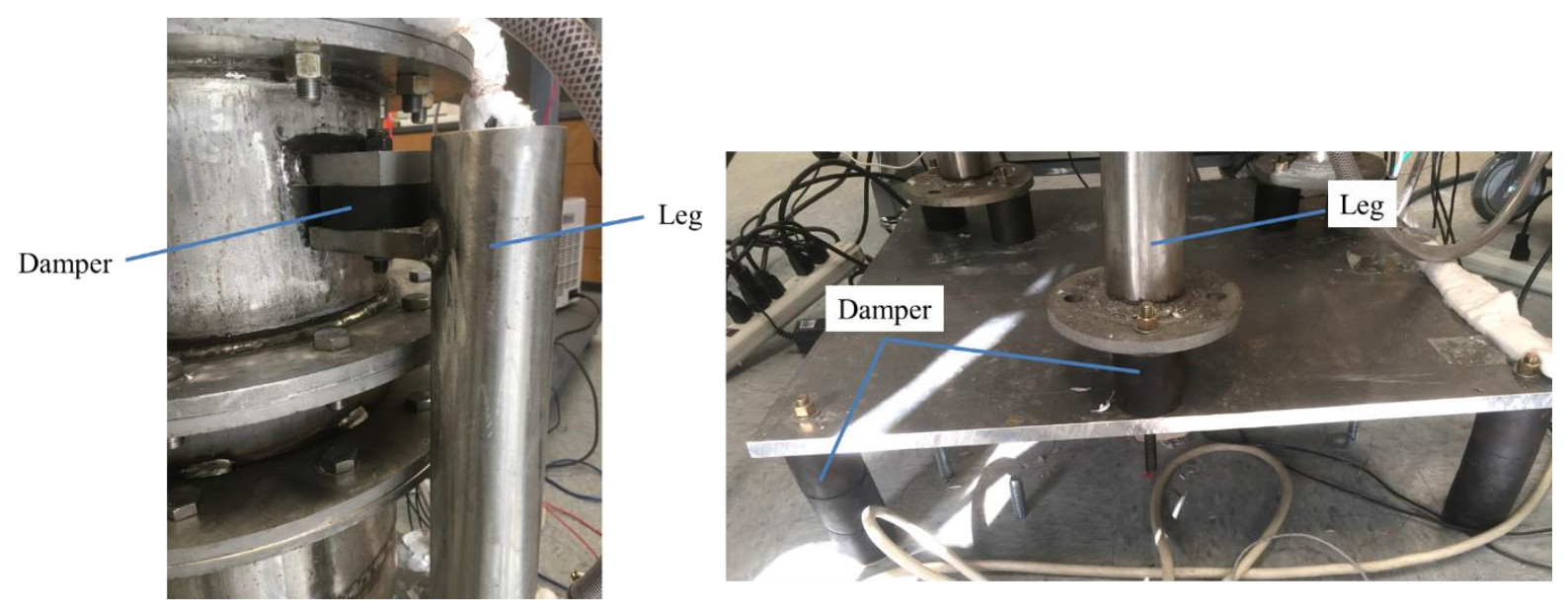

Fig. A-1 Dampers of the test rig

In original design, there are only one connection at the linear motor pressure vessel. Fig. A-2 shows the difference of the original design and actual design. A large pipe was added to the test rig to make space at the bottom of the linear motor for the linear displacement transducer. This was simply a design error. But without the pipe, the linear displacement transducer cannot be installed. The O-rings use at the pressure vessel of the linear alternator can be a low temperature O-ring since the working fluid temperature is below $60^{\circ} \mathrm{C}$. The linear motor and the linear displacement transducers are wired to feedthroughs. 

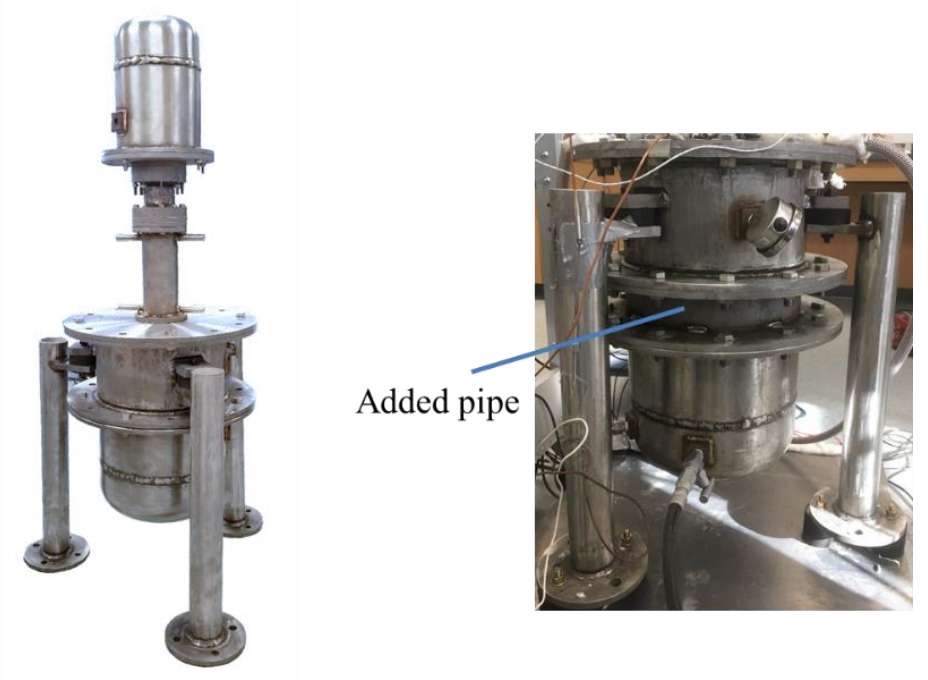

Fig. A-2 Additional pipe for the test rig extension

The cooler and the diffuser mesh are easily installed with the low temperature O-ring. It might have a small leakage from the water jacket, so place smaller O-ring as well to prevent the water goes into the linear motor. On top of the cooler, two O-rings should be installed as the same reason. To prevent the water leakage, also it can be covered by the epoxy. But you have to apply it again every once and while. Ideally, the water jacket should be used EB welding.

O-ring: Small (size 3*54 material Buna N), Large (size 151 material Buna N) from McMaster

The test section should be selected based on the test type. For the flow loss test, two pressure transducers are installed with the special nuts to fit them on the test rig. To avoid the leakage from the transducers, a small O-ring are installed in the transducer prior to the transducer installation. For the heat transfer test, two thermocouple are installed. To get more accurate data, the number of the thermocouples can be improved up to 6 since there are 3 Swagelok on each flanges of the test section. The leakage happen through the Swagelok often, so it should be tightened before the experiment. At the top of the test section, it can be expected to be much hotter than the bottom of the test section due to the short distance to the heater. Thus, the high temperature resistant rubber O-ring must be installed. 
O-ring for transducer: Size $1 * 4$, material Buna-N from McMaster

O-ring for high temperature: Size 151, material Silicon FDA (up to $450^{\circ} \mathrm{F}$ ) from McMaster

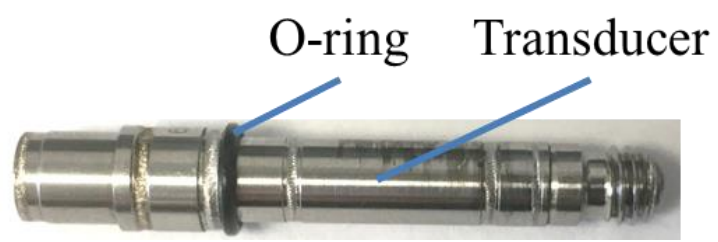

Fig. A-3 Pressure transducer with the O-ring

The heater is composed of three parts which are the pressure vessel, two concentric cylinders, and two band heaters. The band heaters are mounted on the concentric cylinder and fixed by the bolts. The wire from the heater is connected to the feedthrough welded on the pressure vessel. Due to the high temperature environment, the electrical connection cannot use the soldering. Therefore, the electrical crimps were used without the plastic. The O-ring for the pressure vessel is for high temperature O-ring since the temperature inside the pressure vessel is relatively high. The electric supply for the band heater is simply from a variable ac transformer.

O-ring: Size 260, material silicon FDA

For the heat transfer test, the heater pressure vessel, test section, and cooler need to be covered by the thermal insulation material to prevent the heat loss to the environment, and to avoid the measurement errors. 


\section{Appendix B: Data recording program details}

The data recording program is not complicated. The data synchronization is explained in 6-2. Thus, in this appendix, LabVIEW time is explained. The first problem I conflicted to make a data monitoring program is the time of LabVIEW. If you make a simple program, the time showing in the front panel is not correct (time unit is sec.). This is because LabVIEW counts time from 1904. So the value on the front panel is extremely large as the unit is in sec. So what you need to do is define 0 when you start your program. Fig. B-1 shows the program with and without time correction and the graph. By using Current Time VI, the time that the while loop starts are measured as initial time (About $3.6^{*} 10^{9} \mathrm{sec}$ ). Then the corrected time is calculated by subtracting from the time signal to the initial time. As shown in Fig. B-2, the time represented in $\mathrm{x}$-axis are different.

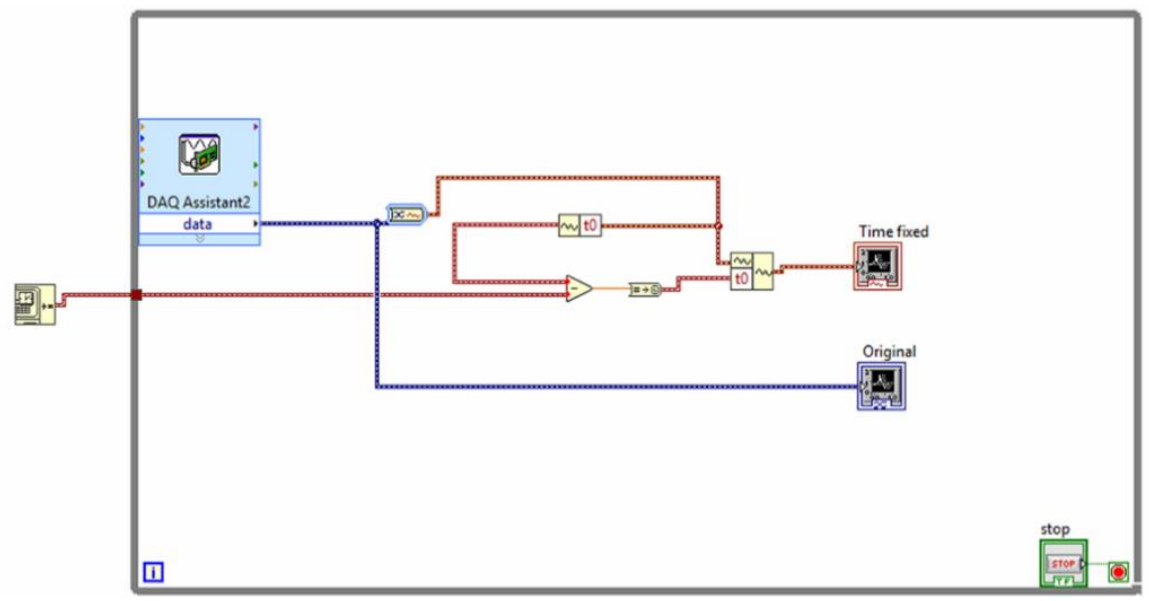

Fig. B-1 Time correction program

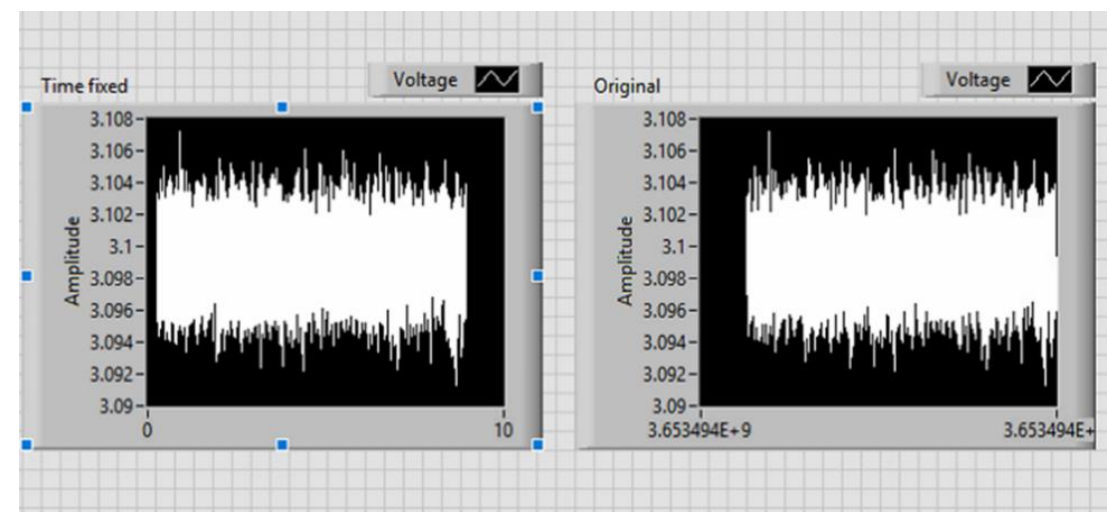

Fig. B-2 Comparison of time difference 


\section{Appendix C: Data processing program details}

\section{Flow loss}

1. Load the recorded data by using Read From Measurement File VI.

2. Find the crossing position using Crossing VI

3. Count number of data points in each cycle by utilizing Crossing VI. If some of the cycles do not have corresponding number of data from the other cycles, those cycles will be skipped for the ensemble average process.

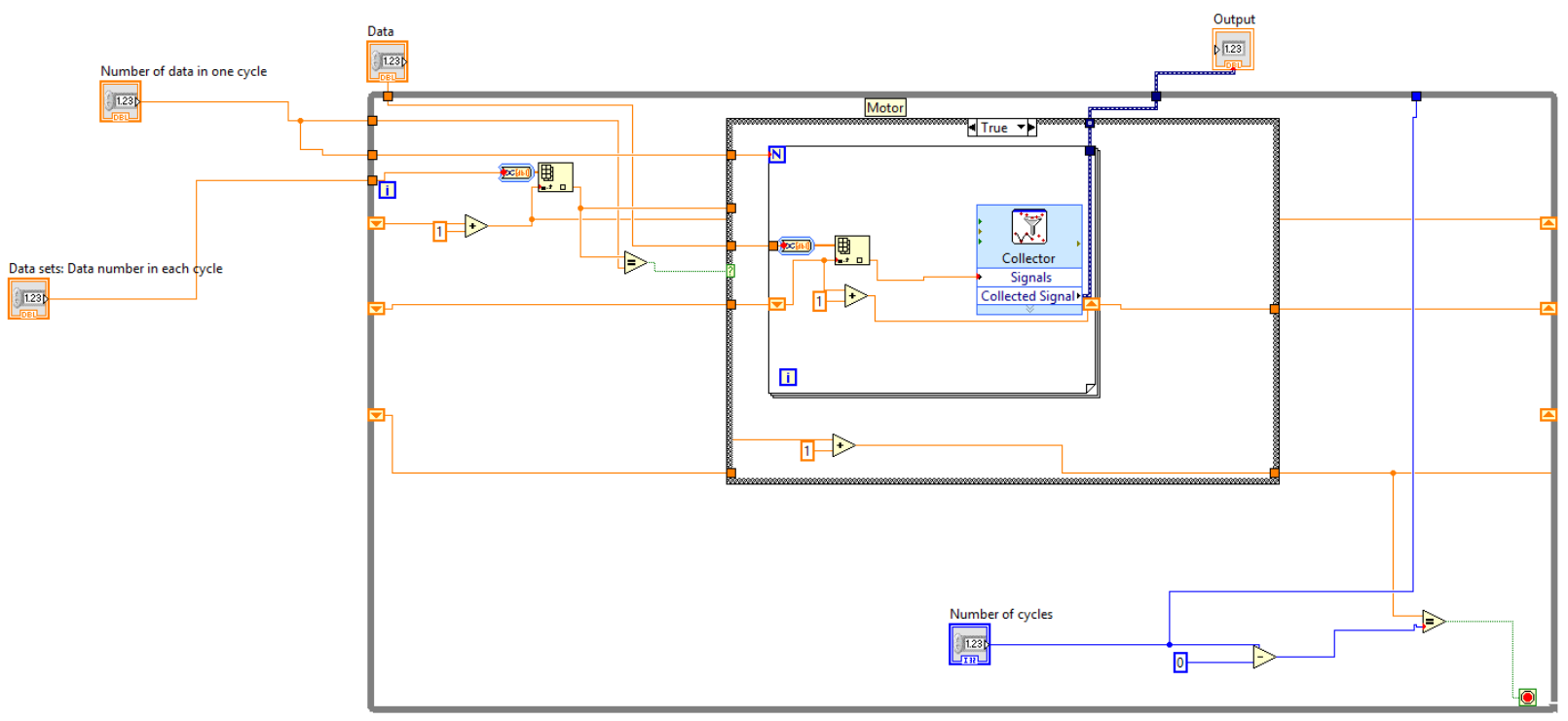

Fig. C-1 Data skip program

4. Ensemble averaging. In the for loop of the program, the average value of the first data in the cycle is calculated. Because of the while loop, the averaging will be continued until the last data point of the cycle is averaged. The ensemble-averaged data should be plotted based on the crank angle of the piston. 


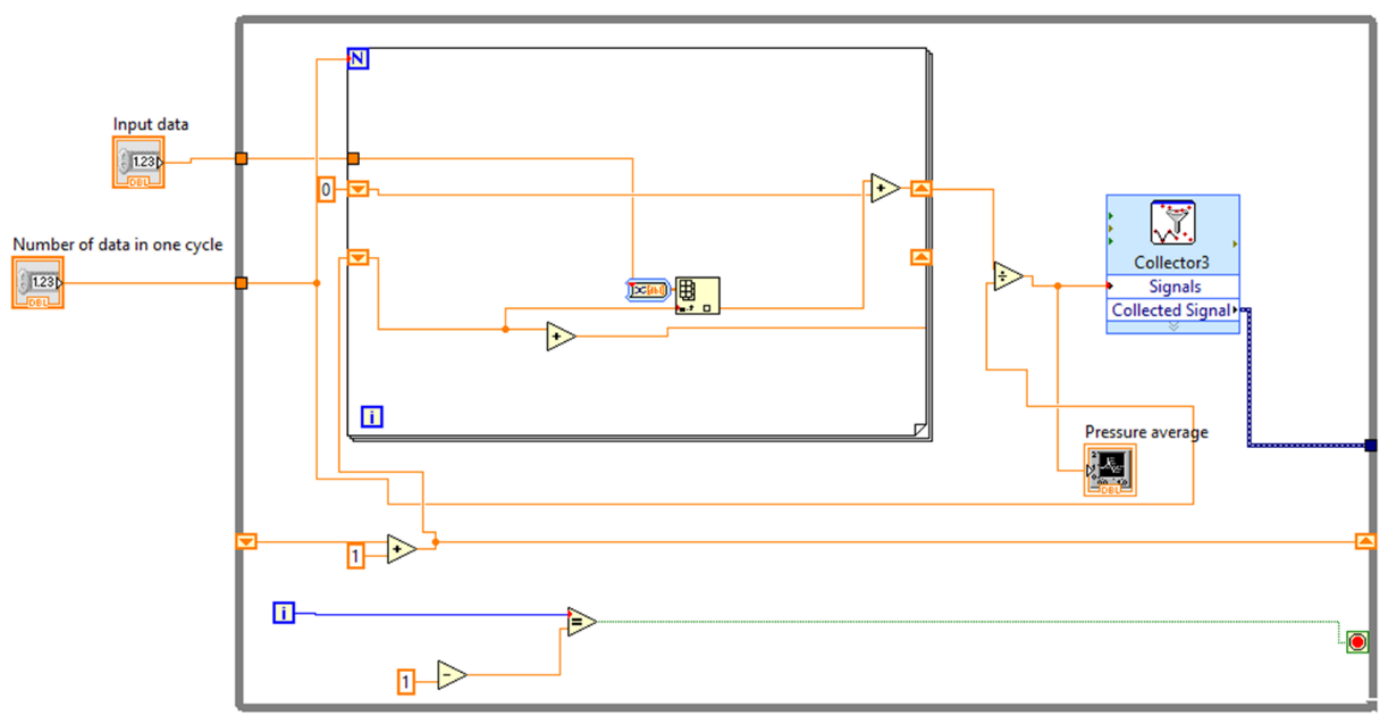

Fig. C-2 Ensemble average program for the flow loss test

5. The ensemble average data is converted to the friction factor and the Reynolds number.

\section{Heat transfer}

1. Load the recorded data by using Read From Measurement File VI.

2. Based on the piston position data, the crank angle should be derived. Note that the crank angle is derived by equation ( $\mathrm{C}-1)$. The $\mathrm{A}$ in the equation is depending on the piston position as explained below.

$$
\text { Crank Angle }=\left|\sin ^{-1}\left(\frac{\text { Piston position }}{\text { Piston Amplitude }}\right) \times \frac{180}{\pi}+A\right|
$$

- When the piston position $\mathrm{X}$ is positive and $\mathrm{X} 2-\mathrm{X} 1>0$, then $\mathrm{A}$ is 0 .

- When the piston position $\mathrm{X}$ is positive and $\mathrm{X} 2-\mathrm{X} 1<0$, then $\mathrm{A}$ is -180 .

- When the piston position $\mathrm{X}$ is negative and $\mathrm{X} 2-\mathrm{X} 1>0$, then $\mathrm{A}$ is -360 .

- When the piston position $\mathrm{X}$ is negative and $\mathrm{X} 2-\mathrm{X} 1<0$, then $\mathrm{A}$ is 180 . 


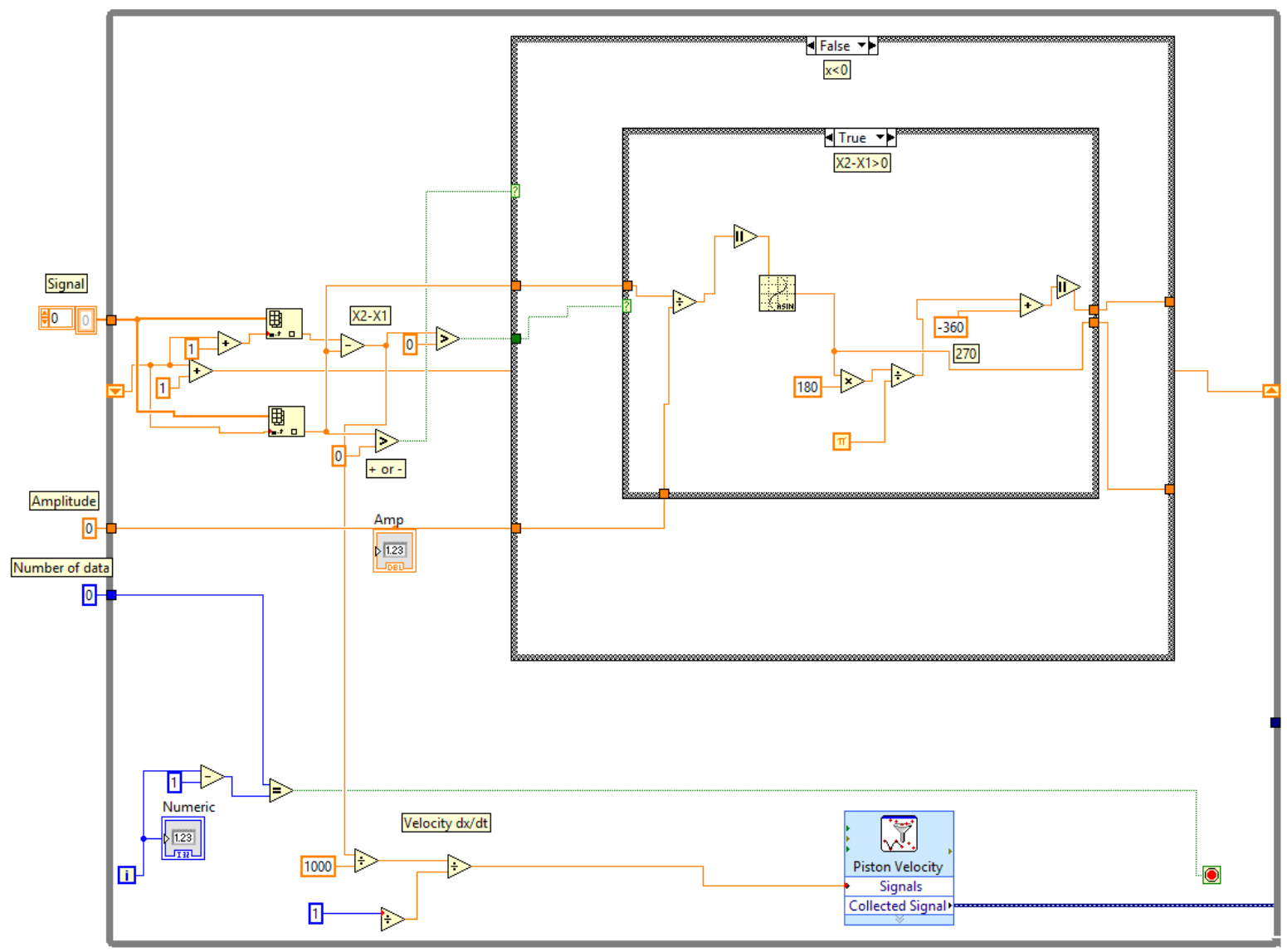

Fig. C-3 Program for the crank angle calculation from the piston position

3. Using the crank angle and the corresponding temperature data, make a one cycle graph. Then based on the plot, the curve fitting VI is used to do the curve fit which is treated as the ensemble average.

4. From the curve fit equation, the Nusselt number and the Reynolds number should be derived. 


\section{Appendix D: David Gedeon's method for the Nusselt number}

The temperature difference measured in the regenerator test rig is converted to time-average total heat flux by equation (D-1).

$$
q_{t}=\dot{m} c_{p}\left(\overline{T_{h}}-\overline{T_{c}}\right) / A
$$

It is composed of the enthalpy transportation $\mathrm{q}_{\mathrm{h}}$ and the axial conduction $\mathrm{q}_{\mathrm{k}}$.

$$
\begin{aligned}
& q_{t}=q_{h}+q_{k} \\
& q_{h}=-k \frac{\partial T}{\partial x}\left\langle\frac{P e^{2}}{4 N_{u}}\right\rangle \\
& q_{k}=-k \frac{\partial T}{\partial x}\left\langle N_{k}\right\rangle
\end{aligned}
$$

The operator $<>$ indicates time average. It is assumed that the temperature gradient in axial direction is roughly constant. The Nusselt number $\mathrm{N}_{\mathrm{u}}$ and the axial conductivity enhancement ratio $\mathrm{N}_{\mathrm{k}}$ are represented by equation (D-5)(D-6) [74]

$$
\begin{aligned}
& N_{u}=\left(1+a_{1} P e^{a_{2}}\right) \beta^{a_{3}} \\
& N_{k}=a_{4} P e^{a_{2}} \beta^{a_{5}}
\end{aligned}
$$

Where Pe is Reynolds number times Prandtl number. a1 to a5 are constant values. By using equation (D3) (D-6), qt is expressed by equation (D-7).

$$
q_{t}=-k \frac{\partial T}{\partial x}\left(\left\langle\frac{P e^{2}}{4\left(1+a_{1} P e^{a_{2}}\right) \beta^{a_{3}}}\right\rangle+\left\langle a_{4} P e^{a_{2}} \beta^{a_{5}}\right\rangle\right)
$$

Starting with initial guesses for a1 to a5, and use least square method to calculate a1 to a5 since $\mathrm{q}_{\mathrm{t}}$ and Pe are known. 


\section{Appendix E: Temperature measurement using a voltage measurement module and a thermocouple}

Because NI9205 is the voltage measurement device, the voltage needs to be converted to the temperature by using the converting equation with some constants. The measured voltage from the thermocouple will be converted to temperature using equation (D-8). The coefficients are depending on the type of thermocouple. The coefficients showing below are for K-type thermocouple.

$$
\mathrm{T}=C_{0}+C_{1} * V+C_{2} * V^{2}+C_{3} * V^{3}+C_{4} * V^{4}+C_{5} * V^{5}+C_{6} * V^{6}+C_{7} * V^{7}+C_{8} * V^{8}+C_{9} * V^{9}
$$

$$
\begin{array}{rlrl}
C_{0} & =0 & & C_{5}=-1.228034 * 10^{-2} \\
C_{1} & =2.508355 * 10^{-1} & C_{6} & =9.804036 * 10^{-4} \\
C_{2} & =7.860106 * 10^{-2} & C_{7}=-4.413030 * 10^{-5} \\
C_{3} & =-2.503131 * 10^{-1} & C_{8}=1.057734 * 10^{-6} \\
C_{4} & =8.315270 * 10^{-2} & C_{9}=-1.052755 * 10^{-8}
\end{array}
$$

Also, a special configuration is required to measure the voltage correctly. 6 thermocouples are used to measure the temperature and 1 thermistor is used to measure the reference temperature since NI9205 does not have the function for measuring the reference temperature by itself. 


\section{Appendix F: Magnetic field and thermocouples}

As it was mentioned in 4-7, the thermocouple can be affected by magnetic field. Since the driving system of the test rig is the linear motor, it generates the magnetic field and it does not allow me to use bare wire thermocouple. To prevent the magnetic field, three attempts were conducted.

1. According to the conversation with a company that sells signal conditioners for the thermocouples, the signal conditioner can decrease the magnetic field effect to the thermocouple. Thus, a signal conditioner which converts the thermocouple signal to 4-20 mA scale signal. The signal conditioner works great and it can actually measure the temperature. However, the signal conditioner only converts 4 data per second. This is not suitable for the heat transfer test under oscillating flow conditions because the instantaneous temperature measurement is required. For this problem, one of the solutions is to decrease the linear motor frequency. But the minimum frequency of the linear motor is $15 \mathrm{~Hz}$. So the sampling frequency through the signal conditioner needs to be improved which could not find in cheap price.

2. The bare wire thermocouple is installed in the shrink tube and the shrink tube is covered by the aluminum tape. Only the thermocouple bead is sticking out from the shrink tube. It was expected that the aluminum tape protects the thermocouple from the magnetic field. As a result, these attempts failed. To prevent the magnetic field, the wire bead should be shielded.

3. For the last attempts, a sheathed thermocouple is utilized to measure the instantaneous temperature of the oscillating flow as in 4-7. The instantaneous temperature is successfully measured. 


\section{Appendix G: Pressure transducer installation hall}

To install the pressure transducer directly to the test section flange, a special hall is required. It is explained in Kistler pressure transducer instruction manual. The link to the instruction manual is not available online, so the part of the manual is shown below.

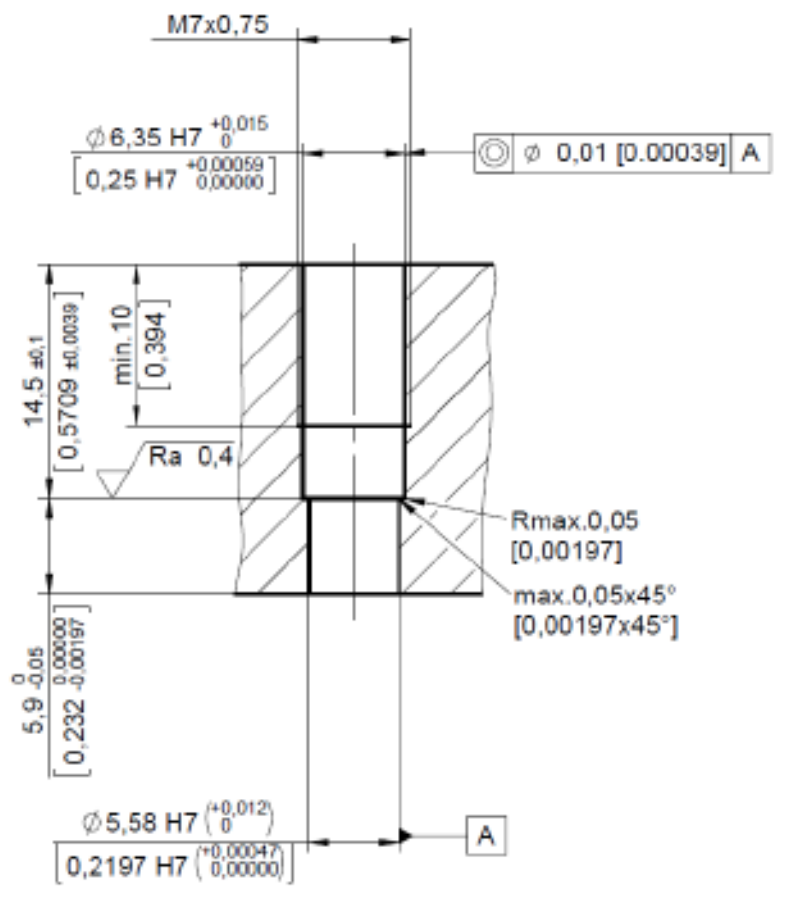

Fig. G-1 The pressure transducer hole dimension sketch

The manufacturing processes for the hall are as follows.

a) Centering, using $2 / 6 \mathrm{~mm}(0.079 / 0.236 \mathrm{inch})$ dia. center drill

$\rightarrow$ Recommended cutting velocity, when using Armco 17-4 PH together with Blasomill 10 (low viscosity cutting oil), is $25 \mathrm{~m} / \mathrm{min}$ ( $82 \mathrm{ft} . / \mathrm{min}$ )

b) Drill through, using $5.5 \mathrm{~mm}(0.217$ inch $)$ dia. drill

$\rightarrow$ Recommended cutting velocity, when using Armco 17-4 PH, is $25 \mathrm{~m} / \mathrm{min}$ ( $82 \mathrm{ft} / \mathrm{min}$ )

c) Drill, using a $6.30 \mathrm{~mm}(0.248 \mathrm{inch})$ dia. drill, so that there's a distance of $0.1 \mathrm{~mm}(0.004 \mathrm{inch})$ to the corner marked in the drawing with "max. $0.05 \times 45^{\circ}$ ".

$\rightarrow$ Recommended cutting velocity, when using Armco 17-4 PH, is $25 \mathrm{~m} / \mathrm{min}(82 \mathrm{ft} / \mathrm{min})$ 
d) Counter-sink, $90^{\circ}$ included angle to $7.1 \mathrm{~mm}(0.28 \mathrm{inch})$ dia., at top of $6.35 \mathrm{~mm}(0.25 \mathrm{inch})$ bore.

$\rightarrow$ Recommended cutting velocity, when using Armco 17-4 PH, is $10 \mathrm{~m} / \mathrm{min}(33 \mathrm{ft} / \mathrm{min})$

e) Ream through, using $5.58 \mathrm{H} 7 \mathrm{~mm}(0.22+0.00047 /-0$ inch $)$ dia. reamer. For this task, a Kistler type 1331B1 reamer can be used.

$\rightarrow$ Recommended cutting velocity, when using Armco 17-4 PH, is $10 \mathrm{~m} / \mathrm{min}(33 \mathrm{ft} / \mathrm{min})$

f) Ream, using a $6.35 \mathrm{H} 7 \mathrm{~mm}(0.25+0.00059 /-0 \mathrm{inch})$ dia. reamer, so that there's a distance of $0.2 \mathrm{~mm}$ ( $0.008 \mathrm{inch})$ to the corner marked in the drawing with "max. $0.05 \times 45^{\circ}$ ". For this task, a Kistler type 1331B2 reamer can be used.

$\rightarrow$ Recommended cutting velocity, when using Armco $17-4 \mathrm{PH}$, is $10 \mathrm{~m} / \mathrm{min}(33 \mathrm{ft} / \mathrm{min})$

g) Ream, using Type 1331B3, to depth of the sealing surface of $15 \mathrm{~mm}$ (0.591inch). The step of this customized drill forms seal-seating surface, which must be flat, contain no radial chatter marks, and have $\mathrm{Ra} 0.4$ or better finish.

$\rightarrow$ Recommended cutting velocity, when using Armco 17-4 PH, is 60 m/min (197 ft/min)

h) Tap M7x0.75 thread forming min. $8.5 \mathrm{~mm}$ (0.335 inch) of perfect threads. For this task, a Kistler Type 1351 tap can be used. Don not touch $6.35 \mathrm{~mm}(0.25 \mathrm{inch})$ sealing surface.

$\rightarrow$ Recommended spindle speed, when using Armco 17-4 PH, is 200 rotations/min

i) Ream threads, bore and sealing surface for burrs an touch-up if necessary

Note that all the processes and the picture are cited from Kistler instruction manual. 


\section{Appendix H: Woven screen regenerator manufacturing process}

1. Cut the screens to oversize conditions $(5 \mathrm{~cm} \times 5 \mathrm{~cm}$ for my case $)$

2. Stack and place between two stainless steel plates. The plates must be coated with STOPIT ( set same stuff used with the brazed parts) to prevent sintering the screens to the plates

3. Clamp the stacked woven screen between the plates.

Use a hydraulic press to clamp the screens if possible and bolts to hold the plates together during the sintering process. Holes on the 4 corners of the SS plats for the bolts.

4. Sinter at $1920 \mathrm{~F}$ for about 150 minutes

1 4 were advised by Mr. Ron Olan from ITC.

5. Wire EDM to cut the sintered mesh block into desired dimension.

It was also advised by Mr. Olan and could be the future work for the woven screen regenerator research.

It would be interesting if there is a difference between

1. A stack of screen where the screen wires running in the same general direction between each screen.

2. A stack where every other screen is rotated 45 degrees. 


\section{Appendix I: Water circulation system}

The water circulation system details are explained in this appendix. The water reservoir size is $16 * 10 * 9$ inch 3 with the lid. From the top opening, the water coming back from cooler and the feedback are poured. Fig. I-1 shows the hose connection part in the water reservoir. The bulkhead tank adaptor is used to make a water outlet. To prevent water leakage, the silicon sealant was utilized to seal the gap. The barbed hose fitting is installed in the adaptor with the Teflon tape to avoid the leakage of the water. Also, the hose is fixed by the metal clamp to prevent the unexpected water leakage and detaching the hose.

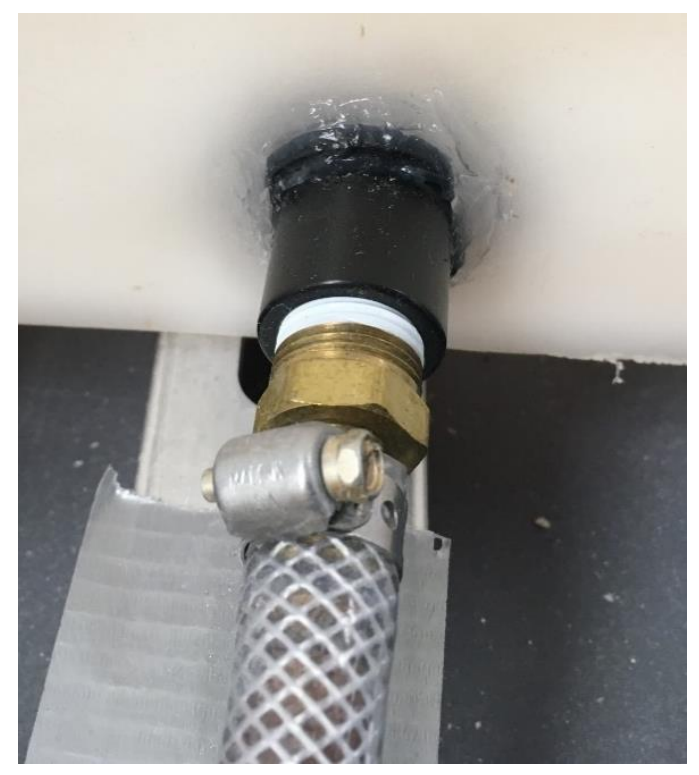

Fig. I-1 Connection on the water tank

A T-shape hose connector is used for the water feedback connection as shown in Fig. I-2. The hoses are also fixed by the metal clamps.

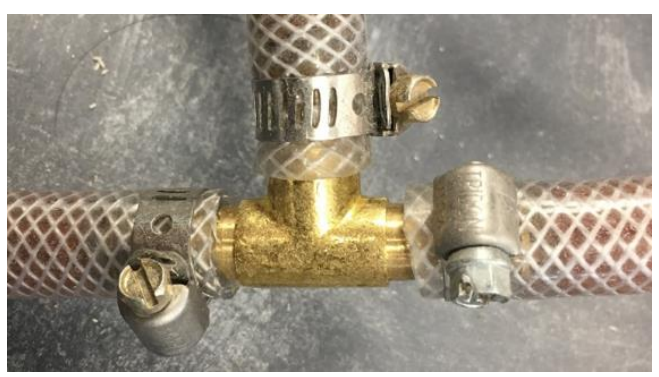

Fig. I-2 T-shape connector 
Also, the barbed hose fitting connector is used to connect valves and the hose which is fixed by the metal clamps as shown in Fig. I-3.

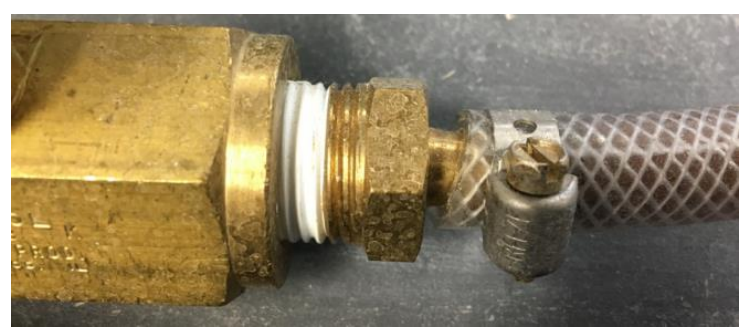

Fig. I-3 Connector at the valve

The cooler inlet and outlet pipes are slightly larger than the barbed hose fitting connector. Therefore, the hose size from the water tank side and cooler are different. To connect two different size hose, a connector for different diameter hose was used as shown in Fig. I-4. The left side hose in Fig. I-4 is from the cooler side and it is slightly bigger than another hose on the right side of Fig. I-4.

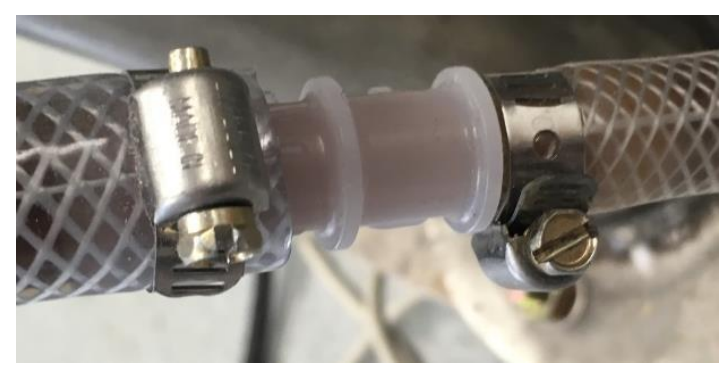

Fig. I-4 Connector for different hose size 


\section{Appendix J: Direct metal laser sintering}

Direct Metal Laser Sintering (DMLS) is one of the methods of metal 3-D printing. It is used to form a complicated geometry that is not able to make by the other methods. In our study, DMLS was utilized to manufacture the robust foil regenerator and the heater head of 1-kW output Stirling engine built in our lab. Fig. J-1 shows the picture of the heater head [143].

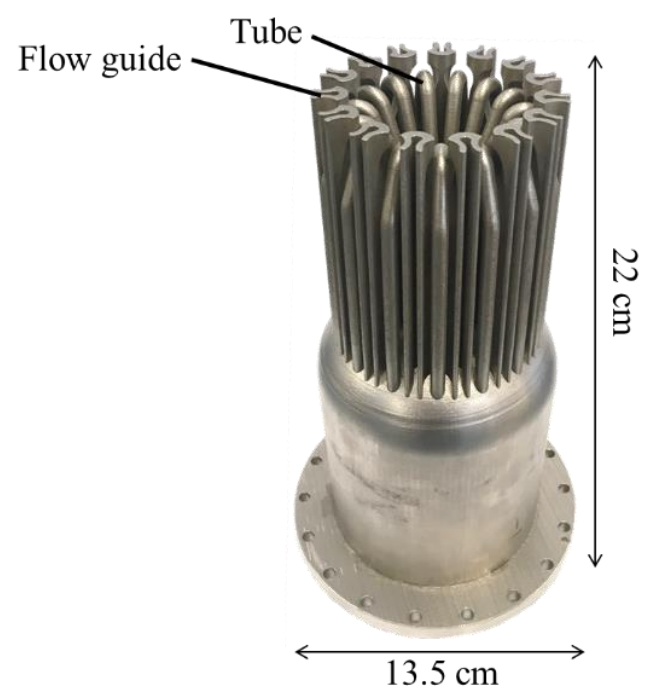

Fig. J-1 Heater head made by DMSL

The material strength by the DMLS is definitely weaker than the original material. However, the strength kept enough higher and denser than casted metal. DMLS uses very accurate laser and micro-weld metal particles which enable them to form a complex geometry based on the CAD data [144]. The tolerance depends on the material, for Inconel 718 it is $\pm 0.0508 \mathrm{~mm}$. The recommended minimum wall thickness is also different from materials. For Inconel 718, the minimum wall thickness is $0.279 \mathrm{~mm}$ to $0.0381 \mathrm{~mm}$. The problem of DMLS is the surface roughness which is 20 to $50 \mu \mathrm{m}$ for Inconel 718 [145]. Thus, DMLS is not suitable manufacturing method for components which is required to have smooth surface. 


\section{Appendix K: Test rig parts details}

In this appendix, all the drawing sheet of the test rig parts are attached. Fig. K-1 shows the name of each part of the test rig.

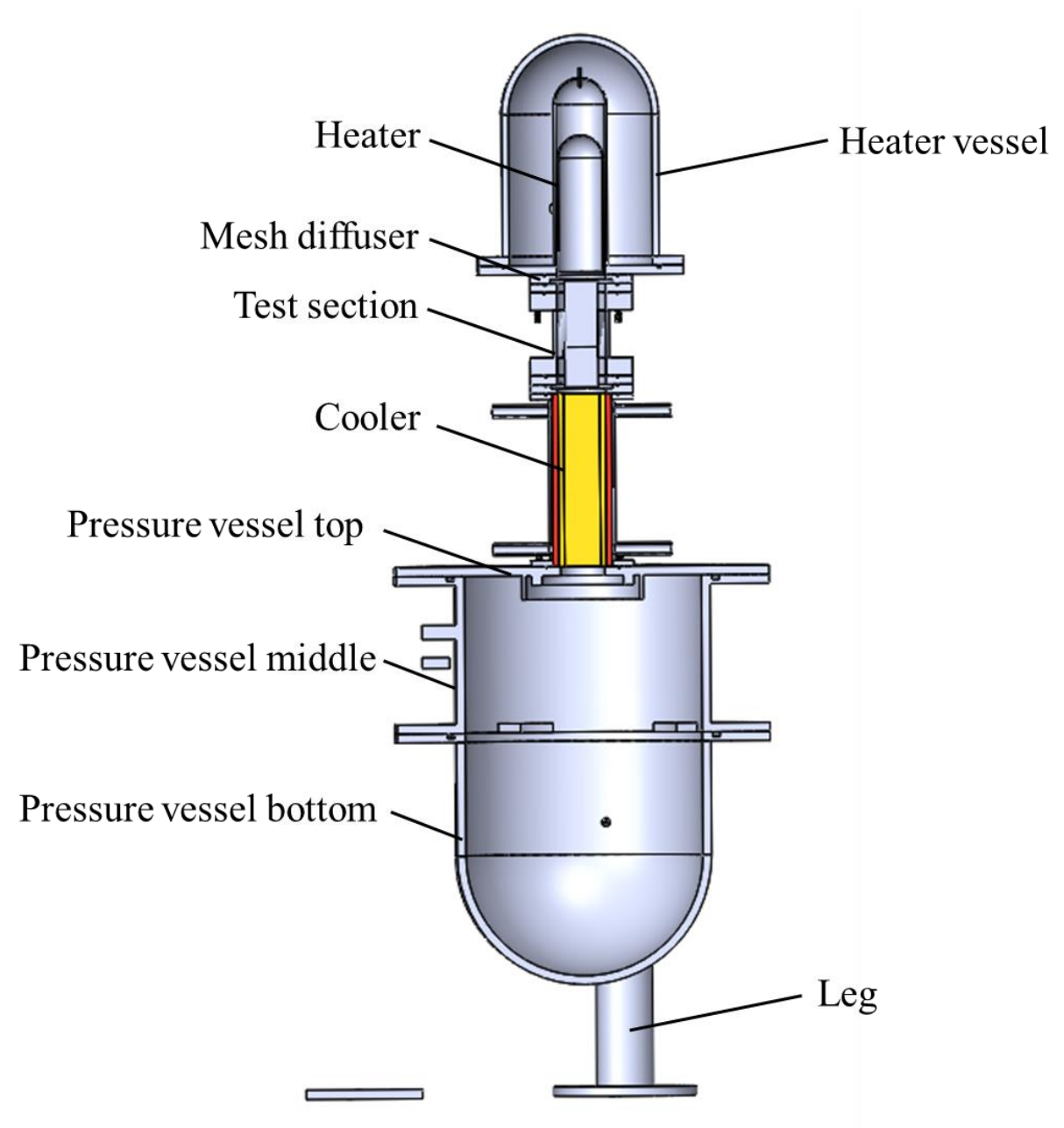

Fig. K-1 Test rig parts name 


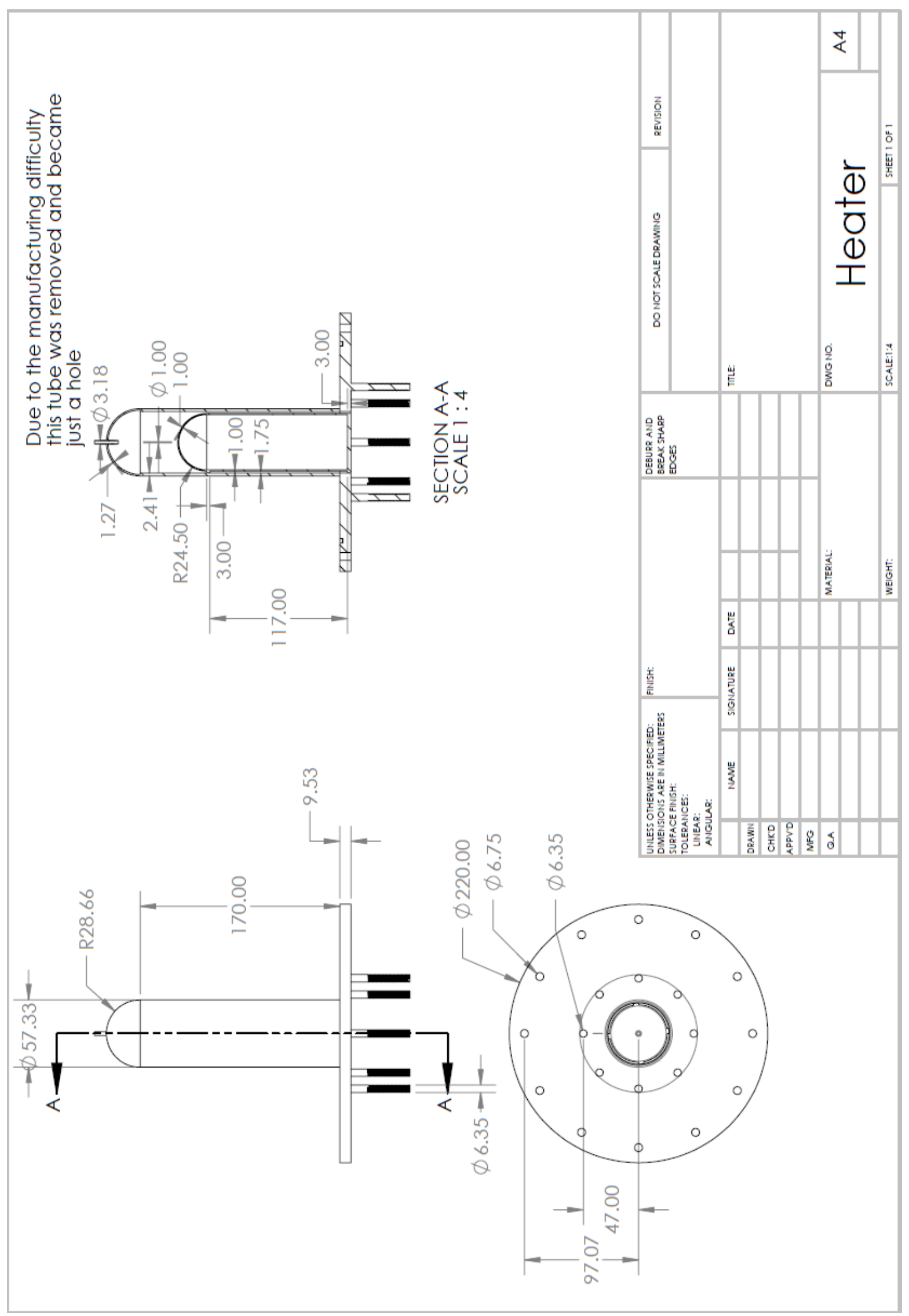




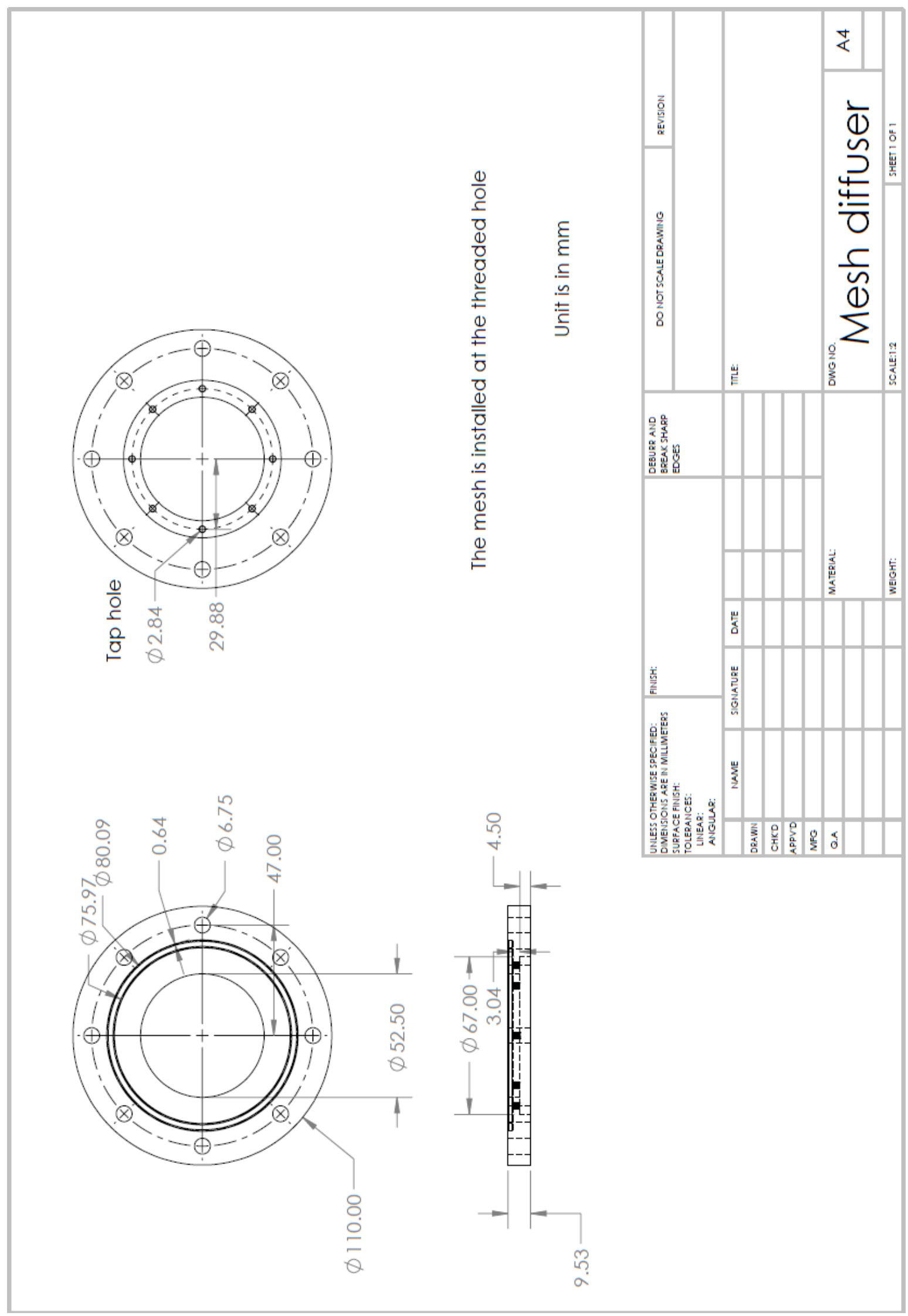




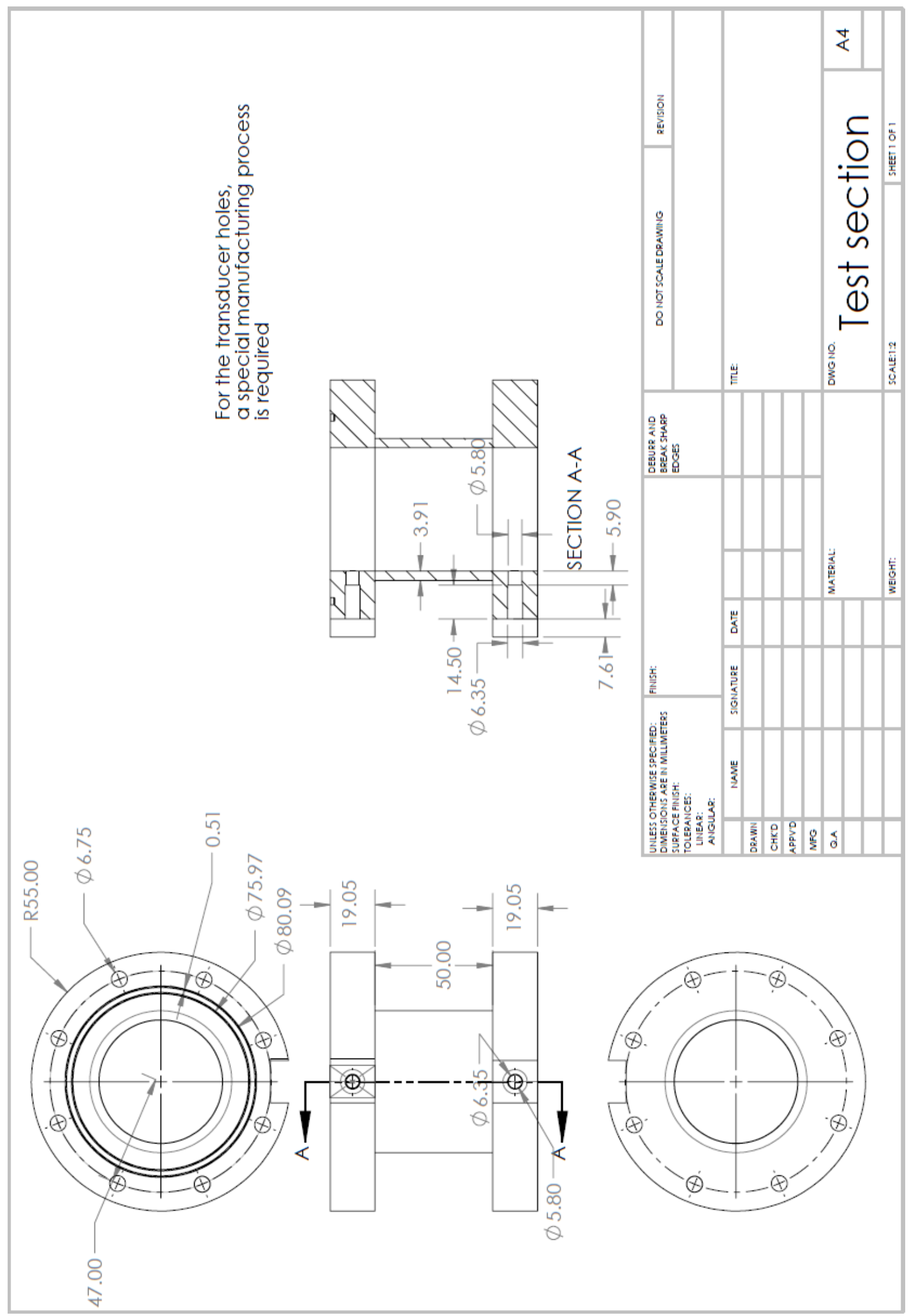




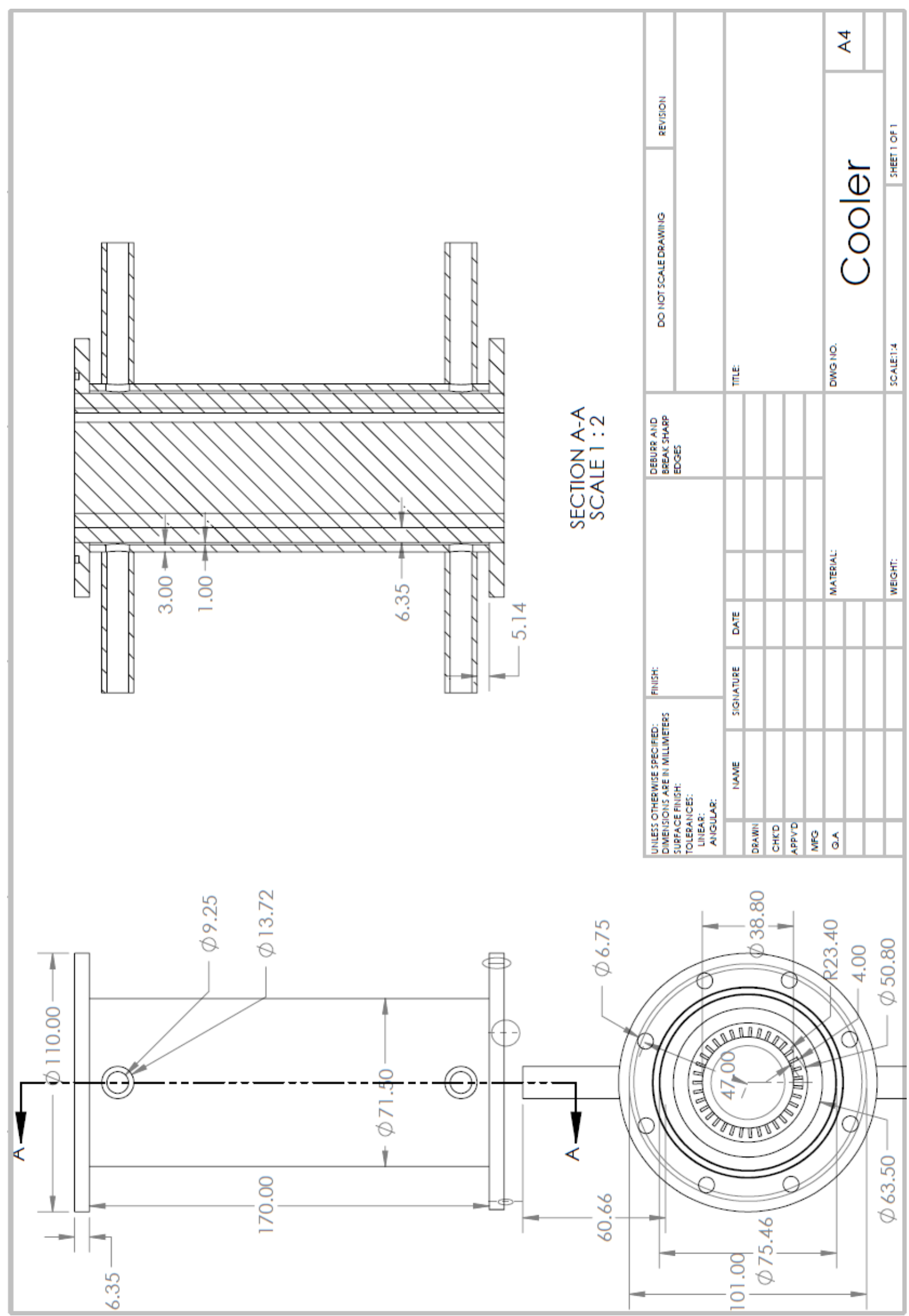




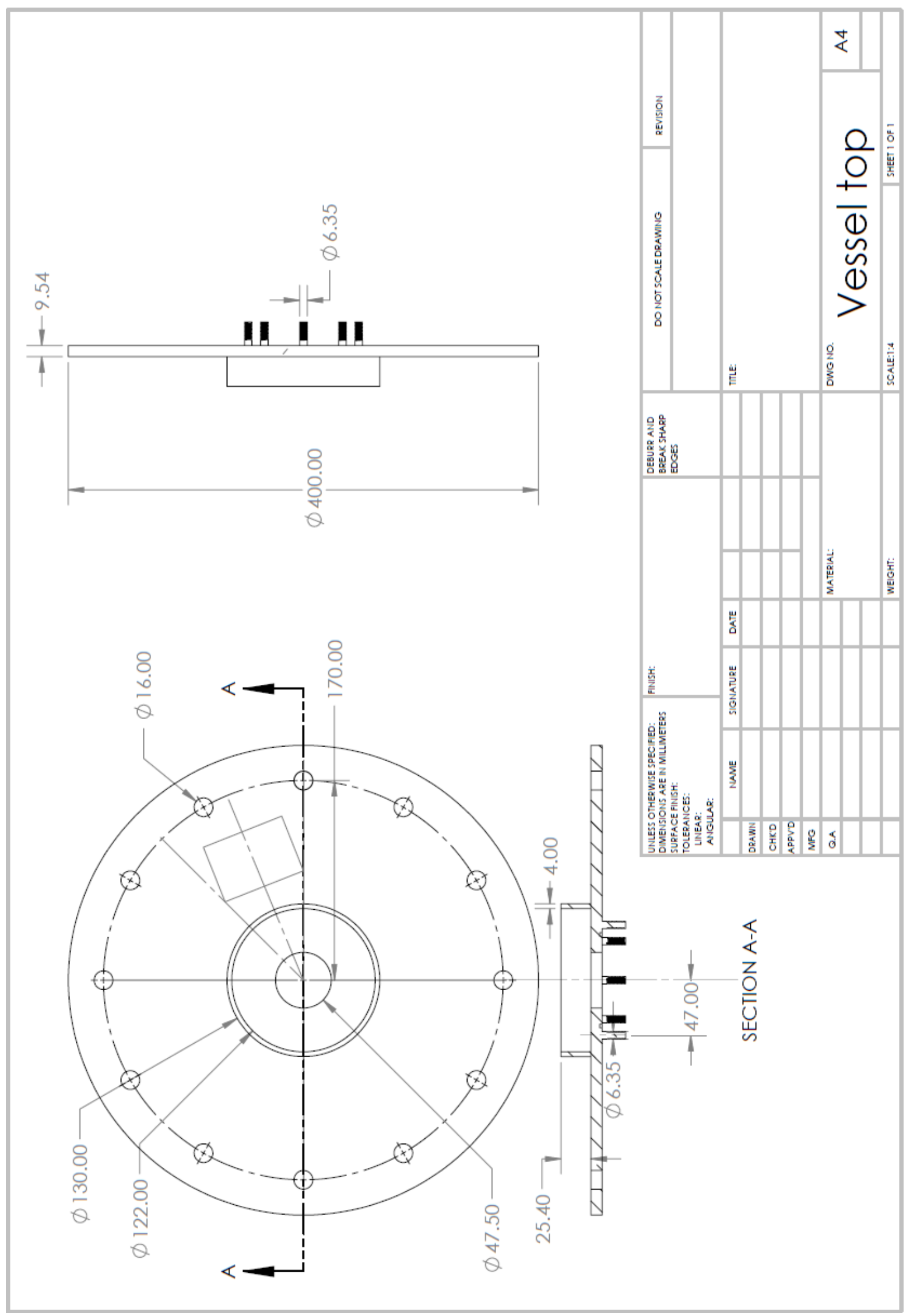




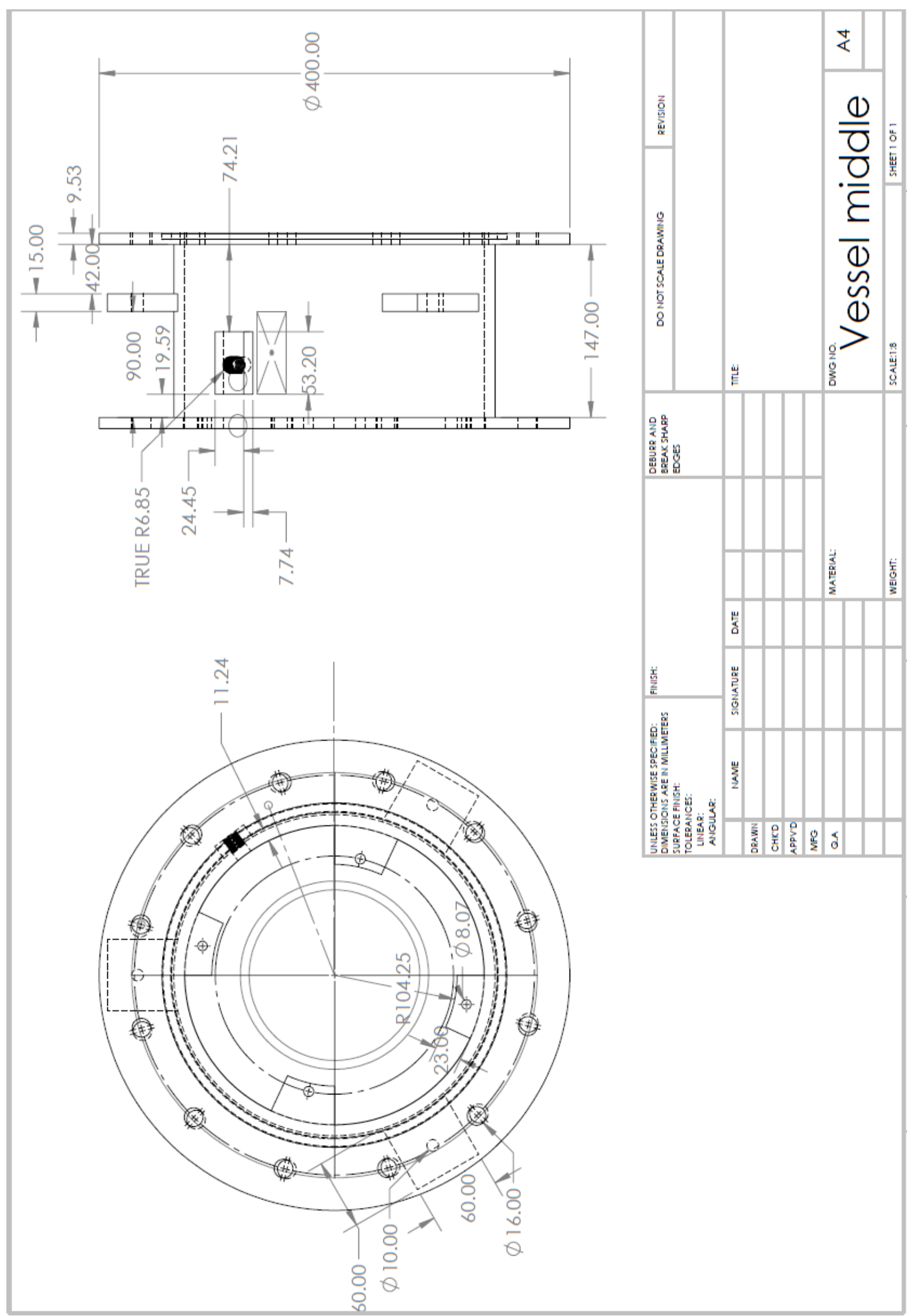




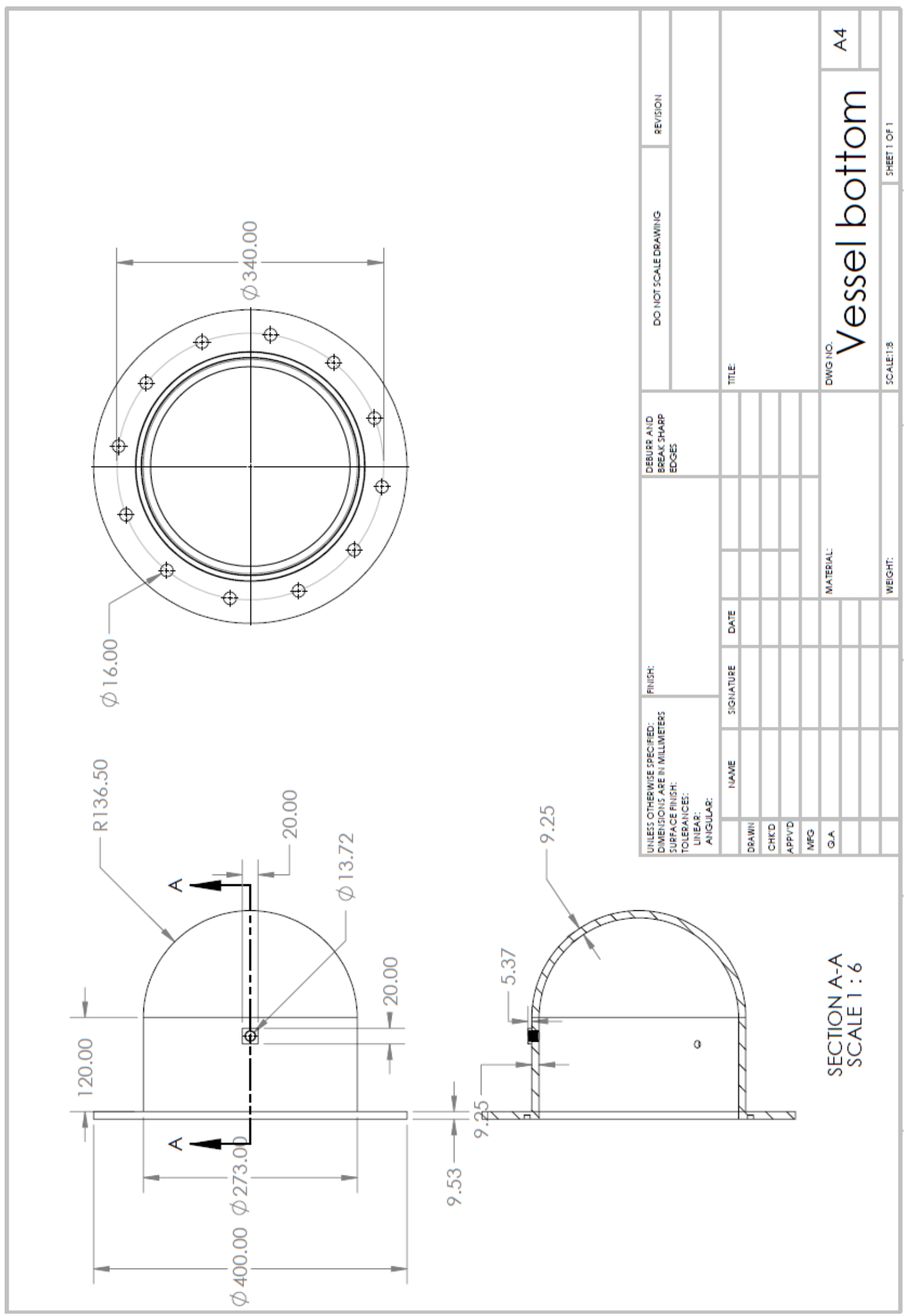

